\title{
Ionic Liquids in Separations: Applications for Pyrolysis Oil and Emulsion Systems
}

Xiaohua Li 



\section{Ionic Liquids in Separations:}

Applications for Pyrolysis Oil and

Emulsion Systems

Xiaohua Li 
Members of the committee

$\begin{array}{lll}\text { Chairman/Secretary: } & \text { Prof.dr.ir. J.W.M. Hilgenkamp } & \text { University of Twente } \\ \text { Promotor: } & \text { Prof.dr. S.R.A. Kersten } & \text { University of Twente } \\ \text { Co-promotor: } & \text { Dr.ir. B. Schuur } & \text { University of Twente } \\ \text { Members: } & \text { Prof.dr.ir. N.E. Benes } & \text { University of Twente } \\ & \text { Prof.dr. J.P. Lange } & \text { University of Twente } \\ & \text { Prof.dr.ir. A.B. de Haan } & \text { Delft University of Technology } \\ & \text { Dr.ir. A.G.J. van der Ham } & \text { University of Twente } \\ & \text { Prof.dr. S. Zhang } & \text { Institute of Process Engineering, } \\ & & \text { Chinese Academy of Sciences }\end{array}$

The research described here was funded by the Dutch foundation for Science and Technology STW; it was carried out in the STW Perspectief Smart Separations programme and was cofunded by the Institute for Sustainable Process Technology.

Ionic Liquids in Separations: Applications for Pyrolysis Oil and Emulsion Systems By Xiaohua Li

$\mathrm{PhD}$ Thesis, University of Twente

Cover page design: Kenan Niu

ISBN: 978-90-365-4293-7

DOI: $10.3990 / 1.9789036542937$

URL: https://doi.org/10.3990/1.9789036542937

Printed by Gildeprint, Enschede, The Netherlands, 2017.

(c) Xiaohua Li, Enschede, The Netherlands 


\title{
IONIC LIQUIDS IN SEPARATIONS: \\ APPLICATIONS FOR PYROLYSIS OIL AND \\ EMULSION SYSTEMS
}

\author{
PROEFSCHRIFT \\ ter verkrijging van \\ de graad van doctor aan de Universiteit Twente, \\ op gezag van de rector magnificus, \\ Prof.dr. T.T.M. Palstra, \\ volgens besluit van het College voor Promoties \\ in het openbaar te verdedigen \\ op vrijdag 10 februari 2017 om 12.45 uur
}

door

\author{
Xiaohua Li \\ geboren op 9 oktober 1984 \\ te Anyang, China
}


This dissertation has been approved by:

Prof.dr. S.R.A. Kersten (Promotor)

Dr.ir. B. Schuur

(Co-Promotor) 
To my family 


\section{Table of Contents}

Summary

Chapter $1 \quad$ General introduction
Part I Applications for pyrolysis oil fractionation

Chapter 2 Extraction of guaiacol from model

pyrolytic sugar stream with ionic liquids

Chapter 3 Aromatics extraction from pyrolytic

sugars using ionic liquid to enhance sugar

fermentability

Chapter 4 Extraction of acetic acid, glycolaldehyde

and acetol from aqueous solutions

mimicking pyrolysis oil cuts using ionic

liquids

\section{Part II Applications in emulsion systems}


Chapter 5 Demulsification of oil-in-water emulsions

using ionic liquids: efficiency and

mechanism

Chapter 6 Studies on the effects of microgel particles

109

on drop size distributions and extraction

kinetics of guaiacol with ionic liquid-in-

water emulsions

Chapter 7 Extraction with a magnetically

125

immobilized ionic liquid

Chapter 8 Conclusion and recommendations

Appendix A Supplementary information of chapter 2

Appendix B Supplementary information of chapter $4 \quad 165$

Appendix C Supplementary information of chapter $6 \quad 173$

Appendix D Supplementary information of chapter 7 177

List of publications

Acknowledgement

183

About the author 



\section{Summary}

Solvent extraction (also known as liquid-liquid extraction) is one of the main separation techniques and has been developed for a wide range of industrial applications. It is applied for the separation of heat-sensitive materials, high-boiling components, inorganic substances and close-boiling liquids. The selection of the solvent and the type of operational equipment are the most important factors for design of liquid-liquid extraction processes. Ionic liquids (ILs) are often considered as environmentally friendly solvents and have been studied widely in various laboratory applications, because of their unique properties, such as low vapor pressure, high thermal stability, poor flammability and designability. Aiming to design effective extraction processes, in this work ILs have been employed for fractionation of pyrolysis oil, for demulsifying oil-in-water emulsions to recover surfactant, and for the design of a novel smart separation process type: fixed liquid extraction.

Pyrolysis oil is the liquid product of fast pyrolysis of lignocellulosic biomass which is a renewable feedstock and has the potential to replace a fraction of fossil oil for production of biofuels and chemicals. Pyrolysis oil is a complex mixture containing hundreds of components, mainly sugars, aromatics and low-boiling oxygenates such as acetic acid, acetol and glycolaldehyde. However, direct use of pyrolysis oil is hindered by its high viscosity, high oxygen content and thermal instability. Upgrading of pyrolysis oil can be done by separating the value-added chemicals. Pyrolysis with fractional condensation results in two fractions. Most sugars and aromatics are collected in the first condenser oil, and most light oxygenates in the second condenser liquid. In the chapters 2 and 3 of this thesis, a study on separation of sugar and aromatics from first condenser oil is described, and in chapter $4 \mathrm{a}$ study on fractionation of oxygenates from second condenser oil.

Due to the complexity of pyrolysis oil, a model feed stream comprising aqueous levoglucosan solution with a guaiacol impurity was applied in the solvent selection study in chapter 2. In this chapter, the use of ILs in liquid-liquid extraction of guaiacol was investigated. Due to the large number of ILs, a software tool COSMO-RS was first employed to simulate the extraction performances of $41 \mathrm{ILs}$ for guaiacol removal. The results demonstrated that ILs with the most hydrophobic cations exhibited the highest affinities for guaiacol, and the distribution coefficients of both guaiacol and levoglucosan could be correlated to the anion polarities. To validate the simulation results, four phosphonium ILs, three imidazolium ILs, and an organic solvent ethyl acetate (EA) were selected to perform the extraction experiments. The trends of the predicted and experimental distribution coefficients with respect to the variation of anions were uniform. 
Trihexyl(tetradecyl)phosphonium dicyanamide $\left(\mathrm{P}_{666,14}\left[\mathrm{~N}(\mathrm{CN})_{2}\right]\right)$ showed the highest experimental selectivity of 2159 and almost no levoglucosan was extracted. To investigate on the energy usage of IL based processes in comparison with low boiling organic solvents, two conceptual processes were designed for separation of guaiacol from water using $\mathrm{P}_{666,14}\left[\mathrm{~N}(\mathrm{CN})_{2}\right]$ and EA respectively, on the basis of experimentally determined liquid-liquid equilibrium data for the systems $\mathrm{P}_{666,14}\left[\mathrm{~N}(\mathrm{CN})_{2}\right]+$ guaiacol + water and $\mathrm{EA}+$ guaiacol + water. The results showed that an EA-based process consisted of more unit operations and required five times more energy $(12.42 \mathrm{MJ} / \mathrm{kg}$ guaiacol) than an IL-based process $(2.15$ $\mathrm{MJ} / \mathrm{kg}$ guaiacol).

In Chapter 3, aromatics removal from sugar-rich aqueous fractions of real first condenser oils was studied by liquid-liquid extraction using $\mathrm{IL} \mathrm{P}_{666,14}\left[\mathrm{~N}(\mathrm{CN})_{2}\right]$ as solvent. For comparison, the extraction of aromatics using the organic solvent EA was also conducted. Two pyrolytic sugar solutions were created from acid-leached and untreated pinewood, with levoglucosan contents (most abundant sugar) of $29.0 \%$ and $8.3 \%(\mathrm{w} / \mathrm{w})$, respectively. In a single stage extraction, $70 \%$ of the aromatics were effectively removed by $\mathrm{P}_{666,14}\left[\mathrm{~N}(\mathrm{CN})_{2}\right]$ and $50 \%$ by EA, while no levoglucosan was extracted. The IL was regenerated by vacuum evaporation (100 mbar) at $220^{\circ} \mathrm{C}$, followed by extraction of aromatics from fresh pyrolytic sugar solutions. The regenerated IL extracted aromatics with similar extraction efficiency as the fresh IL. To be able to evaluate the efficiency of detoxification with IL, the purified sugar fraction from pretreated pinewood was hydrolyzed to glucose and fermented to ethanol, which yielded $0.46 \mathrm{~g}$ ethanol/(g glucose), close to the theoretical maximum yield.

Fractionation of value-added oxygenates (acetic acid, glycolaldehyde and acetol) from artificial aqueous fractions of pyrolysis oil via liquid-liquid extraction is described in Chapter 4. Three phosphonium ionic liquids (ILs), two imidazolium ILs and one benchmark organic mixture (40 wt $\%$ tri- $n$-octylamine in 1-octanol: TOA/1-octanol) were applied as solvents. Although suited as solvent for HAc and glycolaldehyde, the benchmark TOA/1-octanol showed a low acetol distribution coefficient (0.05), which makes it less suitable for use in an integrated oxygenates extraction process. Phosphonium ILs showed the highest affinities for HAc and glycolaldehyde, and reasonable affinity for acetol. However, none of these solvents could be applied to remove all oxygenates from the aqueous solution in a single extraction step, because of the difficulty of evaporation of some of the oxygenates from phosphonium ILs and the reactivity of glycolaldehyde with $\mathrm{P}_{666,14}\left[\mathrm{~N}(\mathrm{CN})_{2}\right]$ in the presence of HAc, as was confirmed by NMR. Based on the good affinity of the imidazolium ILs for acetol, a two-step extraction process was proposed where $\operatorname{Hmim}\left[\mathrm{B}(\mathrm{CN})_{4}\right]$ may be used to extract acetol and HAc in the first step and be regenerated by evaporation of the solutes, and $\mathrm{P}_{666,14}[\mathrm{Phos}$ may 
be applied to extract glycolaldehyde in the second step and be regenerated by back-extraction with water.

Chemical enhanced oil recovery (CEOR) has been applied to increase the oil recovery yield from fields. In CEOR, surfactant together with alkali and polymer are injected in the reservoir to decrease the surface tension between water and oil. Application of CEOR is usually limited by the cost of the chemicals and thus surfactant recovery is desired. The surfactant is usually blended with water and oil in stable emulsions. Therefore, the first step for surfactant recovery is to destabilize these oil emulsions which is called demulsification. In chapter 5, in total 13 ILs including 9 halogenide ILs and 4 non-halogenide ILs were evaluated as demulsifiers for a model oil-in-water emulsion prepared with heptane and water, where sodium dodecylbenzenesulfonate (SDBS) was used as surfactant. The separating efficiency of ILs was investigated and the results showed that halogenide ILs exhibited very fast demulsification, but among the non-halogenide ILs, only $\mathrm{P}_{666,14}\left[\mathrm{~N}(\mathrm{CN})_{2}\right]$ could demulsify effectively, though slower than halogenide ILs. It is suggested that the demulsification efficiency was correlated with the mole ratio of IL and SDBS. For all ILs showing effective demulsification, instead of the desired extraction of the surfactant to an IL phase, it was found that the demulsification mechanism was ion exchange between IL anions and DBS, driven by the large Gibbs energy of hydration of the ions of the sodium salts that dissolve in water. Regeneration of these ILs and surfactants requires water-free reversed ion exchange processes with sodium salts and with salts containing the IL anions, probably limiting commercial applicability of the use of these ILs for demulsification.

ILs have shown excellent potential on laboratory scale, but their application at industrial scale is restricted by the major drawbacks of ILs, such as high viscosity and corrosivity. ILbased emulsion systems that make use of stabilizers can potentially overcome these drawbacks of ILs. In chapter 6 the formation of several IL-based emulsions stabilized by microgel particles (core: polystyrene; shell: poly(N-isopropylacrylamide-co-methacrylic acid)) was studied, including the parametric influences on the drop size distributions, such as the type of IL, power input, microgel concentration, and temperature. The drop size distributions were measured with an in situ endoscope technique (SOPAT GmbH). Four ILs $\left[\mathrm{P}_{666,14}\right]\left[\mathrm{FeCl}_{4}\right]$ (synthesized), $\left[\mathrm{P}_{666,14}\right]\left[\mathrm{NTf}_{2}\right],\left[\mathrm{P}_{666,14}\right]\left[\mathrm{N}(\mathrm{CN})_{2}\right]$ and $[\mathrm{Bmim}]\left[\mathrm{NTf}_{2}\right]$ were employed to form emulsions, and under equal emulsification conditions [Bmim] $\left[\mathrm{NTf}_{2}\right]$ exhibited the smallest Sauter mean diameter $(184 \mu \mathrm{m})$. With the power input or the particle concentration increasing, the drop sizes decreased. Below the lower critical solution temperature (LCST, $35^{\circ} \mathrm{C}$ ) of microgels, the Sauter mean diameter of IL drops decreased 
with temperature increasing. Above the LCST, due to stronger IL drop coalescence, the increased temperature caused larger drop sizes.

The influences of microgel particles on the extraction capacity and kinetics were studied using $\left[\mathrm{P}_{666,14}\right]\left[\mathrm{NTf}_{2}\right]$ for extraction of guaiacol from aqueous solution. It showed that in the studied range of microgel concentration (0-1.5 g/L), microgels did not change the equilibrium extraction capacity, but the extraction rate was slower in the system with particles than without particles, due to the coverage of microgels on the droplet surface.

ILs sometimes have extremely high affinity for solutes so that very low solvent to feed ratios (S/F) are desired. Traditional liquid-liquid contacting methods are not suitable, so that an alternative method of operation needs to be investigated. In chapter 7, a novel separation process concept was explored, referred to as fixed liquid extraction, in which magnetic ionic liquid (MIL) droplets stabilized by microgels were fixed in a tube by the magnetic force while the feed was pumped through the MIL drops for extraction. Extraction of methyl isobutyl ketone (MIBK) from aqueous solutions was performed in this fixed liquid extraction process. It was observed that the MIL drops could be successfully fixated in the tube. Due to the short contact time of the two liquid phases and the relatively large MIL drops caused by coalescence in the pump, the extraction yield of MIBK was $50 \%$ of the thermodynamic maximum yield, but with these preliminary results, the concept of fixed liquid extraction has been demonstrated for the first time.

In conclusion, ILs can effectively remove aromatics from pyrolytic sugar streams and thereby make the fermentability of these sugars for production of bioethanol possible. Valueadded oxygenates (acetic acid, glycolaldehyde and acetol) can be fractionated by a two-step extraction process using $\operatorname{Hmim}\left[\mathrm{B}(\mathrm{CN})_{4}\right]$ and $\mathrm{P}_{666,14}[\mathrm{Phos}]$ subsequently. The studied halogenide ILs and $\mathrm{P}_{666,14}\left[\mathrm{~N}(\mathrm{CN})_{2}\right]$ can demulsify heptane-in-water emulsions, but the mechanism is anion exchange, so that the recovery of surfactant and ILs is difficult. Several IL-based emulsions stabilized by microgel particles has been prepared, and the concept of fixed liquid extraction has been demonstrated for the first time, aiming for the design of separation process for extremely small S/F. 


\section{Samenvatting}

Vloeistof-vloeistof extractie is één van de belangrijkste scheidingstechnieken en heeft zich ontwikkeld voor een breed scala aan industriële toepassingen. Het wordt voornamelijk toegepast in de scheiding van temperatuurgevoelige en hoogkokende componenten, anorganische substanties en vloeistoffen met kookpunten die vlak bij elkaar liggen. De selectie van het oplosmiddel en de hydrodynamica van de toegepaste apparatuur zijn de meest belangrijke factoren voor het ontwerp van vloeistof-vloeistof extractieprocessen. Ionische vloeistoffen ('ionic liquids', ILs) worden vaak gezien als milieuvriendelijke oplosmiddelen en zijn uitgebreid onderzocht in verscheidene laboratoriumtoepassingen vanwege hun unieke eigenschappen, zoals een lage dampspanning, hoge thermische stabiliteit, kleine ontvlambaarheid en de samenstellingsmogelijkheden. Het onderzoek in dit proefschrift beschreven had als doel het bestuderen en het ontwerpen van effectieve op IL gebaseerde extractieprocessen. Hiervoor is onderzocht: fractionering van pyrolyseolie voor het winnen van chemicaliën, demulgeren van olie in water emulsies om de oppervlakte-actieve stoffen gebruikt voor olie winning terug te winnen en een nieuw slim type scheidingsproces: gefixeerde vloeistofextractie.

Pyrolyseolie, vloeistoffase product dat ontstaat bij snelle pyrolyse van uit lignocellulose opgebouwde biomassa, is een hernieuwbare grondstof met de potentie om een deel van de fossiele olie voor de productie van biobrandstoffen en chemicaliën te vervangen. Pyrolyseolie is een complex mengsel van water en honderden organische componenten, waaronder suikers, aromaten en vluchtige zuurstofhoudende verbindingen zoals azijnzuur, acetol en glycolaldehyde. Direct gebruik van pyrolyseolie wordt bemoeilijkt door de hoge viscositeit, hoog zuurstofgehalte en de thermische instabiliteit. Pyrolyseolie kan worden opgewerkt door het afscheiden van de chemicaliën die een verhoogde waarde hebben. Door in het pyrolyseproces de pyrolysedampen fractioneel te condenseren, worden twee oliefracties verkregen. De meeste suikers en aromaten worden geconcentreerd in de eerste oliefractie, terwijl de meeste vluchtige en ook zuurstofhoudende verbindingen in de tweede fractie gecondenseerd worden. In de hoofdstukken 2 en 3 van dit proefschrift wordt de studie beschreven van de scheiding van de suikers en aromaten uit de olie van de eerste condensor. Hoofdstuk 4 beschrijft de studie naar het fractioneren van vluchtige zuurstofhoudende verbindingen uit de tweede condensor olie.

Vanwege de complexiteit van pyrolyseolie, is voor de selectie van het optimale extractiemiddel in hoofdstuk 2 een studie gedaan met een modelmengsel. Dit modelmengsel, een waterige levoglucosan-oplossing met een guaiacol verontreiniging, werd gebruikt om 
met ILs de extractie van guaiacol te onderzoeken. Vanwege het grote aantal mogelijke ILs is eerst het softwarepakket COSMO-RS gebruikt om de extractie van guaiacol te simuleren voor 41 ILs. De simulatieresultaten toonden aan dat de ILs met de meest hydrofobe kationen de grootste affiniteit voor guaiacol vertoonden en dat de distributiecoëfficiënten (verdeling over de twee vloeistoffases) van zowel guaiacol als levoglucosan gecorreleerd kan worden aan de polariteiten van de anionen. Om de simulatieresultaten experimenteel te valideren werden vier fosfonium ILs, drie imidazolium ILs en een organisch oplosmiddel ethylacetaat (EA) geselecteerd om de extractie experimenten uit te voeren. De trends van de gesimuleerde distributiecoëfficiënten en experimenteel bepaalde distributiecoëfficiënten was in overeenstemming met betrekking tot de variatie van anionen. Trihexyl(tetradecyl)fosfonium dicyanamide $\left(\mathrm{P}_{666,14}\left[\mathrm{~N}(\mathrm{CN})_{2}\right]\right)$ had de hoogste experimentele selectiviteit van 2159 en nagenoeg geen levoglucosan werd geëxtraheerd. Om het energieverbruik van IL gebaseerde processen te vergelijken met scheidingsprocessen gebaseerd op vluchtige organische oplosmiddelen, werden twee conceptuele processen ontworpen voor de extractie van guaiacol uit waterige oplossingen met respectievelijk $\mathrm{P}_{666,14}\left[\mathrm{~N}(\mathrm{CN})_{2}\right]$ en ethylacetaat. Het ontwerp was gebaseerd op de experimenteel bepaalde vloeistof-vloeistof evenwichtsdata voor de systemen $\mathrm{P}_{666,14}\left[\mathrm{~N}(\mathrm{CN})_{2}\right]+$ guaiacol + water en EA + guaiacol + water. De resultaten toonden aan dat een op EA gebaseerd proces vijf keer meer energie (12.42 MJ/kg guaiacol) verbruikt dan een op IL gebaseerd proces $(2.15 \mathrm{MJ} / \mathrm{kg}$ guaiacol) en bovendien uit meer proces operaties bestaat.

In hoofdstuk 3 werd de scheiding van aromaten van de suikerrijke water geëxtraheerde fractie van echte eerste condensor olie bestudeerd door middel van vloeistof-vloeistof extractie met IL $\mathrm{P}_{666,14}\left[\mathrm{~N}(\mathrm{CN})_{2}\right]$ als oplosmiddel. Ter referentie werd de extractie met het organisch oplosmiddel EA ook uitgevoerd. Twee pyrolitische suikeroplossingen werden gebruikt die geproduceerd waren met pyrolyse van zuur geloogd en onbehandeld dennenhout, met een levoglucosan gehalte (de meest aanwezige suiker) van respectievelijk $29.0 \%$ en $8.3 \%$ $(w / w)$. In een eentraps extractie werd $70 \%$ van de aromaten effectief verwijderd door $\mathrm{P}_{666,14}\left[\mathrm{~N}(\mathrm{CN})_{2}\right]$ en 50\% door EA, terwijl er geen levoglucosan werd geëxtraheerd. De IL werd na extractie geregenereerd door vacuüm verdamping (100 mbar) bij $220{ }^{\circ} \mathrm{C}$, waarna de IL opnieuw gebruikt werd voor extractie van aromaten van verse pyrolitische suikeroplossingen. De geregenereerde IL was in staat om de aromaten met dezelfde extractie-efficiëntie te verwijderen als de verse IL in de eerste stap. Om de effectiviteit te evalueren van ontgiften met ILs werd ook een fermentatie uitgevoerd met de gepurificeerde suikerfractie van het voorbehandelde dennenhout. Hiertoe werd het levoglucosan gehydrolyseerd tot glucose en gefermenteerd tot ethanol. Dit leverde $0.46 \mathrm{~g}$ ethanol/(g glucose) op, wat overeenkomt met bijna de theoretische maximale opbrengst. 
Het fractioneren van de vluchtige zuurstofhoudende verbindingen met toegevoegde waarde (azijnzuur, glycolaldehyde en acetol) van kunstmatige waterfracties van pyrolyseolie door middel van vloeistof-vloeistof extractie is beschreven in hoofdstuk 4. Drie fosfonium ionic liquids (ILs), twee imidazolium ILs en een organisch benchmark mengsel (40 wt\% trin-octylamine in 1-octanol: TOA/1-octanol) werden toegepast als oplosmiddelen. Hoewel het benchmark oplosmiddel TOA/1-octanol geschikt is als oplosmiddel voor azijnzuur en glycolaldehyde, is de distributiecoëfficiënt voor acetol in dit oplosmiddel erg laag (0.05), wat het minder geschikt maakt voor gebruik in een geïntegreerd extractieproces voor zuurstofhoudende verbindingen. Fosfonium ILs toonden de hoogste affiniteiten voor azijnzuur en glycolaldehyde en een redelijke affiniteit voor acetol. Geen van deze oplosmiddelen kon echter worden toegepast om alle zuurstofhoudende verbindingen te extraheren van de waterige oplossing in een enkele extractiestap. Dit werd veroorzaakt door de moeilijke verdamping van sommige van de zuurstofhoudende verbindingen tijdens de regeneratie van de fosfonium ILs en de reactiviteit van glycolaldehyde met $\mathrm{P}_{666,14}\left[\mathrm{~N}(\mathrm{CN})_{2}\right]$ in aanwezigheid van azijnzuur, zoals ook bevestigd met NMR. Gebaseerd op de goede affiniteit van de imidazolium ILs voor acetol werd een tweestaps extractieproces voorgesteld waar Hmim $\left[\mathrm{B}(\mathrm{CN})_{4}\right]$ gebruikt zou kunnen worden om acetol en azijnzuur in de eerste stap te extraheren waarna deze teruggewonnen kunnen worden door verdamping van de opgeloste stoffen. $\mathrm{P}_{666,14}[\mathrm{Phos}]$ zou in de tweede stap kunnen worden toegepast om glycolaldehyde te extraheren dat teruggewonnen kan worden door terugextractie met water.

'Chemical enhanced oil recovery' (CEOR) wordt toegepast om de productie van olie uit velden te vergroten. Bij CEOR wordt een oppervlakte-actieve stof samen met een alkali en een polymeer geïnjecteerd in het olieveld om de oppervlaktespanning tussen water en olie te verminderen. De toepassing van CEOR is normaal gesproken gelimiteerd door de kosten van de chemicaliën en om die reden is het terugwinnen van de oppervlakte actieve stoffen gewenst. De oppervlakte actieve stof is normaal gesproken met water en olie gemengd tot een stabiele emulsie. Daarom is de eerste stap voor het terugwinnen van de oppervlakteactieve stoffen het destabiliseren van deze emulsies, wat demulgeren genoemd wordt. In hoofdstuk 5 zijn in totaal 13 ILs geëvalueerd als demulgatoren, waarvan 9 halogenide ILs en 4 niet-halogenide ILs. De ILs werden gebruikt voor de demulgatie van een model olie-inwater emulsie bestaand uit heptaan en water, waar natrium dodecylbenzeensulfonaat (NDBS) is toegevoegd als oppervlakte-actieve stof. De demulgatie-efficiëntie van de ILs werd onderzocht en de resultaten toonden aan dat de halogenide ILs erg snelle demulgatie vertoonden. Onder de niet halogenide ILs kon echter alleen $\mathrm{P}_{666,14}\left[\mathrm{~N}(\mathrm{CN})_{2}\right]$ effectief demulgeren, hoewel dit langzamer plaatsvond dan bij halogenide ILs. Er wordt geopperd dat de demulgatie-efficiëntie gecorreleerd kan worden aan de molaire verhouding van de IL en 
NDBS. Voor alle ILs die effectieve demulgatie vertoonden, werd aangetoond dat het demulgatie mechanisme berustte op ionen uitwisseling tussen de anionen van de IL en DBS, gedreven door de grote Gibbs-energie van hydratie van de ionen van het natriumzout dat oplost in water. Dit mechanisme is ongewenst in tegenstelling tot het gewenste mechanisme van extractie van de oppervlakte actieve stof naar een IL-fase. Het regenereren van deze ILs en oppervlakte actieve stoffen vereist watervrije omgekeerde ionenwisselingsprocessen met natriumzouten en met zouten die de IL anionen bevatten. Dit compliceert waarschijnlijk de commerciële toepasbaarheid van deze ILs voor demulgatie.

ILs hebben excellente potentie getoond op labschaal, maar hun toepasbaarheid op industriële schaal wordt beperkt door de belangrijke nadelen van ILs, zoals de hoge viscositeit en corrosiviteit. Op IL gebaseerde emulsiesystemen die gebruik maken van stabilisatoren kunnen deze nadelen van ILs potentieel overwinnen. In hoofdstuk 6 wordt de vorming van verscheidene op IL gebaseerde emulsies bestudeerd. De emulsies worden gestabiliseerd door microgel deeltjes (kern: polystyreen; omhulsel: poly(Nisopropylacrylamide-co-methacrylzuur)). De studie omvat onder andere de invloeden van de parameters op de druppelgrootteverdelingen, zoals het type IL, vermogensinput, microgel concentratie en temperatuur. De druppelgrootteverdelingen werden gemeten met een in situ endoscoop techniek (SOPAT GmbH). Vier ILs werden gebruikt om emulsies te vormen: $\left[\mathrm{P}_{666,14}\right]\left[\mathrm{FeCl}_{4}\right]$ (gesynthetiseerd), $\left[\mathrm{P}_{666,14}\right]\left[\mathrm{NTf}_{2}\right],\left[\mathrm{P}_{666,14}\right]\left[\mathrm{N}(\mathrm{CN})_{2}\right]$ en $[\mathrm{Bmim}]\left[\mathrm{NTf}_{2}\right]$. Onder identieke emulgeeromstandigheden vertoonde $[\mathrm{Bmim}]\left[\mathrm{NTf}_{2}\right]$ de kleinste gemiddelde Sauter diameter $(184 \mu \mathrm{m})$. Met toenemende vermogensinput of deeltjesconcentratie werden de druppels kleiner. Onder de onderste kritische oplossingstemperatuur ('lower critical solution temperature, $\mathrm{LCST}, 35^{\circ} \mathrm{C}$ ) van de microgels, neemt de gemiddelde Sauter diameter van de IL druppels af met toenemende temperatuur. Boven de LCST neemt de druppelgrootte toe met toenemende temperatuur, vanwege sterkere IL-druppel coalescentie. De invloed van microgeldeeltjes op de extractiecapaciteit en kinetiek is bestudeerd met $\left[\mathrm{P}_{666,14}\right]\left[\mathrm{NTf}_{2}\right]$ voor de extractie van guaiacol uit waterige oplossingen. Er werd aangetoond dat in het onderzochte gebied van microgel concentraties (0-1.5 g/L), microgels de extractiecapaciteit niet veranderden, maar de extractiesnelheid was lager in het systeem met deeltjes dan in het systeem zonder deeltjes, door het bedekken van het druppeloppervlak door de microgels.

In sommige gevallen hebben ILs extreem hoge affiniteit voor bepaalde gewenste stoffen waardoor erg lage verhoudingen van extractiemiddel en voedingsstroom (solvent-to-feed ratios, (S/F)) gewenst zijn. Traditionele methodes voor het in contact brengen van de beide vloeistoffen zijn niet geschikt om zulke lage S/F-ratios toe te passen, waardoor onderzoek gedaan werd naar een alternatieve methode. In hoofdstuk 7 is een nieuw concept voor een scheidingsproces bestudeerd, aangeduid met gefixeerde vloeistofextractie. Hierbij worden 
druppels van een magnetische ionische vloeistof (magnetic ionic liquid, MIL), dat gestabiliseerd wordt door microgels, gefixeerd in een buis door een magnetische kracht, terwijl de voeding door de MIL druppels wordt gepompt tijdens het extractieproces. Voor dit gefixeerde vloeistofextractie proces werd de extractie van methylisobutylketon (MIBK) uit waterige oplossingen bestudeerd. Er werd aangetoond dat de MIL druppels succesvol gefixeerd konden worden in de buis en dat $50 \%$ van de thermodynamisch maximale MIBK extractie-opbrengst gehaald werd. Dat de opbrengst niet hoger dan 50\% was, werd veroorzaakt door de korte contacttijd van de twee vloeistoffasen en de relatief grote MIL druppels, die coalesceerden in de pomp. Desondanks is met deze eerste en voorlopige resultaten het concept van gefixeerde vloeistofextractie voor het eerst gedemonstreerd.

Concluderend, ILs kunnen effectief aromaten scheiden uit stromen van pyrolitische suikeroplossingen en daarmee maken ze de fermentatie van deze suikers mogelijk voor de productie van bio-ethanol. Zuurstofhoudende verbindingen met toegevoegde waarde (azijnzuur, glycolaldehyde en acetol) kunnen worden gefractioneerd met een tweestaps extractieproces gebruikmakend van $\operatorname{Hmim}\left[\mathrm{B}(\mathrm{CN})_{4}\right]$ en vervolgens $\mathrm{P}_{666,14}[\mathrm{Phos}]$. De bestudeerde halogenide ILs en $\mathrm{P}_{666,14}\left[\mathrm{~N}(\mathrm{CN})_{2}\right]$ kunnen heptaan-in-water emulsies demulgeren, maar het mechanisme is gebaseerd op anionen uitwisseling, waardoor de terugwinning van de oppervlakte actieve stof en ILs moeilijk is. Er werden verscheidene op IL gebaseerde emulsies geproduceerd die gestabiliseerd zijn door microgels. Het concept van gefixeerde vloeistofextractie is voor het eerst gedemonstreerd, met als doel het ontwerpen van een scheidingsproces voor extreem lage $\mathrm{S} / \mathrm{F}$. 


\section{Chapter 1}

\section{General introduction}

In this thesis a study is described on the use of ionic liquids (ILs) in traditional liquid-liquid extraction processes, demulsification of oil-in-water emulsions and in novel smart separation processes where stimuli responsive materials (also called smart materials) are involved. In this introductory chapter the motivation of the work is described, including the importance of solvent selection and equipment design for liquid-liquid extraction processes, a general introduction of ionic liquids, the background of the representative cases and IL-based smart separations based on temperature responsive core-shell nanoparticles for stabilization of IL emulsions and magneto responsive magnetic ionic liquids. 


\subsection{Separation techniques}

Separation operations are essential for industrial chemical processes, as in most processes a mixture and not a single, highly pure product is produced. As a result, one or more components need to be purified from the reaction mixture [1, 2]. A few from the many examples of industrial processes that heavily rely on separation technology are 1) crude oil refinery for producing a variety of marketable products, e.g. natural gas, gasoline, diesel, waxes, etc.; 2) hydrometallurgy to produce metals from ores; 3) sea water desalination; 4) waste water treatment.

Separation techniques can be divided into mechanical separations and molecular separations [1, 2]. Mechanical separations involve heterogeneous systems, and these separations can be done based on differences in the properties of the phases the system consists of. Molecular separations start with a homogeneous feed and rely on differences in molecular properties of the components in the mixture, such as molecular size, dipole moment, polarizability, that induce differences in macroscopic properties (e.g., melting point, boiling point and chemical affinity between compounds) [1, 2]. Molecular separation techniques include distillation, absorption, extraction, crystallization, adsorption, drying, as well as membrane separation and chromatography. Although distillation is the most applied separation technique in the petrochemical industry, in some cases, extraction processes are preferable over distillation, for example, the separation of 1) heat-sensitive materials; 2) highboiling components present in small concentrations in low-boiling solvent, 3) inorganic substances which are difficult to be evaporated; 4) close-boiling liquids or azeotropic mixtures. Solvent extraction has been developed for a wide range of industrial applications, some arbitrary examples are acetic acid recovery from water and aromatics separation from paraffin [1].

\subsubsection{Solvent extraction}

Solvent extraction, also called liquid-liquid extraction is a process in which one or more solutes are transferred from a liquid feed solution to a second liquid phase (solvent) which is (at least partially) immiscible with the feed. The extraction yield is based on the relative solubilities of the species in the two liquid phases. The solvent phase taking up the solute is called extract, while the solute depleted phase is called raffinate. The suitability of a solvent is usually evaluated by two factors: distribution coefficient (D) and selectivity (S), which are defined in equations (1.1) and (1.2), respectively: 


$$
\begin{array}{r}
D_{i}=\frac{x_{i}^{I}}{x_{i}^{I I}} \\
S=\frac{D_{i}}{D_{j}}
\end{array}
$$

where $x_{i}^{I}$ and $x_{i}^{I I}$ represent the mass (or mole) fraction of solute $i$ in extract phase $I$ and raffinate phase $I I ; D_{i}$ and $D_{j}$ are the distribution coefficients of components $i$ and $j$.

However, comparing to the direct thermal separation, the main drawback of solvent extraction is the need to recover solutes from extracts and regeneration of solvents. The most important factors for design and development of liquid-liquid extraction processes are the selection of solvent and the type of operational equipment.

\subsection{Solvents in liquid-liquid extraction}

\subsubsection{Solvent selection}

Solvent selection is the key to an effective and economical extraction process [2]. A good solvent requires several criteria and the most important ones are shown below:

1) High affinity for the solutes, indicating high $D$ and high $S$, which are defined in equation (1.1) and (1.2). A high value of D permits lower solvent to feed ratio (S/F) and a high selectivity reduces the required number of equilibrium stages, which consequently reduces the operational and capital expenditures.

2) Easily recoverable for a design of sustainable process, in which it is preferred that the solvent has low miscibility with the feed and high boiling point to minimize its loss due to solubility and evaporation.

3) Compatible with the environment (preferably nontoxic, low flammability, low volatility).

Three main extractive solvent systems are often employed to extract (bio)chemicals from aqueous solutions, including organic solvents, aqueous two-phase systems and supercriticalfluid extractions [1]. Organic solvents are commonly used for extraction of acids from fermentation broth, and for separation of aliphatics and aromatics. For some cases where solutes have low affinity for most solvents, reactive extraction is usually considered by using 
a composite solvent comprised of an extractant and a diluent. For example, the solvent system tri-n-octylamine in 2-ethyl-hexanol has been studied for reactive extraction of acids from aqueous pyrolysis oil [3]. However, most of the organic solvents are toxic, flammable and volatile.

Some biomolecules (e.g. proteins) can be denatured in organic solvent, for which reason aqueous two-phase systems (ATPS) have been developed. ATPS can be formed by combination of two aqueous solutions of two polymers, a polymer and a salt, or two salts, and also ATPS formation with ionic liquids (ILs) has been studied extensively [4]. Selective partitioning of the target molecule depends upon the affinity of that molecule for the constituents of the phases (i.e. on polymer and salt type) and system parameters such as $\mathrm{pH}$ and temperature [5].

Supercritical-fluid extraction uses a supercritical fluid as solvent. For some temperatureand viscosity-sensitive solvents, their affinity for solutes can be modulated by changing the conditions. The mostly used solvent is supercritical carbon dioxide, which is considered as an environmentally benign, non-flammable solvent. Supercritical $\mathrm{CO}_{2}$ has been applied in the area of lipid extraction, food processing and pharmaceutical industries $[6,7]$.

In recent decades, ILs and deep eutectic solvents (DESs) have gained much attention in research science [8,9]. DESs are relatively a new type of solvent which was reported in 2001, although the name was not defined in the paper [10]. Although ILs and DESs are considered as two types, they share many similar characteristics. This thesis is focused on the use of ILs for liquid-liquid extractions.

\subsubsection{Ionic liquids}

Ionic liquids (ILs) are completely composed of ions with melting point below $100{ }^{\circ} \mathrm{C}$, typically comprising organic cations and organic or inorganic anions [11]. Due to their low vapor pressure, they are considered as environmentally friendly solvents that may replace conventional volatile solvents in various applications [12]. Moreover, they are known as designer solvent. By adjusting the structures of cation and anion or tuning their combinations, ionic liquids can be designed with desirable physicochemical properties, such as hydrophobicity, density, viscosity, solvation capabilities and even functionality such as luminescence and magnetism [13, 14]. Untill 2008 nearly 2000 ILs have been reported, including 714 different cations and 189 different anions [15]. Commonly used cations and anions are drawn in Figure 1.1. 


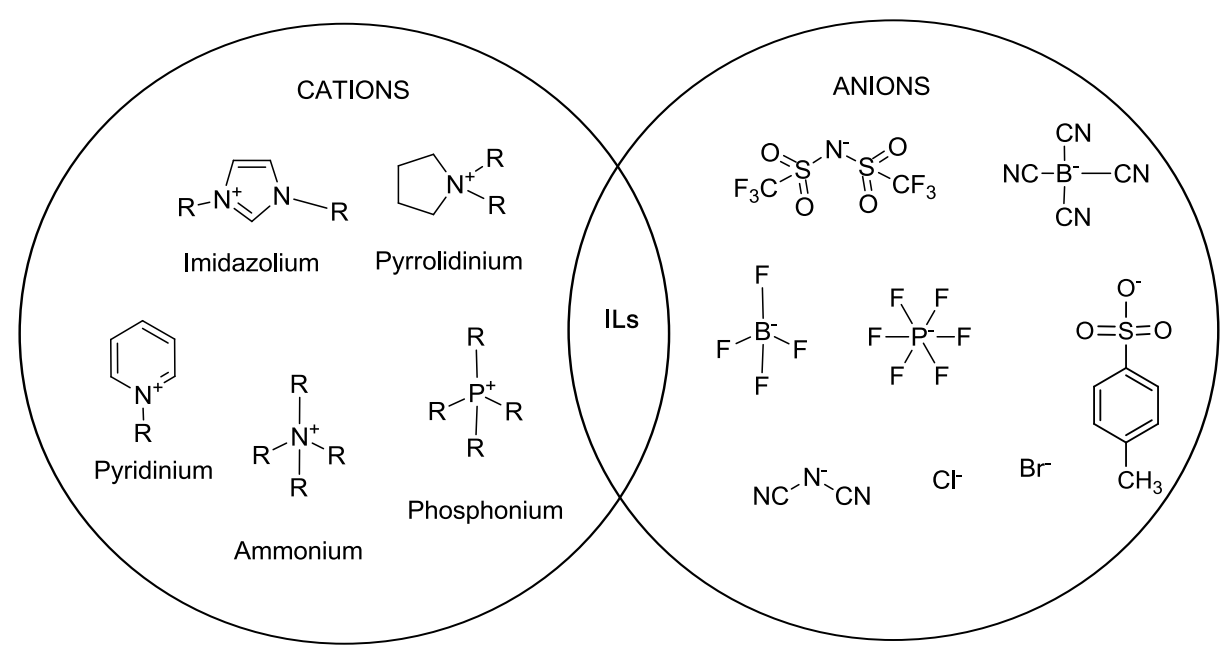

Figure 1.1. Structures of commonly used cations and anions of ionic liquids.

Next to their low vapor pressure and designability, ILs also have many other unique physicochemical properties, such as high thermal stability, wide liquid range, high conductivity, poor flammability and wide electrochemical window. ILs have been applied in various fields, such as separation, synthesis, electrochemistry, catalysis and energy production at both laboratory research and industrial scale [9, 16-19]. The first application of IL on a commercial scale (BASIL process) was announced by BASF in 2003 which is used for acid scavenging [20].

In this thesis, ionic liquids are investigated for three challenging representative cases: for fractionation of pyrolysis oil, recovery of surfactant from oil-in-water emulsions, and for extraction of methyl isobutyl ketone (MIBK) from water. In all of these cases, either due to the heat-sensitivity and complexity of the mixtures, or due to high heat duties, distillation is not applicable and it is wise to explore the potential of solvent extraction. The studies described in this thesis aim to design effective extraction processes for the above mentioned cases in a sustainable way.

\subsection{Liquid-liquid extraction equipment}

The choice of extractor type is substantial for an efficient extraction process design. Different types of extractor have different performance characteristics, such as drop breakup and coalescence, drop velocities, mass transfer and axial mixing behavior [21], which can consequently influence the extraction yield. Two main types of extractors are employed in 
industries, mixer-settlers and columns. For specific applications requiring short contact times or small equipment volume, centrifugal extractors are applied.

Each mixer-settler unit involves one mixer for phase dispersion and one settler to allow phase separation by gravity, which provides one stage of extraction. Several mixer-settler units can be connected to form a multi-stage extraction. Mixer-settler systems usually have sufficient mixing and residence time, so the extraction is commonly close to equilibrium. However, for multi-stage extractions, large floor space and high capital cost are commonly required and large volumes of material are often involved, so that the expensive ILs may lead to uneconomic processes.

Different types of extraction columns are employed in industrial processes, such as spray columns, packed columns and plate columns [1]. A spray column is the simplest column where the droplets of the dispersed phase are generated by spray nozzles. The throughputs are generally large, but the main drawback is the serious axial dispersion (back mixing) of the continuous phase, which limits its applications. Packed columns and plate columns can reduce the back mixing to some extent and increase the mass transfer efficient by breaking the big droplets to increase the interfacial area. However, most extraction columns can operate only in a limited $\mathrm{S} / \mathrm{F}$ window of approximately $0.25<\mathrm{S} / \mathrm{F}<4$, or sometimes more extreme $0.1<\mathrm{S} / \mathrm{F}<10$, but then the mass transfer efficiency goes down significantly.

For extremely small S/F extraction cases, alternative methods are required, such as centrifugal extractors and membrane assisted extractions [22-24]. Centrifugal extractors can be used for extractions involving a tendency of emulsion formation and liquids of small density difference. Because of the short phase contact time and fast phase separation, centrifugal extractors are well suited for the chemically unstable systems. But centrifugal separators are quite capital intensive. The introduction of membranes to extraction process creates additional mass transfer limitations. Therefore, part of the work described in this thesis focuses on development of an alternative operation mode: fixed liquid extraction, in which magnetic ionic liquid (MIL) emulsion droplets stabilized by nanoparticle microgels are fixed in the tube by magnetic force in the center part of the gap between two magnets, and the feed is pumped through the MIL drops for extraction. In order to develop such technology, also good understanding of making and breaking of emulsions is necessary. In this thesis both the use of ILs for breaking emulsions and the use of nanoparticle microgels to form IL emulsions are studied.

In the next section, the background of the three cases studied are introduced, where ILs have been employed for fractionation of pyrolysis oil via liquid-liquid extraction, for 
demulsifying oil-in-water emulsions aiming for surfactant recovery, and for design of novel smart separation processes: fixed liquid extraction.

\subsection{Backgrounds of three studied cases}

\subsubsection{Fractionation of pyrolysis oil}

\subsubsection{Pyrolysis oil}

Global warming and increasing energy demand have urged the development of an alternative renewable energy and chemical sources to replace current major source-fossil fuels. Lignocellulosic biomass sources, such as wood, forestry residues and agricultural residues, have attracted great interest for production of fuels and chemicals [25-28], because of their abundance, widespread availability. Also among all available sustainable energy source (e.g. wind, solar, hydropower), only biomass contains carbon and is a part of natural carbon cycle.

Lignocellulosic biomass is mainly comprised of three types of polymers: cellulose (40$50 \%)$, hemicellulose (25-35\%) and lignin (16-25\%) [29]. Biomass can be converted into small molecules by thermochemical conversions, such as gasification, liquefaction and pyrolysis [30]. Fast pyrolysis is a technique to depolymerize the carbohydrates and lignin into gases, liquids and char, with high heating rate of biomass in absence of oxygen to temperatures above $400{ }^{\circ} \mathrm{C}$ and with rapid quenching of the produced vapors [31]. The obtained liquid product is called pyrolysis oil or bio-oil. 

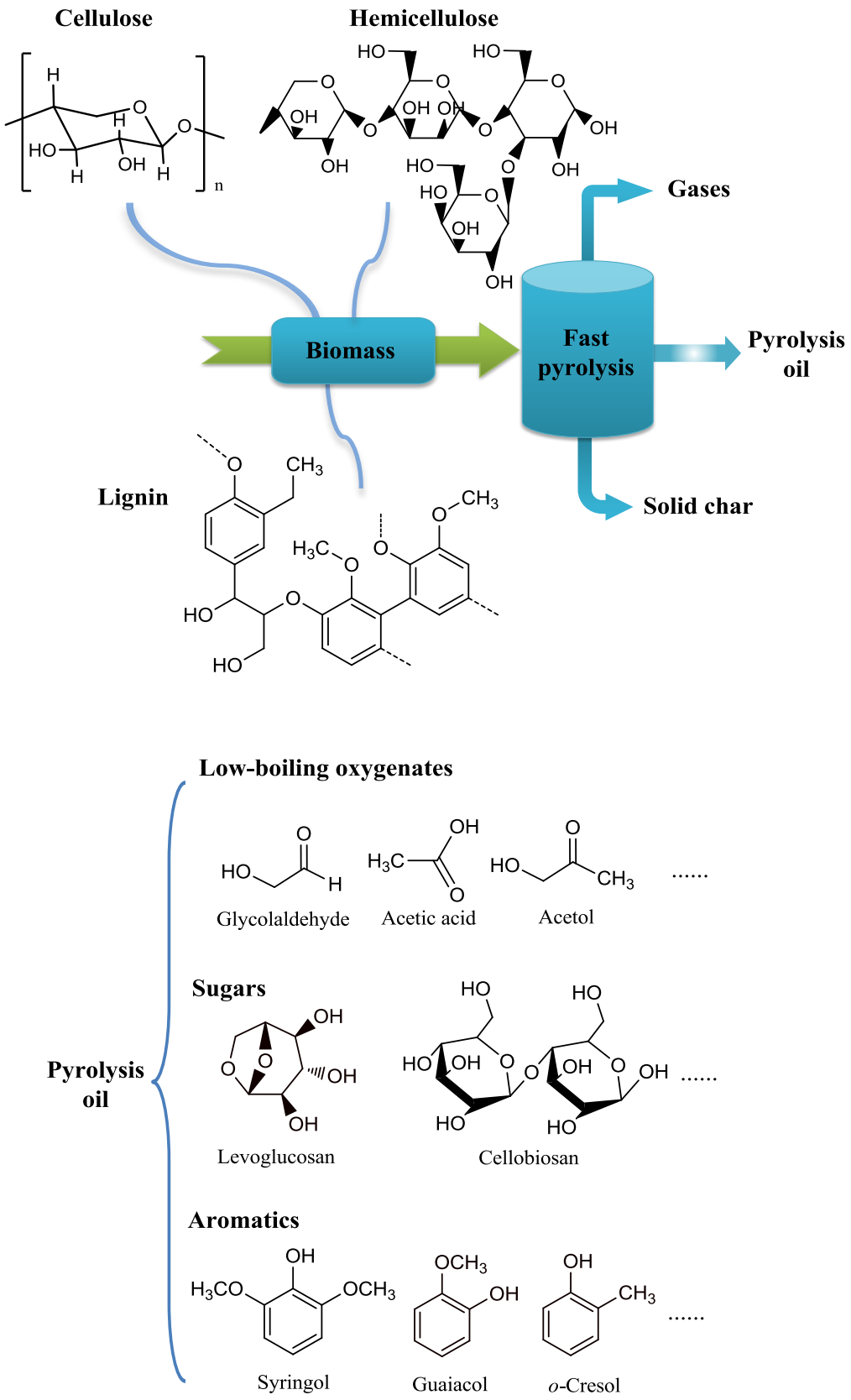

Figure 1.2. Diagram for pyrolysis process including the structures of polymers in biomass and interesting compounds in pyrolysis oil. 
Pyrolysis oil is a complex mixture with hundreds of compounds which are mainly monomers and oligomers of aromatics (e.g., guaiacol, syringol, and cresol), sugars (e.g., levoglucosan, cellobiosan, and glucose) and other classes of oxygenates (e.g., acids, aldehydes and ketones) and certain amount of water. The oil yield and exact composition of pyrolysis oil largely depend on biomass feedstock and operating conditions, such as operating temperature, biomass particle size and reactor type [32-35]. A simplified schematic representation of the pyrolysis process is shown in Figure 1.2 including the structures of polymers in biomass and the interesting compounds in pyrolysis oil.

Direct use of pyrolysis oil as chemicals or transportation fuels is restricted by some physicochemical properties, such as high viscosity, high oxygen content, high corrosivity, thermal instability and high moisture content [36]. Therefore, the pyrolysis oil requires upgrading for production of fuels and chemicals, such as catalytic cracking and deoxygenation.

Aromatics can be refined towards transport fuels or phenol formaldehyde resins [37, 38]. However, upgrading pyrolysis oil to a qualified transport fuel has not been realized at commercial scale yet due to its complex composition, and especially its high oxygen content and high water concentrations. Pyrolytic sugars may be converted into bioethanol or valuable platform chemicals, but the aromatics are one of the main classes of compounds which are toxic to the micro-organisms during fermentation [39]. Hence, aromatics and sugars ought to be separated to reduce the difficulty of upgrading and to obtain valorized chemicals.

The produced oxygenates (e.g. acetic acid, glycolaldehyde and acetol) are interesting chemicals, but their existence in pyrolysis oil causes various problems: (1) High oxygen content of oxygenates lowers the heating value of pyrolysis oil; (2) The presence of acid leads to highly corrosive oil; (3) the reactive functional group of oxygenates causes instable pyrolysis oil, e.g. its viscosity increases with storage [36]. Therefore, it is wise to recover the oxygenates from pyrolysis oil before upgrading.

Fractional condensation is an approach to separate pyrolysis vapors into several fractions based on the boiling points of the species [40, 41]. A simple pyrolysis process employing fractional condensation has been developed in the SPT group of the university of Twente. The first condenser operated at $80{ }^{\circ} \mathrm{C}$ can collect most of the sugars and aromatics, and the obtained liquid is called first condenser oil. Most of the low-boiling oxygenates and water are concentrated in the second condenser operated at $20{ }^{\circ} \mathrm{C}$, and this fraction is named as second condenser oil. The schematic of pyrolysis process with fractional condensations is displayed in Figure 1.3. This thesis investigates the downstream fractionation of these two condenser oils. 


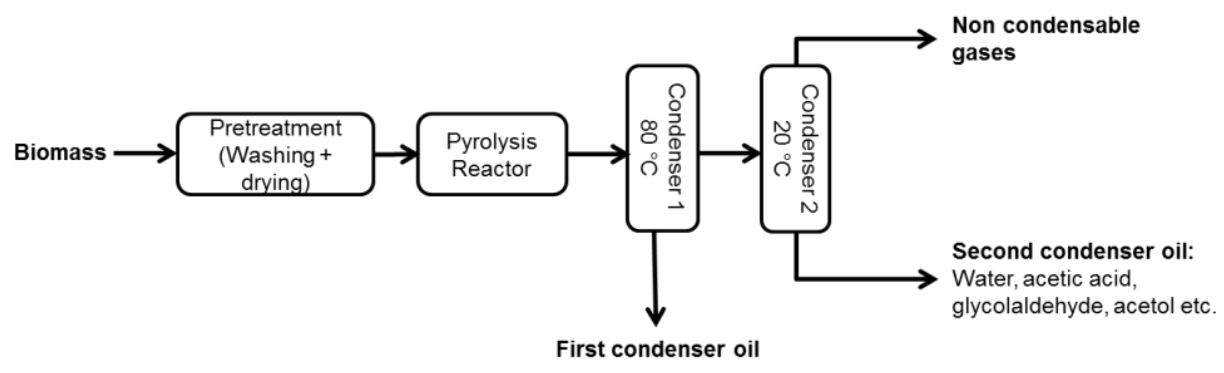

Figure 1.3. The Schematic of pyrolysis process with fractional condensations.

\subsubsection{Fractionation of first condenser oil}

For the first condenser oil, a simple initial step for separation of sugars and aromatics is water extraction where most of polar components are transferred into the aqueous phase such as sugars and oxygenates, and non-polar compounds such as lignin-derived aromatics stay in the oil phase $[42,43]$. To obtain a fermentable sugar stream, certain oxygenates and aromatics which are present in the aqueous phase require to be removed, as they are toxic to most microorganisms in fermentation process [44].

Different strategies have been developed to purify (or detoxify) the pyrolytic sugar streams, including overliming, activated carbon adsorption, air stripping and solvent extraction [4548]. However, air stripping and microbial digestion are not effective for inhibitor removal, and adsorption is restricted by the high costs of adsorbents and their regenerations [49]. Solvent extraction is identified as an effective approach $[45,46]$, and the most used solvents are organic solvents, such as ethyl acetate (EA), butyl acetate and methyl isobutyl ketone. However, the heat duty of the solvent recovery and the associated risks of utilization of large quantities of volatile organic compounds (VOCs) may limit their use in large scales.

Several researchers have successfully utilized ILs to remove aromatics from alkanes [50, 51], which shows the good affinity of ILs for aromatics. Therefore, in this thesis the technical feasibility of solvent extraction with ILs to remove aromatics from sugar-rich aqueous fractions of first condenser oil is studied. Also the fermentability of the purified sugar streams is investigated. 


\subsubsection{Fractionation of second condenser oil}

Most of the produced small oxygenates are collected in second condenser oil and some of them (e.g. acetic acid, glycolaldehyde and acetol) offer interesting commercial opportunities. For valorization, these chemicals need to be purified from the aqueous solutions.

Purification of interesting oxygenates from pyrolysis oil have been studied by several methods, such as nanofiltration [52], physical extraction [53], reactive extraction [54], and crystallization of glycolaldehyde [55]. However, due to the extremely complex and reactive pyrolysis oil, most of the methods fail for a sustainable process design. The reported nanofiltration is not feasible, because the employed membrane is irreversibly damaged by phenolics which also present in the oil stream [52]. Liquid-liquid reactive extractions using tertiary amines have been widely studied for HAc recovery from aqueous solutions $[54,56]$. However, solvent regeneration via vacuum distillation results in the loss of 2-ethyl-hexanol which may co-evaporate with the solute [57]. Stradal and Underwood have invented a process to isolate glycolaldehyde from pyrolysis oil by crystallization [58], but multiple evaporation and condensation steps are not economic and it appears better to selectively extract glycolaldehyde and recover it from the solvent.

De Haan and co-workers have studied extensively the isolation of glycolaldehyde from aqueous fraction of pyrolysis oil by liquid-liquid extraction [53, 54, 57, 59]. High extraction efficiency of glycolaldehyde can be achieved via reactive extraction with primary amines, but the regeneration is challenging due to the high stability of the formed Schiff-base [59]. Physical extraction of glycolaldehyde with 1-octanol was also investigated, but low overall glycolaldehyde yield (17.2\%, the percentage of its initial mass in the feed) were obtained from the proposed process, due to the low D of glycolaldehyde (0.25) [53]. Acetol was also co-extracted with 1-octanol, but the D of acetol was low as well (0.17). The other alternative is co-extraction of glycolaldehyde during reactive extraction of HAc with TOA in 2-ethylhexanol [54]. High HAc recovery yield $(80 \%)$ was obtained but less than $10 \mathrm{wt} \%$ of glycolaldehyde (the percentage of its initial amount in the feed) was extracted due to the low D of glycolaldehyde $(<0.20)$. Thus, exploring of new solvents with higher D of these oxygenates may bring new process options with a smaller impact on the environment.

Ionic liquids (ILs) have shown potential for extraction of acids (e.g. HAc, lactic acid, amino acid) from aqueous solutions [60-63]. Their negligible vapor pressure and high thermal stability allow ILs to be recovered from the extract by solutes evaporation, which uses potentially less energy than recovery of low boiling organic solvents where large amount of solvents are typically evaporated. Moreover, the extractability of the solutes can be enhanced by tuning the combination of cations and anions. Therefore, the feasibility and 
reusability of ILs to extract the oxygenates (acetol, HAc and glycolaldehyde) from the model aqueous solutions of pyrolysis oil is investigated in this thesis.

\subsubsection{Surfactant recovery from enhanced oil recovery}

Conventional primary and secondary oil recovery methods can only extract $35-45 \%$ of the original oil in place and leave most of the oil in reservoirs. Due to the increasing energy demand, the need for enhanced oil recovery (EOR) techniques has become imperative, which usually can extract an additional 5-15\% of the original oil. Major techniques of EOR include gas injection, thermal injection and chemical injection. Chemical enhanced oil recovery (CEOR) has been identified as an effective process with high recovery yield. Surfactant together with alkali and polymer are the main injected chemicals for the enhancement of oil recovery by decreasing the oil-water interfacial tension and increasing the water viscosity to increases the oil/water mobility ratio which consequently enhance the recovery of oil [64, 65]. However, application of CEOR is usually limited by the cost of the chemicals and CEOR process only accounts for about one percent of EOR production in the United States. Therefore, surfactant recovery is desired from a cost perspective.

However, the surfactant is usually blended with water and oil in the stable emulsions. Thus the first step for surfactant recovery is to destabilize these oil emulsions which is called demulsification. It is also a crucial step for producing qualified water (containing $<200 \mathrm{ppm}$ of oil) and qualified oil ( $<0.3-0.5$ vol \% water) for pipeline transportation to the refinery [66, 67].

The designability of ILs permits well tuning of the physical properties of ILs to form cationic surface-active compounds by altering the cation and anion combinations, so that they have been employed as demulsifiers to break oil-in-water or water-in-oil emulsions [68-71]. However, as a result of the complexity of crude oils, no mechanism has been proposed in the literature. To recover surfactant and ILs, it is essential to understand in which phases IL and surfactant present after demulsification; i.e., are they dissolved in aqueous phase or organic phase? Or does IL form a third phase? Are there any structure changes of IL and surfactant after demulsification? Therefore, in this thesis the efficiency and mechanism of the demulsifications with IL are investigated and the possibility of surfactant recovery is discussed.

\subsubsection{Smart separations aiming for design of a novel extraction process}


Stimuli responsive materials are often called smart materials, such as the temperature responsive microgel particles and the magneto responsive magnetic ionic liquids [14, 72]. In this thesis, smart separation indicates the use of smart materials in separations. The above mentioned two smart materials are both involved in this thesis. Aiming for design of a novel extraction process, two parts are studied: 1) The formation of IL emulsions using the temperature responsive microgel particles as stabilizer; 2) design of a novel fixed liquid extraction process by combining both smart materials.

\subsubsection{IL-based emulsions}

Many IL-based applications have shown excellent potential on laboratory scale, but their application at industrial scale is restricted by the major drawbacks of ILs, such as high viscosity and corrosivity [73, 74]. ILs generally have viscosities two or three orders of magnitude higher than conventional organic solvents, which has negative effect on the mass transfer rate and enhance the difficulty of pumping and mixing. Corrosion behavior of ILs requires special material for equipment and frequent maintenance, which leads to a costly process. Therefore, a new strategy for smart use of ILs may be beneficial.

IL-based emulsion systems that make use of stabilizers can potentially overcome these drawbacks of ILs. On the one hand, stabilized emulsions can provide smaller droplets than traditional liquid-liquid systems. On the other hand, the stabilizer (e.g. surfactants, polymers or particles) of IL-in-water emulsions, residing at the interface of IL and water, could limit or even avoid the direct contact of ILs with metal equipment, which might limit the corrosion due to the use of ILs.

Recently, IL emulsions stabilized by smart microgel particles (solvent-swollen, crosslinked polymers) have been reported [72], which can be broken on-demand and show multiple responses to temperature, $\mathrm{pH}$, ionic strength, and even to magnetic fields when magnetic ILs are employed. After the separation, the microgel particles can be collected and reused for emulsification. Thus these emulsions may have great potential for smart applications in green (bio)chemical processes. The confocal microscopy images of IL-based emulsions have been reprinted in Figure 1.4 from reference [72], which shows clearly both IL-in water and water-in-IL are produced and the microgels sit on the interface of IL and water.

However, these emulsions are usually prepared by a vortex mixer or handshaking, which have low reproducibility in terms of droplet size and numbers in large scales. Moreover, the densely packed IL-water interfaces are permeable and can also achieve fast extraction [72], but the influences of microgels on the extraction yield and the kinetics are still unknown. 


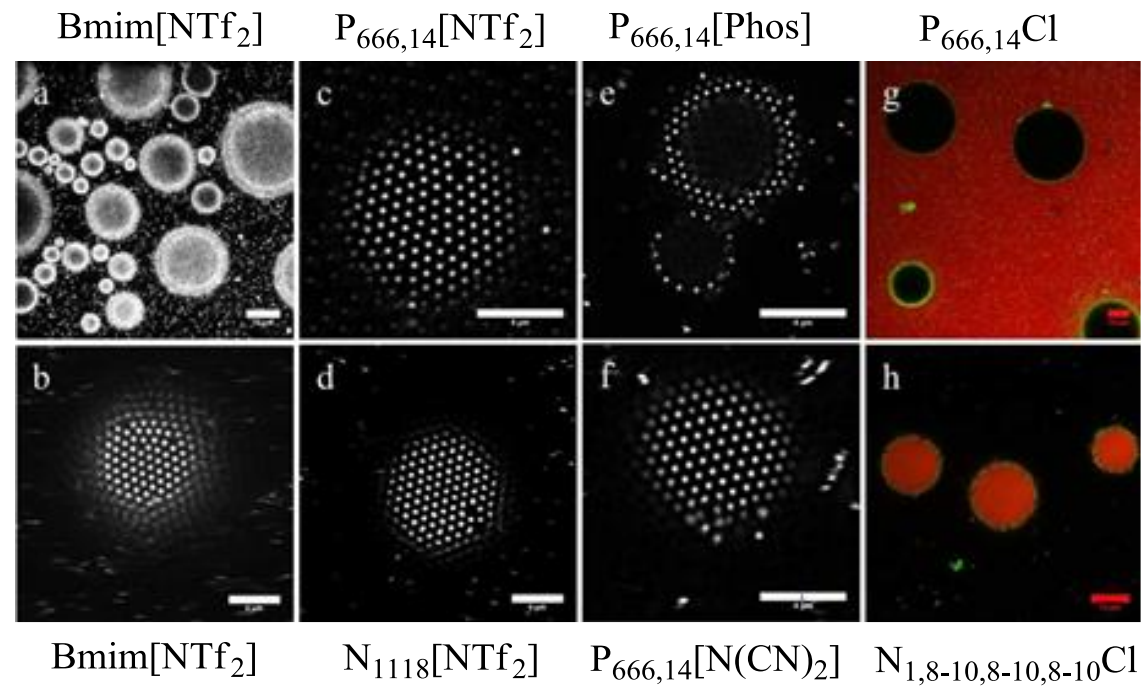

Figure 1.4. Confocal microscopy images of IL droplets in water stabilized with microgels (a-f). Confocal microscopy images of emulsions of ILs containing $\mathrm{Cl}^{-}$, the IL is colored red and the microgel particles green: (g) water-in-IL and (h) IL-in-water. Reprinted from reference [72] with permission, (C) 2014 RSC.

\subsubsection{Magnetic field effects and magnetic separation}

MILs are a subclass of ILs, which have paramagnetic properties, induced by magnetic cations, anions or both. Their strong response to an external magnetic field allows them to be separated and recycled with the aid of magnetic field [75]. MILs have attracted great interest over the past decade. Since the first MIL 1-butyl-3-methylimidazolium tetrachloroferrate (Bmim[ $\left.\mathrm{FeCl}_{4}\right]$ ) was synthesized by Hayashi in 2004 [75], more MILs have been reported, which are mainly based on transition metal containing anions (e.g. $\left[\mathrm{FeCl}_{3} \mathrm{Br}\right],\left[\mathrm{Co}(\mathrm{NCS})_{4}\right]^{2-}$, $\left[\mathrm{CoCl}_{4}\right]^{2-}$ and $\left[\mathrm{MnCl}_{4}\right]^{2-}$ ) [76-79], lanthanide-metal containing anions (e.g. $\left[\mathrm{GdCl}_{6}\right]^{3-}$ and $\left.\left[\mathrm{Dy}(\mathrm{SCN})_{6}(\mathrm{H} 2 \mathrm{O})_{2}\right]\right)[79,80]$, or organic radical ion containing cations or anions (e.g. 2,2,6,6tetramethyl-1-piperidinyl-oxy-4-sulfate) [81, 82]. Besides magnetic behavior of MILs, they can also have photo-physical or catalytic properties, owning to the metal ions in their structures, and MILs have been studied in various lab applications, such as separations, synthesis and catalysis [83-91].

In some reported cases, MILs have shown extremely high D of solutes, and even higher than non-magnetic ILs, such as in the applications of phenolic removal and benzene 
absorption $[92,93]$. With the high D in these cases, only small amounts of MIL are required. When extreme small $\mathrm{S} / \mathrm{F}$ is desired, traditional liquid-liquid contacting methods are not suitable, so that an alternative method of operation needs to be investigated. Therefore, a novel separation process concept is explored in this thesis, referred as fixed liquid extraction, aiming to apply MIL in a continuous extraction process with a very low solvent to feed ratio $(<10)$.

Magnetic field effects on the transport phenomena have been observed in several separation processes upon application of an external magnetic field [94-99]. For example, it has been shown that a magnetic field with an intensity of $2 \mathrm{~T}$ can induce a decrease of $10 \%$ of the viscosity for $\left[\mathrm{C}_{4} \mathrm{mim}\right]\left[\mathrm{FeCl}_{4}\right]$ and even $15 \%$ for $\left[\mathrm{C}_{8} \mathrm{mim}\left[\mathrm{FeCl}_{4}\right]\right.$ [100]. A permeability increase of $51 \%$ for $\alpha$-pinene in dodecane through supported MIL membranes with $\mathrm{Bmim}\left[\mathrm{FeCl}_{4}\right]$ was observed under a magnetic field of $1.2 \mathrm{~T}$ [100]. Also a magnetic orientation upon solidification of [butyloctamethylferrocenium] $\left[\mathrm{NTf}_{2}\right.$ ] was observed in a magnetic field $(0.6 \mathrm{~T})$ near room temperature, where the liquid crystallized into needles arranged perpendicular to the field [101]. It has been reported that aromatic hydrocarbons are packed in the imidazolium ILs crystals with the form of cation-aromatic 'sandwich' [102]. If the magnetic alignment could happen in a liquid state of ILs, the space in between the imidazolium cations would be changed, which may influence the structure of aromatic-IL sandwich, and hence, the distribution of the aromatic in an extraction system could then be manipulated by switching on and off a magnetic field. Therefore, in this study, also the magnetic field effects on the liquid-liquid equilibria are studied, where toluene extractions from heptane with two imidazolium-based MILs are selected. This model system furthermore allows for comparison with a wide range of literature on aromatics-aliphatics separation.

\subsection{Outline of thesis}

This work aims to study the feasibility of ILs on three challenging cases, including fractionation of pyrolysis oil (chapter 2-4), demulsification of emulsion for surfactant recovery (chapter 5), and development of a smart separation process with extreme low S/F (chapter 6-7). For a sustainable process design, solvent regeneration is a crucial aspect, thus in each case, the reusability of ILs is discussed.

Due to the complexity of pyrolysis oil, a model feed stream comprising aqueous levoglucosan solution with a guaiacol impurity is applied in Chapter 2. The use of liquidliquid extraction with ILs for guaiacol extraction from this model stream is studied. Due to the large number of ILs, the software tool COSMO-RS is first employed to simulate the extraction performances of ILs for guaiacol removal, based on a quantum-chemical approach. 
Subsequently the validation of simulation results is conducted by using seven representative ILs to perform the extraction experiments. To investigate whether ILs are more promising solvents than traditional organic solvents, conceptual processes are designed for IL-based process and ethyl acetate-based process and their heat duties are compared.

In Chapter 3, aromatics removal from sugar-rich aqueous fractions of real first condenser oils is studied by liquid-liquid extraction using IL trihexyltetradecylphosphonium dicyanamide $\left(\mathrm{P}_{666,14}\left[\mathrm{~N}(\mathrm{CN})_{2}\right]\right)$ as solvent. As comparison, the extraction of aromatics using the organic solvent EA is also conducted. Two pyrolytic sugar solutions are employed, which are created from acid-leached and untreated pinewood, respectively. To be able to evaluate the efficiency of detoxification with IL, the fermentability of the purified sugar streams is also investigated.

Chapter 4 focuses on the fractionation of the second condenser oil stream by liquid-liquid extraction using ILs, where an artificial aqueous solution comprising three oxygenates (acetic acid, glycolaldehyde and acetol) is utilized. Also an organic solvent mixture (40 wt $\%$ tri-noctylamine in 1-octanol) is studied as comparison. The temperature effect on the extraction yield of oxygenates is also investigated. To be able to interpret the experimental results, the extraction mechanism is discussed as well. Finally, the IL regeneration and reusability are studied.

To recover surfactants from oil emulsions, the emulsion needs to be demulsified in the first step, thus in Chapter 5, first, the demulsification efficiencies of 13 ILs are measured by employing tube tests and traditional bottle tests, for a model oil-in-water emulsion prepared with heptane and water, where sodium dodecylbenzenesulfonate (SDBS) is used as a surfactant. To investigate the role of ILs in demulsification and understand in which phase the surfactant stays, the mechanism of the demulsification is explained with the aid of NMR analyses. Finally, the possibility of IL regeneration and surfactant recovery is discussed.

In order to increase the interfacial area of IL and aqueous phase in solvent extraction, and decrease the viscosity and limit the corrosion behavior of ILs, one approach is to form IL-inwater emulsions. Because the drop size distribution is a critical point for extraction kinetics, Chapter 6 investigates the formation of several IL-based emulsions stabilized by microgel particles and studies the parameter influences on the drop size distributions, including the type of ILs, power input, microgel concentration. To study the smart behavior of IL emulsions, the temperature responsive behavior of IL droplets is also examined by measuring the drop size distributions when varying temperatures. Moreover, the extraction efficiency and kinetics of guaiacol extraction from aqueous solutions are compared by using IL and IL emulsions, to study the influence of microgel particles on extractions. 
Chapter 7 aims at the design of a novel extraction process to enable extremely low S/F in liquid-liquid extractions. A first prototype is designed and operated. In this setup, the magnetic field effect on liquid-liquid equilibria is investigated, in order to know the possibility of manipulating the solute distributions by the magnetic field. In the same setup, a fixed liquid extraction process is then designed to allow a continuous extraction process with extremely low S/F. To select a proper MIL emulsion, several MIL are synthesized and applied for emulsion preparation. Then the extraction of a model contaminant (methyl isobutyl ketone) from an aqueous feed is conducted for a proof of concept.

The last Chapter 8 presents the conclusions of this thesis and recommendations for future work.

\section{References}

[1] J.D. Seader, E.J. Henley, D.K. Roper, Separation Process Principles, 3rd Edition, John Wiley \& Sons, 2010.

[2] A.B. de Haan, H. Bosch, Industrial Separation Processes: Fundamentals, De Gruyter, 2013.

[3] C.B. Rasrendra, B. Girisuta, H.H. van de Bovenkamp, J.G.M. Winkelman, E.J. Leijenhorst, R.H. Venderbosch, M. Windt, D. Meier, H.J. Heeres, Recovery of acetic acid from an aqueous pyrolysis oil phase by reactive extraction using tri-n-octylamine, Chemical Engineering Journal, 176 (2011) 244-252.

[4] M.G. Freire, A.F.M. Claudio, J.M.M. Araujo, J.A.P. Coutinho, I.M. Marrucho, J.N.C. Lopes, L.P.N. Rebelo, Aqueous biphasic systems: a boost brought about by using ionic liquids, Chemical Society Reviews, 41 (2012) 4966-4995.

[5] R.K. Desai, M. Streefland, R.H. Wijffels, M. H. M. Eppink, Extraction and stability of selected proteins in ionic liquid based aqueous two phase systems, Green Chemistry, 16 (2014) 2670-2679.

[6] F. Sahena, I.S.M. Zaidul, S. Jinap, A.A. Karim, K.A. Abbas, N.A.N. Norulaini, A.K.M. Omar, Application of supercritical CO2 in lipid extraction - A review, Journal of Food Engineering, 95 (2009) 240-253.

[7] E. Reverchon, I. De Marco, Supercritical fluid extraction and fractionation of natural matter, Journal of Supercritical Fluids, 38 (2006) 146-166.

[8] E.L. Smith, A.P. Abbott, K.S. Ryder, Deep Eutectic Solvents (DESs) and Their Applications, Chemical Reviews, 114 (2014) 11060-11082.

[9] T. Welton, Room-temperature ionic liquids. Solvents for synthesis and catalysis, Chemical Reviews, 99 (1999) 2071-2083. 
[10] A.P. Abbott, G. Capper, D.L. Davies, H.L. Munro, R.K. Rasheed, V. Tambyrajah, Preparation of novel, moisture-stable, Lewis-acidic ionic liquids containing quaternary ammonium salts with functional side chains, Chemical Communications, (2001) 2010-2011. [11] K.N. Marsh, A. Deev, A.C.T. Wu, E. Tran, A. Klamt, Room temperature ionic liquids as replacements for conventional solvents - A review, Korean Journal of Chemical Engineering, 19 (2002) 357-362.

[12] R.D. Rogers, K.R. Seddon, Ionic liquids - Solvents of the future?, Science, 302 (2003) $792-793$.

[13] A.-V. Mudring, A. Babai, S. Arenz, R. Giernoth, K. Binnemans, K. Driesen, P. Nockemann, Strong luminescence of rare earth compounds in ionic liquids: Luminescent properties of lanthanide(III) iodides in the ionic liquid 1-dodecyl-3-methylimidazolium bis(trifluoromethanesulfonyl)imide, Journal of Alloys and Compounds, 418 (2006) 204-208. [14] E. Santos, J. Albo, A. Irabien, Magnetic ionic liquids: synthesis, properties and applications, Rsc Advances, 4 (2014) 40008-40018.

[15] S. Zhang, X. Lu, Q. Zhou, X. Li, X. Zhang, S. Li, Ionic Liquids:: Physicochemical Properties, Elsevier Science, 2009.

[16] J.P. Hallett, T. Welton, Room-Temperature Ionic Liquids: Solvents for Synthesis and Catalysis. 2, Chemical Reviews, 111 (2011) 3508-3576.

[17] V.I. Parvulescu, C. Hardacre, Catalysis in ionic liquids, Chemical Reviews, 107 (2007) 2615-2665.

[18] S.D. Zhu, Y.X. Wu, Q.M. Chen, Z.N. Yu, C.W. Wang, S.W. Jin, Y.G. Ding, G. Wu, Dissolution of cellulose with ionic liquids and its application: a mini-review, Green Chemistry, 8 (2006) 325-327.

[19] M.C. Buzzeo, R.G. Evans, R.G. Compton, Non-haloaluminate room-temperature ionic liquids in electrochemistry - A review, Chemphyschem, 5 (2004) 1106-1120.

[20] M. Freemantle, BASF'S smart ionic liquid, Chemical \& Engineering News, 81 (2003) 9-9.

[21] J.C. Godfrey, M.J. Slater, Liquid-Liquid Extraction Equipment, Wiley, 1995.

[22] B. Schuur, A.J. Hallet, J.G.M. Winkelman, J.G. de Vries, H.J. Heeres, Scalable Enantioseparation of Amino Acid Derivatives Using Continuous Liquid-Liquid Extraction in a Cascade of Centrifugal Contactor Separators, Organic Process Research \& Development, 13 (2009) 911-914.

[23] B. Schuur, A.J. Hallett, J.G.M. Winkelman, J.G. de Vries, H.J. Heeres, Scalable Enantioseparation of Amino Acid Derivatives Using Continuous Liquid-Liquid Extraction in a Cascade of Centrifugal Contactor Separators, Organic Process Research \& Development, 13 (2009) 911-914. 
[24] Š. Schlosser, R. Kertész, J. Marták, Recovery and separation of organic acids by membrane-based solvent extraction and pertraction: An overview with a case study on recovery of MPCA, Separation and Purification Technology, 41 (2005) 237-266.

[25] W.P.M. van Swaaij, S.R.A. Kersten, W. Palz, Biomass Power for the World, Pan Stanford Publishing, 2015.

[26] C.H. Zhou, X. Xia, C.X. Lin, D.S. Tong, J. Beltramini, Catalytic conversion of lignocellulosic biomass to fine chemicals and fuels, Chemical Society Reviews, 40 (2011) 5588-5617.

[27] J. Lee, Biological conversion of lignocellulosic biomass to ethanol, Journal of Biotechnology, 56 (1997) 1-24.

[28] J.B. Binder, R.T. Raines, Simple Chemical Transformation of Lignocellulosic Biomass into Furans for Fuels and Chemicals, Journal of the American Chemical Society, 131 (2009) 1979-1985.

[29] D. Mohan, C.U. Pittman, P.H. Steele, Pyrolysis of wood/biomass for bio-oil: A critical review, Energy \& Fuels, 20 (2006) 848-889.

[30] S.R.A. Kersten, W.P.M. van Swaaij, L. Lefferts, K. Seshan, Options for Catalysis in the Thermochemical Conversion of Biomass into Fuels, in: Catalysis for Renewables, WileyVCH Verlag GmbH \& Co. KGaA, 2007, pp. 119-145.

[31] S. Kersten, M. Garcia-Perez, Recent developments in fast pyrolysis of ligno-cellulosic materials, Current Opinion in Biotechnology, 24 (2013) 414-420.

[32] A. Oasmaa, I. Fonts, M.R. Pelaez-Samaniego, M.E. Garcia-Perez, M. Garcia-Perez, Pyrolysis Oil Multiphase Behavior and Phase Stability: A Review, Energy \& Fuels, 30 (2016) 6179-6200.

[33] R.J.M. Westerhof, H.S. Nygard, W.P.M. van Swaaij, S.R.A. Kersten, D.W.F. Brilman, Effect of Particle Geometry and Microstructure on Fast Pyrolysis of Beech Wood, Energy \& Fuels, 26 (2012) 2274-2280.

[34] R.J.M. Westerhof, D.W.F. Brilman, W.P.M. van Swaaij, S.R.A. Kersten, Effect of Temperature in Fluidized Bed Fast Pyrolysis of Biomass: Oil Quality Assessment in Test Units, Industrial \& Engineering Chemistry Research, 49 (2010) 1160-1168.

[35] S.R.G. Oudenhoven, R.J.M. Westerhof, S.R.A. Kersten, Fast pyrolysis of organic acid leached wood, straw, hay and bagasse: Improved oil and sugar yields, Journal of Analytical and Applied Pyrolysis, 116 (2015) 253-262.

[36] A.R.K. Gollakota, M. Reddy, M.D. Subramanyam, N. Kishore, A review on the upgradation techniques of pyrolysis oil, Renewable \& Sustainable Energy Reviews, 58 (2016) 1543-1568.

[37] S.S. Kelley, X.-M. Wang, M.D. Myers, D.K. Johnson, J.W. Scahill, Use of Biomass Pyrolysis Oils for Preparation of Modified Phenol Formaldehyde Resins, in: A.V. Bridgwater, 
D.G.B. Boocock (Eds.) Developments in Thermochemical Biomass Conversion: Volume $1 /$ Volume 2, Springer Netherlands, Dordrecht, 1997, pp. 557-572.

[38] S. Czernik, A.V. Bridgwater, Overview of applications of biomass fast pyrolysis oil, Energy \& Fuels, 18 (2004) 590-598.

[39] L. Luque, R. Westerhof, G. Van Rossum, S. Oudenhoven, S. Kersten, F. Berruti, L. Rehmann, Pyrolysis based bio-refinery for the production of bioethanol from demineralized ligno-cellulosic biomass, Bioresource technology, 161 (2014) 20-28.

[40] A. Effendi, H. Gerhauser, A.V. Bridgwater, Production of renewable phenolic resins by thermochemical conversion of biomass: A review, Renewable and Sustainable Energy Reviews, 12 (2008) 2092-2116.

[41] R.J.M. Westerhof, D.W.F. Brilman, M. Garcia-Perez, Z. Wang, S.R.G. Oudenhoven, W.P.M. van Swaaij, S.R.A. Kersten, Fractional Condensation of Biomass Pyrolysis Vapors, Energy \& Fuels, 25 (2011) 1817-1829.

[42] C.R. Vitasari, G.W. Meindersma, A.B. de Haan, Water extraction of pyrolysis oil: the first step for the recovery of renewable chemicals, Bioresource technology, 102 (2011) 7204 7210 .

[43] N.M. Bennett, S.S. Helle, S.J.B. Duff, Extraction and hydrolysis of levoglucosan from pyrolysis oil, Bioresource technology, 100 (2009) 6059-6063.

[44] L.R. Jarboe, Z. Wen, D. Choi, R.C. Brown, Hybrid thermochemical processing: fermentation of pyrolysis-derived bio-oil, Applied microbiology and biotechnology, 91 (2011) 1519-1523.

[45] L. Luque, R. Westerhof, G. Van Rossum, S. Oudenhoven, S. Kersten, F. Berruti, L. Rehmann, Pyrolysis based bio-refinery for the production of bioethanol from demineralized ligno-cellulosic biomass, Bioresource technology, 161 (2014) 20-28.

[46] H. Wang, D. Livingston, R. Srinivasan, Q. Li, P. Steele, F. Yu, Detoxification and Fermentation of Pyrolytic Sugar for Ethanol Production, Applied Biochemistry and Biotechnology, 168 (2012) 1568-1583.

[47] Y.C. Li, J.A. Shao, X.H. Wang, H.P. Yang, Y.Q. Chen, Y. Deng, S.H. Zhang, H.P. Chen, Upgrading of Bio-oil: Removal of the Fermentation Inhibitor (Furfural) from the Model Compounds of Bio-oil Using Pyrolytic Char, Energy \& Fuels, 27 (2013) 5975-5981.

[48] Z.Y. Chi, M. Rover, E. Jun, M. Deaton, P. Johnston, R.C. Brown, Z.Y. Wen, L.R. Jarboe, Overliming detoxification of pyrolytic sugar syrup for direct fermentation of levoglucosan to ethanol, Bioresource technology, 150 (2013) 220-227.

[49] S.-H. Lin, R.-S. Juang, Adsorption of phenol and its derivatives from water using synthetic resins and low-cost natural adsorbents: A review, Journal of Environmental Management, 90 (2009) 1336-1349. 
[50] A. Arce, M.J. Earle, H. Rodriguez, K.R. Seddon, Separation of aromatic hydrocarbons from alkanes using the ionic liquid 1-ethyl-3-methylimidazolium bis\{(trifluoromethyl) sulfonyl \} amide, Green Chemistry, 9 (2007) 70-74.

[51] U. Domanska, A. Pobudkowska, M. Krolikowski, Separation of aromatic hydrocarbons from alkanes using ammonium ionic liquid C2NTf2 at T=298.15 K, Fluid Phase Equilibria, 259 (2007) 173-179.

[52] A. Teella, G.W. Huber, D.M. Ford, Separation of acetic acid from the aqueous fraction of fast pyrolysis bio-oils using nanofiltration and reverse osmosis membranes, Journal of Membrane Science, 378 (2011) 495-502.

[53] C.R. Vitasari, G.W. Meindersma, A.B. de Haan, Laboratory scale conceptual process development for the isolation of renewable glycolaldehyde from pyrolysis oil to produce fermentation feedstock, Green Chemistry, 14 (2012) 321-325.

[54] C.R. Vitasari, G.W. Meindersma, A.B. de Haan, Glycolaldehyde co-extraction during the reactive extraction of acetic acid with tri-n-octylamine/2-ethyl-1-hexanol from a woodbased pyrolysis oil-derived aqueous phase, Separation and Purification Technology, 95 (2012) 39-43.

[55] J.A. Stradal, G.L. Underwood, Process for producing hydroxyacetaldehyde United States Patent, 5393542 (1995).

[56] Y.K. Hong, W.H. Hong, Removal of acetic acid from aqueous solutions containing succinic acid and acetic acid by tri-n-octylamine, Separation and Purification Technology, 42 (2005) 151-157.

[57] C.R. Vitasari, G.W. Meindersma, A.B. de Haan, Conceptual process design of an integrated bio-based acetic acid, glycolaldehyde, and acetol production in a pyrolysis oilbased biorefinery, Chemical Engineering Research \& Design, 95 (2015) 133-143.

[58] J.A. Stradal, G.L. Underwood, Process for producing hydroxyacetaldehyde, United States Patent, 5393542 (1995).

[59] C.R. Vitasari, G.W. Meindersma, A.B. de Haan, Renewable glycolaldehyde isolation from pyrolysis oil-derived aqueous solution by reactive extraction with primary amines, Separation and Purification Technology, 95 (2012) 103-108.

[60] E. Reyhanitash, B. Zaalberg, S.R.A. Kersten, B. Schuur, Extraction of volatile fatty acids from fermented wastewater, Separation and Purification Technology, 161 (2016) 61-68.

[61] F.S. Oliveira, J.M.M. Araujo, R. Ferreira, L.P.N. Rebelo, I.M. Marrucho, Extraction of L-lactic, L-malic, and succinic acids using phosphonium-based ionic liquids, Separation and Purification Technology, 85 (2012) 137-146.

[62] J. Marták, Š. Schlosser, Extraction of lactic acid by phosphonium ionic liquids, Separation and Purification Technology, 57 (2007) 483-494. 
[63] M. Matsumoto, K. Mochiduki, K. Fukunishi, K. Kondo, Extraction of organic acids using imidazolium-based ionic liquids and their toxicity to Lactobacillus rhamnosus, Separation and Purification Technology, 40 (2004) 97-101.

[64] J.R. Hou, Z.C. Liu, S.F. Zhang, X. Yue, J.Z. Yang, The role of viscoelasticity of alkali/surfactant/polymer solutions in enhanced oil recovery, Journal of Petroleum Science and Engineering, 47 (2005) 219-235.

[65] A. Bera, A. Mandal, B.B. Guha, Synergistic Effect of Surfactant and Salt Mixture on Interfacial Tension Reduction between Crude Oil and Water in Enhanced Oil Recovery, Journal of Chemical and Engineering Data, 59 (2014) 89-96.

[66] K.K. Salam, A.O. Alade, A.O. Arinkoola, A. Opawale, Improving the Demulsification Process of Heavy Crude Oil Emulsion through Blending with Diluent, Journal of Petroleum Engineering, 2013 (2013) 1-6.

[67] G.J. Hirasaki, C.A. Miller, O.G. Raney, M.K. Poindexter, D.T. Nguyen, J. Hera, Separation of Produced Emulsions from Surfactant Enhanced Oil Recovery Processes, Energy and Fuels, 25 (2011) 555-561.

[68] C.A. Flores, E.A. Flores, E. Hernandez, L.V. Castro, A. Garcia, F. Alvarez, F.S. Vazquez, Anion and cation effects of ionic liquids and ammonium salts evaluated as dehydrating agents for super-heavy crude oil: Experimental and theoretical points of view, Journal of Molecular Liquids, 196 (2014) 249-257.

[69] E.B. Silva, D. Santos, D.R.M. Alves, M.S. Barbosa, R.C.L. Guimaraes, B.M.S. Ferreira, R.A. Guarnieri, E. Franceschi, C. Dariva, A.F. Santos, M. Fortuny, Demulsification of Heavy Crude Oil Emulsions Using Ionic Liquids, Energy and Fuels, 27 (2013) 6311-6315.

[70] R.C.B. Lemos, E.B. da Silva, A. dos Santos, R.C.L. Guimaraes, B.M.S. Ferreira, R.A. Guarnieri, C. Dariva, E. Franceschi, A.F. Santos, M. Fortuny, Demulsification of Water-inCrude Oil Emulsions Using Ionic Liquids and Microwave Irradiation, Energy and Fuels, 24 (2010) 4439-4444.

[71] D. Guzman-Lucero, P. Flores, T. Rojo, R. Martinez-Palou, Ionic Liquids as Demulsifiers of Water-in-Crude Oil Emulsions: Study of the Microwave Effect, Energy and Fuels, 24 (2010) 3610-3615.

[72] H. Monteillet, M. Workamp, X. Li, B. Schuur, J.M. Kleijn, F.A.M. Leermakers, J. Sprakel, Multi-responsive ionic liquid emulsions stabilized by microgels, Chemical Communications, 50 (2014) 12197-12200.

[73] G. Yu, D. Zhao, L. Wen, S. Yang, X. Chen, Viscosity of ionic liquids: Database, observation, and quantitative structure-property relationship analysis, AIChE Journal, 58 (2012) 2885-2899.

[74] M. Uerdingen, C. Treber, M. Balser, G. Schmitt, C. Werner, Corrosion behaviour of ionic liquids, Green Chemistry, 7 (2005) 321-325. 
[75] S. Hayashi, H.O. Hamaguchi, Discovery of a magnetic ionic liquid bmim FeCl4, Chemistry Letters, 33 (2004) 1590-1591.

[76] S. Hayashi, S. Saha, H.O. Hamaguchi, A new class of magnetic fluids: bmim FeCl4 and nbmim FeCl4 ionic liquids, Ieee Transactions on Magnetics, 42 (2006) 12-14.

[77] I. de Pedro, D.P. Rojas, J. Albo, P. Luis, A. Irabien, J.A. Blanco, J. Rodriguez Fernandez, Long-range magnetic ordering in magnetic ionic liquid: Emim FeCl4, Journal of PhysicsCondensed Matter, 22 (2010).

[78] T. Peppel, M. Kockerling, M. Geppert-Rybczynska, R.V. Ralys, J.K. Lehmann, S.P. Verevkin, A. Heintz, Low-viscosity paramagnetic ionic liquids with doubly charged [Co(NCS)4]2- ions, Angew Chem Int Ed Engl, 49 (2010) 7116-7119.

[79] R.E. Del Sesto, T.M. McCleskey, A.K. Burrell, G.A. Baker, J.D. Thompson, B.L. Scott, J.S. Wilkes, P. Williams, Structure and magnetic behavior of transition metal based ionic liquids, Chemical Communications, (2008) 447-449.

[80] B. Mallick, B. Balke, C. Felser, A.-V. Mudring, Dysprosium room-temperature ionic liquids with strong luminescence and response to magnetic fields, Angewandte ChemieInternational Edition, 47 (2008) 7635-7638.

[81] C.-X. Miao, J.-Q. Wang, B. Yu, W.-G. Cheng, J. Sun, S. Chanfreau, L.-N. He, S.-J. Zhang, Synthesis of bimagnetic ionic liquid and application for selective aerobic oxidation of aromatic alcohols under mild conditions, Chemical Communications, 47 (2011) 2697 2699.

[82] Y. Yoshida, H. Tanaka, G. Saito, Organic Paramagnetic Ionic Liquids Based on Anion Containing 2,2,6,6-Tetramethyl-1-piperidinyloxyl Radical Moiety, Chemistry Letters, 36 (2007) 1096-1097.

[83] K.D. Clark, O. Nacham, H. Yu, T. Li, M.M. Yamsek, D.R. Ronning, J.L. Anderson, Extraction of DNA by Magnetic Ionic Liquids: Tunable Solvents for Rapid and Selective DNA Analysis, Analytical Chemistry, 87 (2015) 1552-1559.

[84] T. Yao, S. Yao, C.H. Pan, X.Z. Dai, H. Song, Deep Extraction Desulfurization with a Novel Guanidinium-Based Strong Magnetic Room-Temperature Ionic Liquid, Energy \& Fuels, 30 (2016) 4740-4749.

[85] W. Jiang, W. Zhu, H. Li, J. Xue, J. Xiong, Y. Chang, H. Liu, Z. Zhao, Fast Oxidative Removal of Refractory Aromatic Sulfur Compounds by a Magnetic Ionic Liquid, Chemical Engineering \& Technology, 37 (2014) 36-42.

[86] W. Zhu, P. Wu, L. Yang, Y. Chang, Y. Chao, H. Li, Y. Jiang, W. Jiang, S. Xun, Pyridinium-based temperature-responsive magnetic ionic liquid for oxidative desulfurization of fuels, Chemical Engineering Journal, 229 (2013) 250-256. 
[87] M. Khodajoo, S. Sayyahi, S.J. Saghanezhad, Straightforward and solvent-free synthesis of 2-amino-4H-chromenes in the presence of a choline-based magnetic ionic liquid as catalyst, Russian Journal of General Chemistry, 86 (2016) 1177-1181.

[88] B.M. Goodajdar, S. Soleimani, One-pot and efficient synthesis of triazolo 1,2-a indazole-triones catalyzed by poly(ethylene glycol) based magnetic dicationic ionic liquid, Iranian Journal of Catalysis, 6 (2016) 43-49.

[89] A. Akbari, Tri(1-butyl-3-methylimidazolium) gadolinium hexachloride, ( bmim (3) GdCl6 ), a magnetic ionic liquid as a green salt and reusable catalyst for the synthesis of tetrasubstituted imidazoles, Tetrahedron Letters, 57 (2016) 431-434.

[90] S. Sayyahi, S. Shabani, S. Ghasemi, A. Azin, S.M. Hasani, Magnetic Ionic Liquid bmim $\mathrm{FeCl} 4$ as an Efficient Catalyst for the Synthesis of 2-Aryl Benzimidazoles and 2-Aryl Benzothiazoles Derivatives, Oriental Journal of Chemistry, 31 (2015) 1773-1778.

[91] J. Wang, H. Yao, Y. Nie, L. Bai, X. Zhang, J. Li, Application of Iron-Containing Magnetic Ionic Liquids in Extraction Process of Coal Direct Liquefaction Residues, Industrial \& Engineering Chemistry Research, 51 (2012) 3776-3782.

[92] N. Deng, M. Li, S.L. de Rooy, B. El-Zahab, I.M. Warner, Highly Efficient Extraction of Phenols from Aqueous Solution Using Magnetic Room Temperature Ionic Liquids, in: D.M. Fox, M. Mizuhata, H.C. DeLong, R.A. Mantz, P.C. Trulove (Eds.) Molten Salts and Ionic Liquids 17, 2010, pp. 73-77.

[93] Y. Jiang, C. Guo, H. Liu, Magnetically rotational reactor for absorbing benzene emissions by ionic liquids, China Particuology, 5 (2007) 130-133.

[94] S.H. Lee, S.H. Ha, S.-S. Ha, H.-B. Jin, C.-Y. You, Y.-M. Koo, Magnetic behavior of mixture of magnetic ionic liquid bmim $\mathrm{FeCl}(4)$ and water 10.1063/1.2710462, Journal of Applied Physics, 101 (2007).

[95] E. Santos, J. Albo, C.I. Daniel, C.A.M. Portugal, J.G. Crespo, A. Irabien, Permeability modulation of Supported Magnetic Ionic Liquid Membranes (SMILMs) by an external magnetic field, Journal of Membrane Science, 430 (2013) 56-61.

[96] C.I. Daniel, A.M. Rubio, P.J. Sebastiao, C.A.M. Afonso, J. Storch, P. Izak, C.A.M. Portugal, J.G. Crespo, Magnetic modulation of the transport of organophilic solutes through Supported Magnetic Ionic Liquid Membranes, Journal of Membrane Science, 505 (2016) 3643.

[97] Q. Yang, H.H. Himstedt, X. Qian, M. Ulbricht, S.R. Wickramasinghe, Magnetically Responsive Membranes, Procedia Engineering, 44 (2012) 221-224.

[98] D. Wandera, S.R. Wickramasinghe, S.M. Husson, Stimuli-responsive membranes, Journal of Membrane Science, 357 (2010) 6-35.

[99] S. Darvishmanesh, X.H. Qian, S.R. Wickramasinghe, Responsive membranes for advanced separations, Current Opinion in Chemical Engineering, 8 (2015) 98-104. 
[100] C.I. Daniel, A.M. Rubio, P.J. Sebastião, C.A.M. Afonso, J. Storch, P. Izák, C.A.M. Portugal, J.G. Crespo, Magnetic modulation of the transport of organophilic solutes through Supported Magnetic Ionic Liquid Membranes, Journal of Membrane Science, 505 (2016) 3643.

[101] Y. Funasako, T. Mochida, T. Inagaki, T. Sakurai, H. Ohta, K. Furukawa, T. Nakamura, Magnetic memory based on magnetic alignment of a paramagnetic ionic liquid near room temperature, Chemical Communications, 47 (2011) 4475-4477.

[102] J.D. Holbrey, W.M. Reichert, M. Nieuwenhuyzen, O. Sheppard, C. Hardacre, R.D. Rogers, Liquid clathrate formation in ionic liquid-aromatic mixtures, Chemical Communications, (2003) 476-477. 


\section{Chapter 2}

\section{Extraction of guaiacol from model}

\section{pyrolytic sugar stream with ionic liquids}

Pyrolytic sugars can be converted to bioethanol or valuable platform chemicals through fermentation. However, the aromatic contaminants need to be removed from the sugar stream before the refinery. The use of liquid-liquid extraction with ionic liquids (ILs) for this separation was investigated using a model system comprising aqueous levoglucosan solutions with a guaiacol impurity. The extraction performances of 41 ILs were simulated using COSMO-RS. The simulation results demonstrated that ILs with the most hydrophobic cations exhibited the highest affinities for guaiacol, and the distribution coefficients of both guaiacol and levoglucosan could be correlated to the anion polarities and hence their hydrogen bond interaction abilities with the solutes. Four phosphonium ILs, three imidazolium ILs, and an organic solvent ethyl acetate (EA) were selected to perform the extraction experiments. Trihexyl(tetradecyl)phosphonium dicyanamide $\left(\mathrm{P}_{666,14}\left[\mathrm{~N}(\mathrm{CN})_{2}\right]\right)$ showed the highest experimental selectivity of 2159 and almost no levoglucosan was extracted. Two conceptual processes were designed for separation of guaiacol from water using $\mathrm{P}_{666,14}\left[\mathrm{~N}(\mathrm{CN})_{2}\right]$ and EA respectively, based on liquid-liquid equilibrium data for the systems $\mathrm{P}_{666,14}\left[\mathrm{~N}(\mathrm{CN})_{2}\right]+$ guaiacol $+\mathrm{H} 2 \mathrm{O}$ and $\mathrm{EA}+$ guaiacol $+\mathrm{H} 2 \mathrm{O}$, experimentally determined in this work. The results showed that an EA-based process consisted of more unit operations and required five times more energy (12.42 MJ/kg guaiacol) than an IL-based process (2.15 MJ/kg guaiacol).

This chapter has been published as:

Li, X.; Kersten, S. R. A.; Schuur, B., Extraction of Guaiacol from Model Pyrolytic Sugar Stream with Ionic Liquids. Industrial \& Engineering Chemistry Research 2016, 55, 4703 4710. 


\subsection{Introduction}

Lignocellulosic biomass has the potential to replace a fraction of fossil oil for production of biofuels and chemicals. This requires breaking down the complicated structure of the lignocellulose into smaller molecules. Fast pyrolysis is a technology to depolymerize the carbohydrates and the lignin into gases, liquids, and char [1]. The liquid product, termed pyrolysis oil or simply bio-oil, is a complex mixture that contains water, aromatics (e.g., guaiacol, syringol and cresol), sugars (e.g., levoglucosan, cellobiosan, glucose) and other classes of compounds (e.g., acids, aldehydes and ketones) [2]. The aromatics can be refined towards transport fuels or phenol formaldehyde resins [3, 4]. However, upgrading pyrolysis oil to a quality of transport fuel has not been realized at commercial scale yet, due to its complex composition, and especially its high oxygen content and high water concentrations. Pyrolytic sugars may be converted into bioethanol or valuable platform chemicals [5-8], but the aromatics are one of the main classes of compounds which are toxic to the microorganisms during fermentation [9].

A known method to separate aromatics and sugars is based on water solubility [10, 11]. Addition of water to pyrolysis oil leads to phase splitting into a viscous oligomeric aromatic fraction and an aqueous sugar-rich fraction. However, the latter fraction also contains small percentages of aromatics that are toxic to micro-organisms [9]. In order to ferment the pyrolytic sugars to bioethanol, it is required to remove these aromatics.

Solvent extraction has been reported for detoxification of aqueous fractions in downstream fractionation of pyrolysis oil, for example, using ethyl acetate (EA) [8, 9], butyl acetate [12] and methyl isobutyl ketone [13] as solvents. However, these low boiling organic solvents need to be evaporated during solvent recovery, which may lead to energy intensive recovery processes. When using high boiling point solvents instead, only the solutes have to be evaporated, and the use of such solvents may be very energy efficient, and thus can be a more sustainable process option for scaling up.

Ionic liquids (ILs) are considered as environmentally friendly solvents in various application areas [14-20], due to their properties (e.g., low vapor pressure and high chemical and thermal stability). Moreover, these properties can be tuned and modulated by altering the cation and anion combination. Because of the complicated matrix of compounds in the pyrolysis oil, hydrophobic ILs, being able to form biphasic systems with water, can be of potential use. Several researchers have successfully removed aromatics from alkanes using ILs [21-27], but as far as we know, there is no work reported on the use of ILs to separate aromatics and sugars. 
The objective of this chapter is to study the opportunities for extraction of light aromatics from pyrolytic sugar streams by ILs. The studied pyrolytic sugar stream comprised an aqueous levoglucosan solution with a guaiacol impurity representing the light aromatics, due to its relatively high concentration in pyrolysis oils $[28,29]$. The software COSMO-RS, a tool for molecular description and solvent screening based on a quantum-chemical approach $[30,31]$, was used to simulate extraction performances of ILs for removal of guaiacol from aqueous levoglucosan solutions. Four phosphonium and three imidazolium ILs were subsequently chosen to perform the extraction experiments. One was eventually selected for a process evaluation study. The separation of guaiacol using EA (as benchmark solvent) was also studied and the energy consumption for that extraction plus recovery process was calculated as well.

\subsection{Theory}

\subsubsection{COSMO-RS}

COSMO-RS is a software tool that can be used to predict thermodynamic equilibria, e.g. of fluid systems and of solid-liquid systems, using a statistical thermodynamics approach. In this approach, on the basis of quantum chemical calculations (density functional theory) the molecular geometry is obtained, and the probability distribution of the screening charge density $\sigma$ for a molecule is calculated, called $\sigma$-profile $p^{i}(\sigma)$. Using this $\sigma$-profile, the macroscopic chemical potential is calculated based on a statistical thermodynamic approach. Then this chemical potential is used to calculate a wide variety of thermodynamic properties, e.g. the activity coefficient:

$$
\gamma_{S}^{i}=\exp \left\{\frac{\mu_{S}^{i}-\mu_{i}^{i}}{R T}\right\}
$$

where $\mu_{S}^{i}$ is the chemical potential in the solvent $S$ and $\mu_{i}^{i}$ is the chemical potential of the pure compound $i$.

In this project, the turbomole program package (version 7.0, 2015) was used for the quantum chemical calculations in order to obtain the charge density functions of the compounds, and the activity coefficient of the solute was predicted with COSMOthermX (2015). 


\subsubsection{Liquid-Liquid distribution coefficient and selectivity}

To characterize the suitability of a solvent for liquid-liquid extraction, the solute distribution coefficient (D) and the selectivity (S) are widely used parameters. The distribution coefficient is defined in equation (2.2):

$$
D_{i}=\frac{x_{i}^{I}}{x_{i}^{I I}}
$$

where $x_{i}^{I}$ and $x_{i}^{I I}$ represent the mole fraction of solute $i$ in phase I and phase II respectively. In this work, phase I is the IL (or EA) phase and phase II is the aqueous phase.

The selectivity $\mathrm{S}$ is calculated from the ratio of the distribution coefficients of solute $i$ and $j$ as defined in equation (2.3):

$$
S=\frac{D_{i}}{D_{j}}
$$

The equilibrium condition for liquid-liquid systems is defined in equation (2.4):

$$
\gamma_{i}^{I} \mathrm{x}_{i}^{I}=\gamma_{i}^{I I} \mathrm{x}_{i}^{I I} \quad i=1,2, \ldots N
$$

where $\gamma_{i}$ is the activity coefficient of component $i$ in a phase (I or II), and $\mathrm{N}$ is the number of compounds. By combining equations (2.2) and (2.4), the distribution coefficients can be redefined as:

$$
D_{i}=\frac{x_{i}^{I}}{x_{i}^{I I}}=\frac{\gamma_{i}^{I I}}{\gamma_{i}^{I}}
$$

\subsection{Experimental}

\subsubsection{Materials}

The ILs used in this work are listed in Table 2.1 and were supplied by Iolitec with a purity $>95 \mathrm{wt} \%$ and used directly without purification. Levoglucosan (> 98\%) was acquired from Carbosynth. Guaiacol (99\%) and EA (99.8\%) were from Sigma-Aldrich. 
Table 2.1. ILs used for extraction experiments.

\begin{tabular}{ll}
\hline \multicolumn{1}{c}{ Solvents } & Abbreviations \\
$\begin{array}{l}\text { 1-butyl-3-methylimidazolium } \\
\text { bis(trifluoromethylsulfonyl)imide }\end{array}$ & BMIM[NTf2] \\
1-butyl-3-methylimidazolium & \\
hexafluorophosphate & BMIM[PF6] \\
1-butyl-3-methylimidazolium & \\
tetracyanoborate & BMIM[B(CN)4] \\
$\begin{array}{l}\text { Trihexyl(tetradecyl)phosphonium } \\
\text { chloride }\end{array}$ & \\
$\begin{array}{l}\text { Trihexyl(tetradecyl)phosphonium } \\
\text { bis(trifluoromethylsulfonyl)imide }\end{array}$ & $\mathrm{P}_{666,14} \mathrm{Cl}$ \\
$\begin{array}{l}\text { Trihexyl(tetradecyl)phosphonium } \\
\text { 2,4,4-(trimethylpentyl)phosphinate }\end{array}$ & bis- \\
$\begin{array}{l}\text { Trihexyl(tetradecyl)phosphonium } \\
\text { dicyanamide }\end{array}$ & $\mathrm{P}_{666,14}[\mathrm{Phos}]$ \\
\hline
\end{tabular}

\subsubsection{Extraction procedure}

The feed was prepared by mixing $1.5 \mathrm{wt} \%$ guaiacol and $5.0 \mathrm{wt} \%$ levoglucosan in demineralized water. Liquid-liquid extraction experiments were carried out in $15 \mathrm{~mL}$ disposable centrifuge tubes. For these, $1 \mathrm{~g}$ IL (or EA) and $2 \mathrm{~g}$ feed were added to the tubes, respectively, and mixed using a mechanical vortexer for $2 \mathrm{~min}$ and then the tubes were introduced in a shaking bath at $20{ }^{\circ} \mathrm{C}$ for $24 \mathrm{~h}$ at $200 \mathrm{rpm}$. The mixtures were then centrifuged for $10 \mathrm{~min}$ at $9000 \mathrm{rpm}$ to break the emulsions and accelerate phase separation.

\subsubsection{Analytical methods}

The separated raffinate and extract phases were weighed (accuracy $<0.5 \%$ ) and the amount of levoglucosan and guaiacol in raffinates were analyzed by high performance liquid chromatography (HPLC, accuracy < 1.5\%). By mass balance, the percentages of levoglucosan and guaiacol in the IL phase (accuracy $<2.2 \%$ ) were calculated using equation (2.6). 


$$
x_{i}^{I L}=\frac{m_{F} x_{i}^{F}-m_{R} x_{i}^{R}}{m_{I L}}
$$

where $x_{i}^{I L}, x_{i}^{F}$ and $x_{i}^{R}$ are the concentrations of component $i$ in the extract (IL phase), the feed and the raffinate phases, respectively; $m_{\mathrm{F}}, m_{\mathrm{R}}$ and $m_{\mathrm{IL}}$ are the masses of the feed, raffinate and extracts.

HPLC (Agilent 1200 system) was equipped with a refractive index detector (RID, accuracy $<1.5 \%$ ) and a Hi-Plex-H column operated at $60{ }^{\circ} \mathrm{C}$. A $5 \mathrm{mM}$ sulfuric acid was employed as mobile phase at a flow rate of $0.6 \mathrm{~mL} / \mathrm{min}$. For liquid-liquid equilibrium experiments, the water content of raffinates and extracts was determined by Karl Fisher titration (titrant: hydranal composite 5, Metrohm 787 KFTitrino). A solution of methanol and dichloromethane (3:1, volumetric ratio) was used as solvent. The content of $\mathrm{P}_{666,14}\left[\mathrm{~N}(\mathrm{CN})_{2}\right]$ leached to the aqueous phase was measured with ion chromatography using an anion column (Metrosep A Supp 16-150/4.0) and a UV-vis detector.

\subsection{Results and discussion}

\subsubsection{ILs screening with COSMO-RS predictions}

The activity coefficients of guaiacol and levoglucosan were predicted at infinite dilution in 41 ILs and in water using COSMO-RS, and the distribution coefficients were subsequently calculated according to equation (2.5). The cation set covered typical categories, including imidazolium, pyridinium, pyrrolidinium, ammonium, isoquinolinium and phosphonium. The anions included Phos, $\mathrm{N}(\mathrm{CN})_{2}, \mathrm{~B}(\mathrm{CN})_{4}, \mathrm{NTf}_{2}$ and $\mathrm{PF}_{6}$. In addition, only one IL with a $\mathrm{Cl}$ anion $\left(\mathrm{P}_{666,14} \mathrm{Cl}\right)$ was calculated by COSMO-RS, because ILs made from chloride with the other cations in the set are water-soluble. The structures, names, and abbreviations of guaiacol, levoglucosan, and the applied ions are shown in Figure 2.1.

The calculated distribution coefficients for guaiacol $\left(\mathrm{D}_{\text {guai }}\right)$ at infinite dilution are displayed in Figure 2.2(a). This figure shows that $\mathrm{D}_{\text {guai }}$ are large, $2.5<\log \left(\mathrm{D}_{\text {guai }}\right)<5.5$ for all investigated ILs, which implies that they all have good affinities for guaiacol. The highest predicted $\mathrm{D}_{\text {guai }}$ were observed for the most hydrophobic cations, $\mathrm{N}_{4444}, \mathrm{P}_{4444}$ and $\mathrm{P}_{666,14}$, in line with the hydrophobic character of guaiacol as visualized by its $\sigma$-profile in Figure S2.1 in Appendix A (the supporting information of chapter 2). In spite of the hydrophobicity of guaiacol, it is recognized that the more polar the anion, the higher $\mathrm{D}_{\text {guai }}$. The order in distribution coefficients for anions is $\mathrm{Phos}>\mathrm{Cl}>\mathrm{N}(\mathrm{CN})_{2}>\mathrm{B}(\mathrm{CN})_{4}>\mathrm{NTf}_{2}>\mathrm{PF}_{6}$, which is consistent with the hydrogen bond accepting properties of the anions based on their $\sigma$-profiles 
shown in Figure S2.2. This suggests that the hydrogen bond interaction between anions and guaiacol also plays an important role in the guaiacol distribution.

MODEL COMPOUNDS:<smiles>COc1ccccc1O</smiles>

guaiacol

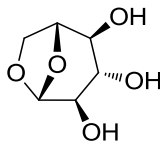

levoglucosan

CATIONS:

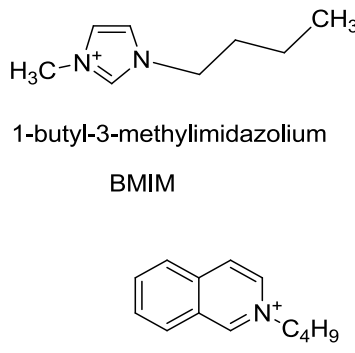

N-butyl-isoquinolinium

BIsoQ<smiles>CCCC[N+]1(C)CCCC1</smiles>

1-butyl-1-methylpyrrolidinium

BMPyrro<smiles>CCCC[n+]1ccccc1</smiles>

1-butylpyridinium

BPy

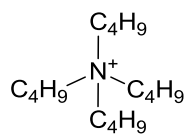

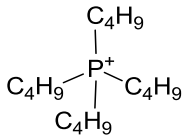

tetrabutylammonium $\mathrm{N}_{4444}$ tetrabutylphosphonium $\mathrm{P}_{4444}$<smiles>CCCCn1cc[n+](C)c1C</smiles>

1-butyl-2,3-dimethylimidazolium

BMMIM

ANIONS:

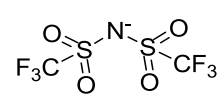<smiles>[N][B-](C#N)(C#N)C#N</smiles>

Tetracyanoborate

$\mathrm{B}(\mathrm{CN})_{4}$

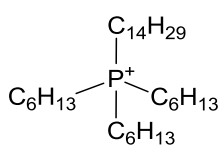

tetradecyltrihexylphosphonium

$\mathrm{P}_{666,14}$

Bis((trifluoromethyl)sulfonyl)imide

$\mathrm{NTf}_{2}$

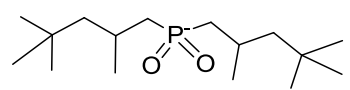

Bis(2,4,4-trimethylpentyl)phosphinate

Phos

$$
\begin{gathered}
F_{\backslash} F^{\prime} \\
F-P^{\prime}-F \\
F^{\prime} F
\end{gathered}
$$

hexafluorophosphate

$\mathrm{PF}_{6}$

$$
\mathrm{NC}^{-} \mathrm{N}_{-}^{-} \mathrm{CN}
$$

Dicyanamide

$\mathrm{N}(\mathrm{CN})_{2}$

Figure 2.1. Chemical structures, names and abbreviations of guaiacol, levoglucosan and the cations and anions of the ILs studied by COSMO-RS. 

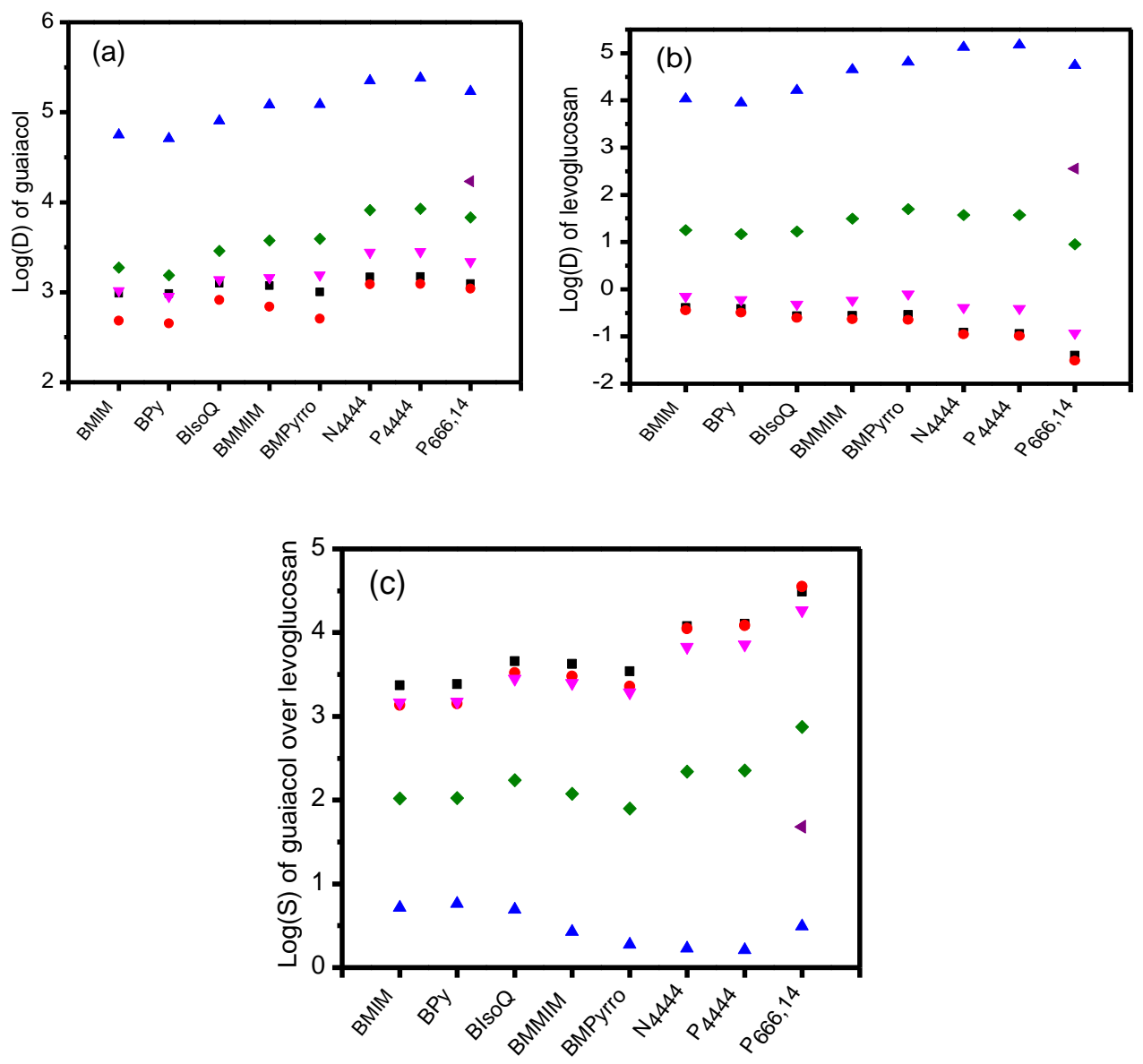

Figure 2.2. Distribution and selectivity data predicted by COSMO-RS. (a) Log(D) of guaiacol; (b) $\log (\mathrm{D})$ of levoglucosan; (c) $\log (\mathrm{S})$ of guaiacol over levoglucosan. Symbols: Phos ${ }^{-} \boldsymbol{\Delta}, \mathrm{Cl}^{-} \boldsymbol{\mathrm { N }}(\mathrm{CN})_{2}^{-} \boldsymbol{\mathrm { B }}(\mathrm{CN})_{4}^{-} \boldsymbol{\nabla}, \mathrm{NTf}_{2}^{-} \boldsymbol{\square}, \mathrm{PF}_{6}$

From Figure 2.2(b), it follows that the distribution coefficients that were calculated for levoglucosan $\left(\mathrm{D}_{\text {levo }}\right)$ are typically much lower than those of guaiacol, with the exception of Phos. The values of $\log \left(\mathrm{D}_{\text {levo }}\right)$ for anions $\mathrm{B}(\mathrm{CN})_{4}, \mathrm{NTf}_{2}$ and $\mathrm{PF}_{6}$ are below zero, indicating that levoglucosan has strong affinity for water. This is caused by the large amount of $\mathrm{OH}$ groups in levoglucosan, providing strong hydrogen bonding interaction between levoglucosan and water. When considering the effect of the anions of the ILs on $\mathrm{D}_{\text {levo, }}$, the same trend as for $\mathrm{D}_{\text {guai }}$ : $\mathrm{Phos}>\mathrm{Cl}>\mathrm{N}(\mathrm{CN})_{2}>\mathrm{B}(\mathrm{CN})_{4}>\mathrm{NTf}_{2}>\mathrm{PF}_{6}$ can be observed, and it 
is suggested that the trend in $\mathrm{D}_{\text {levo }}$ also correlates to the strength of the hydrogen bond between levoglucosan and the anions.

The resulting selectivities are displayed in Figure 2.2(c) which shows a considerable difference in the predicted selectivities for the various anions, indicating that the choice of the anion is important.

\subsubsection{Experimental validation of the ILs screening}

In the prescreening results with COSMO-RS, for most of the anions, the ILs with $\mathrm{P}_{666,14}$ cation showed the highest $\mathrm{S}$ and ILs with BMIM exhibited the lowest S. To validate the COSMO-RS predictions, four phosphonium ILs and three imidazolium ILs were chosen to perform the extraction experiments.

Table 2.2. Experimental distribution coefficients and selectivities for guaiacol and levoglucosan and water solubilities in ILs and EA (errors are from duplicate experiments).

\begin{tabular}{lllll}
\hline Solvents & $\mathrm{D}_{\text {levo }}$ & $\mathrm{D}_{\text {guai }}$ & $\mathrm{S}$ & $\mathrm{x}_{\mathrm{w}} \mathrm{b}^{\mathrm{b}}$ \\
\hline BMIM$\left[\mathrm{NTf}_{2}\right]$ & $0^{\mathrm{a}}$ & $510.1( \pm 27.6)$ & Infinite & $0.257[32]$ \\
BMIM$\left[\mathrm{PF}_{6}\right]$ & $0^{\mathrm{a}}$ & $300.7( \pm 8.2)$ & Infinite & $0.272[33]$ \\
BMIM[B(CN) $]$ & $0.4( \pm 0.1)$ & $876.9( \pm 6.6)$ & 2088 & $-^{\mathrm{c}}$ \\
$\mathrm{P}_{666,14} \mathrm{Cl}$ & $11.8( \pm 0.1)$ & $4617.4( \pm 70.6)$ & 394 & $0.817[34]$ \\
$\mathrm{P}_{666,14}\left[\mathrm{NTf}_{2}\right]$ & $1.5( \pm 0.2)$ & $418.3( \pm 2.3)$ & 284 & $0.087[34]$ \\
$\mathrm{P}_{666,14}[\mathrm{Phos}]$ & $24.0( \pm 0.2)$ & $5929.2( \pm 135.6)$ & 247 & $0.891[34]$ \\
$\mathrm{P}_{666,14}\left[\mathrm{~N}(\mathrm{CN})_{2}\right]$ & $1.8( \pm 0.5)$ & $3778.8( \pm 113.6)$ & 2159 & $0.510[34]$ \\
$\mathrm{EA}$ & $0.19( \pm 0.0)$ & $218.4( \pm 0.5)$ & 1122 & $0.139[35]$ \\
\hline
\end{tabular}

a: based on the raffinate concentration being higher than the feed concentration, the extract concentration was set to zero. ${ }^{\mathrm{b}}$ : $\mathrm{x}_{\mathrm{w}}$ is water solubility (mole fraction) in solvents at $298.15 \mathrm{~K}$. ${ }^{c}$ : not found in literature.

The experimental values for $\mathrm{D}_{\text {levo }}, \mathrm{D}_{\text {guai }}$, and $\mathrm{S}$ for the selected ILs and EA are given in Table 2.2. The concentration of levoglucosan in BMIM[PF 6 and BMIM[NTf $\left.{ }_{2}\right]$ was assumed 
to be zero, because the concentration in the raffinate was higher than the concentration in the feed. Therefore, the values of $\mathrm{D}_{\text {levo }}$ and $\mathrm{S}$ were not given for these two ILs. From Table 2.2, it follows that $\mathrm{D}_{\text {guai }}$ is much higher than $\mathrm{D}_{\text {levo }}$ for all ILs, and hence, all the ILs exhibit excellent selectivities for guaiacol.

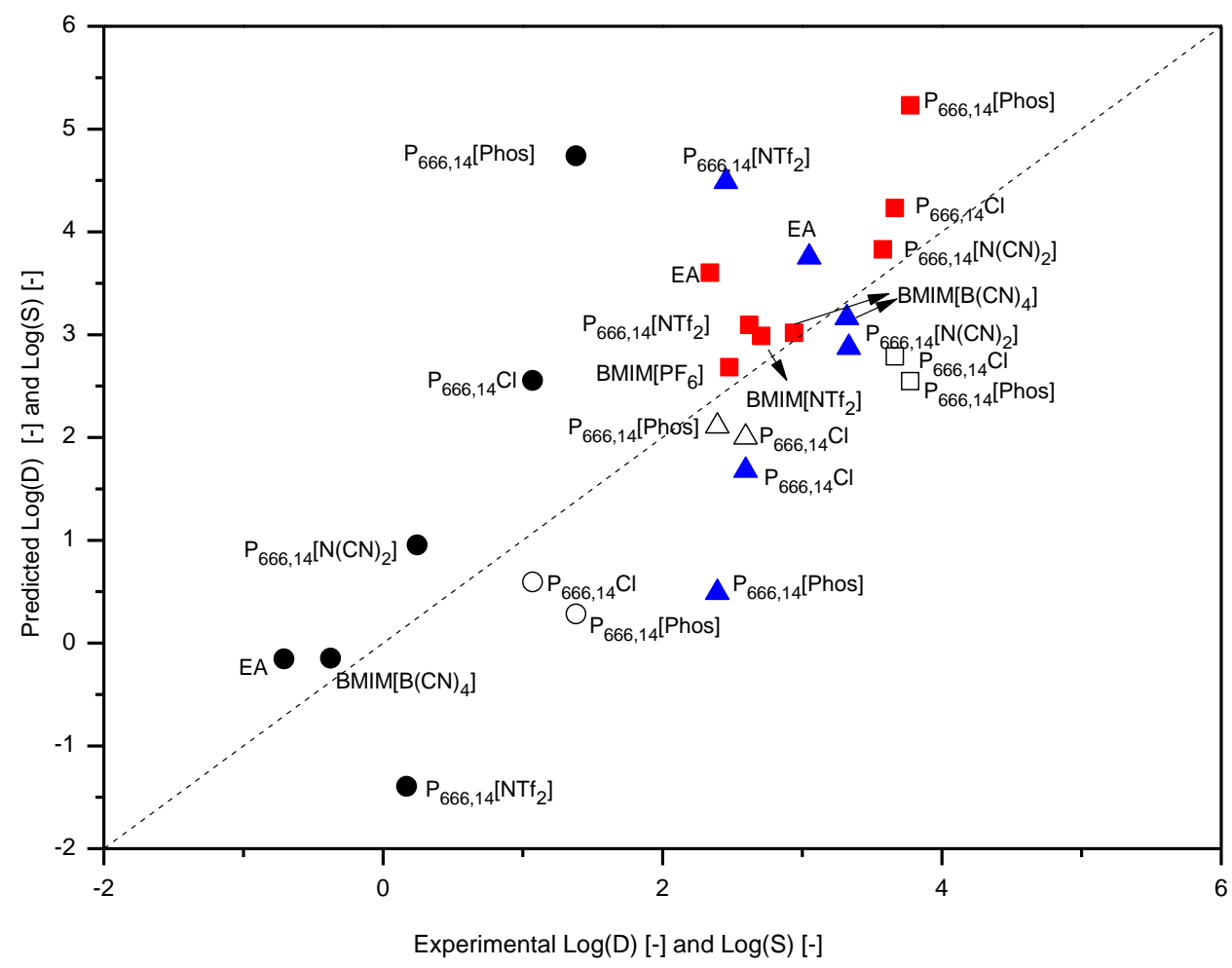

Figure 2.3. Comparison of experimental distribution coefficients and selectivities with those predicted by COSMO-RS at infinite dilution $\left(\log \left(\mathrm{D}_{\text {guai }}\right) \boldsymbol{\square}, \log \left(\mathrm{D}_{\text {levo }}\right) \bullet, \log (\mathrm{S})\right.$ $\boldsymbol{\Delta})$. Open symbols represent simulation results considering water partially soluble in ILs.

The comparison of the COSMO-RS predictions with the experimental data is demonstrated in Figure 2.3. Phosphonium ILs indeed exhibit higher $\mathrm{D}_{\text {guai }}$ than imidazolium ILs, as was predicted with the COSMO-RS method. The predicted values for $\mathrm{D}_{\text {guai }}$ for the three selected imidazolium ILs are in good agreement with the experimental results. Although for those four phosphonium ILs, there are significant quantitative deviations, the trends of the predicted and the experimental distribution coefficients with respect to variation 
of the anions are uniform, following the order: Phos $>\mathrm{Cl}>\mathrm{N}(\mathrm{CN})_{2}>\mathrm{NTf}_{2}$. This order is consistent with the anion polarities. The large deviation for $\mathrm{P}_{666,14}[\mathrm{Phos}]$ and $\mathrm{P}_{666,14} \mathrm{Cl}$ is most likely caused by the assumption of immiscible phases, while in reality, for these two ILs significant amounts of water were transferred to the IL phases (up to $15 \mathrm{wt} \%$, which expressed in mole fraction appears much more dramatic, see Table 2.2). When correcting for the amount of water in the mixture, the predictions by COSMO-RS for these two ILs become much better, as shown in Figure 2.3 with the open symbols. This indicates that predictions of $\mathrm{D}$ and $\mathrm{S}$ based on activity coefficients at infinite dilution need to be executed with caution, especially when solvent systems are partially miscible. This has to be taken into account in the prediction, and can be done either by simulation of the mutual solubility of the solvents, or more preferred, by entering the experimentally determined mutual solubilities as input in the simulation of the activities of the solutes in those phases. In spite of these deviations, for all ILs $\mathrm{D}_{\text {guai }}$ is very large and $\mathrm{D}_{\text {levo }}$ small, therefore, all these seven ILs, as well as EA, are able to separate guaiacol and levoglucosan effectively. Based on the selectivity predicted by COSMO-RS and the experimental validation, the IL $\mathrm{P}_{666,14}\left[\mathrm{~N}(\mathrm{CN})_{2}\right]$ was selected for further studies.

\subsubsection{Conceptual Process Design}

A liquid-liquid extraction is a feasible separation technology only when in combination with an effective solvent regeneration. To investigate which solvent is more promising for the levoglucosan - guaiacol separation, two conceptual processes were designed, one for $\mathrm{P}_{666,14}\left[\mathrm{~N}(\mathrm{CN})_{2}\right]$ and one for EA, both involving extraction and solvent regeneration sections. Energy requirements were calculated for both processes based on the same feed (1.5 wt \% aqueous guaiacol solution) and the same separation target (50 ppm guaiacol impurity levels in raffinate). Levoglucosan was not included in the calculations for the recovery operations, because $\mathrm{D}_{\text {levo }}$ for both $\mathrm{P}_{666,14}\left[\mathrm{~N}(\mathrm{CN})_{2}\right]$ and EA was very low, 0.060 and 0.042 respectively (based on mass fraction), which indicates that levoglucosan does not need to be recovered from the solvent phase. Also in the case of the EA-process, it is assumed that the rather limited amount of levoglucosan in the aqueous raffinate will not affect the relative volatility of the leached EA significantly.

\subsubsection{Extraction Process using EA as solvent}

The designed conceptual process using EA includes one extraction column, two distillation columns and two heat exchangers (see Figure 2.4). A countercurrent extraction process was employed by adding the feed from the top and EA from the bottom of the column. 
The stream 'Extract' leaving the process from the top, contains EA, guaiacol and small amount of water. The bottom stream 'Raffinate' contains mainly water, a certain amount of EA and traces of guaiacol. EA was recovered by distillation from both the raffinate and the extract stream. Before entering the distillation columns 1 and 2, extract and raffinate streams were heated via heat exchangers in which the minimal temperature difference for heat exchange was set at $10{ }^{\circ} \mathrm{C}$.

To simulate the involved columns, a thermodynamic description of the system EA + guaiacol $+\mathrm{H} 2 \mathrm{O}$ was developed using the non-random two liquid (NRTL) model. The binary interaction parameters involving guaiacol were regressed in ASPEN PLUS, based on liquidliquid equilibrium (LLE) data which were experimentally obtained in this work. The full ternary phase diagram for system $\mathrm{EA}+$ guaiacol $+\mathrm{H} 2 \mathrm{O}$ is demonstrated in Figure 2.5 and LLE data and the NRTL parameters are presented in the Appendix A.

In the process design, the solvent-to-feed $(\mathrm{S} / \mathrm{F})$ ratio was first determined. Based on the $\mathrm{D}_{\text {guai }}$ the calculated minimum $\mathrm{S} / \mathrm{F}$ ratio would be 0.034 , but due to the EA solubility of 83 $\mathrm{g} / \mathrm{L}$ in water [36], the $\mathrm{S} / \mathrm{F}$ ratio was set at 0.2 for proper operation. Furthermore, to achieve the target extraction efficiency, an extraction process with three theoretical stages was required. The number of equilibrium stages (NTS), reflux ratio (R), and distillate rate were optimized for those two distillation columns: DST1 and DST2. For both columns, the optimal NTS was 8 and feed stage was 5. The calculation method for minimum S/F ratio and optimization details are displayed in the Appendix A.

On the basis of the above conditions and optimal $\mathrm{R}$ and distillate rate, the heat duties of reboiler (Qreb) and condenser (Qcond) for both columns were evaluated (see Table 2.3). In total, the energy consumption of the reboilers for recovering EA was $12.42 \mathrm{MJ} / \mathrm{kg}$ guaiacol at atmospheric pressure. A reduced pressure of 0.25 bar resulted in slightly decreased heat duties of the reboilers. 
EA 1

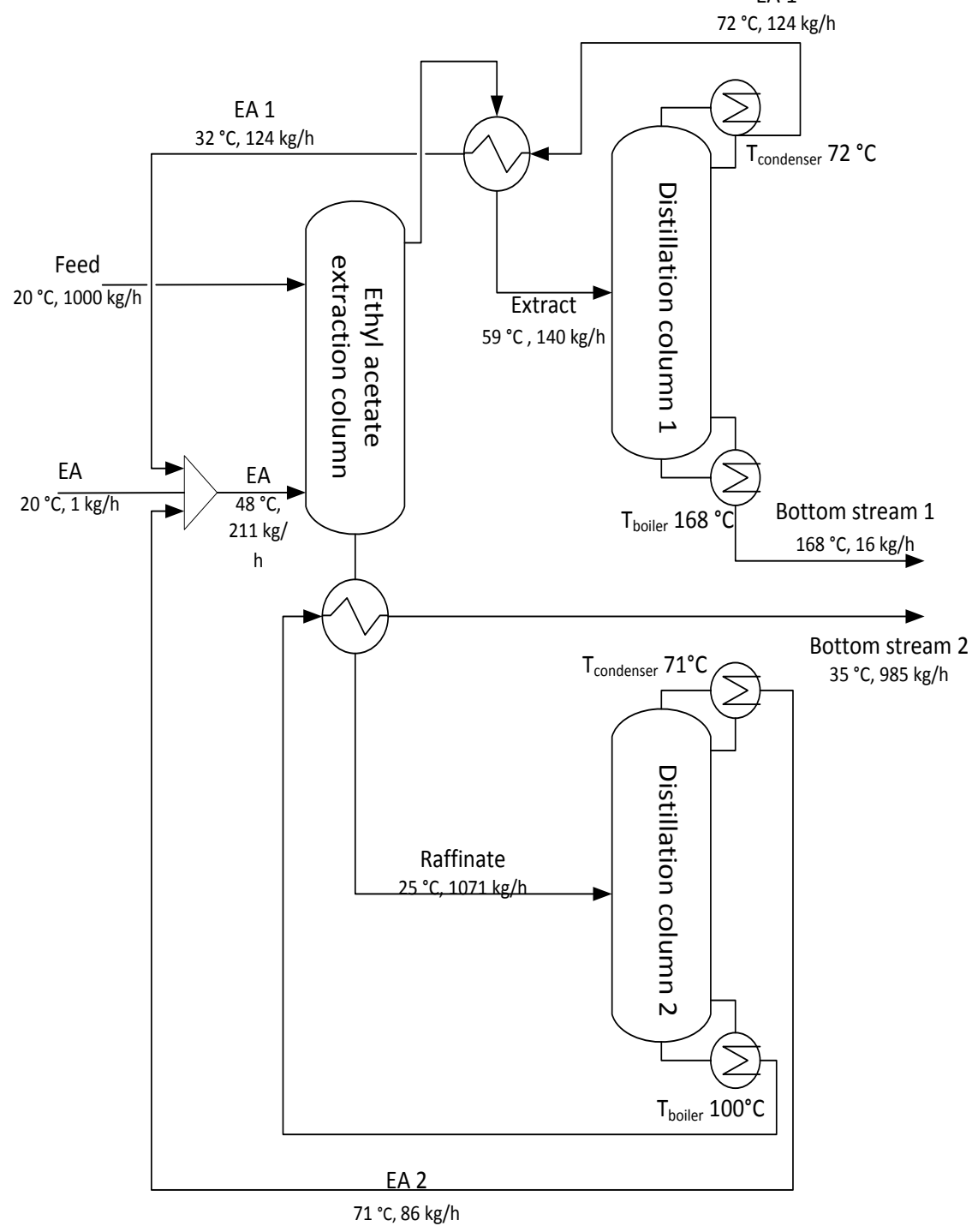

Figure 2.4. Conceptual process scheme for separating guaiacol from water at 1 bar using solvent EA. EA1 = EA stream from distillation column 1; EA2 = EA stream from distillation column 2 . 


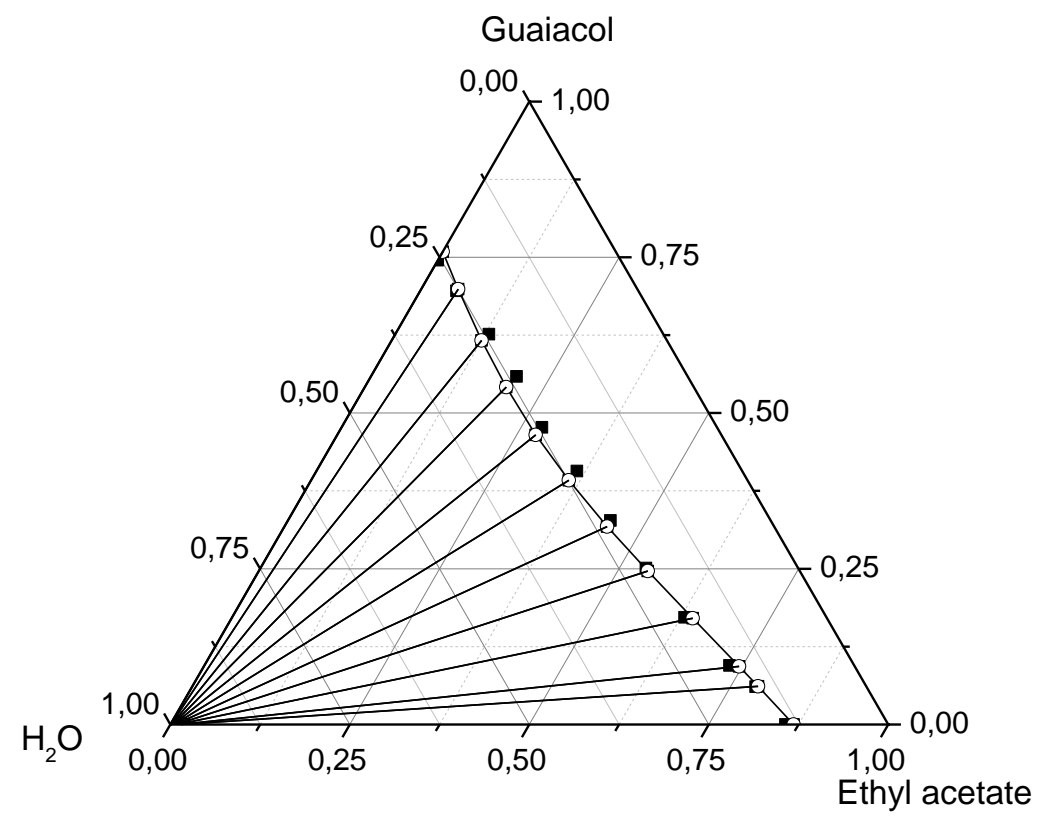

Figure 2.5. Ternary diagrams of the system $\left(\mathrm{EA}+\right.$ guaiacol $\left.+\mathrm{H}_{2} \mathrm{O}\right)$ at $293.15 \mathrm{~K}$. Experimental values $(\mathbf{\square})$; Fitted NRTL model $(0,-)$.

Table 2.3. Heat duties of reboilers and condensers in DST1 and DST2 column for system $\mathrm{EA}+$ guaiacol + $\mathrm{H} 2 \mathrm{O}$.

\begin{tabular}{lcccccc}
\hline Column & $\begin{array}{l}\text { Ditillate rate } \\
(\mathrm{kg} / \mathrm{h})\end{array}$ & $\begin{array}{l}\text { Reflux } \\
\text { ratio }\end{array}$ & $\begin{array}{l}\text { Qreb } \\
(\mathrm{MJ} / \mathrm{kg} \text { guaiacol })\end{array}$ & $\begin{array}{l}\text { Qcond } \\
(\mathrm{MJ} / \mathrm{kg} \text { guaiacol })\end{array}$ \\
\hline $\begin{array}{l}\text { Pressure } \\
(\text { bar })\end{array}$ & & & 1 & 0.25 & 1 & 0.25 \\
DST1 & 124 & 0.1 & 4.42 & 4.56 & -3.93 & -4.20 \\
DST2 & 86 & 0.5 & 8.00 & 7.61 & -4.22 & -4.30 \\
TOTAL & & & 12.42 & 12.17 & -8.15 & -8.50 \\
\hline
\end{tabular}




\subsubsection{Extraction Process using $P_{666,14}\left[\mathrm{~N}(\mathrm{CN})_{2}\right]$ as solvent}

The conceptual process of fractionating guaiacol using $\mathrm{P}_{666,14}\left[\mathrm{~N}(\mathrm{CN})_{2}\right]$ is demonstrated in Figure 2.6. In the process, only one extraction column and one evaporator are included, since the leaching of $\mathrm{P}_{666,14}\left[\mathrm{~N}(\mathrm{CN})_{2}\right]$ is negligible. In the evaporator, the guaiacol and a small amount of coextracted water are evaporated to recover the $\mathrm{P}_{666,14}\left[\mathrm{~N}(\mathrm{CN})_{2}\right]$. The feed flow rate was $1000 \mathrm{~kg} / \mathrm{h}$ and the extraction was carried out at $20^{\circ} \mathrm{C}$ and atmospheric pressure.

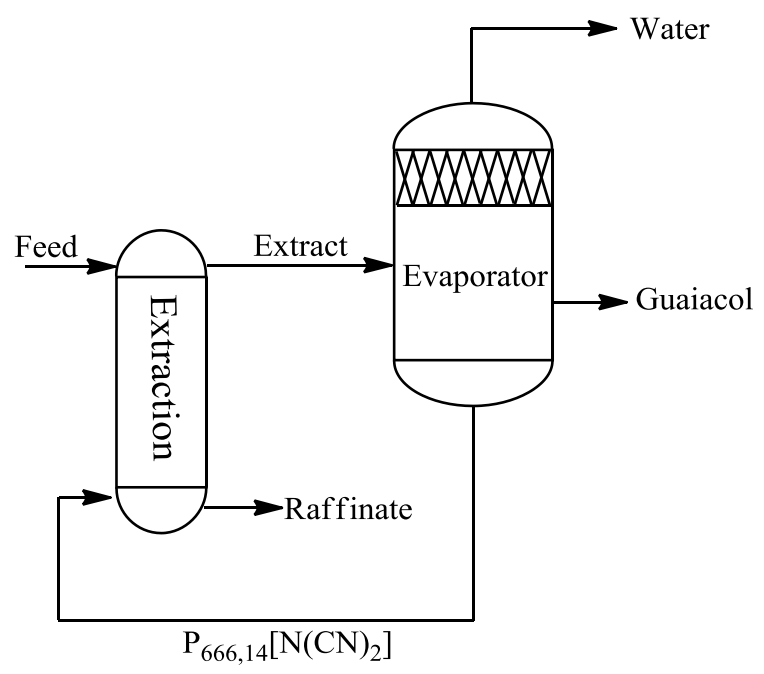

Figure 2.6. Conceptual process for fractionating guaiacol from water using solvent $\mathrm{P}_{666,14}\left[\mathrm{~N}(\mathrm{CN})_{2}\right]$

To facilitate calculations on the extraction process, the ternary diagram for $\mathrm{P}_{666,14}\left[\mathrm{~N}(\mathrm{CN})_{2}\right]$ + Guaiacol $+\mathrm{H}_{2} \mathrm{O}$ was experimentally determined (see Figure 2.7). This diagram reflects that this system can be regarded as a mutually immiscible solvent system because water hardly dissolves in $\mathrm{P}_{666,14}\left[\mathrm{~N}(\mathrm{CN})_{2}\right]$ and this IL is virtually insoluble in water $(<90 \mathrm{ppm}$, measured). With this trace amount of IL impurity, the raffinate can be used for fermentation directly. Therefore, only the solvent in extract stream needs to be recovered, and due to the large difference in volatility between guaiacol and the IL, no distillation column but a simple evaporator is sufficient.

The minimum $\mathrm{S} / \mathrm{F}$ ratio was determined using the assumption that the outgoing solvent phase is in equilibrium with the entering feed. At the feed composition with $\mathrm{x}_{\text {guai }}=0.015$, the 
$\mathrm{D}_{\text {guai }}$ is 33.4 which results in a $\mathrm{S} / \mathrm{F}_{\min }$ of 0.030 and a $\mathrm{S} / \mathrm{F}_{\text {real }}$ of 0.045 . At the solvent to feed ratio of 0.045 , seven theoretical extraction stages are required to achieve the guaiacol impurity level of $50 \mathrm{ppm}$ in the raffinate stream at $20{ }^{\circ} \mathrm{C}$ and atmospheric pressure. The LLE data for system $\mathrm{P}_{666,14}\left[\mathrm{~N}(\mathrm{CN})_{2}\right]+$ Guaiacol $+\mathrm{H}_{2} \mathrm{O}$ and minimum $\mathrm{S} / \mathrm{F}$ ratio calculations are displayed in the Appendix A.

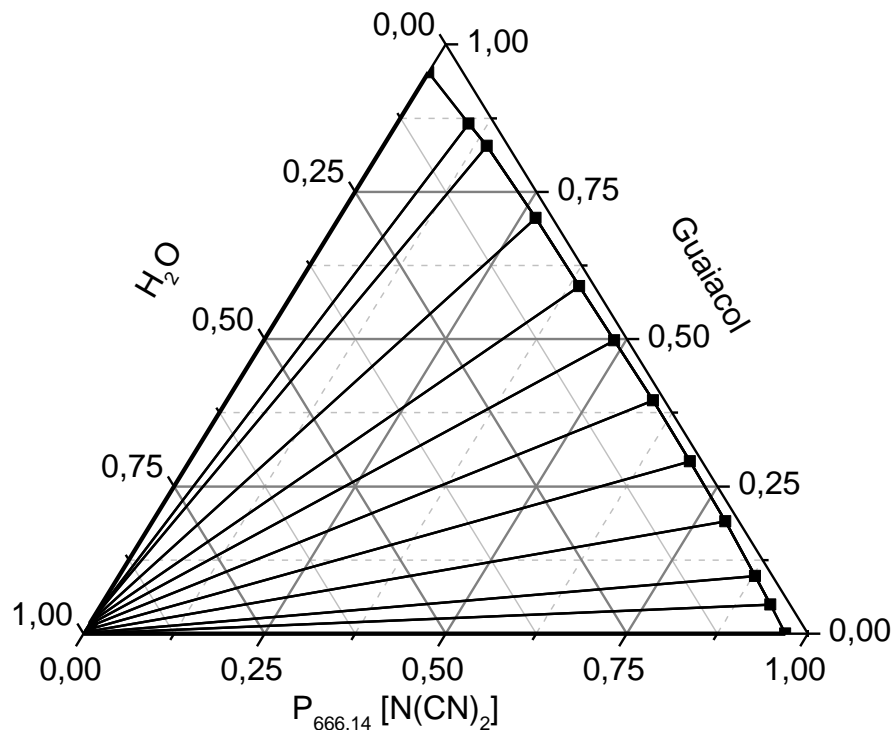

Figure 2.7. Ternary diagrams of the system $\left(\mathrm{P}_{666,14}\left[\mathrm{~N}(\mathrm{CN})_{2}\right]+\right.$ guaiacol $\left.+\mathrm{H}_{2} \mathrm{O}\right)$ at 293.15 K and atmospheric pressure.

Using the above conditions, it was calculated that the extract stream contains $24.5 \%$ guaiacol and $2.0 \%$ water. The energy duty of the reboiler comprises of the heating of the solvent to the boiling point of guaiacol and evaporating the guaiacol and the coextracted water. This corresponds to $2.15 \mathrm{MJ} / \mathrm{kg}$ guaiacol (see Table S2.4 in Appendix A for supporting information).

On the basis of the calculations on the conceptual designs, it can be concluded that the energy consumption for recovering EA is 5 times higher than that for recovering IL. This mainly results from the need to evaporate large amounts solvent from both the extract phase 
and the raffinate phase in the EA-based process, whereas it is only the extracted guaiacol with a little coextracted water being evaporated in IL-based process.

Next to the energy costs, also the comparison of the capital expenditure of the two processes turns out in favor of the IL-based process, because instead of three columns and two heat exchangers in EA-process, only one column and one evaporator are required in the IL-process.

\subsection{Conclusions}

Ionic liquid extraction can be used effectively to separate guaiacol from aqueous levoglucosan solutions. COSMO-RS simulations and experimental verification on a model feed containing levoglucosan and guaiacol identified $\mathrm{P}_{666,14}\left[\mathrm{~N}(\mathrm{CN})_{2}\right]$ as a suitable solvent for such a process. Process simulations on a simplified stream indicate that an organic solvent (EA) based process would require five times more energy than an IL-based process (2.15 $\mathrm{MJ} / \mathrm{kg}$ guaiacol). Furthermore, the IL-based process requires much less equipment (only one column, and a flash evaporator, where the EA-based process requires three columns and two heat exchangers).

\section{References}

[1] D. Carpenter, T.L. Westover, S. Czernik, W. Jablonski, Biomass feedstocks for renewable fuel production: a review of the impacts of feedstock and pretreatment on the yield and product distribution of fast pyrolysis bio-oils and vapors, Green Chem., 16 (2014) 384.

[2] P.K. Kanaujia, Y.K. Sharma, U.C. Agrawal, M.O. Garg, Analytical approaches to characterizing pyrolysis oil from biomass, Trac-Trends in Analytical Chemistry, 42 (2013) 125-136.

[3] D. Nguyen, D. Honnery, Combustion of bio-oil ethanol blends at elevated pressure, Fuel, 87 (2008) 232-243.

[4] S.S. Kelley, X. Wang, M. Myers, D. Johnson, J. Scahill, Use of biomass pyrolysis oils for preparation of modified phenol formaldehyde resins, in: A.V. Bridgwater, D.G.B. Boocock (Eds.) Developments in thermochemical biomass conversion, Blackie Academic and Professional, London, U.K., 1997.

[5] R.J. van Putten, J.C. van der Waal, E. de Jong, C.B. Rasrendra, H.J. Heeres, J.G. de Vries, Hydroxymethylfurfural, A Versatile Platform Chemical Made from Renewable Resources, Chem. Rev., 113 (2013) 1499-1597.

[6] X. Hu, C.Z. Li, Levulinic esters from the acid-catalysed reactions of sugars and alcohols as part of a bio-refinery, Green Chem., 13 (2011) 1676-1679. 
[7] B. Girisuta, L.P.B.M. Janssen, H.J. Heeres, A kinetic study on the decomposition of 5hydroxymethylfurfural into levulinic acid, Green Chem., 8 (2006) 701.

[8] L. Luque, R. Westerhof, G. Van Rossum, S. Oudenhoven, S. Kersten, F. Berruti, L. Rehmann, Pyrolysis based bio-refinery for the production of bioethanol from demineralized ligno-cellulosic biomass, Bioresource technology, 161 (2014) 20-28.

[9] J. Lian, S. Chen, S. Zhou, Z. Wang, J. O'Fallon, C.Z. Li, M. Garcia-Perez, Separation, hydrolysis and fermentation of pyrolytic sugars to produce ethanol and lipids, Bioresour. Technol., 101 (2010) 9688-9699.

[10] N.M. Bennett, S.S. Helle, S.J.B. Duff, Extraction and hydrolysis of levoglucosan from pyrolysis oil, Bioresource technology, 100 (2009) 6059-6063.

[11] E. Hassan, H. Abou-Yousef, P. Steele, Increasing the efficiency of fast pyrolysis process through sugar yield maximization and separation from aqueous fraction bio-oil, Fuel Process. Technol., 110 (2013) 65-72.

[12] K.W. Won, J.M. Prausnitz, Distribution of phenolic solutes between water and polar organic-solvents, J. Chem. Thermodyn., 7 (1975) 661-670.

[13] L. Fele Žilnik, A. Jazbinšek, Recovery of renewable phenolic fraction from pyrolysis oil, Sep. Purif. Technol., 86 (2012) 157-170.

[14] R. Patel, M. Kumari, A.B. Khan, Recent Advances in the Applications of Ionic Liquids in Protein Stability and Activity: A Review, Appl. Biochem. Biotechnol., 172 (2014) 3701 3720 .

[15] A.B. Pereiro, J.M.M. Araujo, J. Esperanca, I.M. Marrucho, L.P.N. Rebelo, Ionic liquids in separations of azeotropic systems - A review, Journal of Chemical Thermodynamics, 46 (2012) 2-28.

[16] M. Ramdin, T.W. de Loos, T.J.H. Vlugt, State-of-the-Art of CO2 Capture with Ionic Liquids, Ind. Eng. Chem. Res., 51 (2012) 8149-8177.

[17] E. Torralba-Calleja, J. Skinner, D. Gutierrez-Tauste, CO2 Capture in Ionic Liquids: A Review of Solubilities and Experimental Methods, Journal of Chemistry, (2013).

[18] T. Welton, Room-temperature ionic liquids. Solvents for synthesis and catalysis, Chemical Reviews, 99 (1999) 2071-2083.

[19] H. Zhao, G.A. Baker, Ionic liquids and deep eutectic solvents for biodiesel synthesis: a review, J. Chem. Technol. Biotechnol., 88 (2013) 3-12.

[20] S. Zhang, J. Sun, X. Zhang, J. Xin, Q. Miao, J. Wang, Ionic liquid-based green processes for energy production, Chem. Soc. Rev., 43 (2014) 7838-7869.

[21] A. Arce, M.J. Earle, H. Rodriguez, K.R. Seddon, Separation of aromatic hydrocarbons from alkanes using the ionic liquid 1-ethyl-3-methylimidazolium bis\{(trifluoromethyl) sulfonyl \} amide, Green Chemistry, 9 (2007) 70-74. 
[22] U. Domanska, A. Pobudkowska, M. Krolikowski, Separation of aromatic hydrocarbons from alkanes using ammonium ionic liquid C2NTf2 at T=298.15 K, Fluid Phase Equilibria, 259 (2007) 173-179.

[23] M. Matsumoto, Y. Inomoto, K. Kondo, Selective separation of aromatic hydrocarbons through supported liquid membranes based on ionic liquids, J. Membr. Sci., 246 (2005) 77 81.

[24] T.T. Jiao, X.L. Zhuang, H.Y. He, L.H. Zhao, C.S. Li, H.N. Chen, S.J. Zhang, An ionic liquid extraction process for the separation of indole from wash oil, Green Chem., 17 (2015) 3783-3790.

[25] M.T.G. Jongmans, B. Schuur, A.B. de Haan, Ionic Liquid Screening for Ethylbenzene/Styrene Separation by Extractive Distillation, Ind. Eng. Chem. Res., 50 (2011) 10800-10810.

[26] G.W. Meindersma, A.R. Hansmeier, A.B. de Haan, Ionic Liquids for Aromatics Extraction. Present Status and Future Outlook, Ind. Eng. Chem. Res., 49 (2010) 7530-7540. [27] A.R. Hansmeier, M. Jongmans, G.W. Meindersma, A.B. de Haan, LLE data for the ionic liquid 3-methyl-N-butyl pyridinium dicyanamide with several aromatic and aliphatic hydrocarbons, J. Chem. Thermodyn., 42 (2010) 484-490.

[28] R.J.M. Westerhof, D.W.F. Brilman, M. Garcia-Perez, Z.H. Wang, S.R.G. Oudenhoven, W.P.M. van Swaaij, S.R.A. Kersten, Fractional Condensation of Biomass Pyrolysis Vapors, Energy Fuels, 25 (2011) 1817-1829.

[29] E.-b.M. Hassan, P.H. Steele, L. Ingram, Characterization of Fast Pyrolysis Bio-oils Produced from Pretreated Pine Wood, Appl. Biochem. Biotechnol., 154 (2009) 182-192.

[30] A. Klamt, F. Eckert, COSMO-RS: a novel and efficient method for the a priori prediction of thermophysical data of liquids, Fluid Phase Equilib., 172 (2000) 43-72.

[31] F. Eckert, A. Klamt, Fast solvent screening via quantum chemistry: COSMO-RS approach, AlChE J., 48 (2002) 369-385.

[32] M.G. Freire, P.J. Carvalho, R.L. Gardas, I.M. Marrucho, L. Santos, J.A.P. Coutinho, Mutual solubilities of water and the $\mathrm{C}(\mathrm{n}) \mathrm{mim} \mathrm{Tf}(2) \mathrm{N}$ hydrophobic ionic liquids, J. Phys. Chem. B, 112 (2008) 1604-1610.

[33] M.G. Freire, C. Neves, P.J. Carvalho, R.L. Gardas, A.M. Fernandes, I.M. Marrucho, L. Santos, J.A.P. Coutinho, Mutual Solubilities of water and hydrophobic ionic liquids, J. Phys. Chem. B, 111 (2007) 13082-13089.

[34] M.G. Freire, P.J. Carvalho, R.L. Gardas, L.M.N.B.F. Santos, I.M. Marrucho, J.A.P. Coutinho, Solubility of Water in Tetradecyltrihexylphosphonium-Based Ionic Liquids, J. Chem. Eng. Data, 53 (2008) 2378-2382. 
[35] R.W. Merriman, CXCIII.-The mutual solubilities of ethyl acetate and water and the densities of mixtures of ethyl acetate and ethyl alcohol, Journal of the Chemical Society, Transactions, 103 (1913) 1774-1789.

[36] A.P. Altshuller, H.E. Everson, The solubility of ethyl acetate in water, J. Am. Chem. Soc., 75 (1953) 1727-1727. 


\section{Chapter 3}

\section{Aromatics extraction from pyrolytic}

\section{sugars using ionic liquid to enhance}

\section{sugar fermentability}

Fermentative bioethanol production from pyrolytic sugars was improved via aromatics removal by liquid-liquid extraction. As solvents, the ionic liquid (IL) trihexyltetradecylphosphonium dicyanamide $\left(\mathrm{P}_{666,14}\left[\mathrm{~N}(\mathrm{CN})_{2}\right]\right)$ and ethyl acetate $(\mathrm{EA})$ were compared. Two pyrolytic sugar solutions were created from acid-leached and untreated pinewood, with levoglucosan contents (most abundant sugar) of $29.0 \%$ and $8.3 \%(\mathrm{w} / \mathrm{w}$ ), respectively. In a single stage extraction, $70 \%$ of the aromatics were effectively removed by $\mathrm{P}_{666,14}\left[\mathrm{~N}(\mathrm{CN})_{2}\right]$ and $50 \%$ by EA, while no levoglucosan was extracted. The IL was regenerated by vacuum evaporation $(100 \mathrm{mbar})$ at $220{ }^{\circ} \mathrm{C}$, followed by extraction of aromatics from fresh pyrolytic sugar solutions. Regenerated IL extracted aromatics with similar extraction efficiency as the fresh IL, and the purified sugar fraction from pretreated pinewood was hydrolyzed to glucose and fermented to ethanol, yielding $0.46 \mathrm{~g}$ ethanol $/ \mathrm{g}$ glucose), close to the theoretical maximum yield.

\section{This chapter has been published as:}

Li, X.; Luque-Moreno, L. C.; Oudenhoven, S. R. G.; Rehmann, L.; Kersten, S. R. A.; Schuur, B., Aromatics extraction from pyrolytic sugars using ionic liquid to enhance sugar fermentability. Bioresource technology 2016, 216, 12-18. 


\subsection{Introduction}

Lignocellulosic biomass, as a renewable feedstock, has become an alternative source for the production of chemicals and fuels [1]. Fast pyrolysis (heating biomass in absence of oxygen to temperatures above $400{ }^{\circ} \mathrm{C}$ ) is a promising technology to thermally depolymerize the polysaccharides and the lignin into a liquid product, named pyrolysis oil or bio-oil [2].

Pyrolysis oil is a complex mixture containing hundreds of oxygenated organic compounds, mainly sugars and aromatics, and in addition water is present in significant amount. The exact composition of pyrolysis oil depends on the feedstock, process conditions and the recovery method. By applying fractional condensation, sugars and aromatics can be concentrated in one fraction, whereas the more volatile compounds such as glycolaldehyde and acetic acid are condensed in a second fraction [3]. Pyrolytic sugars, especially levoglucosan, can be produced with high yields up to $17 \%$ by pyrolysis of pretreated biomass (by acid leaching or infusing) [4-6].

Pyrolytic sugars have potential to be transformed into valuable chemicals or fermented into bioethanol or lipids [7-10]. However, aromatics in the oil are inhibitory to most microorganisms in fermentation process $[10,11]$. Hence, removal of these contaminants is necessary prior to fermentation. Next to sugars, the aromatics also can be valorized towards transport fuels or phenol formaldehyde resins $[12,13]$.

One strategy to separate sugars and aromatics is by adding water to pyrolysis oil to obtain two fractions, a sugar-rich aqueous fraction and an aromatic-rich oil fraction [14]. However, after this split, the fermentability of the aqueous sugar fraction is still limited, due to the presence of a certain amount of inhibitors [15]. These inhibitors need to be removed to enhance the fermentability of the aqueous pyrolytic sugar fractions.

Different strategies have been developed to purify (or detoxify) the pyrolytic sugar streams, including overliming [11, 16], activated carbon adsorption [17], air stripping [18] and solvent extraction [15, 19]. Several techniques for inhibitor removal from pyrolytic sugar fractions were compared by Wang, et al. who found that air stripping and microbial digestion were not effective for inhibitor removal, while solvent extraction and activated carbon adsorption worked successfully [18]. Although adsorption can be a strong technique with possibly high selectivity, applicability of the technique can have limitations due to the high cost associated either with the adsorbents and/or with the high costs of regenerating them [20].

Solvent extraction is an alternative method for inhibitor removal, and solvent capacities are typically higher than sorbent capacities, so that at high loading, extraction may be beneficial over adsorption. Most used solvents are organic solvents such as ethyl acetate (EA), 
butyl acetate and methyl isobutyl ketone [10, 21, 22], but for large scale applications the energy efficiency of the solvent recovery and the associated risks of utilization of large quantities of volatile organic compounds (VOCs) might be limiting.

Ionic liquids (ILs), considered as environmentally friendly solvents, have been applied in various fields of e.g. synthesis, separation and energy production [23-26]. Several researchers have successfully utilized ILs to remove aromatics from alkanes [27-30]. Recently, this group has used ILs to effectively remove aromatics from artificial sugar solutions [31]. The IL trihexyltetradecylphosphonium dicyanamide $\left(\mathrm{P}_{666,14}\left[\mathrm{~N}(\mathrm{CN})_{2}\right]\right)$ exhibited higher selectivity for guaiacol than EA. Furthermore, the conceptual process design study showed that the ILbased process was five times less energy intensive than the EA-based process [31]. Based on this study with a model mixture, it was decided to further study the potential of using $\mathrm{P}_{666,14}\left[\mathrm{~N}(\mathrm{CN})_{2}\right]$ to extract aromatics from real aqueous pyrolytic sugars for production of fermentable sugar streams.

This study investigates the technical feasibility of liquid-liquid extraction with $\mathrm{P}_{666,14}\left[\mathrm{~N}(\mathrm{CN})_{2}\right]$ to detoxify sugar-rich aqueous fractions of real pyrolysis oils. After detoxification also the fermentability of the purified sugar streams is investigated. The applied fermentation approach uses glucose obtained from hydrolysis of the levoglucosan in the sugar stream, however, in future, there may be options to work also directly with levoglucosan $[16,32]$. The two studied pyrolytic sugar solutions were prepared from first condenser fractions of pyrolysis oils from acid leached pinewood and untreated pinewood, respectively. Figure 3.1 shows the conceptual process scheme, including the pre-treatment, pyrolysis, fractionation, solvent recovery and fermentation.

\subsection{Materials and methods}

\subsubsection{Materials}

Trihexyltetradecylphosphonium dicyanamide $\left(\mathrm{P}_{666,14}\left[\mathrm{~N}(\mathrm{CN})_{2}\right]\right)$ was supplied by Iolitec with a purity $>95 \mathrm{wt} \%$ and used directly without purification. Levoglucosan $(>98 \%)$ and cellobiosan (>98\%) standards were obtained from Carbosynth. Guaiacol (99\%), glucose (99\%), acetic acid (99\%), phenol (99\%), furfural (99\%), cresol (99\%), vanillin (99\%), tetrahydrofuran (THF, $\geq 99.9 \%$ ) and ethyl acetate $(99.8 \%)$ were acquired from SigmaAldrich. 


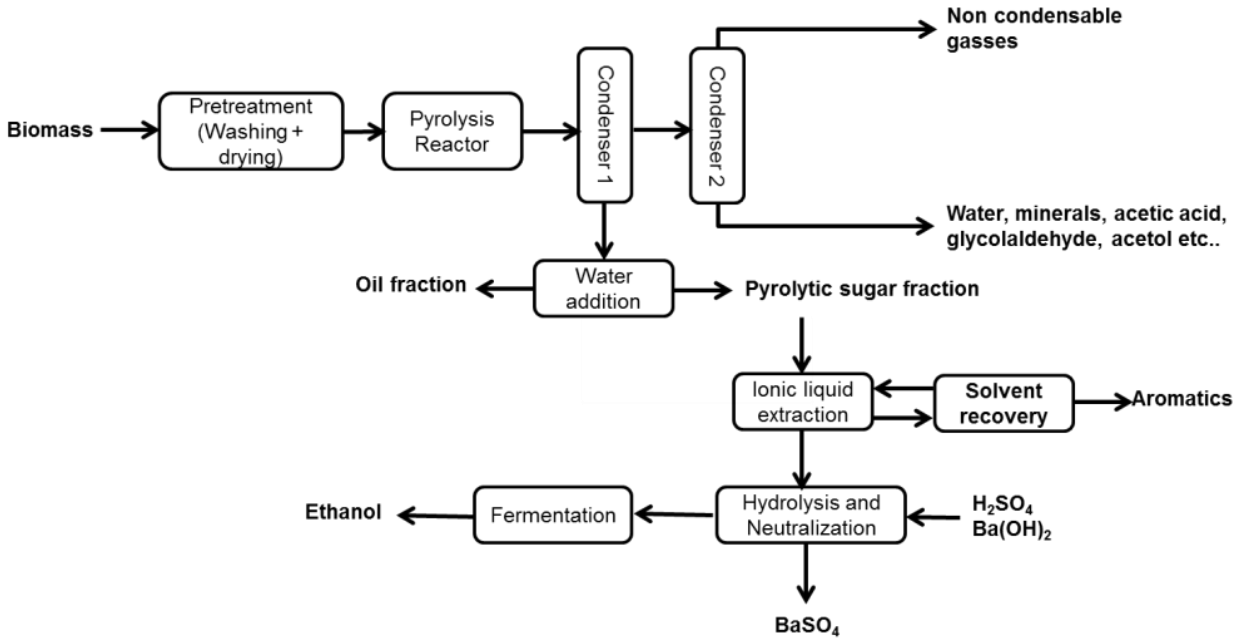

Figure 3.1. Conceptual process scheme for pyrolysis process including downstream fractionation and fermentation operations.

\subsubsection{Preparation of pyrolysis oils}

Two pyrolysis oils were studied in this work, generated from acid leached pinewood and untreated pinewood (lignocel 9, J Rettenmaier \& Söhne) using a pyrolysis process with fractional condensation. Detailed information on the pretreatment, pyrolysis and fractional condensation methods can be found in a previous publication [5]. For pyrolysis including pretreatment, the pinewood was leached with an artificial light pyrolysis fraction (rich in acetic acid) at $90{ }^{\circ} \mathrm{C}$ for $2 \mathrm{~h}$, followed by rinsing and drying. The pretreated pinewood was pyrolyzed in a fluidized-bed reactor at $530{ }^{\circ} \mathrm{C}$. Pyrolysis of untreated pinewood was done at $500{ }^{\circ} \mathrm{C}$. For both oils the first condenser was operated at $80^{\circ} \mathrm{C}$ (outgoing gas), and the second condenser was operated at $-5^{\circ} \mathrm{C}$ (outgoing gas). For the current study, only the first condenser oils are of interest, and to identify the two oils from the different processes, hereafter pyrolysis oil 1 (PO1) refers to the first condenser oil from acid leached pinewood and pyrolysis oil 2 (PO2) is the first condenser oil from untreated pinewood.

\subsubsection{Production of aqueous sugar fractions by water addition}

Both PO1 and PO2 were washed with water at a weight ratio of 1:2 in an ultrasonic bath for $12 \mathrm{~h}$ at $20{ }^{\circ} \mathrm{C}$ to obtain, an oil fraction and an aqueous fraction. Phase separation was enhanced by centrifugation for $5 \mathrm{~min}$ at $9000 \mathrm{rpm}$, after which the aqueous fraction was used 
in liquid-liquid extraction studies. Aqueous sugar fractions from PO1 and PO2 are further referred to as sugar fraction 1 (SF1) and sugar fraction 2 (SF2), respectively.

\subsubsection{Liquid-liquid extraction procedure}

Liquid-liquid extraction experiments were carried out in $50 \mathrm{~mL}$ centrifuge tubes, in which $15 \mathrm{~g} \mathrm{P}_{666,14}\left[\mathrm{~N}(\mathrm{CN})_{2}\right]$ or EA was added to $30 \mathrm{~g} \mathrm{SF} 1 \mathrm{or} \mathrm{SF} 2$. The mixtures were intensely mixed for 20 minutes at room temperature and then centrifuged for 10 minutes at $9000 \mathrm{rpm}$ to achieve phase separation. The raffinates were then analyzed by High Pressure Liquid Chromatography (HPLC) and Gel Permeation Chromatography (GPC). The thus obtained raffinate results are identified with the following codes:

RSF1-EA: raffinate after extraction of SF1 using EA.

RSF1-IL: raffinate after extraction of SF1 using IL.

RSF2-EA: raffinate after extraction of SF2 using EA.

RSF2-IL1: raffinate after extraction of SF2 using fresh IL.

\subsubsection{IL recovery}

IL recovery was investigated using the IL after aromatics extraction from SF2. In these experiments, $15 \mathrm{~g}$ extract were stirred and heated at $220^{\circ} \mathrm{C}$ and $100 \mathrm{mbar}$ in a $100 \mathrm{~mL}$ flask for $1 \mathrm{~h}$ while bubbling the flask with $\mathrm{N}_{2}$ to avoid condensation in the neck of the flask. $\mathrm{P}_{666,14}\left[\mathrm{~N}(\mathrm{CN})_{2}\right]$ was thus recovered three times, followed by reuse as solvent in liquid-liquid extractions to extract aromatics from aliquots of fresh SF2. The obtained raffinates from the multiple extractions of SF2 are given the following identification codes:

RSF2-IL2: raffinate after extraction of SF2 using IL for the second time after recovery.

RSF2-IL3: raffinate after extraction of SF2 using IL for the third time after recovery.

RSF2-IL4: raffinate after extraction of SF2 using IL for the fourth time after recovery.

\subsubsection{Acid hydrolysis and fermentation}

Acid hydrolysis of levoglucosan to glucose was performed by adding $5 \mathrm{~mL}$ aliquots of the raffinate RSF1-IL to microwave vials (VWR, Canada), followed by the addition of $\mathrm{H}_{2} \mathrm{SO}_{4}$ (final concentration of $0.5 \mathrm{~mol} / \mathrm{L}$ ) and hydrolysis in an autoclave for $20 \mathrm{~min}$ at $121^{\circ} \mathrm{C}$. The resulting hydrolysates were neutralized by adding solid $\mathrm{Ba}(\mathrm{OH})_{2}$ to reach a final $\mathrm{pH}$ of 6.5 . Following neutralization, samples were transferred to $15 \mathrm{~mL}$ centrifuge tubes and solids were 
precipitated via centrifugation at $3500 \mathrm{rpm}$ for $20 \mathrm{~min}$. Supernatant was recovered and filtered with a microfilter $(0.20 \mu \mathrm{m})$ and transferred to a new sterile $15 \mathrm{~mL}$ centrifuge tube.

Hydrolysates were diluted with demineralized water to a final glucose concentration of 40 $\mathrm{g} / \mathrm{L} .10 \mathrm{~g} / \mathrm{L}$ solid yeast extract (BD, USA) and $20 \mathrm{~g} / \mathrm{L}$ peptone (BD, USA) were added to prepare YPG (yeast, peptone and glucose) media. Once prepared, the media were filtered and sterilized. Then this YPG media was blended in different fractions with model YPG which contains the same concentrations of yeast, peptone and glucose with the former YPG media, but was prepared with laboratory grade glucose (Alfa Aesar, USA).

Microtiter plates were filled with $180 \mu \mathrm{L}$ of each blend, and inoculated with $20 \mu \mathrm{L}$ of active seed culture of Saccharomyces ceevisiae DSM 1334 (Braunschweig, Germany). The seed culture was in mid-exponential growth phase with an average DCW of $1.3 \pm 0.07 \mathrm{~g} / \mathrm{L}$. After inoculation, plates were sealed with a sterile PCR film (VWR, Canada). The film was punctured using a sterile $16 \mathrm{~g}$ needle (BD, USA). Incubation was performed at $30{ }^{\circ} \mathrm{C}$ and 80 rpm using a Micro Titer plate reader (Tecan, Austria). Growth was monitored by measuring optical density at $600 \mathrm{~nm}$ every 10 minutes for $24 \mathrm{~h}$. Anaerobic conditions (Nitrogen environment) were guaranteed using a gas control unit connected to the microplate reader. Ethanol and glucose concentrations were monitored using HPLC at the end of the incubation.

\subsubsection{Analytical methods}

The SF1, SF2 and raffinates were analyzed with HPLC, for which an Agilent 1200 system equipped with Hi-Plex-H column was operated at $60{ }^{\circ} \mathrm{C}$. Two detectors were applied, a Refractive Index Detector (RID, relative standard deviation from 5 measurements: $1.2 \%$ ) and a Variable Wavelength Detector (UV, operated at $285 \mathrm{~nm}$ with relative standard deviation from five measurements: $0.2 \%$ ). A $5 \mathrm{mM}$ of sulfuric acid was used as mobile phase at a flow rate of $0.6 \mathrm{~mL} / \mathrm{min}$. Ethanol and glucose concentrations at the end of the incubation were also monitored using HPLC, using mobile phase $0.5 \mathrm{mM} \mathrm{H}_{2} \mathrm{SO}_{4}$ at $0.7 \mathrm{~mL} / \mathrm{min}$, keeping the RID detector at $55^{\circ} \mathrm{C}$ and the Hi-Plex-H column at $60^{\circ} \mathrm{C}$.

The SF1, SF2 and all raffinates were also studied with GPC using a system from Agilent Technologies 1200. Samples were dissolved in THF and filtered over a microfilter $(0.20 \mu \mathrm{m})$. For the measurement, $20 \mu \mathrm{L}$ of sample was injected to a system composed by three columns placed in series $(7.5 \times 300 \mathrm{~mm}$, particle size $3 \mu \mathrm{m})$, and UV detectors operated at $254 \mathrm{~nm}$ were applied. A highly crosslinked polystyrene-divinylbenzene copolymer gel was used as column packing (Varian, PLgelMIXED-bed E). The chromatography was performed during $40 \mathrm{~min}$ at $40{ }^{\circ} \mathrm{C}$ and with $1 \mathrm{~mL} / \mathrm{min}$ of $\mathrm{THF}$ as eluent. The calibration to correlate elution 
time and molecular weight was performed using polystyrene of $162-29510 \mathrm{~g} / \mathrm{mol}$ as standard.

Levoglucosan in the pyrolysis oils, sugar fractions and raffinates was quantified using an Agilent 7890A gas chromatograph with a Varian CP9154 column and coupled with an Agilent 5975C mass spectrometer (GC/MS). The samples were diluted ten times with acetone and filtered with a microfilter $(0.20 \mu \mathrm{m}) .1 \mu \mathrm{L}$ of sample was injected into the injection port set at $250{ }^{\circ} \mathrm{C}$, with a split ratio of 20:1. The column was operated in a constant flow mode using $2 \mathrm{~mL} / \mathrm{min}$ of helium as a carrier gas. Identification of levoglucosan was based on retention time and matching the mass spectrum recorded with those in the spectral library (NIST/EPA/NIH Mass Spectral Library, Version 2.0f, FairCom Corporation).

Water contents of sugar fractions and raffinates were determined with relative standard deviations from triplicate measurements of $<1.5 \%$ by Karl Fisher titration (titrant: hydranal composite 5, Metrohm 787 KFTitrino). A solution of methanol and dichloromethane (3:1, volumetric ratio) was used as solvent.

\subsection{Results and discussion}

\subsubsection{Pyrolytic sugar fractions production}

The pyrolytic sugar fractions SF1 and SF2 were created by adding two mass equivalents of water to the first condenser fractions of the pyrolysis oils PO1 and PO2. In this procedure, biphasic systems are created to wash out the sugars, while the remaining viscous oil fraction consists primarily of lignin-derived aromatic oligomers and some leached water [14]. The amount of washed out matter was strongly dependent on the applied pyrolysis method, i.e. $69.3( \pm 1.5)$ wt $\%$ of PO1 and $49.3( \pm 0.3)$ wt $\%$ of PO2 ended up in the aqueous fractions SF1 and SF2, respectively. This marked difference is due to the reduced catalytic activity in pyrolysis of pretreated wood, leading to a higher sugar fraction, as was also observed by other researchers $[33,34]$. The amount of levoglucosan in the pyrolysis oils and the sugar fractions could be determined with GC/MS analysis (see Table 3.1), and it was found that the levoglucosan concentration increased significantly from $8.3( \pm 0.5) \mathrm{wt} \%$ in PO2 to $29.0( \pm 0.5)$ wt\% in PO1 where acid leached pinewood was used. The levoglucosan in SF1 was thus much more concentrated than in SF2. After a single wash, $96.1( \pm 0.7) \mathrm{wt} \%$ of the levoglucosan was transferred from PO1 to SF1, and $96.1( \pm 0.2)$ wt\% from PO2 to SF2. Thus, with a single wash the majority of the sugars is washed from the pyrolysis oils. 
Table 3.1. The compositions of sugar fractions SF1 and SF2.

\begin{tabular}{lll}
\hline & SF1 & SF2 \\
\hline Levoglucosan (wt\%) & $10.0( \pm 0.6)$ & $3.4( \pm 0.2)$ \\
Total sugars (wt $)$ & 21.8 & 13.0 \\
Water (wt $\%)$ & $73.7( \pm 0.7)$ & $79.5( \pm 0.5)$ \\
The rest compounds $(w t \%)$ & 4.5 & 7.5 \\
\hline
\end{tabular}

Due to the complex compositions of pyrolysis oils, it is difficult to identify and quantify all the individual components, so the lumped sugars and aromatics are analyzed in this work. The total amount of sugars are roughly estimated from HPLC-RID chromatograms. As reference, a known mixture was also analyzed with HPLC, containing glucose, cellobiosan, levoglucosan, acetic acid, phenol, guaiacol, furfural, cresol and vanillin. It was found that the various sugars have very similar response factors, i.e. levoglucosan $\left(1.38^{*} 10^{8}\right)$, glucose $\left(1.43 * 10^{8}\right)$, cellobiosan $\left(1.42 * 10^{8}\right)$ and cellobiose $\left(1.49 * 10^{8}\right)$. Figure $3.2(a)$ and (b) show that in the known mixture most sugars have retention times less than $15 \mathrm{~min}$, whereas for aromatics the retention times exhibit longer than $20 \mathrm{~min}$. Assuming that the compounds with retention times between 7.0 to 14.5 min are all sugars, and because of the similar response factors, the total amounts of sugars in SF1 (21.8 wt\%) and in SF2 (13.0 wt\%) were obtained by estimation based on the response factor of levoglucosan. According to the water content in these fractions shown in Table 3.1, the rest compounds, mostly phenolics and aromatics, are approximately $4.5 \mathrm{wt} \%$ and $7.5 \mathrm{wt} \%$ in SF1 and SF2 respectively. 

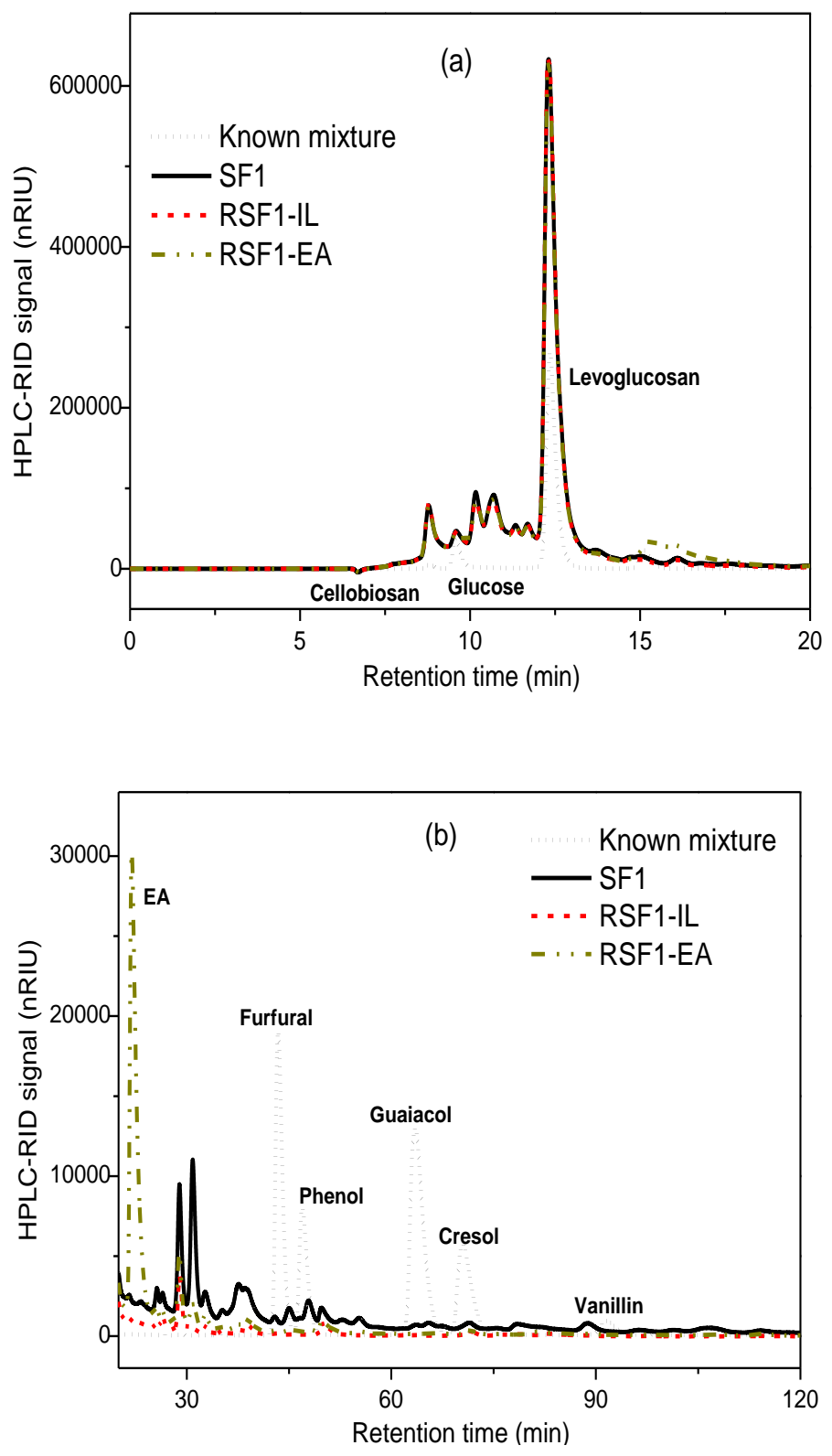

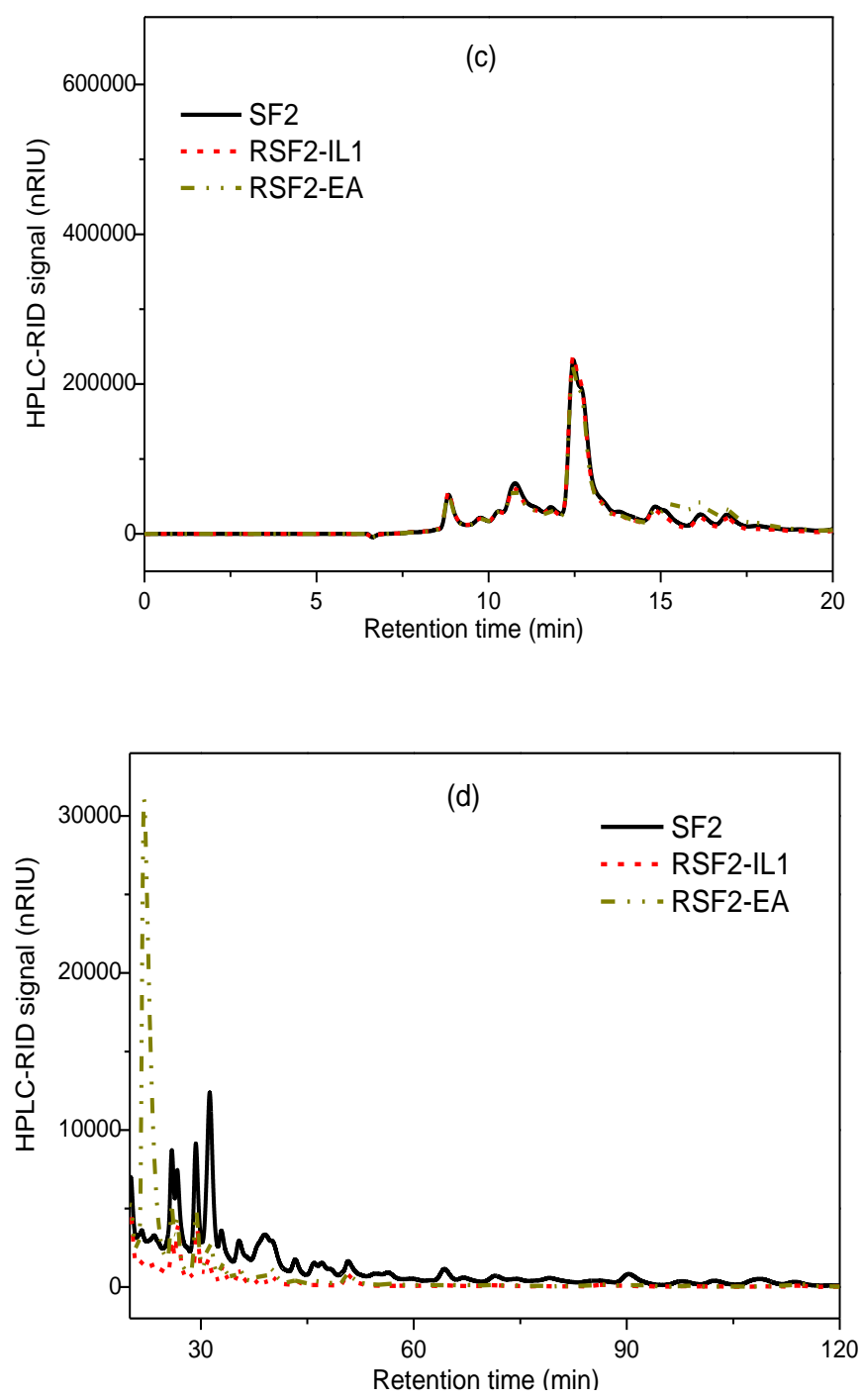

Figure 3.2. HPLC-RID signals for the known mixture, SF1, SF2 and their corresponding raffinates. Retention time: (a) and (c) from 0 to $20 \mathrm{~min}$; (b) and (d) from 20 to $120 \mathrm{~min}$. Scales of y axis differ.

Molecular weight distributions (MWD) of the aromatics present in SF1 and SF2 were recorded using GPC-UV at $254 \mathrm{~nm}$. Since most aromatics can be detected at $254 \mathrm{~nm}$ whereas carbohydrates and most organic acids are transparent, it is assumed that the measured UV signals correspond to the UV absorption of aromatics. This analysis thus provides further 
insight in the composition of the sugar fractions. Figure 3.3 (a) and (b) shows that the fraction of large molecules (molecular weight $>1000 \mathrm{~g} / \mathrm{mol}$ ) is negligible in both sugar fractions. Furthermore, the peaks around $108 \mathrm{~g} / \mathrm{mol}$ are assigned to be mono-aromatics and the ones around $182 \mathrm{~g} / \mathrm{mol}$ to aromatic dimers. By comparison of the GPC-UV results from both sugar fractions, it can be concluded that the SF2 from untreated pinewood contains a higher amount of aromatics than SF1 from pretreated pinewood.
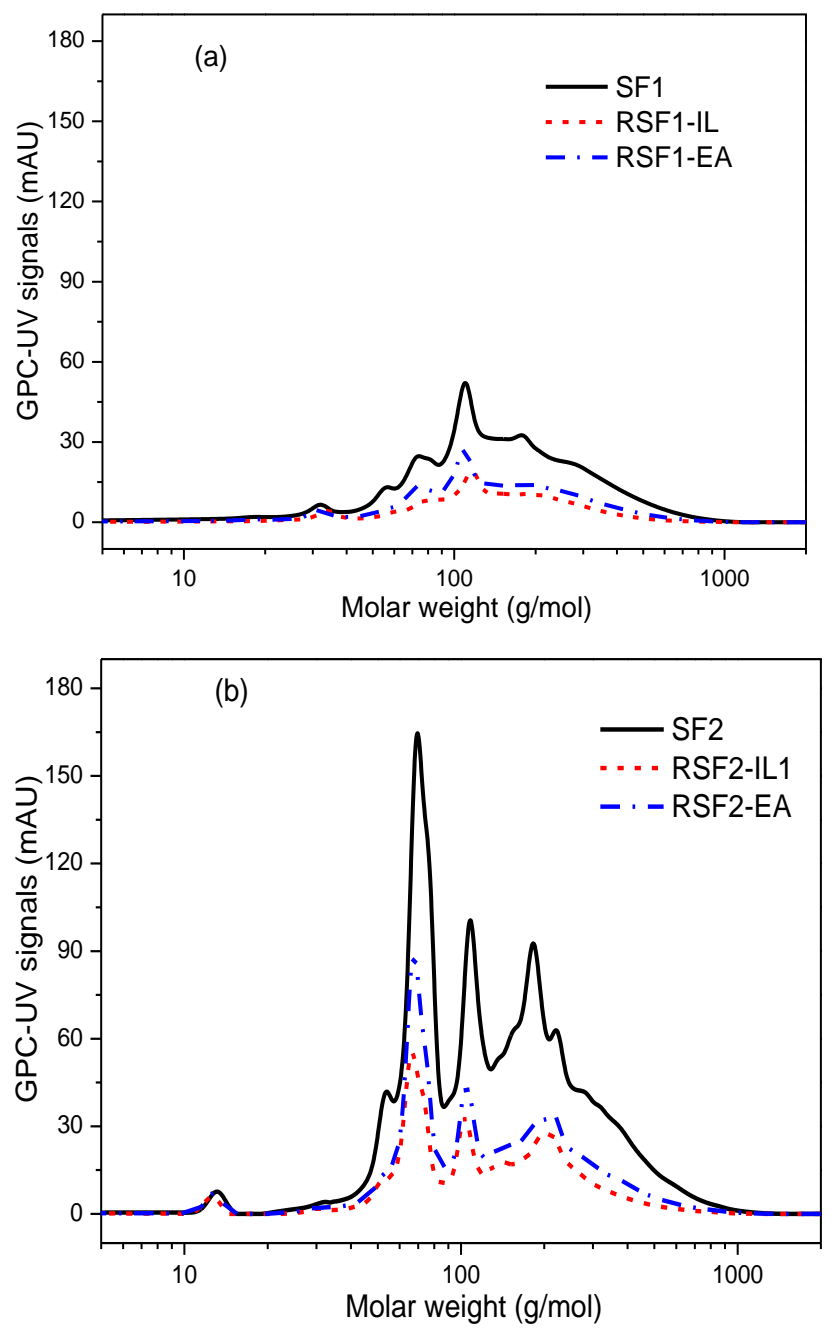

Figure 3.3. MWD UV-spectra of sugar fractions from (a) acid leached and (b) untreated pinewood and their corresponding raffinates. 
SF1 is thus clearly the preferred sugar fraction to examine the fermentability after extraction of the aromatics, whereas SF2 with its higher aromatics content is well suited to examine more closely the recyclability of the IL after extraction.

\subsubsection{Extraction of aromatics from SF1 and SF2}

In liquid-liquid extraction experiments using either $\mathrm{P}_{666,14}\left[\mathrm{~N}(\mathrm{CN})_{2}\right]$ or $\mathrm{EA}$, the extent of the extraction was measured using GPC and HPLC analyses, as described in the experimental section.

Table 3.2. Levoglucosan and water concentrations in SF1 and its raffinates (RSF1-EA, RSF1-IL) after extraction with IL or EA.

\begin{tabular}{ccc}
\hline Fraction & $\begin{array}{c}\text { Levoglucosan content } \\
(\mathrm{wt} \%)\end{array}$ & $\begin{array}{c}\text { Water content } \\
(\mathrm{wt} \%)\end{array}$ \\
\hline SF1 & 10.0 & 73.7 \\
RSF1-EA & 10.5 & 68.7 \\
RSF1-IL & 12.1 & 78.2 \\
\hline
\end{tabular}

For analysis of the sugar distributions, the first 20 min retention in the HPLC-RID chromatograms is considered, whereas for the aromatics the RID-signal from 20-120 min is considered. Figures 3.2 (a) and (b) represent SF1 and its raffinates after extraction, and Figures 3.2 (c) and (d) represent SF2 and its raffinates after extraction. The split in the results before and after 20 minutes was made to allow a change in the scale on the y-axis. It follows from Figure 3.2 (a) that the sugar signals from SF1 overlap with the signals of the raffinates, implying that the amount of sugars did not change, i.e. the sugars were not extracted. More specifically for levoglucosan, this negligible extractability was confirmed with GC/MS (see Table 3.2). Therefore, it was concluded that the levoglucosan and other sugars are hardly extracted from SF1 with either IL or EA. Similarly for SF2, it can be seen in Figure 3.2 (c) and Table 3.3, that sugars are not extracted by either the IL or EA. Thus, levoglucosan was collected in the raffinates to be subsequently hydrolyzed and fermented. 
Table 3.3. Levoglucosan and water concentrations in SF2 and its raffinates after extraction with IL or EA.

\begin{tabular}{|c|c|c|}
\hline Fraction & $\begin{array}{l}\text { Levoglucosan content } \\
(\mathrm{wt} \%)\end{array}$ & $\begin{array}{l}\text { Water content } \\
(\mathrm{wt} \%)\end{array}$ \\
\hline SF2 & 3.4 & 78.8 \\
\hline RSF2-EA & 3.3 & 75.7 \\
\hline RSF2-IL1 & 3.4 & 82.9 \\
\hline RSF2-IL2 & 3.6 & 83.7 \\
\hline RSF2-IL3 & 3.4 & 84.7 \\
\hline RSF2-IL4 & 3.4 & 84.4 \\
\hline
\end{tabular}

The aromatics extraction efficiency can be interpreted using the chromatograms in Figures 3.2 (b) and (d). In these Figures, the signal intensities for all raffinates are lower than those for the original sugar fractions SF1 and SF2. This shows that both the IL and EA extract aromatics. The amount of extracted aromatics was quantified by normalizing the total area of all HPLC-UV peaks for the raffinates with those of SF1 and SF2, respectively (in Figure 3.4). Using the IL as solvent, for both SF1 and SF2, significant and comparable reductions in peak area of $72 \%$ and $70 \%$, respectively, were observed. When EA was applied instead, the reduction in peak area was only $48 \%$ for SF1, and $56 \%$ for SF2. That the relative reduction in aromatics using EA was more for SF2 than for SF1 could be due to the higher aromatics content in this sugar fraction. In order to get a more complete understanding of the aromatics extraction, the raffinates were also analyzed using GPC-UV.

The MWD of aromatics before and after extraction are presented in Figure 3.3 (a) for SF1, and in Figure 3.3 (b) for SF2. In these figures it can be seen that the decrease in the area of the UV spectra for all raffinates happens for both the IL and EA over the entire weight range. There is thus no visible preference of either the IL or EA with regard to molecular size of the solutes that are extracted. Furthermore, the integrated results in Figure 3.4 show a good resemblance with the HPLC results, and indicate once more that $\mathrm{P}_{666,14}\left[\mathrm{~N}(\mathrm{CN})_{2}\right]$ extracts more aromatics than EA and the behavior is similar for both sugar fractions SF1 and SF2.

These results of single stage extractions, at a solvent to feed ratio of only 0.5 , show an aromatics removal of over $70 \%$ for the IL, which is a clear indication that achieving very high extraction yields should be straight forward when multistage contacting is applied. 


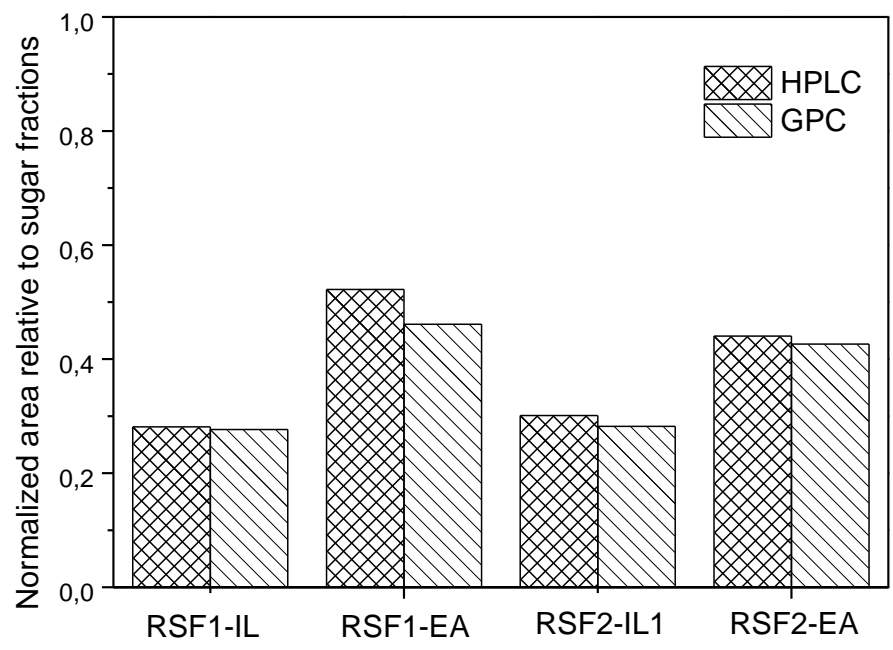

Figure 3.4. Normalized area of peaks recorded with HPLC-UV and GPC-UV for raffinates relative to the area of the original sugar fractions SF1 and SF2.

\subsubsection{Recycling of $P_{666,14}\left[N(C N)_{2}\right]$}

For economically feasible processing, it is key that the IL is recyclable, which may be done by evaporating the extracted aromatics. Because SF2 contains more aromatics than SF1, IL recovery was studied for this sugar fraction. It is esteemed that if recovery works for SF2, it will also work for SF1. Extraction with $\mathrm{P}_{666,14}\left[\mathrm{~N}(\mathrm{CN})_{2}\right]$ followed by regeneration was repeated three times, and thus four extraction cycles were studied in total.

The aromatics extraction efficiency of reused IL was evaluated with the analyses of HPLC and GPC. In Figure 3.5 (a) the integrated area of HPLC-UV signals normalized to SF2 is displayed. It can be seen that for all four raffinates the integrated aromatics signal is approximately $30 \%$, showing no deterioration of the extraction capacity. From the overlapping GPC signals of the raffinates RSF2-IL1 to RSF2-IL4 in Figure 3.5 (b) it becomes clear that the molecular weight distribution of aromatics in the raffinates is similar after all extraction cycles, i.e. the extraction performance is stable for recycled IL, confirming the HPLC-results displayed in Figure 3.5 (a). The stable performance confirms the high thermal stability of the phosphonium IL[35], as well as the minimal leaching of the IL to the raffinate, similar to earlier studies with a simplified feed [31]. Thus, vacuum evaporation of aromatic solutes originating from aqueous pyrolytic sugar solutions is an effective method for IL recovery. Not only the aromatics content was analyzed after the extractions, but also the levoglucosan content (see Table 3.3). The levoglucosan content remained constant in all 
extractions, validating the use of the recycled IL for selective removal of aromatics from sugar fractions.
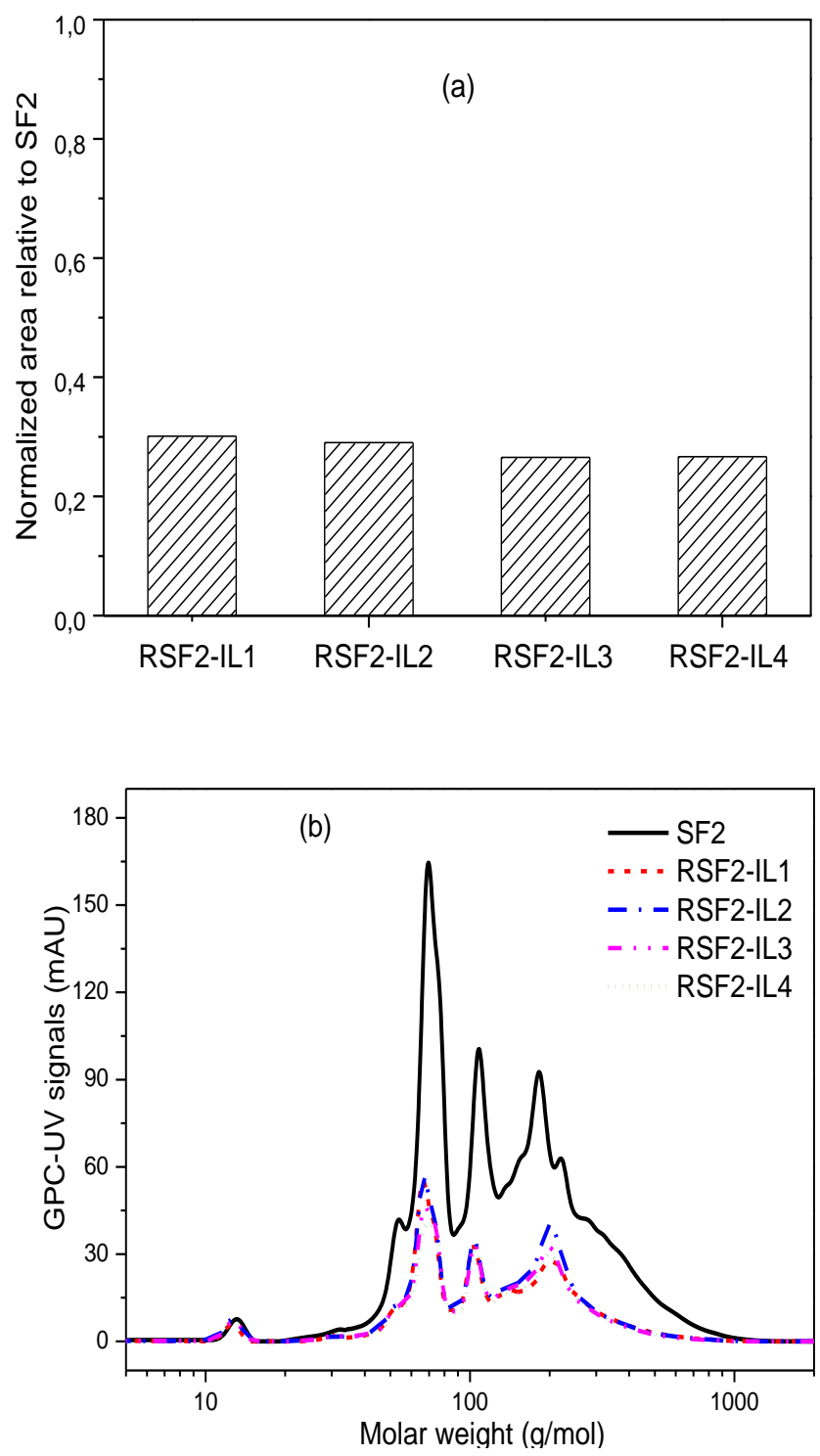

Figure 3.5. Aromatics removal efficiency of recycled $\mathrm{P}_{666,14}\left[\mathrm{~N}(\mathrm{CN})_{2}\right]$. (a) Normalized area of peaks for raffinates of SF2 detected by HPLC-UV; (b) Spectra for raffinates of SF2 detected by GPC-UV. 


\subsubsection{Fermentation}

The suitability of the pyrolytic sugar from SF1 as a fermentation substrate after detoxification by extraction with IL was investigated. The data in Figures 3.2 to 3.4 show substantial removal of aromatic compounds, however, the combined effect of the complex mixture, including possible negative effects of any leached solvent is difficult to predict, hence experimental determination is preferred [36]. Most yeast cannot directly convert levoglucosan which was therefore hydrolyzed to glucose and subsequently fermented to ethanol.

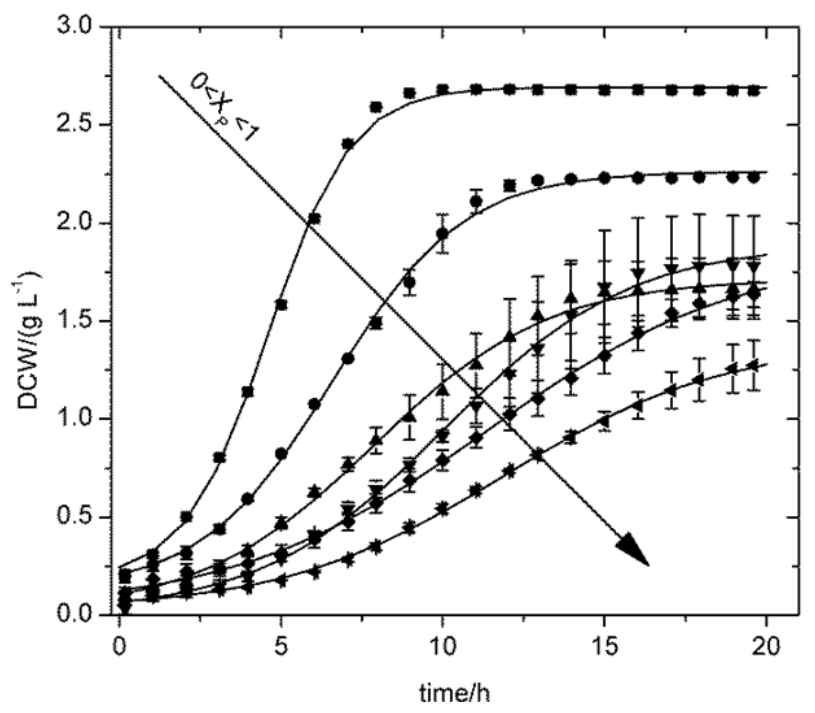

Figure 3.6. Growth curves of S.cerevisiae in $40 \mathrm{~g} / \mathrm{L}$ glucose with an increasing fraction of pyrolysis derived glucose $(\mathrm{Xp}=0-\boldsymbol{\mathbf { a }}, \mathrm{Xp}=0.2-\bullet ; \mathrm{Xp}=0.4-\boldsymbol{\Delta}, \mathrm{Xp}=0.6-\boldsymbol{\nabla}, \mathrm{Xp}=0.8$ $\checkmark, \mathrm{Xp}=1-4)$. The error bars represent the standard deviation of 6 replicates and the solid line a model fit based on Baranyi and Roberts as described elsewhere [36].

Parallel experiments were conducted with an initial glucose concentration of $40 \mathrm{~g} \mathrm{~L}^{-1}$, using mixtures of pure glucose and pyrolytic-glucose (glucose derived from RSF1-IL). The fraction of pyrolytic-glucose $(\mathrm{Xp})$ was varied from 0 to 1 in order to assess the inhibitory effect of residual aromatics or other inhibitory compounds. The respective growth curves are shown in Figure 3.6. It can be seen that growth rate and final biomass concentration (dry cell weight $(\mathrm{DCW}))$ decreased with an increased fraction of pyrolytic-glucose as the carbon 
source. However, the pure pyrolytic-glucose stream $(\mathrm{Xp}=1)$ could directly be fermented at initial concentrations of $40 \mathrm{~g} \mathrm{~L}^{-1}$, and an ethanol yield of $Y_{\text {ethanol/glucose }}$ of $0.46 \mathrm{~g} \mathrm{~g}^{-1}$ was achieved, which is close to the theoretical maximum $\left(0.51 \mathrm{~g} \mathrm{~g}^{-1}\right)$ and similar to values obtained with pure glucose under the employed conditions. No significant difference in the ethanol yields was observed between pure glucose, pyrolytic glucose, or the tested blends $(0<\mathrm{Xp}<1)$. However, the growth rate was reduced, as clearly shown in Figure 3.6, indicating that the presence of residual aromatics would still have a negative impact on ethanol fermentation. This limitation might be addressed through simple adaption of the strains or active strain development. The pyrolytic sugar fractions without any extraction could only be fermented up to $\mathrm{Xp}=0.2$, as reported in detail elsewhere [15], thus highlighting the importance of detoxification steps. The results therefore show that pyrolysis in combination with ionic liquid mediated upgrading can be used to produce fermentable sugars from biomass.

\subsection{Conclusions}

Solvent extraction with ionic liquids can be used effectively to separate aromatics from pyrolytic sugar rich streams. In a single extraction stage approximately $70 \%$ of aromatics can be removed by IL $\mathrm{P}_{666,14}\left[\mathrm{~N}(\mathrm{CN})_{2}\right]$, and only $50 \%$ by EA. The IL was regenerated three times by vacuum evaporation, and the recycled IL showed similar extraction performance as fresh IL. The sugar stream can further be fermented to ethanol in a close to the theoretical maximum yield, indicating the toxic molecules were extracted effectively. Thus, solvent extraction with $\mathrm{P}_{666,14}\left[\mathrm{~N}(\mathrm{CN})_{2}\right]$ is an effective detoxification method for obtaining fermentable sugars from pyrolysis oil.

\section{References}

[1] S.C.a.A.V. Bridgwater, Overview of Applications of Biomass Fast Pyrolysis Oil, Energy Fuels, 18 (2004) 590-598.

[2] D. Mohan, C.U. Pittman, P.H. Steele, Pyrolysis of wood/biomass for bio-oil: A critical review, Energy \& Fuels, 20 (2006) 848-889.

[3] R.J.M. Westerhof, D.W.F. Brilman, M. Garcia-Perez, Z.H. Wang, S.R.G. Oudenhoven, W.P.M. van Swaaij, S.R.A. Kersten, Fractional Condensation of Biomass Pyrolysis Vapors, Energy Fuels, 25 (2011) 1817-1829.

[4] D. Carpenter, T.L. Westover, S. Czernik, W. Jablonski, Biomass feedstocks for renewable fuel production: a review of the impacts of feedstock and pretreatment on the yield and product distribution of fast pyrolysis bio-oils and vapors, Green Chem., 16 (2014) 384. 
[5] S.R.G. Oudenhoven, R.J.M. Westerhof, N. Aldenkamp, D.W.F. Brilman, S.R.A. Kersten, Demineralization of wood using wood-derived acid: Towards a selective pyrolysis process for fuel and chemicals production, J. Anal. Appl. Pyrolysis, 103 (2013) 112-118.

[6] N. Kuzhiyil, D. Dalluge, X. Bai, K.H. Kim, R.C. Brown, Pyrolytic Sugars from Cellulosic Biomass, Chemsuschem, 5 (2012) 2228-2236.

[7] R.J. van Putten, J.C. van der Waal, E. de Jong, C.B. Rasrendra, H.J. Heeres, J.G. de Vries, Hydroxymethylfurfural, A Versatile Platform Chemical Made from Renewable Resources, Chem. Rev., 113 (2013) 1499-1597.

[8] X. Hu, C.Z. Li, Levulinic esters from the acid-catalysed reactions of sugars and alcohols as part of a bio-refinery, Green Chem., 13 (2011) 1676-1679.

[9] B. Girisuta, L.P.B.M. Janssen, H.J. Heeres, A kinetic study on the decomposition of 5hydroxymethylfurfural into levulinic acid, Green Chem., 8 (2006) 701.

[10] J.N. Lian, S.L. Chen, S.A. Zhou, Z.H. Wang, J. O'Fallon, C.Z. Li, M. Garcia-Perez, Separation, hydrolysis and fermentation of pyrolytic sugars to produce ethanol and lipids, Bioresource technology, 101 (2010) 9688-9699.

[11] L.R. Jarboe, Z. Wen, D. Choi, R.C. Brown, Hybrid thermochemical processing: fermentation of pyrolysis-derived bio-oil, Applied microbiology and biotechnology, 91 (2011) 1519-1523.

[12] D. Nguyen, D. Honnery, Combustion of bio-oil ethanol blends at elevated pressure, Fuel, 87 (2008) 232-243.

[13] S.S. Kelley, X. Wang, M. Myers, D. Johnson, J. Scahill, Use of biomass pyrolysis oils for preparation of modified phenol formaldehyde resins, in: A.V. Bridgwater, D.G.B. Boocock (Eds.) Developments in thermochemical biomass conversion, Blackie Academic and Professional, London, U.K., 1997.

[14] N.M. Bennett, S.S. Helle, S.J.B. Duff, Extraction and hydrolysis of levoglucosan from pyrolysis oil, Bioresource technology, 100 (2009) 6059-6063.

[15] L. Luque, R. Westerhof, G. Van Rossum, S. Oudenhoven, S. Kersten, F. Berruti, L. Rehmann, Pyrolysis based bio-refinery for the production of bioethanol from demineralized ligno-cellulosic biomass, Bioresource technology, 161 (2014) 20-28.

[16] Z.Y. Chi, M. Rover, E. Jun, M. Deaton, P. Johnston, R.C. Brown, Z.Y. Wen, L.R. Jarboe, Overliming detoxification of pyrolytic sugar syrup for direct fermentation of levoglucosan to ethanol, Bioresource technology, 150 (2013) 220-227.

[17] Y.C. Li, J.A. Shao, X.H. Wang, H.P. Yang, Y.Q. Chen, Y. Deng, S.H. Zhang, H.P. Chen, Upgrading of Bio-oil: Removal of the Fermentation Inhibitor (Furfural) from the Model Compounds of Bio-oil Using Pyrolytic Char, Energy \& Fuels, 27 (2013) 5975-5981. 
[18] H. Wang, D. Livingston, R. Srinivasan, Q. Li, P. Steele, F. Yu, Detoxification and Fermentation of Pyrolytic Sugar for Ethanol Production, Applied Biochemistry and Biotechnology, 168 (2012) 1568-1583.

[19] J. Lian, S. Chen, S. Zhou, Z. Wang, J. O'Fallon, C.Z. Li, M. Garcia-Perez, Separation, hydrolysis and fermentation of pyrolytic sugars to produce ethanol and lipids, Bioresour. Technol., 101 (2010) 9688-9699.

[20] S.-H. Lin, R.-S. Juang, Adsorption of phenol and its derivatives from water using synthetic resins and low-cost natural adsorbents: A review, Journal of Environmental Management, 90 (2009) 1336-1349.

[21] K.W. Won, J.M. Prausnitz, Distribution of phenolic solutes between water and polar organic-solvents, J. Chem. Thermodyn., 7 (1975) 661-670.

[22] L. Fele Žilnik, A. Jazbinšek, Recovery of renewable phenolic fraction from pyrolysis oil, Sep. Purif. Technol., 86 (2012) 157-170.

[23] T. Welton, Room-temperature ionic liquids. Solvents for synthesis and catalysis, Chemical Reviews, 99 (1999) 2071-2083.

[24] G.W. Meindersma, A.R. Hansmeier, A.B. de Haan, Ionic Liquids for Aromatics Extraction. Present Status and Future Outlook, Industrial \& Engineering Chemistry Research, 49 (2010) 7530-7540.

[25] R.D. Rogers, K.R. Seddon, Ionic liquids - Solvents of the future?, Science, 302 (2003) 792-793.

[26] S. Zhang, J. Sun, X. Zhang, J. Xin, Q. Miao, J. Wang, Ionic liquid-based green processes for energy production, Chemical Society Reviews, 43 (2014) 7838-7869.

[27] U. Domanska, A. Pobudkowska, M. Krolikowski, Separation of aromatic hydrocarbons from alkanes using ammonium ionic liquid C2NTf2 at T=298.15 K, Fluid Phase Equilibria, 259 (2007) 173-179.

[28] A. Arce, M.J. Earle, H. Rodriguez, K.R. Seddon, Separation of aromatic hydrocarbons from alkanes using the ionic liquid 1-ethyl-3-methylimidazolium bis\{(trifluoromethyl) sulfonyl \} amide, Green Chemistry, 9 (2007) 70-74.

[29] T.T. Jiao, X.L. Zhuang, H.Y. He, L.H. Zhao, C.S. Li, H.N. Chen, S.J. Zhang, An ionic liquid extraction process for the separation of indole from wash oil, Green Chemistry, 17 (2015) 3783-3790.

[30] M.T.G. Jongmans, B. Schuur, A.B. de Haan, Ionic Liquid Screening for Ethylbenzene/Styrene Separation by Extractive Distillation, Ind. Eng. Chem. Res., 50 (2011) 10800-10810.

[31] X. Li, S.R.A. Kersten, B. Schuur, Extraction of guaiacol from model pyrolytic sugar stream with ionic liquids, Ind. Eng. Chem. Res., (2016) Accepted for publication, DOI 10.1021/acs.iecr.1026b00100. 
[32] J.N. Lian, M. Garcia-Perez, S.L. Chen, Fermentation of levoglucosan with oleaginous yeasts for lipid production, Bioresour. Technol., 133 (2013) 183-189.

[33] S.R.G. Oudenhoven, C. Lievens, R.J.M. Westerhof, S.R.A. Kersten, Effect of temperature on the fast pyrolysis of organic-acid leached pinewood; the potential of low temperature pyrolysis, Biomass Bioenergy, (2015).

[34] D.L. Dalluge, T. Daugaard, P. Johnston, N. Kuzhiyil, M.M. Wright, R.C. Brown, Continuous production of sugars from pyrolysis of acid-infused lignocellulosic biomass, Green Chem., 16 (2014) 4144-4155.

[35] K.J. Fraser, D.R. MacFarlane, Phosphonium-Based Ionic Liquids: An Overview, Aust. J. Chem., 62 (2009) 309-321.

[36] J.A. Wood, V.C.A. Orr, L. Luque, V. Nagendra, F. Berruti, L. Rehmann, HighThroughput Screening of Inhibitory Compounds on Growth and Ethanol Production of Saccharomyces cerevisiae, Bioenerg Res, 8 (2015) 423-430. 


\section{Chapter 4}

\section{Extraction of acetic acid, glycolaldehyde and}

\section{acetol from aqueous solutions mimicking}

\section{pyrolysis oil cuts using ionic liquids}

Value-added oxygenates, such as acetic acid (HAc), glycolaldehyde and acetol, are present in pyrolysis oil and its cuts in substantial amounts. This work describes the separation of these value-added oxygenates from artificial aqueous fractions of pyrolysis oil via liquidliquid extraction. Three phosphonium ionic liquids (ILs), two imidazolium ILs and one benchmark organic mixture (40 wt\% tri- $n$-octylamine in 1-octanol: TOA/1-octanol) were applied as solvents. Although suited as solvent for HAc and glycolaldehyde, the benchmark TOA/1-octanol showed a low acetol distribution coefficient (0.05), which makes it less suitable for use in an integrated oxygenates extraction process. Phosphonium ILs showed the highest affinities for HAc and glycolaldehyde, and reasonable affinity for acetol. However, none of these solvents could be applied to remove all oxygenates from the aqueous solution in a single extraction step, because of the difficulty of oxygenates evaporation from phosphonium ILs and the reactivity of glycolaldehyde with $\mathrm{P}_{666,14}\left[\mathrm{~N}(\mathrm{CN})_{2}\right]$ in the presence of HAc, as was confirmed by NMR. Based on the good affinity of the imidazolium ILs for acetol, a two-step extraction process was proposed where $\operatorname{Hmim}\left[\mathrm{B}(\mathrm{CN})_{4}\right]$ may be used to extract acetol and HAc in the first step and be regenerated by evaporation of the solutes, and $\mathrm{P}_{666,14}[\mathrm{Phos}]$ may be applied to extract glycolaldehyde in the second step and be regenerated by back-extraction with water.

This chapter has been published as:

X. Li, S.R.A. Kersten, B. Schuur, Extraction of acetic acid, glycolaldehyde and acetol from aqueous solutions mimicking pyrolysis oil cuts using ionic liquids. Separation and Purification Technology 2016, $175,498-505$. 


\subsection{Introduction}

Due to the rising concerns on climate change, biomass as renewable resource has gained growing interest for production of bio-based fuels and chemicals. Pyrolysis oil (also known as bio-oil), the liquid product of fast pyrolysis (heating biomass in absence of oxygen to temperatures above $400{ }^{\circ} \mathrm{C}$ ), has been applied as a renewable fuel for generation of heat and power [1]. Next to direct use of the oil as fuel, also separation and valorization of attractive chemicals present in the pyrolysis oil such as aromatics and sugars have been widely studied [2-5]. Within the pyrolysis oil some other value-added oxygenates are also present in substantial amounts, such as acetic acid (HAc, 12\%), glycolaldehyde (13\%) and acetol (7.4\%) [6].

These oxygenates offer interesting commercial opportunities. Glycolaldehyde can be used as an effective meat-browning agent [7] or as fermentation feedstock for production of ethylene glycol [8]. HAc as an important chemical reagent is primarily employed in the production of cellulose acetate and polyvinyl acetate [9]. Additionally, acetol can promote various reactions (e.g. dehydration, hydrogenation, oxidation) and produce numerous products including propylene glycol, acrolein, acetone and furan derivatives [10].

Prior to further upgrading, these chemicals need to be isolated from the pyrolysis oil mixtures. Direct distillation of these oxygenates is not feasible due to the poor thermal stability of the pyrolysis oil [11], and direct extraction with an organic solvent is not attractive as a certain amount of the solvent ends up in the pyrolysis oil phase [12]. A potential initial step is to apply a water wash, and collect the polar oxygenates in the aqueous fraction. Upon water addition to the pyrolysis oil, 80-90\% of the oxygenates can be extracted to the aqueous phase, based on their polarity [13]. An elegant alternative for water wash can be a thermal fractionation by employing a series of condensers operated at different temperatures to condense fractions of the pyrolysis vapors based on the boiling points of the species in the fractions. By careful control of the condenser temperatures, aqueous fractions containing up to $10 \% \mathrm{HAc}$ and $8 \%$ acetol can be obtained directly from one of the condensers [14]. Because both methods are not highly selective, many other compounds with either similar polarity or boiling points are present in the mixtures as well.

Several methods have been investigated to separate specific oxygenates from the aqueous fractions of pyrolysis oil. Nanofiltration has been employed by Ford and coworkers to recover HAc, but the membrane was irreversibly damaged by the phenolics that were also present in the solutions [15]. Liquid-liquid reactive extractions using tertiary amines have been widely studied for HAc recovery from aqueous solutions [16-18]. In one single stage, about $84 \mathrm{wt} \%$ HAc was recovered with $40 \mathrm{wt} \%$ tri- $n$-octylamine in 2-ethyl-hexanol at room temperature 
from the aqueous fraction of pyrolysis oil with $3.33 \mathrm{wt} \%$ HAc in the mixture at a 1:1 solvent to feed ratio [17]. However, solvent regeneration via vacuum distillation results in the loss of 2-ethyl-hexanol which may co-evaporate with the solute [19].

Stradal and Underwood have invented a process to isolate glycolaldehyde from pyrolysis oil [20]. The process shown in Scheme 4.1 comprises several steps: i) water extraction to produce a water soluble fraction of pyrolysis oil; ii) water evaporation to reduce water content; iii) multiple evaporation and fractionation steps to remove the low and high boiling components and further concentrate glycolaldehyde; iv) precipitation of glycolaldehyde from methylene chloride. The separation steps of evaporation and distillations should be operated carefully to prevent reactions of glycolaldehyde, e.g., low temperature, vacuum pressure, short residence time at high temperature. Multiple evaporation and condensation steps are not economic and it appears better to selectively extract glycolaldehyde and recover it from the solvent.

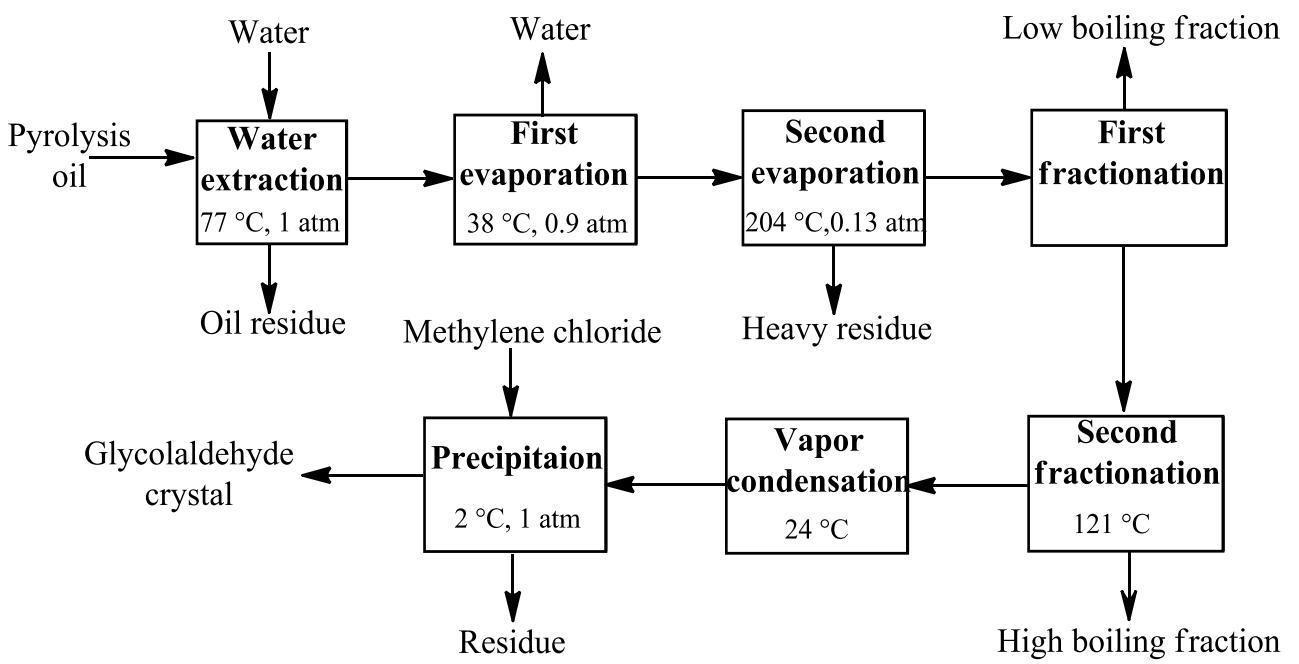

Scheme 4.1. Glycolaldehyde isolation process designed by Stradal and Underwood. The missing temperatures and pressures in the scheme are not given in the reference [20].

De Haan and co-workers have studied extensively on isolation of glycolaldehyde from aqueous fraction of pyrolysis oil by liquid-liquid extraction [8, 18, 19, 21]. High extraction efficiency of glycolaldehyde can be achieved via reactive extraction with primary amines, but the regeneration is challenging due to the high stability of the formed Schiff-base [21]. Physical extraction of glycolaldehyde with 1-octanol was also investigated, but low overall 
glycolaldehyde yield $(17.2 \%$, the percentage of its initial mass in the feed) were obtained from the proposed process, due to the low distribution coefficient of glycolaldehyde $(0.25)$ [8]. Acetol was also co-extracted with 1-octanol, but the distribution coefficient of acetol was low as well (0.17). The other alternative is co-extraction of glycolaldehyde during reactive extraction of HAc with TOA in 2-ethyl-hexanol [18]. High HAc recovery yield (80\%) was obtained but less than $10 \mathrm{wt} \%$ of glycolaldehyde (the percentage of its initial amount in the feed) was extracted due to the low distribution coefficient of glycolaldehyde $(<0.20)$. Thus, exploring of new solvents with higher distribution coefficients of these oxygenates may bring new process options with a smaller impact on the environment.

Ionic liquids (ILs), known as environmentally friendly solvents, have been proposed to be used for liquid-liquid extractions, e.g., separation of aromatics from aliphatics [22-24] or from sugar solutions $[3,5]$, recovery of precious metals for recycling [25]. Their negligible vapor pressure and high thermal stability allow ILs to be recovered from the extract by solutes evaporation, which uses potentially less energy than recovery of low boiling organic solvents where large amount of solvents are typically evaporated [3]. Moreover, the extractability of the solutes can be enhanced by tuning the combination of cations and anions. ILs have shown potential for extraction of acids (e.g. HAc, lactic acid, amino acid) from aqueous solutions [26-32]. However, there is no report on utilization of ILs to extract oxygenates from aqueous solutions of pyrolysis oil.

In this work, the feasibility and reusability of ILs to extract the oxygenates acetol, HAc and glycolaldehyde from the model aqueous solutions of pyrolysis oil is investigated. Three phosphonium ILs have been studied in this work due to their hydrophobicity and high affinity for acids [30, 33]. Two other commercially available hydrophobic imidazolium ILs with tetracyanoborate anion are also investigated, as they have shown potential in extraction of polar compounds [34], and the solvent recovery may be straightforward through solute evaporation. The names and abbreviations of the studied ILs are shown in Table 4.1 and the structures of ILs and the oxygenates are drawn in Scheme 4.2. The organic solvent $40 \mathrm{wt} \%$ TOA in 1-octanol is also studied as comparison, because of its high distribution of HAc [30]. 1-octanol is used as diluent in this work, since it is available in the lab and has similar distribution coefficient for HAc as 2-ethyl-1-hexanol [17]. 
Table 4.1. Names and abbreviations of solvents studied in this work

\begin{tabular}{ll}
\hline Name of solvents & Abbreviations \\
\hline Trihexyltetradecylphosphonium chloride & $\mathrm{P}_{666,14} \mathrm{Cl}$ \\
Trihexyltetradecylphosphonium dicyanamide & $\mathrm{P}_{666,14}\left[\mathrm{~N}(\mathrm{CN})_{2}\right]$ \\
$\begin{array}{l}\text { Trihexyltetradecylphosphonium bis-2,4,4- } \\
\text { trimethylpentyl)phosphinate }\end{array}$ & $\mathrm{P}_{666,14}[\mathrm{Phos}]$ \\
1-hexyl-3-methylimidazolium tetracyanoborate & $\mathrm{Hmim}\left[\mathrm{B}(\mathrm{CN})_{4}\right]$ \\
1-octyl-3-methylimidazolium tetracyanoborate & Omim[B $\left.(\mathrm{CN})_{4}\right]$ \\
40 wt\% tri- $n$-octylamine in 1-octanol & TOA/1-octanol \\
\hline
\end{tabular}

Oxygenates:<smiles>CC(=O)O</smiles>

Acetic acid<smiles>O=CCO</smiles>

Glycolaldehyde<smiles>CC(=O)CO</smiles>

Acetol

ILs:<smiles>C[n+]1ccn(-c2ccccc2)c1</smiles>

$\operatorname{Hmim}\left[\mathrm{B}(\mathrm{CN})_{4}\right]$

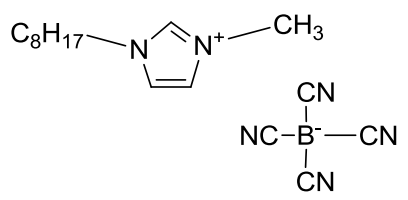

$\operatorname{Omim}\left[\mathrm{B}(\mathrm{CN})_{4}\right]$<smiles>[CH2][P-](Cl)(CCCCC)c1ccccc1</smiles>

$\mathrm{P}_{666,14} \mathrm{Cl}$<smiles></smiles>

$\mathrm{P}_{666,14}\left[\mathrm{~N}(\mathrm{CN})_{2}\right]$<smiles>CC(CC(C)CP(=O)(O)CC(C)CC(C)(C)C)CC(C)(C)C</smiles>

$\mathrm{P}_{666,14}[\mathrm{Phos}]$

Scheme 4.2. Structures of the oxygenates and the studied ILs. 


\subsection{Experimental}

\subsubsection{Materials}

Acetic acid (>99.7\%), acetol (hydroxyacetone, 90\%), glycolaldehyde dimer, tri- $n$ octylamine (98\%), 1-octanol (>99\%), toluene (>99.8\%) and dimethyl sulfoxide- $d_{6}(>99.96 \%$, DMSO) were purchased from Sigma Aldrich. The phosphonium ILs $\mathrm{P}_{666,14} \mathrm{Cl}, \mathrm{P}_{666,14}\left[\mathrm{~N}(\mathrm{CN})_{2}\right]$ and $\mathrm{P}_{666,14}[\mathrm{Phos}]$ were obtained from Iolitec with a purity $>95 \%$. The imidazolium ILs $\operatorname{Hmim}\left[\mathrm{B}(\mathrm{CN})_{4}\right]$ and $\operatorname{Omim}\left[\mathrm{B}(\mathrm{CN})_{4}\right]$ were purchased from Merck with a purity $>98 \%$.

\subsubsection{Liquid-liquid extraction}

Three single solute solutions (10 wt $\%$ acetol, $10 \mathrm{wt} \%$ HAc and $5 \mathrm{wt} \%$ glycolaldehyde solution, respectively) and one mixed solutes solution (with $10 \mathrm{wt} \%$ acetol, $10 \mathrm{wt} \% \mathrm{HAc}$ and $5 \mathrm{wt} \%$ glycolaldehyde together in milli-Q water) were prepared as feed solutions. Extraction experiments were conducted by adding $2 \mathrm{~g}$ feed solution and $2 \mathrm{~g}$ solvent in glass vials which were then introduced in a shaking bath at $200 \mathrm{rpm}$ at the desired temperatures $(25<\mathrm{T}<$ $60^{\circ} \mathrm{C}$ ). After $18 \mathrm{~h}$ shaking, the phases were allowed to settle down for $2 \mathrm{~h}$ while keeping the correct temperature. The raffinate and extract phases were then separated and weighed. The raffinates were analyzed with HPLC to obtain the concentrations of acetol, HAc and glycolaldehyde. The contents of these compounds in the extracts were calculated by mass balance [3]. Water concentration in the pure solvents and the extract phases was measured with Karl Fisher titration.

For the study on the mutual influence of HAc and glycolaldehyde on extraction efficiency, as well as on the solvent influence five feed solutions, i.e. 0.01-0.2 M (0.15-1.21 wt\%) glycolaldehyde solutions were prepared by dissolving varying amounts of glycolaldehyde in milli-Q water, to which solvent phase containing HAc was added. The solvent phases were $0.5 \mathrm{M} \mathrm{P}_{666,14}\left[\mathrm{~N}(\mathrm{CN})_{2}\right]$ in toluene with five different concentrations of HAc (0-1.0 M, 0-6.2 wt $\%)$. HAc was added to the solvent mixture instead of to the feed, in order to simplify the experimental procedure, i.e. 5 feeds and 5 solvents were prepared instead of 25 feeds and 1 solvent. To prepare the solvent, in the first step, IL was diluted to $0.5 \mathrm{M}(29 \mathrm{wt} \%)$ in toluene, then certain amount of HAc was added to IL/Toluene mixture to obtain the desired concentrations. The liquid-liquid extractions were carried out by contacting $2 \mathrm{~mL}$ solvents with $10 \mathrm{~mL}$ feeds at $40{ }^{\circ} \mathrm{C}$. By combining different feed and solvent, the ratios of glycolaldehyde to IL and to HAc were tuned. The concentrations of the HAc and glycolaldehyde in the aqueous feed were recalculated, based on the initial amount of 
glycolaldehyde and water in the feed and the added HAc in the solvent. The concentrations of HAc and glycolaldehyde in the raffinates were analyzed with HPLC.

\subsubsection{Samples preparation for NMR analysis}

Four mixtures were prepared for the analysis of ${ }^{1} \mathrm{H}$ NMR and ${ }^{13} \mathrm{C} \mathrm{NMR}$, including HAc + glycolaldehyde, $\mathrm{P}_{666,14}\left[\mathrm{~N}(\mathrm{CN})_{2}\right]+$ glycolaldehyde, $\mathrm{HAc}+\mathrm{P}_{666,14}\left[\mathrm{~N}(\mathrm{CN})_{2}\right]$ and $\mathrm{HAc}+$ glycolaldehyde $+\mathrm{P}_{666,14}\left[\mathrm{~N}(\mathrm{CN})_{2}\right]$. In order to keep similar conditions as extraction experiments, after being diluted in DMSO- $d_{6}$, these mixtures were mixed at $40{ }^{\circ} \mathrm{C}$ for $18 \mathrm{~h}$ in a shaking bath at $200 \mathrm{rpm}$. Then all samples were analyzed with a Bruker NMR machine to obtain the ${ }^{1} \mathrm{H}$ NMR (400 MHz) and ${ }^{13} \mathrm{C}$ NMR (100 MHz) spectra.

\subsubsection{IL regeneration}

After extraction from the mixed solutes feed, the ILs $\mathrm{P}_{666,14} \mathrm{Cl}, \mathrm{P}_{666,14}\left[\mathrm{~N}(\mathrm{CN})_{2}\right]$ and $\mathrm{P}_{666,14}[\mathrm{Phos}]$ were regenerated from their corresponding extract phases $(10 \mathrm{~g})$ by evaporating the solutes at $100{ }^{\circ} \mathrm{C}$ and 20 mbar in a $100 \mathrm{~mL}$ flask for $1 \mathrm{~h}$ while bubbling the flask with $\mathrm{N}_{2}$ to avoid condensation in the neck of the flask. The regenerated $\mathrm{P}_{666,14}$ [Phos] was then used for the second round of extraction from a fresh feed solution.

After extraction from the mixed solutes feed with $\operatorname{Hmim}\left[\mathrm{B}(\mathrm{CN})_{4}\right]$, this IL was recovered at $60{ }^{\circ} \mathrm{C}$ and $20 \mathrm{mbar}$ for $30 \mathrm{~min}$, and the regenerated $\mathrm{IL}$ was reused as solvent to extract oxygenates from the fresh feed. This IL was recycled three times for four extractions in total. The raffinate after each extraction was analyzed with HPLC to obtain the concentrations of the oxygenates. The contents of these compounds in the extracts were calculated by mass balance.

\subsubsection{Analysis}

High performance liquid chromatography (HPLC, Agilent 1200 system) was employed to analyze the concentrations of HAc, glycolaldehyde and acetol in the raffinates. HPLC was equipped with a Hi-Plex-H column operated at $60{ }^{\circ} \mathrm{C}$ and a refractive index detector at $55^{\circ} \mathrm{C}$ (RID, relative standard deviation from 5 measurements: $1.2 \%$ ), using mobile phase $5 \mathrm{mM}$ sulfuric acid at a flow rate of $0.6 \mathrm{~mL} / \mathrm{min}$. Water uptake in the pure solvents and the extract phases was determined with Karl Fisher titration (titrant: hydranal composite 5, Metrohm 787 KFTitrino) and the relative standard deviations from triplicate measurements were lower than $8 \%$. A solution of methanol and dichloromethane (3:1, volumetric ratio) was used as solvent. 


\subsubsection{Definitions}

The extraction efficiency of the solvents is designated as distribution coefficient of solutes in solvents which is defined in equation (1):

$$
D_{i}=\frac{x_{i}^{I}}{x_{i}^{I I}}
$$

where $x_{i}^{I}$ and $x_{i}^{I I}$ represent the weight fraction of solute $i$ in phase I (an IL or TOA/1-octanol phase) and phase II (the aqueous raffinate phase) respectively.

\subsubsection{COSMO-RS predictions}

COSMO-RS, the conductor-like-screening-model for real solvents, which is based on the molecular quantum chemical calculations of the individual species in the system, can be used for prediction of the equilibrium thermodynamic properties of pure components and mixtures $[3,35,36]$. In this work, the turbomole program package (version 7.0) was used to predict the distributions of the molecular surface charge densities ( $\sigma$-profiles). The software tool COSMOthermX (C30-1501) was applied to predict the partition coefficients of the oxygenates in octanol and water $(\log \mathrm{P})$.

\subsection{Results and discussion}

\subsubsection{Solvent efficiency for extraction of oxygenates from artificial aqueous fraction of pyrolysis oil}

Liquid-liquid extraction experiments were carried out to study the extraction efficiency of the solvents in the removal of glycolaldehyde, HAc and acetol from the artificial aqueous mixture at room temperature $\left(25^{\circ} \mathrm{C}\right)$. To study the competitive effect of the solutes on extraction, both single solute solutions and a mixed solutes solution were applied as feeds. The equilibrium distribution coefficients of the solutes $\left(\mathrm{D}_{i}\right)$ for all the solvents are presented in Figure 4.1. The results of $\mathrm{D}_{\mathrm{HAc}}$ for $\mathrm{P}_{666,14}$ [Phos] and TOA/1-octanol are in the same order of magnitude with what was reported by previous studies [17, 29, 30, 33], confirming the reliability of the data in this work.

By comparing the extractions from the single solute solutions ( $D_{i}^{\text {Single }}$ shown as symbols) with the extractions from the mixed solutes solution ( $D_{i}^{M i x}$ shown as column bars), it is found that for all three solutes, $D_{i}^{\text {Single }}$ was either higher or similar than/as $D_{i}^{\text {Mix }}$ for most studied 
solvents, indicating that in most solvents, the three solutes were competing with each other in the extraction. However, for $\mathrm{P}_{666,14}\left[\mathrm{~N}(\mathrm{CN})_{2}\right]$ the result showed an opposite trend, with $D_{i}^{\text {Single }}$ being lower than $D_{i}^{M i x}$, indicating that the solutes were mutually enhancing their extractability.

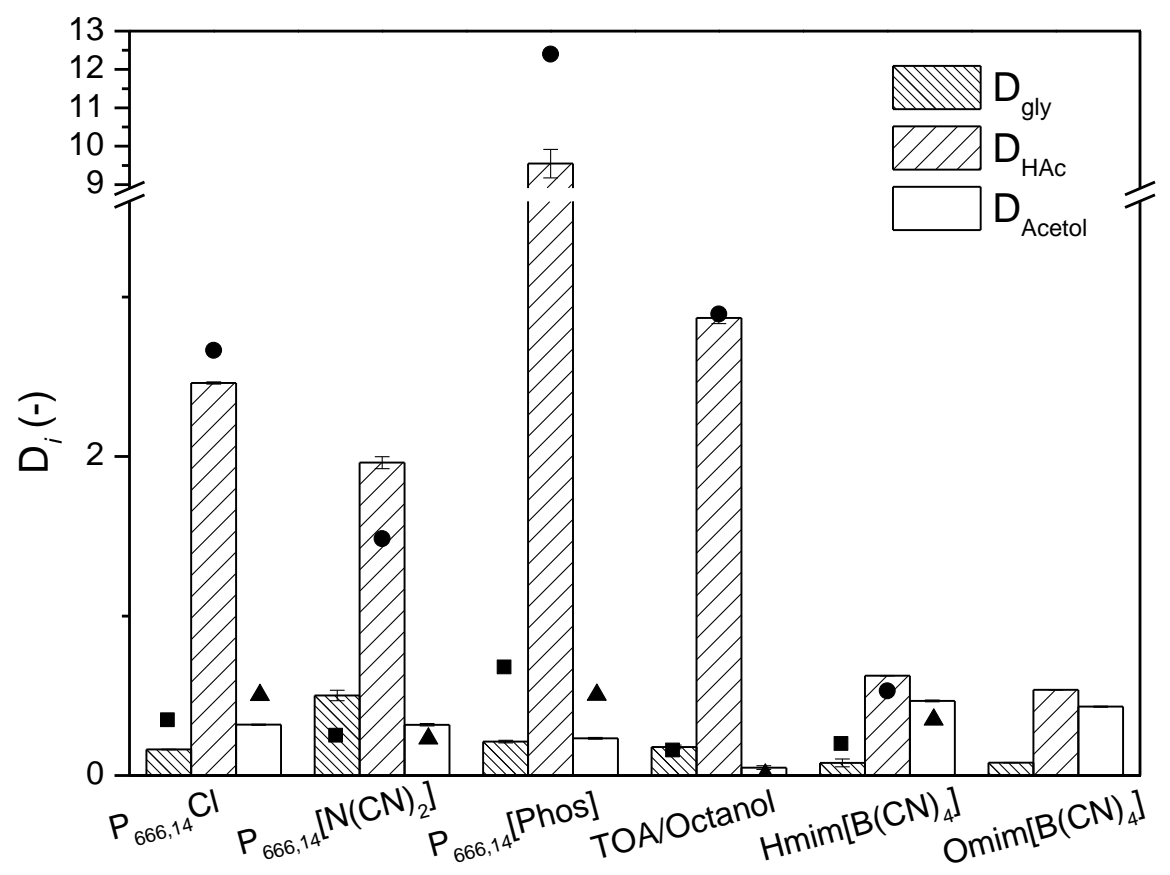

Figure 4.1. Distribution coefficients $\left(\mathrm{D}_{i}\right)$ of glycolaldehyde, HAc and acetol as obtained in liquid-liquid equilibria at $1: 1$ solvent to feed ratio (mass based) at $25{ }^{\circ} \mathrm{C}$. Column bars for mixed solutes solution; Symbols for single solute solutions. ( $\mathbf{a}$ ): $\mathrm{D}_{\mathrm{gly}}$, $(\bullet): \mathrm{D}_{\mathrm{HAc}},(\boldsymbol{\Delta})$ : $\mathrm{D}_{\text {Acetol. }}$

It is observed from Figure 4.1 that all the solvents had the strongest affinity for HAc, whereas their affinity for glycolaldehyde and acetol were significantly lower. For $\mathrm{P}_{666,14}\left[\mathrm{Phos}\right.$, $\mathrm{D}_{\mathrm{HAc}}$ was 42-45 times higher than $\mathrm{D}_{\text {Acetol }}$ and $\mathrm{D}_{\text {gly }}$, and around 10 times in the case of $\mathrm{P}_{666,14} \mathrm{Cl}$. This observation is related to the polarity of the solutes: HAc > glycolaldehyde $>$ acetol, deduced from the $\sigma$-profiles of these solutes shown in Figure S4.1 in the supplementary information in the Appendix B. The stronger polar molecular surfaces of HAc correspond with the hydrogen bond donating capabilities and thus are more likely to 
form hydrogen bonds with the anion of ILs. The high $\mathrm{D}_{\mathrm{HAc}}$, attributed to the strong hydrogen bonding interaction between acid and the solvents has also been reported in the literature [30].

The similar $\sigma$-profiles (see Figure S4.1) of glycolaldehyde and acetol indicate that they exhibit alike surface polarities, which results in comparable $D_{\text {gly }}$ and $D_{\text {Acetol }}$ for the phosphonium ILs. However, it was not experimentally observed for the imidazolium ILs. Because for the imidazolium ILs the distribution coefficients of the solutes are in the same order as the COSMO-RS predicted Log P values (the partition coefficient of the solutes in 1octanol/water biphasic system): glycolaldehyde $(\log \mathrm{P}=-1.103)<\operatorname{acetol}(\log \mathrm{P}=-0.584)$ $<$ HAc $(\log \mathrm{P}=-0.266)$, it is suggested that in the oxygenates extraction with these two imidazolium ILs, the solute hydrophobicities (expressed as $\log \mathrm{P}$ ) are the governing factor. The lowest Log P of glycolaldehyde indicates that this solute has very strong affinity towards water and thus it is the most difficult one to be extracted. Although the imidazolium ILs have a hydrophobic character, preferring HAc over acetol over glycolaldehyde in their hydrophobic order, they also contain the hydrogen bond accepting $\mathrm{CN}$-functionality. A slightly higher distribution was observed with $\operatorname{Hmim}\left[\mathrm{B}(\mathrm{CN})_{4}\right]$ than with $\operatorname{Omim}\left[\mathrm{B}(\mathrm{CN})_{4}\right]$ for all solutes, which may suggest that the functional group density (mol CN per kg solvent) of the hydrogen bond accepting group is positively affecting the extraction and a shorter alkyl chain in the cations results in a higher distribution.

The distribution of HAc for the studied ILs follows the order: Phos $>\mathrm{Cl}>\mathrm{N}(\mathrm{CN})_{2}>$ $\mathrm{B}(\mathrm{CN})_{4}$, which is in line with the polarities of the anions, based on their $\sigma$-profiles shown in Figure S4.2 in the Appendix B. The remarkably high $\mathrm{D}_{\mathrm{HAc}}$ for $\mathrm{P}_{666,14}[\mathrm{Phos}]$ is suspected to be at least partly due to the proton transfer from the HAc to the Phos anion, resulting in a long chain hydrophobic phosphinic acid and phosphonium acetate. Moreover, it is suggested in the literature that the IL with Phos anion could form complexes with acid and water [33], which may enhance the extraction of HAc, and this probably does not happen for ILs with other anions.

The organic solvent TOA/1-octanol showed comparable extraction efficiencies for HAc and glycolaldehyde with phosphonium ILs (except for $\mathrm{P}_{666,14}[\mathrm{Phos}]$ which showed a much higher extraction efficiency), and even higher than imidazolium ILs. But on the other hand, $\mathrm{D}_{\text {Acetol }}$ was extremely low $(0.05 \pm 0.01)$ in TOA/1-octanol, which is comparable with the literature where $40 \mathrm{wt} \%$ TOA in 2-ethyl-1-hexanol were applied as solvents [17]. This suggests TOA/1-octanol exhibits a high selectivity of HAc over acetol, but this also implies a poor extractability of acetol.

The water concentrations in the pure solvents and the extract phases measured with Karl Fisher are shown in Table 4.2. It is seen that the water solubility decreased in the extract 
phases of $\mathrm{P}_{666,14} \mathrm{Cl}$ and $\mathrm{P}_{666,14}[\mathrm{Phos}$, compared with the values in the pure ILs, which is in line with the observations from other researchers [37]. It is suggested that the high water uptake of $\mathrm{P}_{666,14}[\mathrm{Phos}]$ is due to the formation of water-IL clusters, which break with increasing amounts of extracted solutes, and because of that the water solubility in the solvents decreases after extraction [37]. The data in the last column in Table 4.2 are from the reference [30] where the water solubilities in the extract phases are similar as those in the pure solvents. This is because of the relatively low concentration of HAc ( $1 \mathrm{wt} \%)$ in the feed, resulting in low amount of solute in the extract phase, and hence negligible influence on water solubility. On the contrary, for the other three solvents, the water concentration of the organic phase increased slightly after extraction. This may result from the strong interaction of the oxygenates with water which was pulled by oxygenates to the organic phase. The water in the extract phase will be evaporated in the process of solute recovery from the extract phase via evaporation, which will use extra energy. Thus, $\mathrm{P}_{666,14}\left[\mathrm{~N}(\mathrm{CN})_{2}\right]$ is the preferable solvent solely based on the water concentration in the extract phase.

Table 4.2. Water concentrations of the pure solvents and the extract phases at 1:1 solvent to feed ratio at $25{ }^{\circ} \mathrm{C}$

\begin{tabular}{lccc}
\hline Extract phases & $\begin{array}{c}\text { Water concentration } \\
\text { in pure solvents } \\
(\mathrm{wt} \%)\end{array}$ & $\begin{array}{c}\text { Water concentration } \\
\text { in extract phase } \\
(\mathrm{wt} \%)\end{array}$ & $\begin{array}{c}\text { Water concentration } \\
\text { in extract phase from } \\
\text { reference [30] (wt\%) }\end{array}$ \\
\hline $\mathrm{P}_{666,14} \mathrm{Cl}$ & $14.4[33]$ & 8.85 & 13.6 \\
$\mathrm{P}_{666,14}\left[\mathrm{~N}(\mathrm{CN})_{2}\right]$ & $3.31[33]$ & 3.63 & 3.9 \\
$\mathrm{P}_{666,14}[\mathrm{Phos}]$ & $14.4[33]$ & 6.82 & 14.1 \\
Hmim[B(CN) $\left.)_{4}\right]$ & 4.89 & 5.91 & Not available \\
TOA/1-octanol & 2.03 & 4.87 & 2.5 \\
\hline
\end{tabular}

With the aim of extracting all three compounds in an integrated process, the phosphonium ILs are the most suitable solvents for oxygenates extraction, as they have high affinity towards not only HAc but also the most difficult extracted solute glycolaldehyde. TOA/1octanol has very low extraction efficiency for acetol, thus it is less suited for use in an integrated extraction process. However, as a benchmark solvent, it was also studied together with phosphonium ILs for the temperature influence on the extraction efficiency. 


\subsubsection{Temperature influence on extraction efficiency}

The measured $\mathrm{D}_{i}$ at four different temperatures are given for the various solvents in Figure 4.2a-c. From Figure 4.2 it follows that the temperature influence differs for varying solutes. It is shown in Figure 4.2a that $\mathrm{D}_{\text {Acetol }}$ gradually increased from 25 to $50{ }^{\circ} \mathrm{C}$, which might be attributed to the weaker intermolecular interactions (e.g. hydrogen bonding) at higher temperature. The considerable increase between $50{ }^{\circ} \mathrm{C}$ and $60{ }^{\circ} \mathrm{C}$ might be due to the instability of acetol at higher temperature where acetol can be converted to other compounds [38].

No clear trend of temperature effect on $\mathrm{D}_{\mathrm{HAc}}$ was observed for most solvents from Figure $4.2 \mathrm{~b}$, but it is obviously decreasing for $\mathrm{P}_{666,14}[\mathrm{Phos}]$ with the temperature increasing. This suggests that at high temperature the hydrogen bonding interaction was weakened, and probably also the level of organization of the hydrophilic clusters, which is supported by the decreasing water content in the IL phase with increasing temperature [33].

The general trends of the temperature influence on $\mathrm{D}_{\text {gly }}$ are the same as those observed for $\mathrm{D}_{\text {Acetol }}$ for the solvents $\mathrm{P}_{666,14} \mathrm{Cl}, \mathrm{P}_{666,14}[\mathrm{Phos}]$ and TOA/Octanol. Above $50{ }^{\circ} \mathrm{C}$ there is a remarkable increase of the distribution coefficient, which most likely is the result of thermal instability of glycolaldehyde especially in basic solutions such as TOA/1-octanol. However, for $\mathrm{P}_{666,14}\left[\mathrm{~N}(\mathrm{CN})_{2}\right]$ the distribution already increases strongly between 25 and $40{ }^{\circ} \mathrm{C}$, and a maximum was observed at $50{ }^{\circ} \mathrm{C}$, and then drops again at further temperature increase to $60{ }^{\circ} \mathrm{C}$. Compared with the increase in $\mathrm{D}_{\mathrm{gly}}$ for other solvents, the increase was considerable (26 times vs 1.5 times for TOA/1-octanol) from $25{ }^{\circ} \mathrm{C}$ to $40{ }^{\circ} \mathrm{C}$. Correspondingly, the glycolaldehyde extraction yield increased from $39 \%$ to $94 \%$. In order to understand better the phenomena occurring during the extraction, a more detailed analysis was performed using ${ }^{1} \mathrm{H}$ NMR and ${ }^{13} \mathrm{C}$ NMR. 

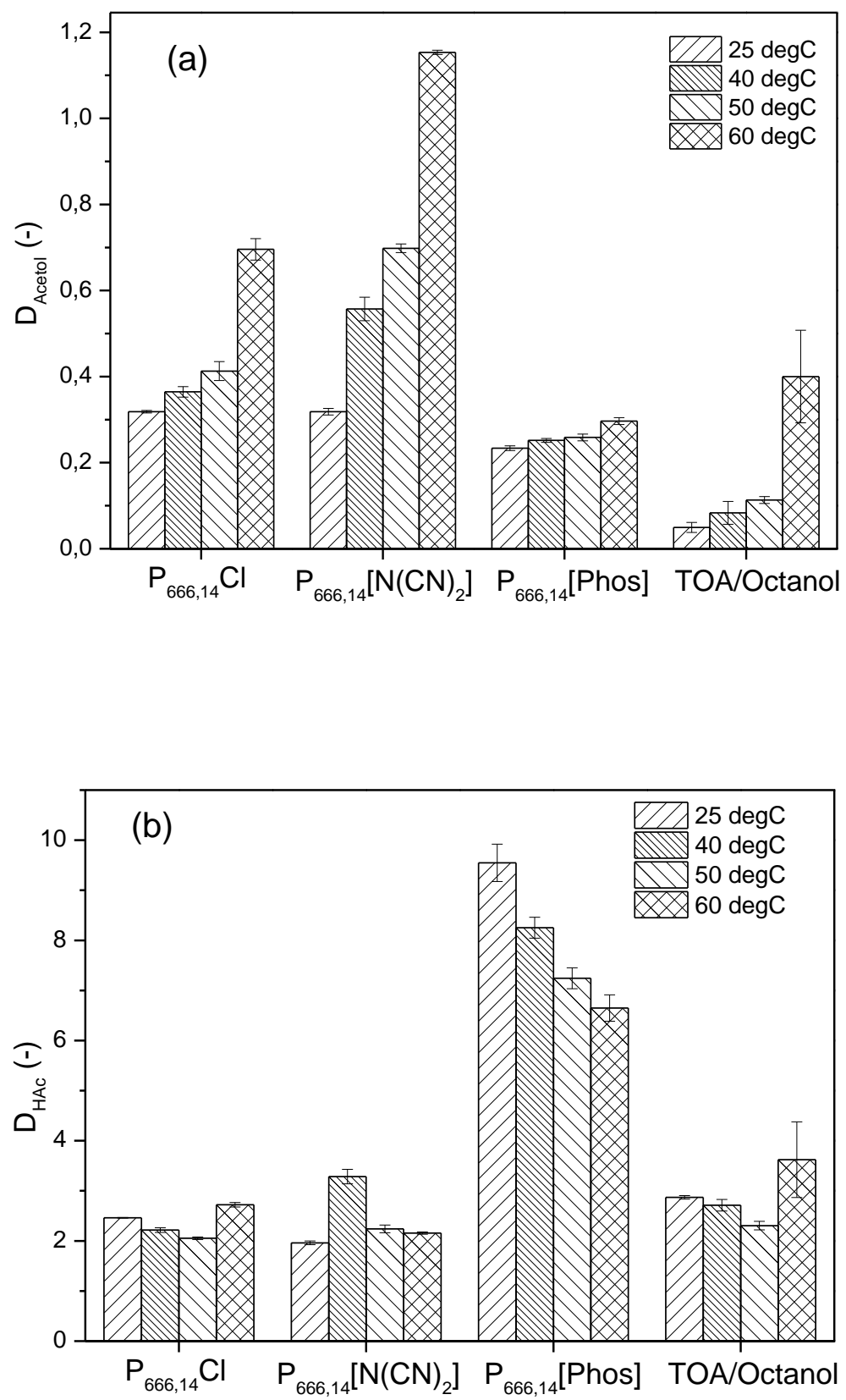


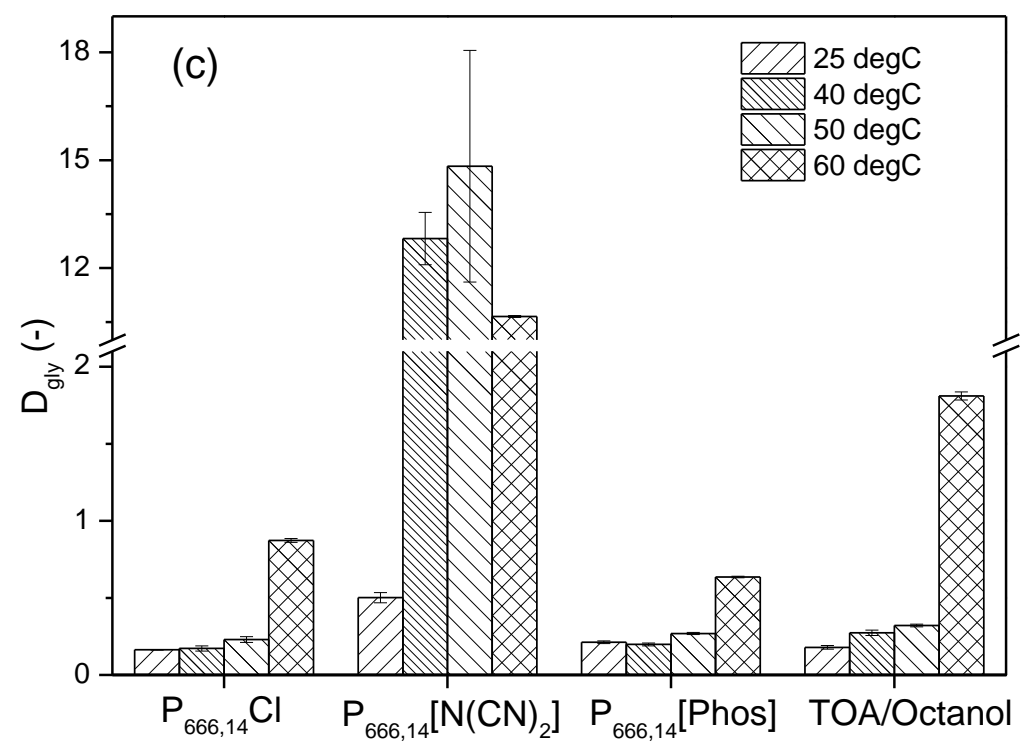

Figure 4.2. The distribution coefficients of the solutes at different temperatures in phosphonium ILs and TOA/1-octanol. (a) $\mathrm{D}_{\text {Acetol }}$; (b) $\mathrm{D}_{\mathrm{HAc}}$; (c) $\mathrm{D}_{\text {gly }}$.

\subsubsection{Extraction mechanism}

To elucidate on the phenomena and the possible mechanism of glycolaldehyde extraction with $\mathrm{P}_{666,14}\left[\mathrm{~N}(\mathrm{CN})_{2}\right]$, a series of extraction experiments was carried out with various ratio of HAc to IL and glycolaldehyde to IL at $40{ }^{\circ} \mathrm{C}$, followed by the NMR analysis.

The raffinate concentrations of glycolaldehyde $\left(x_{\mathrm{gly}}\right)$ and HAc $\left(x_{\mathrm{HAc}}\right)$ are displayed in Figure $4.3 \mathrm{a}$ and $\mathrm{b}$, respectively, for the various IL : glycolaldehyde ratios. The feed concentrations are indicated with open symbols and the raffinate concentrations with closed symbols. It can be seen in Figure 4.3a that for all IL : glycolaldehyde ratios, the raffinate concentration $x_{\text {gly }}$ reduced with increasing initial HAc concentration, and when no HAc was present $(\diamond)$, the $x_{\text {gly }}$ in the raffinates were comparable with that in the feed, implying almost no glycolaldehyde was extracted. From this trend, it is concluded that HAc enhances the glycolaldehyde extraction.

In Figure $4.3 \mathrm{~b}$, the $x_{\mathrm{HAc}}$ from the same experiments are displayed, and here the feed concentrations with open symbols are displayed as the most right series, while going from right to left in the figure, the IL : glycolaldehyde is reduced, also increasing thus the glycolaldehyde to HAc ratio. Also in this figure, a reduction of HAc concentration in the 
raffinate was observed with increasing initial concentration of glycolaldehyde, from which it is concluded that both HAc and glycolaldehyde are mutually enhancing their extractability.
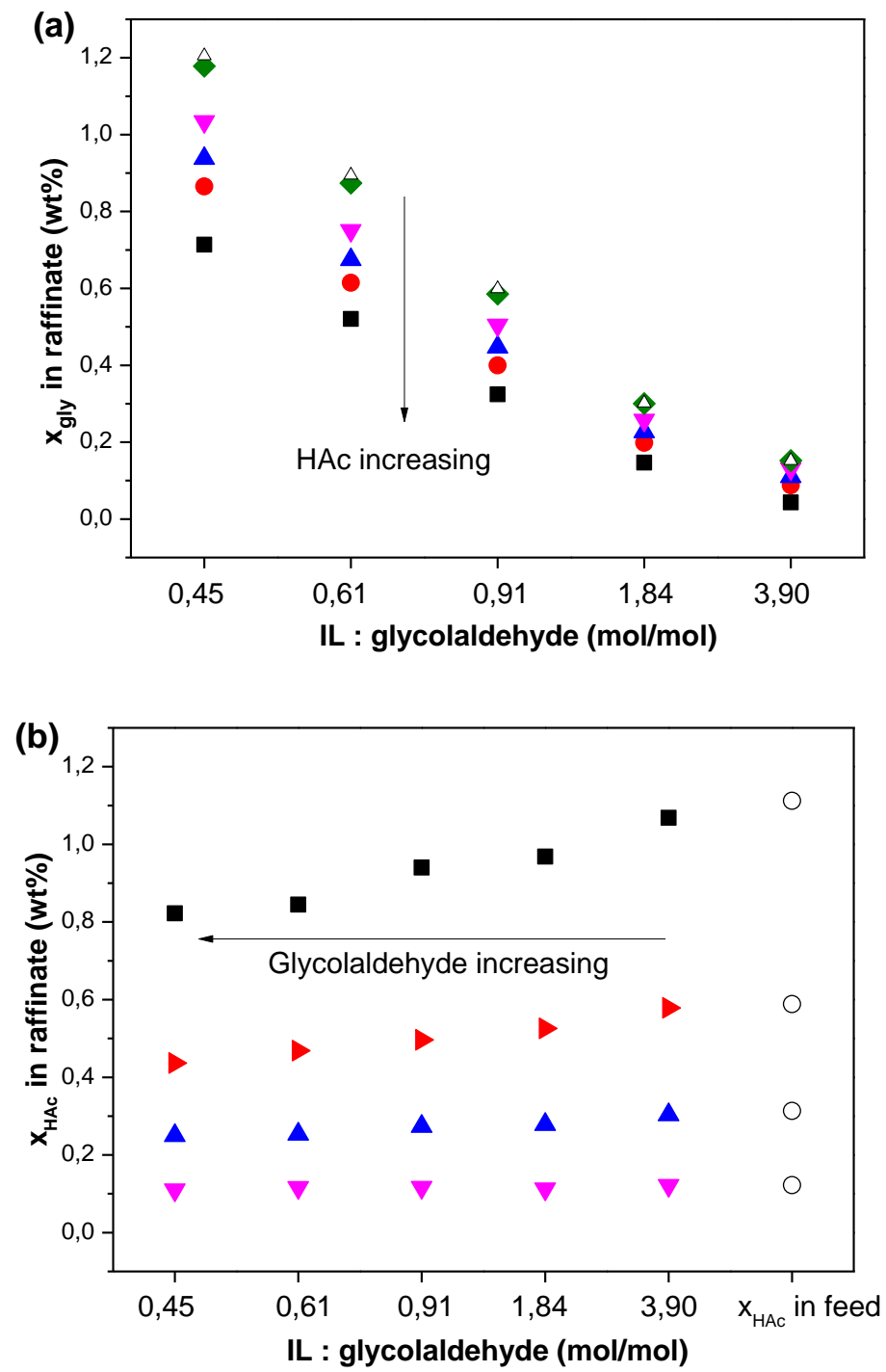

Figure 4.3. The concentration of glycolaldehyde (a) and HAc (b) in the feeds (hollow symbols) and raffinates (full symbols) after extraction with $\mathrm{P}_{666,14}\left[\mathrm{~N}(\mathrm{CN})_{2}\right]$. The HAc : IL $(\mathrm{mol} / \mathrm{mol})$ are $2.10: 1(\boldsymbol{\bullet}), 1.10: 1(\bullet), 0.56: 1(\boldsymbol{\Delta}), 0.22: 1(\boldsymbol{\nabla})$ and $0: 1(\diamond)$. Symbol $\Delta: x_{\mathrm{gly}}$ in feed; $\circ: x_{\mathrm{HAc}}$ in feed. 
Furthermore, since the strong effect of temperature was shown only for $\mathrm{P}_{666,14}\left[\mathrm{~N}(\mathrm{CN})_{2}\right]$, it is suspected that this solvent plays a role in the reaction/extraction mechanism, and to study this role, the reaction between glycolaldehyde and $\mathrm{P}_{666,14}\left[\mathrm{~N}(\mathrm{CN})_{2}\right]$ was justified by NMR analyses. The ${ }^{13} \mathrm{C}$ NMR and ${ }^{1} \mathrm{H}$ NMR spectra of four mixtures are shown in Figure S4.3 and S4.4 in the supplementary information in the Appendix B. It is observed from the ${ }^{13} \mathrm{C}$ NMR spectra in Figure S4.3a-c that no peak diminished or appeared in all of the spectra with only two components present, i.e. glycolaldehyde + HAc, glycolaldehyde $+\mathrm{P}_{666,14}\left[\mathrm{~N}(\mathrm{CN})_{2}\right]$ or $\mathrm{HAc}+\mathrm{P}_{666,14}\left[\mathrm{~N}(\mathrm{CN})_{2}\right]$, implying no reaction would take place when any of two components were mixed. However, when mixing HAc, glycolaldehyde and IL all together, it is shown in the ${ }^{13} \mathrm{C}$ NMR spectra in Figure S4.3d that the signal of aldehyde diminished and new signal characteristic for ester groups at $\delta=165$ and some other unknown peaks at $\delta=120-135$ and $\delta=72-88$ emerged. In the ${ }^{1} \mathrm{H}$ NMR spectra in Figure S4.4c also newly appeared peaks were observed at $6.5<\delta<8.5$. Both ${ }^{1} \mathrm{H}$ NMR and ${ }^{13} \mathrm{C}$ NMR confirm the formation of new compounds and this only happens when all three components are present in the mixture.

Due to the low intensity and resolution of the NMR signals, it is difficult to determine the structure of the new formed compounds and the reaction mechanism is not clearly known at this stage. Also a clear stoichiometric relation between the IL, the extracted HAc and glycolaldehyde was not found. However, on the basis of our results, possible reactions are proposed and shown in the Appendix B. It is suspected that the negatively charged $\mathrm{N}$ in the anion of IL acts as a nucleophile, attacking the carbonyl carbon from the glycolaldehyde that is activated in the presence of acid, and form a new C-N single bond. The new peak of ester group suggests that the esterification reaction was improved. Furthermore, HAc appears to promote this reaction which is likely in the role of an acid catalyst.

\subsubsection{Recycling of ILs}

To design a sustainable extraction process, solvent recovery, in this case thus IL recovery is an essential step. Therefore, the recovery of four ILs (see Table 4.3) is studied by evaporating the oxygenates from corresponding extract phases under vacuum conditions as described in Experimental section 4.2.4.

The IL recoverability is presented as the percentage of evaporated solutes (oxygenates and water) based on the initial mass of solutes that was present in the extracts. Assuming all the water could be evaporated and thus the remaining solutes after evaporation were all considered as oxygenates, the percentage of the evaporated oxygenates were then calculated based on the initial mass of oxygenates in the extracts. The results and the operating conditions are shown in Table 4.3. It can be seen that removal of the solutes from all of the 
phosphonium ILs was very difficult by evaporation, and only a fraction of the oxygenates was removed, which is likely due to the strong interaction of the oxygenates (especially HAc) with phosphonium ILs and the reactive extraction of $\mathrm{P}_{666,14}\left[\mathrm{~N}(\mathrm{CN})_{2}\right]$ with glycolaldehyde.

The relatively low distribution coefficients of $\mathrm{HAc}$ for $\mathrm{Hmim}\left[\mathrm{B}(\mathrm{CN})_{4}\right]$ indicate less strong interactions than for phosphonium ILs, and it is seen that the evaporative recovery achieved $100 \%$ at relatively benign conditions. Considering the thermal instability of the glycolaldehyde and acetol, the recovery method needs to be optimized towards lower temperature, which could be achieved by lowering the pressure or increasing the evaporation time.

Table 4.3. Evaporation of the extracted solutes at 20 mbar with $\mathrm{N}_{2}$ flushing.

\begin{tabular}{lcccc}
\hline Solvents & $\mathrm{P}_{666,14} \mathrm{Cl}$ & $\mathrm{P}_{666,14}\left[\mathrm{~N}(\mathrm{CN})_{2}\right]$ & $\mathrm{P}_{666,14}[\mathrm{Phos}]$ & $\mathrm{Hmim}\left[\mathrm{B}(\mathrm{CN})_{4}\right]$ \\
\hline $\begin{array}{l}\text { Percentage of evaporated } \\
\text { oxygenates and water } \\
\text { based on their initial mass }\end{array}$ & 86.3 & 70.7 & 70.3 & 100 \\
$\begin{array}{l}\text { in the extracts (wt\%) } \\
\text { Percentage of evaporated }\end{array}$ & & & & \\
$\begin{array}{l}\text { oxygenates based on the } \\
\text { initial mass of oxygenates }\end{array}$ & 74.0 & 62.0 & 51.5 & 100 \\
$\begin{array}{l}\text { in the extracts (wt\%) } \\
\left.\text { Temperature ( }{ }^{\circ} \mathrm{C}\right)\end{array}$ & 100 & 100 & 100 & 60 \\
Heating time (h) & 1 & 1 & 1 & 0.5 \\
\hline
\end{tabular}

The regenerated $\mathrm{P}_{666,14}[\mathrm{Phos}]$ and $\operatorname{Hmim}\left[\mathrm{B}(\mathrm{CN})_{4}\right]$ were chosen for studying the solvent reusability by performing the second cycle of extraction from the fresh mixed solutes feed. When extracting with the regenerated $\mathrm{P}_{666,14}[\mathrm{Phos}], \mathrm{D}_{i}$ decreased significantly (e.g. around half for glycolaldehyde), suggesting that the remained solutes in the regenerated IL have strong negative effect on the next extraction cycle. When extracting with the regenerated $\mathrm{Hmim}\left[\mathrm{B}(\mathrm{CN})_{4}\right]$, it was found out that the extraction efficiency of the recycled ILs was similar with the fresh ILs. Hmim[B(CN) $\left.)_{4}\right]$ was used in a total of four extraction cycles with a stable $\mathrm{D}_{i}$ for all four cycles as shown in Figure 4.4. This confirms the thermal stability of the IL and the stable extraction performance of the recycled IL, and the suitability of vacuum evaporation to recover the solutes for $\operatorname{Hmim}\left[\mathrm{B}(\mathrm{CN})_{4}\right]$ recovery. 
For the ILs that could not be regenerated by direct evaporation, the use of a back-wash is suggested. For example, in the case of glycolaldehyde, with a distribution coefficient below unity, the back-wash with water may regenerate the solvent at the cost of an additional operation. For HAc, the regeneration through back-wash is less effective due to the higher distribution. Therefore, a combination of extraction steps is suggested.

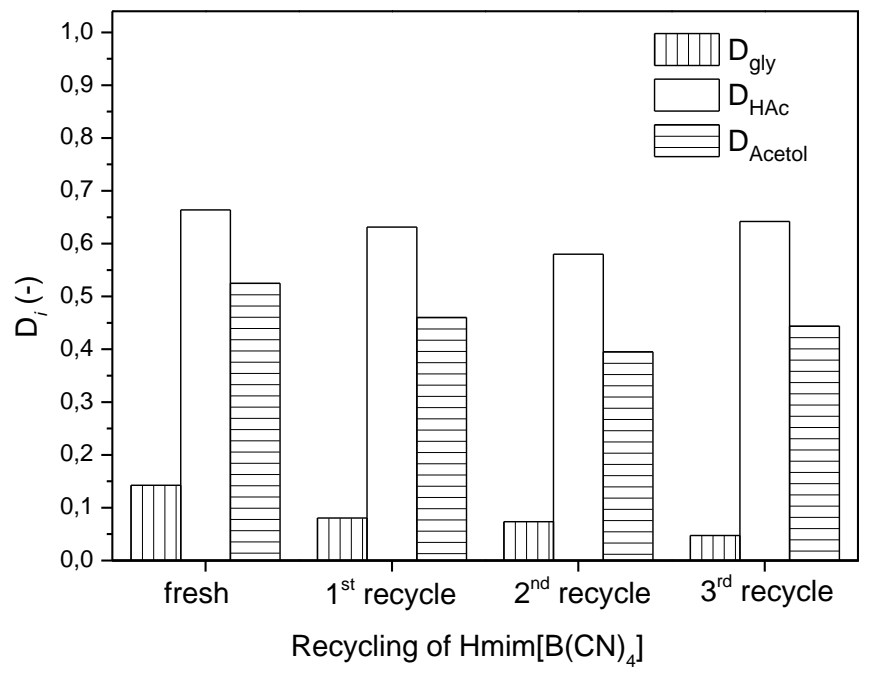

Figure 4.4. Distribution coefficients of the solutes for the recycled $\operatorname{Hmim}\left[\mathrm{B}(\mathrm{CN})_{4}\right]$.

To avoid difficulties, the irreversible reactive extraction of glycolaldehyde with $\mathrm{P}_{666,14}\left[\mathrm{~N}(\mathrm{CN})_{2}\right]$ should be omitted. As $\mathrm{D}_{\text {Acetol }}$ for $\mathrm{Hmim}\left[\mathrm{B}(\mathrm{CN})_{4}\right]$ was 3-10 times higher than that for the studied solvents and other reported solvents (e.g. 1-octanol, 2-ethyl-1-hexanol and TOA) $[8,19]$, the required solvent to feed ratio for $\operatorname{Hmim}\left[\mathrm{B}(\mathrm{CN})_{4}\right]$ would decrease significantly to achiever same recovery target. Also $\mathrm{P}_{666,14}[\mathrm{Phos}]$ has a 2-4 times higher $\mathrm{D}_{\text {gly }}$ than other studied solvents when extracting from single solute solution. Although TOA/1octanol has a higher $\mathrm{D}_{\mathrm{HAc}}$ than $\operatorname{Hmim}\left[\mathrm{B}(\mathrm{CN})_{4}\right]$ and thus less solvent would be required for HAc extraction, it is not necessary to use TOA/1-octanol for HAc extraction in a separate step, because HAc can be co-extracted when extracting acetol with $\mathrm{Hmim}\left[\mathrm{B}(\mathrm{CN})_{4}\right]$. Thus, a two-step extraction was proposed where HAc and acetol are extracted in the first step with $\mathrm{Hmim}\left[\mathrm{B}(\mathrm{CN})_{4}\right]$ and glycolaldehyde is removed in the second step with $\mathrm{P}_{666,14}$ [Phos]. HAc and acetol will be then recovered through vacuum evaporation and glycolaldehyde via water back-extraction. 


\subsection{Conclusions}

From the comparison of the distributions in the extraction stage, it was found that the benchmark solvent TOA/1-octanol has the lowest extraction efficiency for acetol, and phosphonium ILs the highest. However, due to occurring reactions and difficult regenerations, the phosphonium ILs cannot be applied for extraction of all oxygenates at once. In absence of HAc, however, $\mathrm{P}_{666,14}[\mathrm{Phos}]$ shows the highest glycolaldehyde distribution coefficient and can be regenerated by a water wash. This step can follow an initial extraction of HAc and acetol by $\mathrm{Hmim}\left[\mathrm{B}(\mathrm{CN})_{4}\right]$, which was shown to have the highest acetol distribution coefficient and could be completely thermally regenerated. Thus, a two-step extraction is proposed by employing $\mathrm{Hmim}\left[\mathrm{B}(\mathrm{CN})_{4}\right]$ in the first step to extract acetic acid and acetol, and using $\mathrm{P}_{666,14}[\mathrm{Phos}]$ in the second step to remove glycolaldehyde, followed by recovery of $\mathrm{Hmim}\left[\mathrm{B}(\mathrm{CN})_{4}\right]$ through solute evaporation and recovery of $\mathrm{P}_{666,14}[\mathrm{Phos}]$ via water backextraction.

\section{References}

[1] S.C.a.A.V. Bridgwater, Overview of Applications of Biomass Fast Pyrolysis Oil, Energy Fuels, 18 (2004) 590-598.

[2] L. Fele Žilnik, A. Jazbinšek, Recovery of renewable phenolic fraction from pyrolysis oil, Sep. Purif. Technol., 86 (2012) 157-170.

[3] X. Li, S.R.A. Kersten, B. Schuur, Extraction of Guaiacol from Model Pyrolytic Sugar Stream with Ionic Liquids, Industrial \& Engineering Chemistry Research, 55 (2016) 4703 4710 .

[4] M.R. Rover, P.A. Johnston, T. Jin, R.G. Smith, R.C. Brown, L. Jarboe, Production of Clean Pyrolytic Sugars for Fermentation, Chemsuschem, 7 (2014) 1662-1668.

[5] X. Li, L.C. Luque-Moreno, S.R.G. Oudenhoven, L. Rehmann, S.R.A. Kersten, B. Schuur, Aromatics extraction from pyrolytic sugars using ionic liquid to enhance sugar fermentability, Bioresour. Technol., 216 (2016) 12-18.

[6] A.V. Bridgwater, The production of biofuels and renewable chemicals by fast pyrolysis of biomass, International Journal of Global Energy Issues, 27 (2007) 160.

[7] G.L. Underwood, R.G. Graham, Methods of using fast pyrolysis liquids as liquid smoke, (1989) U.S. Patent 4.876.108.

[8] C.R. Vitasari, G.W. Meindersma, A.B. de Haan, Laboratory scale conceptual process development for the isolation of renewable glycolaldehyde from pyrolysis oil to produce fermentation feedstock, Green Chemistry, 14 (2012) 321-325. 
[9] H. Cheung, R.S. Tanke, G.P. Torrence, Acetic Acid, in: Ullmann's Encyclopedia of Industrial Chemistry, Wiley-VCH Verlag GmbH \& Co. KGaA, 2000.

[10] M.H. Mohamad, R. Awang, W.M.Z.W. Yunus, A Review of Acetol: Application and Production American Journal of Applied Sciences, 8 (2011) 1135-11399.

[11] A. Oasmaa, J. Korhonen, E. Kuoppala, An Approach for Stability Measurement of Wood-Based Fast Pyrolysis Bio-Oils, Energy Fuels, 25 (2011) 3307-3313.

[12] F.H. Mahfud, F.P. van Geel, R.H. Venderbosch, H.J. Heeres, Acetic Acid Recovery from Fast Pyrolysis Oil. An Exploratory Study on Liquid-Liquid Reactive Extraction using Aliphatic Tertiary Amines, Sep. Sci. Technol., 43 (2008) 3056-3074.

[13] C.R. Vitasari, G.W. Meindersma, A.B. de Haan, Water extraction of pyrolysis oil: The first step for the recovery of renewable chemicals, Bioresour. Technol., 102 (2011) 72047210 .

[14] R.J.M. Westerhof, D.W.F. Brilman, M. Garcia-Perez, Z. Wang, S.R.G. Oudenhoven, W.P.M. van Swaaij, S.R.A. Kersten, Fractional Condensation of Biomass Pyrolysis Vapors, Energy Fuels, 25 (2011) 1817-1829.

[15] A. Teella, G.W. Huber, D.M. Ford, Separation of acetic acid from the aqueous fraction of fast pyrolysis bio-oils using nanofiltration and reverse osmosis membranes, Journal of Membrane Science, 378 (2011) 495-502.

[16] Y.K. Hong, W.H. Hong, Removal of acetic acid from aqueous solutions containing succinic acid and acetic acid by tri-n-octylamine, Sep. Purif. Technol., 42 (2005) 151-157.

[17] C.B. Rasrendra, B. Girisuta, H.H. van de Bovenkamp, J.G.M. Winkelman, E.J. Leijenhorst, R.H. Venderbosch, M. Windt, D. Meier, H.J. Heeres, Recovery of acetic acid from an aqueous pyrolysis oil phase by reactive extraction using tri-n-octylamine, Chem. Eng. J., 176 (2011) 244-252.

[18] C.R. Vitasari, G.W. Meindersma, A.B. de Haan, Glycolaldehyde co-extraction during the reactive extraction of acetic acid with tri-n-octylamine/2-ethyl-1-hexanol from a woodbased pyrolysis oil-derived aqueous phase, Sep. Purif. Technol., 95 (2012) 39-43.

[19] C.R. Vitasari, G.W. Meindersma, A.B. de Haan, Conceptual process design of an integrated bio-based acetic acid, glycolaldehyde, and acetol production in a pyrolysis oilbased biorefinery, Chemical Engineering Research \& Design, 95 (2015) 133-143.

[20] J.A. Stradal, G.L. Underwood, PROCESS FOR PRODUCING HYDROXYACETALDEHYDE United States Patent, 5393542 (1995).

[21] C.R. Vitasari, G.W. Meindersma, A.B. de Haan, Renewable glycolaldehyde isolation from pyrolysis oil-derived aqueous solution by reactive extraction with primary amines, Sep. Purif. Technol., 95 (2012) 103-108. 
[22] M.T.G. Jongmans, B. Schuur, A.B. de Haan, Ionic Liquid Screening for Ethylbenzene/Styrene Separation by Extractive Distillation, Ind. Eng. Chem. Res., 50 (2011) 10800-10810.

[23] G.W. Meindersma, A.R. Hansmeier, A.B. de Haan, Ionic Liquids for Aromatics Extraction. Present Status and Future Outlook, Ind. Eng. Chem. Res., 49 (2010) 7530-7540.

[24] T.T. Jiao, X.L. Zhuang, H.Y. He, L.H. Zhao, C.S. Li, H.N. Chen, S.J. Zhang, An ionic liquid extraction process for the separation of indole from wash oil, Green Chem., 17 (2015) 3783-3790.

[25] T. Vander Hoogerstraete, K. Binnemans, Highly efficient separation of rare earths from nickel and cobalt by solvent extraction with the ionic liquid trihexyl(tetradecyl)phosphonium nitrate: a process relevant to the recycling of rare earths from permanent magnets and nickel metal hydride batteries, Green Chemistry, 16 (2014) 1594-1606.

[26] M. Matsumoto, K. Mochiduki, K. Fukunishi, K. Kondo, Extraction of organic acids using imidazolium-based ionic liquids and their toxicity to Lactobacillus rhamnosus, Sep. Purif. Technol., 40 (2004) 97-101.

[27] S.V. Smirnova, Torocheshnikova, II, A.A. Formanovsky, I.V. Pletnev, Solvent extraction of amino acids into a room temperature ionic liquid with dicyclohexano-18-crown6, Analytical and Bioanalytical Chemistry, 378 (2004) 1369-1375.

[28] J. Martak, S. Schlosser, Extraction of lactic acid by phosphonium ionic liquids, Sep. Purif. Technol., 57 (2007) 483-494.

[29] F.S. Oliveira, J.M.M. Araujo, R. Ferreira, L.P.N. Rebelo, I.M. Marrucho, Extraction of L-lactic, L-malic, and succinic acids using phosphonium-based ionic liquids, Sep. Purif. Technol., 85 (2012) 137-146.

[30] E. Reyhanitash, B. Zaalberg, S.R.A. Kersten, B. Schuur, Extraction of volatile fatty acids from fermented wastewater, Sep. Purif. Technol., 161 (2016) 61-68.

[31] E. Reyhanitash, B. Zaalberg, H.M. Ijmker, S.R.A. Kersten, B. Schuur, CO2-enhanced extraction of acetic acid from fermented wastewater, Green Chemistry, 17 (2015) 4393-4400. [32] K. Tonova, I. Svinyarov, M.G. Bogdanov, Hydrophobic 3-alkyl-1-methylimidazolium saccharinates as extractants for l-lactic acid recovery, Sep. Purif. Technol., 125 (2014) 239246.

[33] J. Marták, Š. Schlosser, Extraction of lactic acid by phosphonium ionic liquids, Sep. Purif. Technol., 57 (2007) 483-494.

[34] M. Stoffers, A. Gorak, Continuous multi-stage extraction of n-butanol from aqueous solutions with 1-hexyl-3-methylimidazolium tetracyanoborate, Sep. Purif. Technol., 120 (2013) 415-422.

[35] F. Eckert, A. Klamt, Fast solvent screening via quantum chemistry: COSMO-RS approach, AlChE J., 48 (2002) 369-385. 
[36] X. Li, S.R.A. Kersten, B. Schuur, Efficiency and Mechanism of Demulsification of Oilin-Water Emulsions Using Ionic Liquids, Energy Fuels, (2016).

[37] M. Blahusiak, S. Schlosser, J. Martak, Extraction of butyric acid with a solvent containing ammonium ionic liquid, Sep. Purif. Technol., 119 (2013) 102-111.

[38] Z. Wang, W.G. Lin, W.L. Song, J.Z. Yao, Preliminary investigation on concentrating of acetol from wood vinegar acetol extraction with EA and other organic solvent, Energy Convers. Manage., 51 (2010) 346-349. 


\section{Chapter 5}

\section{Demulsification of oil-in-water emulsions}

\section{using ionic liquids: efficiency and mechanism}

In this chapter, 13 ionic liquids (ILs), including 9 halogenide ILs and 4 non-halogenide ILs, were evaluated as demulsifiers for a model oil-in-water emulsion prepared with heptane and water, where sodium dodecylbenzenesulfonate (SDBS) was used as surfactant. The separating efficiency (the fraction of heptane that has phase separated from the emulsion) of ILs was investigated using bottle tests and tube tests. Bottle tests show that halogenide ILs exhibited very fast demulsification, and among non-halogenide ILs, only trihexyltetradecylphosphonium dicyanamide $\left(\mathrm{P}_{666,14}\left[\mathrm{~N}(\mathrm{CN})_{2}\right]\right)$ could demulsify effectively but slower than halogenide ILs. Tube tests suggest that the demulsification efficiency is correlated with the mole ratio of IL and SDBS. For all ILs showing effective demulsification, instead of the desired extraction of the surfactant to an IL phase, it was found that the demulsification mechanism was ion exchange between IL anions and DBS, driven by the large Gibbs energy of hydration of the anions of the sodium salts that dissolve in water. Regeneration of these ILs and surfactants requires water-free reversed ion exchange processes with sodium salts and with salts containing the IL anions, probably limiting commercial applicability of the use of these ILs for demulsification.

This chapter has been published as:

Li, X.; Kersten, S. R. A.; Schuur, B., Efficiency and Mechanism of Demulsification of Oil-in-Water Emulsions Using Ionic Liquids. Energy \& Fuels 2016, 30, 7622-7628. 


\subsection{Introduction}

Chemical enhanced oil recovery (EOR) methods are applied in the oil industry to recover more oil after primary and secondary recovery techniques. In EOR processes, alkalines, surfactants, polymers, or their combinations are injected to increase the viscosity of water and to reach ultralow interfacial tension between oil and flooding water solutions $[1,2]$. However, part of the produced oils are in the form of stable emulsions which need to be separated to obtain qualified water (containing $<200 \mathrm{ppm}$ oil) and qualified oil $(<0.3-0.5$ vol $\%$ water) for pipeline transportation to the refinery $[3,4]$.

Chemical demulsification is an effective method to accelerate the separation of oil and water [5-7]. Some demulsifiers, such as ethoxylated and/or propoxylated alkylphenol formaldehyde resins and polymeric flocculants, have been developed to separate the waterin-oil emulsions from normal production operations, stabilized by natural surfactants (asphaltenes and resins) in the crude oil. However, these demulsifiers are not effective in separating EOR produced oil-in-water emulsions, which differ from the naturally occurring oil field emulsions [8], as a result of the injected alkali, surfactant and polymer that are tightly bound to the oil and water [9]. As in EOR processes, anionic surfactant (e.g., dodecyl alkyl sulfate) blends are usually injected $[10,11]$ cationic surfactants can be effective in breaking oil-in-water emulsions by reducing the electrostatic repulsion among drops, hence, reducing the emulsion stability $[3,8]$.

Ionic liquids (ILs), which can be tuned to form cationic surface-active compounds by altering the cation and anion combinations, have been employed as demulsifiers to break oilin-water or water-in-oil emulsions [3, 12-15]. Some halogenide ILs with imidazolium or ammonium cations and non-halogenide ILs with fluorinated anions (e.g., $\mathrm{BF}_{4}, \mathrm{PF}_{6}$, and $\mathrm{NTf}_{2}$ ) have been used to break water-in-crude oil emulsions [12-14], and all of these ILs showed good performance, especially in conjunction with microwave irradiation, which was applied to accelerate the heating rate and reduce the viscosity. However, fluorinated anions are expensive and are environmentally less benign. Ammonium ILs with different anions (e.g., $[\mathrm{Cl}]^{-},\left[\mathrm{HSO}_{4}\right]^{-}$, or $\left[\mathrm{H}_{2} \mathrm{PO}_{4}\right]^{-}$) were also employed to separate water from crude oil emulsions, and the demulsification efficiency varies when applying different ILs [15]. For EOR produced emulsions, octyltrimethylammonium bromide was used as a demulsifier by Hirasaki and co-workers [3], as well as a commercial cationic surfactant, and both of them were successful in producing qualified oil and water phases.

In each paper, the separation efficiency has been correlated with the structure of ILs, but different conclusions were reported in the literature. Flores et al. claimed that ILs with more hydrophilic anions were more efficient demulsifiers [15], while Furtuny and co-workers 
showed that ILs with a hydrophobic anion provided high separation efficiency [14]. Flores and co-workers concluded that ILs with longer alkyl chain length cations should perform better as demulsifiers than ILs with shorter alkyl chain length cations, but Guzman-Lucero et al. observed the opposite phenomenon [12]. However, it is not valid to compare these observations, because many other factors also influence the separation efficiency, such as oil properties (e.g, density, viscosity, and water content) and demulsification conditions (e.g., heating method, temperature, demulsifier amount, stirring time, and rate). As a result of the complexity of the crude oils in none of these papers, a mechanism is proposed [3, 12-15]. It is of essential importance to understand where the IL stays, because leaving the IL unrecycled is not a sustainable approach as a result of the high price. Ideally, both the surfactant and the IL should be recyclable. This could be best achieved if a separate IL phase would be formed in which the surfactant would be dissolved; i.e. the surfactant would then be extracted by the IL. Even if a phase is created based on the IL, surfactant extraction might compete with the less desired ion exchange mechanism [16].

To guide the selection/design of ILs for demulsification purposes and to gain understanding of the role of ILs in the demulsification, aiding future process development, studies were carried out with rather simple model emulsions (heptane-in-water), which were prepared with sodium dodecylbenzenesulfonate (SDBS) as the model anionic surfactant. In this work, 13 ILs were studied with varying hydrophobicity, including some of the ILs that were reported previously [3] as well as a series of phosphonium and imidazolium ILs with varying hydrocarbon chain lengths that were not reported for this purpose before. The studies here reported include the preparation and characterization of the model emulsions, demulsification efficiency studies at room temperature using conventional bottle tests and tube tests, and investigation on the mechanism of the demulsifications.

\subsection{Experimental}

\subsubsection{Materials}

Heptane (> 99\%), acetonitrile (> 99.9\%), potassium permanganate (> 99\%), SDBS (technical grade), and dimethyl sulfoxide- $d_{6}(>99.9 \%$, DMSO) were purchased from Sigma Aldrich. The ILs were supplied by Iolitec with a purity $>95 \%$ and were used as supplied. Their names, abbreviations, and structures are presented in Table 5.1 and Scheme 5.1. 
Table 5.1. Names and abbreviations of investigated ILs

\begin{tabular}{ll}
\hline Name of ILs & Abbreviations \\
\hline 1-Hexyl-3-methylimidazolium chloride & {$\left[\mathrm{C}_{6} \mathrm{mim}\right] \mathrm{Cl}$} \\
1-Octyl-3-methylimidazolium chloride & {$\left[\mathrm{C}_{8} \mathrm{mim}\right] \mathrm{Cl}$} \\
1-Decyl-3-methylimidazolium chloride & {$\left[\mathrm{C}_{10} \mathrm{mim}\right] \mathrm{Cl}$} \\
Trihexyltetradecylphosphonium chloride & $\mathrm{P}_{666,14} \mathrm{Cl}$ \\
Trihexyltetradecylphosphonium bromide & $\mathrm{P}_{666,14} \mathrm{Br}$ \\
Trimethyloctylammonium bromide & $\mathrm{N}_{111,8} \mathrm{Br}$ \\
Trihexyltetradecylphosphonium dicyanamide & $\mathrm{P}_{666,14}\left[\mathrm{~N}(\mathrm{CN})_{2}\right]$ \\
Trihexyltetradecylphosphonium bis $(2,4,4-$ & $\mathrm{P}_{666,14}[\mathrm{Phos}]$ \\
trimethylpentyl)phosphinate & \\
Trihexyltetradecylphosphonium & $\mathrm{P}_{666,14}\left[\mathrm{NTf} f_{2}\right]$ \\
bis((trifluoromethyl)sulfonyl)imide & \\
Tetrabutylphosphonium chloride & $\mathrm{P}_{4444} \mathrm{Cl}$ \\
Tetraoctylphosphonium bromide & $\mathrm{P}_{8888} \mathrm{Br}$ \\
Tributyltetradecylphosphonium chloride & $\mathrm{P}_{444,14} \mathrm{Cl}$ \\
Triethylbutylammonium dicyanamide & $\mathrm{N}_{2224}\left[\mathrm{~N}(\mathrm{CN})_{2}\right]$ \\
\hline
\end{tabular}

\subsubsection{Emulsion preparation}

In this work, heptane was used as oil and the surfactant SDBS was used as an emulsifier to make model emulsions. SDBS aqueous solutions $(1 \mathrm{wt} \%, 70 \mathrm{~mL})$ were mixed with heptane $(420 \mathrm{~mL})$ in a glass bottle $(1 \mathrm{~L})$ with a four-blade impeller. The mixture was first stirred at the speed of $600 \mathrm{rpm}$ for $2 \mathrm{~min}$ to obtain pre-emulsions and then at $1800 \mathrm{rpm}$ for $10 \mathrm{~min}$ to obtain stable emulsions, because after $24 \mathrm{~h}$, no phase separation was observed. The emulsions were applied immediately in the demulsification studies to enhance the reproducibility. 


\section{CATIONS:}<smiles>C[n+]1ccn(-c2ccccc2)c1</smiles>

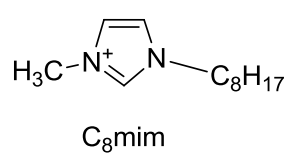

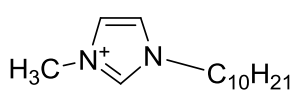

$\mathrm{C}_{10} \mathrm{mim}$

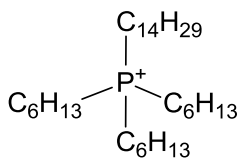

$\mathrm{P}_{666,14}$<smiles>CCCCCCCCCCCCC</smiles>

$\mathrm{P}_{4444}$<smiles>CCCCCCCCCCCCCCCCCC</smiles>

$\mathrm{P}_{444,14}$

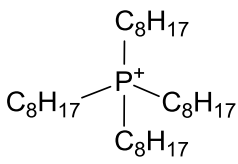

$\mathrm{P}_{8888}$<smiles>CC[N+](CC)(CC)CC</smiles>

$\mathrm{N}_{2224}$<smiles>CCC(C)(C)[N+](C)(C)CC</smiles>

$\mathrm{N}_{1118}$

\section{ANIONS:}

$\begin{array}{ll}\mathrm{Cl}^{-} & \mathrm{Br} \\ \mathrm{Cl} & \mathrm{Br}\end{array}$<smiles>CC(CC(C)(C)C)CP(=O)(O)CC(C)CC(C)(C)C</smiles><smiles>O=S(=O)(O)[N-]S(=O)(=O)OS(=O)(=O)C(F)(F)F</smiles><smiles>[N][N-]N</smiles>

$\mathrm{Br}$

Phos

$\mathrm{NTf}_{2}$

$\mathrm{N}(\mathrm{CN})_{2}$

Scheme 5.1. Structures of studied cations and anions of ILs.

\subsubsection{Emulsion characterization}

A colored emulsion was prepared by mixing potassium permanganate into the aqueous phase and applying the same method described in section 2.2. Visual observation was performed using an Olympus BH-2 optical microscope $10 \times$ magnification to confirm the nature of the emulsion (oil-in-water or water-in-oil).

Drop size distributions were determined at $20{ }^{\circ} \mathrm{C}$ with a Lasentec S400A focused beam reflectance measurement (FBRM) device, equipped with an 8 mm PI 14/206 probe (Mettler Toledo). The tip of the probe was positioned under an angle of $45^{\circ}$ below the surface of emulsions in bottles that were stirred at the speed of $800 \mathrm{rpm}$ to minimize the chance of droplets sticking to the probe. The FBRM uses a rotating laser beam that is reflected by drops. The reflection times are converted into chord size distributions, which were corrected to the actual droplet size distributions by applying a correction factor. For perfectly spherical droplets and assuming that the system is well-mixed, the average chord size is $79 \%$ of the average droplet size [17]. 


\subsubsection{Demulsification efficiency tests}

Bottle tests were performed similar to the method reported by Guzman-Lucero et al. [12] and Flores et al. [15]. The prepared emulsions (35 g) were first transferred to a graduated glass bottle $(100 \mathrm{~mL})$, to which the investigated ILs (20 wt $\%$ in isopropanol) were subsequently added. The mole ratio of IL/SDBS was 1 . All of the bottles were stirred by a four-blade impeller at the speed of $800 \mathrm{rpm}$ for $1 \mathrm{~min}$ at room temperature. Then, the bottles were allowed to settle down while recording the separated heptane volumes against time immediately after stopping the impeller.

Tube tests to study on the demulsification rate were carried out in $20 \mathrm{~mL}$ graduated tubes. First, the prepared emulsions $(16 \mathrm{~mL})$ were transferred to the tubes. Then, the ILs $(20 \mathrm{wt} \%$ in isopropanol) were added without stirring. The mole ratio of IL/SDBS varies from 0.2 to 1.4. A tube containing $16 \mathrm{~mL}$ of emulsion and $0.2 \mathrm{~g}$ of isopropanol without any ILs was employed as a reference (blank). The separated heptane volumes against time were recorded immediately after adding the ILs.

\subsubsection{Study on the ion exchange between ILs and SDBS}

During demulsification experiments, in some cases flocculation was observed (vide infra), and to investigate the chemical nature of the species generating the flocculates, the possible salt formation through ion exchange was studied in the absence of the heptane phase and in much higher concentrations.

1-Decyl-3-methylimidazolium dodecylbenzenesulfonate ([C $\left.\left.C_{10 m i m}\right][D B S]\right)$. A total of 5.0 $\mathrm{mmol}$ of $\left[\mathrm{C}_{10} \mathrm{mim}\right] \mathrm{Cl}$ was mixed with $5.5 \mathrm{mmol}$ of SDBS (8 wt $\%$ in aqueous solutions) under magnetic stirring for $24 \mathrm{~h}$ at room temperature. A cloudy mixture was observed to which $1 \mathrm{~g}$ ethyl acetate (EA) was added to induce phase separation. The aqueous and EA phases were separated, and after isolation of the EA phase, EA and some dissolved water were removed in a rotary evaporator at $60{ }^{\circ} \mathrm{C}$ and 50 mbar and a viscous liquid product was obtained. Characterization was performed using ${ }^{1} \mathrm{H}$ and ${ }^{13} \mathrm{C}$ nuclear magnetic resonance (NMR) on a Bruker NMR machine (400MHz and $100 \mathrm{MHz}) .{ }^{1} \mathrm{H}$ NMR (400 MHz, DMSO- $\left.d_{6}\right) \delta: 9.1$ (s, $1 \mathrm{H}), 7.8(\mathrm{~s}, 1 \mathrm{H}), 7.7(\mathrm{~s}, 1 \mathrm{H}), 7.5-7.6(\mathrm{~d}, 2 \mathrm{H}), 7.2-7.1(\mathrm{~m}, 2 \mathrm{H}), 4.1-4.2(\mathrm{t}, 2 \mathrm{H}), 3.85(\mathrm{~s}, 3 \mathrm{H})$, $1.75(\mathrm{~m}, 2 \mathrm{H}), 1.7-1.0(\mathrm{~m}, 33 \mathrm{H})$, and 0.9-0.7 (m, 9H). ${ }^{13} \mathrm{C} \mathrm{NMR}\left(100 \mathrm{MHz}, \mathrm{DMSO}-d_{6}\right) \delta$ : $136.5,126.6,125.5,123.5,122.2,48.7,35.7,31.2$, 28.3-29.0, 29.3, 27.0, 25.4, 22.0, and 13.9.

1-Octyl-3-methylimidazolium dodecylbenzenesulfonate ([C $C_{8}$ mim] [DBS]). [ $\left.\mathrm{C}_{8} \mathrm{mim}\right][\mathrm{DBS}]$ was prepared with a procedure similar to the procedure for $\left[\mathrm{C}_{10} \mathrm{mim}\right][\mathrm{DBS}]$; however, now, $\left[\mathrm{C}_{8} \mathrm{mim}\right] \mathrm{Cl}$ was used as the starting material and a viscous liquid product was obtained. ${ }^{1} \mathrm{H}$ 
NMR (400 MHz, DMSO-d $\left.d_{6}\right) \delta: 9.1(\mathrm{~s}, 1 \mathrm{H}), 7.8(\mathrm{~s}, 1 \mathrm{H}), 7.7(\mathrm{~s}, 1 \mathrm{H}), 7.5(\mathrm{~d}, 2 \mathrm{H}), 7.2-7.1(\mathrm{~m}$, 2H), 4.1-4.2 (t, 2H), $3.85(\mathrm{~s}, 3 \mathrm{H}), 1.75(\mathrm{~m}, 2 \mathrm{H}), 1.7-1.0(\mathrm{~m}, 29 \mathrm{H})$, and $0.9-0.75(\mathrm{~m}, 9 \mathrm{H}) .{ }^{13} \mathrm{C}$ NMR (100 MHz, DMSO- $\left.d_{6}\right) \delta$ : 145.8-146.1, 136.5, 126.6, 125.5, 123.5, 122.2, 48.7, 35.7, $31.2,30.7,28.3-29.0,29.3,27.0,25.4,22.0$, and 13.9.

1-Hexyl-3-methylimidazolium dodecylbenzenesulfonate ([C ${ }_{6}$ mim $\left.][D B S]\right) .\left[\mathrm{C}_{6} \mathrm{mim}\right][\mathrm{DBS}]$ was prepared with a procedure similar to the procedure for $\left[\mathrm{C}_{10} \mathrm{mim}\right][\mathrm{DBS}]$; however, now, $\left[\mathrm{C}_{6} \mathrm{mim}\right] \mathrm{Cl}$ was used as the starting material, and a viscous liquid product was obtained. ${ }^{1} \mathrm{H}$ NMR (400 MHz, DMSO- $\left.d_{6}\right) \delta: 9.1(\mathrm{~s}, 1 \mathrm{H}), 7.8(\mathrm{~s}, 1 \mathrm{H}), 7.7(\mathrm{~s}, 1 \mathrm{H}), 7.5(\mathrm{~d}, 2 \mathrm{H}), 7.2-7.1(\mathrm{~m}$, 2H), 4.1-4.2 (t, 2H), $3.85(\mathrm{~s}, 3 \mathrm{H}), 1.75(\mathrm{~m}, 2 \mathrm{H}), 1.7-0.85(\mathrm{~m}, 25 \mathrm{H})$, and $0.85-0.7(\mathrm{~m}, 9 \mathrm{H}) .{ }^{13} \mathrm{C}$ NMR (100 MHz, DMSO- $\left.d_{6}\right) \delta$ : 145.8-146.1, 136.5, 126.6, 125.5, 123.5, 122.2, 48.7, 35.7, $31.2,30.7,28.3-29.0,29.3,27.0,25.4,22.0$, and 13.9.

Trimethyloctylammonium dodecylbenzenesulfonate $\left(N_{1118}[D B S]\right)$. Following a similar procedure as for $\left[\mathrm{C}_{10} \mathrm{mim}\right][\mathrm{DBS}]$, here, $\mathrm{N}_{1118} \mathrm{Br}$ was used as the starting material and a viscous liquid product was obtained. ${ }^{1} \mathrm{H}$ NMR (400 MHz, DMSO- $\left.d_{6}\right) \delta: 7.5(\mathrm{~d}, 2 \mathrm{H}), 7.1(\mathrm{~m}$, $2 \mathrm{H}), 3.25(\mathrm{~m}, 2 \mathrm{H}), 3.05(\mathrm{~s}, 9 \mathrm{H}), 1.7-0.9(\mathrm{~m}, 31 \mathrm{H})$, and 0.9-0.75 $(\mathrm{m}, 9 \mathrm{H}) .{ }^{13} \mathrm{C} \mathrm{NMR}(100 \mathrm{MHz}$, DMSO- $\left.d_{6}\right) \delta: 145.8-146.1,126.6,125.5,65.0,52.0,35.3,31.2,28.3-29.2,27.0,25.7,22.0$, and 13.9 .

Trihexyltetradecylphosphonium dodecylbenzenesulfonate $\left(P_{666.14}[D B S]\right)$. Following a similar procedure as for $\left[\mathrm{C}_{10} \mathrm{mim}\right][\mathrm{DBS}]$, here $\mathrm{P}_{666.14} \mathrm{Cl}$ was used as the starting material and a viscous liquid product was obtained. ${ }^{1} \mathrm{H}$ NMR (400 MHz, DMSO- $\left.d_{6}\right) \delta: 7.5(\mathrm{~d}, 2 \mathrm{H}), 7.1(\mathrm{~m}$, $2 \mathrm{H}), 2.25-2.1(\mathrm{~m}, 8 \mathrm{H}), 1.7-0.9(\mathrm{~m}, 67 \mathrm{H})$, and $0.9-0.75(\mathrm{~m}, 18 \mathrm{H}) .{ }^{13} \mathrm{C} \mathrm{NMR}(100 \mathrm{MHz}$, DMSO- $\left.d_{6}\right) \delta: 145.8-146.1,126.6,125.5,28.0-31.3,27.0,22.0,20.5$ 17.0-17.7, and 13.9.

\subsubsection{Analysis}

High Pressure Liquid Chromatography (HPLC) was applied to analyze the presence of DBS $^{-}$and $\mathrm{N}(\mathrm{CN})_{2}{ }^{-}$in the aqueous and IL phases after demulsification with $\mathrm{P}_{666,14}\left[\mathrm{~N}(\mathrm{CN})_{2}\right]$, for which an Agilent 1200 system equipped with a ZORBAX Eclipse XDB-C18 column was operated at $40{ }^{\circ} \mathrm{C}$. A Variable Wavelength Detector [ultraviolet (UV), accuracy of $<0.2 \%$ )] was applied at $220 \mathrm{~nm}$. A mixture of $35 \%$ (volume) $20 \mathrm{mM} \mathrm{Na} \mathrm{HPO}_{4}$ aqueous solution and $65 \%$ (volume) acetonitrile was used as the mobile phase at a flow rate of $0.2 \mathrm{~mL} / \mathrm{min}$. Standard samples for calibration of $\mathrm{DBS}^{-}$and $\mathrm{N}(\mathrm{CN})_{2}{ }^{-}$were prepared from $\mathrm{P}_{666,14}\left[\mathrm{~N}(\mathrm{CN})_{2}\right]$ and SDBS.

Ion chromatography (IC) was applied to analyze on the presence of $\mathrm{Na}^{+}, \mathrm{Cl}^{-}$and $\mathrm{Br}^{-}$in the aqueous phase after demulsification. A Metrohm IC apparatus was equipped with a cation 
column (Metrosep C6-150-4.0), an anion column (Metrosep A supp 16-150-4.0) and a conductivity detector. The eluent for the cation column was an acidic solution with $1.7 \mathrm{mM}$ 2,6-Pyridinedicarboxylic acid and $1.7 \mathrm{mM}$ nitric acid, and the flow rate of $1.25 \mathrm{~mL} / \mathrm{min}$ was applied. The eluent for the anion column was a basic solution with $7.5 \mathrm{mM} \mathrm{Na}_{2} \mathrm{CO}_{3}$ and 0.75 $\mathrm{mM} \mathrm{KOH}$, and the flow rate was $1.0 \mathrm{~mL} / \mathrm{min}$. Standard samples of $\mathrm{Na}^{+}, \mathrm{Cl}^{-}$and $\mathrm{Br}^{-}$were prepared for calibration.

\subsubsection{Demulsification efficiency definition}

The demulsification efficiency is defined as the volume of the separated heptane layer divided by the initial volume of heptane that was dispersed.

$$
\text { demulsification efficiency }(\mathrm{vol} \%)=\frac{\mathrm{V}_{\mathrm{t}, \text { hept }}}{\mathrm{V}_{\mathrm{t} 0 \text {,hept }}} \times 100 \%
$$

where $\mathrm{V}_{\mathrm{t} 0 \text {,hept }}$ is the original heptane volume present in the emulsions at $\mathrm{t}=0$, and $\mathrm{V}_{\mathrm{t} \text {,hept }}$ is the separated heptane volume at $\mathrm{t}=\mathrm{t}$. All the tests were duplicated and the errors are presented in the corresponding figures.

\subsubsection{COSMO-RS Prediction of distribution coefficients of cations and anions in octanol and water $\left(\log _{10}\left(\mathbf{P}_{\mathrm{o} / \mathrm{w}}\right)\right)$}

COSMO-RS is a software tool that can be used to predict thermodynamic equilibria of fluid systems using a statistical thermodynamics approach [18-20]. In this project, the turbomole program package (version 7.0) was used for the quantum chemical calculations to obtain the charge density functions of the compounds and the $\log _{10}\left(\mathrm{P}_{\mathrm{o} / \mathrm{w}}\right)$ of the cations and anions was predicted with COSMOthermX.

\subsection{Results and discussion}

\subsubsection{Emulsion characterization}

Emulsion stability is related to its properties, including emulsion type, drop size distribution, and phase volume ratio. Before studying on demulsification, the prepared emulsions were characterized to obtain the basic information. The microscopy image in Figure 5.1 shows that most of the area is occupied by droplets, indicating that the phase with the larger volume is the dispersed phase. According to the preparation method, where water and heptane were added in the volume ratio of $1: 6$, it is thus concluded that oil-in-water 
emulsions were produced. This is confirmed by the pink color in the continuous phase caused by potassium permanganate that was dissolved in the water. Since SDBS is water-soluble, this is in agreement with the Bancroft rule, which states that the phase in which the emulsifying agent is the most soluble will tend to be the continuous phase [21].

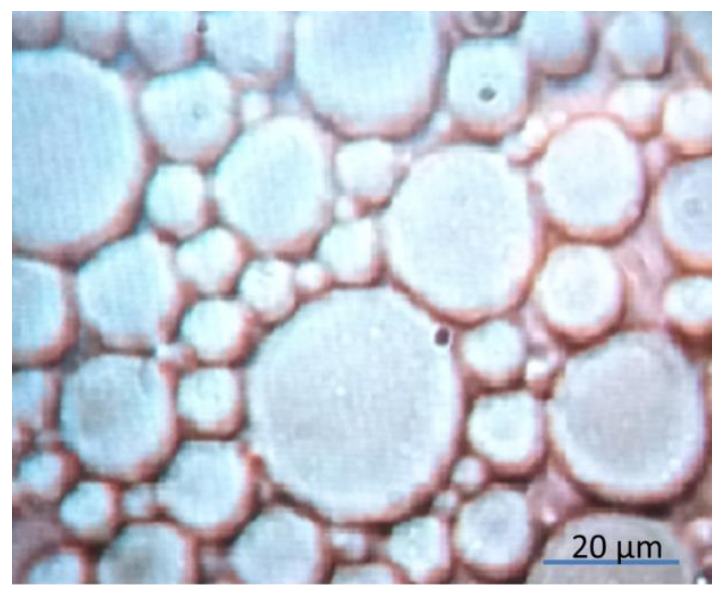

Figure 5.1. Microscopy image of the prepared emulsion.

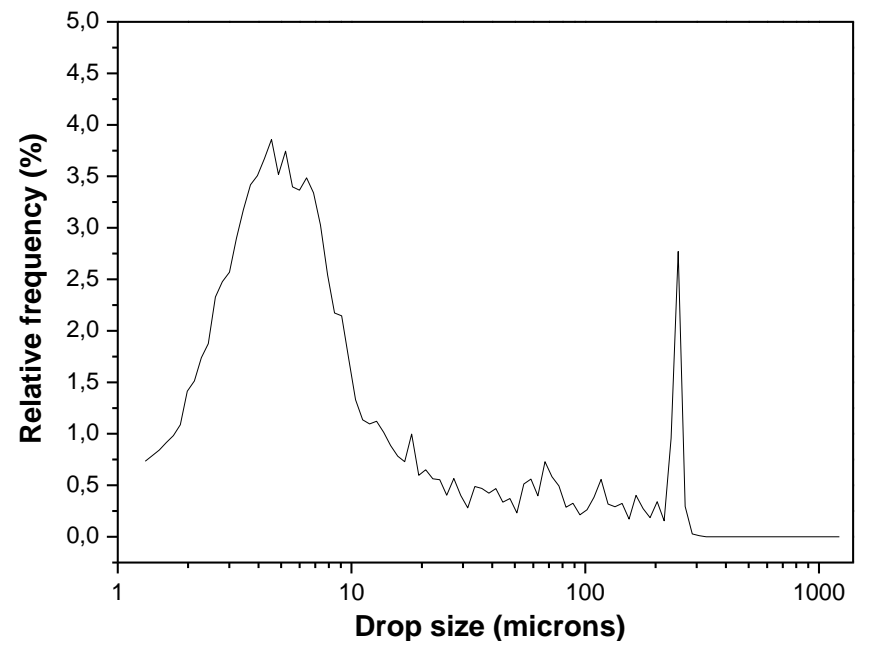

Figure 5.2. Drop size distribution of the prepared heptane-in-water emulsion. 
The drop size distribution of the emulsion was measured in a stirred vessel stirred at 800 rpm using FBRM. Figure 5.2 shows that the diameters of the droplets were mostly smaller than $100 \mu \mathrm{m}$, and the most frequently detected drops were concentrated in the range of 1-15 $\mu \mathrm{m}$, which is in agreement with the observation in Figure 5.1. This drop size range is also comparable with the other demulsification literatures $[13,14]$. The peak around $250 \mu \mathrm{m}$ is suspected to be caused by air bubbles. Excluding the influence of air bubbles by taking into account only droplets up to $210 \mu \mathrm{m}$, the Sauter mean diameter of $130 \mu \mathrm{m}$ was obtained according to equation (5.2) [17]:

$$
\overline{d_{v S}}=\frac{\sum_{i=1}^{N} n_{i} d_{i}^{3}}{\sum_{i=1}^{N} n_{i} d_{i}^{2}}
$$

\subsubsection{Demulsification efficiency of ILs in bottle tests}

To compare the demulsification efficiencies of various ILs with ion properties ranging from hydrophilic to hydrophobic, bottle tests were carried out as described in section 5.2.4 at an IL/SDBS mole ratio of $1: 1$. As a measure for the hydrophilicity, the $\log _{10}\left(\mathrm{P}_{\mathrm{o} / \mathrm{w}}\right)$ was taken and predicted with COSMO-RS. From the predicted values of $\log _{10}\left(\mathrm{P}_{\mathrm{o} / \mathrm{w}}\right)$ (in Table 5.2), it follows that all selected cations are hydrophobic, whereas the anions are hydrophilic. The halogenide anion shows a $\mathrm{P}_{\mathrm{o} / \mathrm{w}}$ that is a factor 100 smaller than the most hydrophilic nonhalogenide anion. Therefore, the following discussion on demulsification is split in a discussion on non-halogenide ILs and halogenide ILs.

\subsubsection{Demulsification with non-halogenide ILs}

For all of the investigated non-halogenide ILs, the results of the bottle tests after mixing IL with emulsions for $1 \mathrm{~min}$ and settling down for $24 \mathrm{~h}$ are shown in Figure 5.3. It is clearly shown that, after $24 \mathrm{~h}$, sample $\mathrm{A}$, where $\mathrm{P}_{666,14}\left[\mathrm{~N}(\mathrm{CN})_{2}\right]$ was used, was completely demulsified, but the other three samples, where $\mathrm{P}_{666,14}[\mathrm{Phos}], \mathrm{P}_{666,14}\left[\mathrm{NTf}_{2}\right]$, and $\mathrm{N}_{2224}$ $\left[\mathrm{N}(\mathrm{CN})_{2}\right]$ were applied, were still stable emulsions. It is concluded that, in the cases of $\mathrm{P}_{666,14}[\mathrm{Phos}]$ and $\mathrm{P}_{666,14}\left[\mathrm{NTf}_{2}\right]$, the combination of the cation and anion is too hydrophobic to show any interfacial effect; i.e., the $\log _{10}\left(\mathrm{P}_{\mathrm{o} / \mathrm{w}}\right)$ of the anion is too small $(-0.8$ and -3.1 , respectively; see Table 5.2) to counteract the large value of the cations (16.7). In other cases, with much larger negative values for $\log _{10}\left(\mathrm{P}_{\mathrm{o} / \mathrm{w}}\right)$ of the anion, e.g., $\mathrm{P}_{666,14}\left[\mathrm{~N}(\mathrm{CN})_{2}\right]$, surface activity was observed as a result of the combination of the hydrophobic cation and the hydrophilic anion $[\mathrm{N}(\mathrm{CN}) 2]$, which allows IL to interfere with the surfactant on the interface and, hence, to destabilize the emulsions. Despite the same anion in $\mathrm{N}_{2224}\left[\mathrm{~N}(\mathrm{CN})_{2}\right]$ as in $\mathrm{P}_{666,14}\left[\mathrm{~N}(\mathrm{CN})_{2}\right]$, no effect on demulsification was observed in sample D in Figure 5.3, because 
the overall effect of a very hydrophilic anion with a relatively small cation makes $\mathrm{N}_{2224}\left[\mathrm{~N}(\mathrm{CN})_{2}\right]$ too hydrophilic to be surface-active but completely water-soluble.

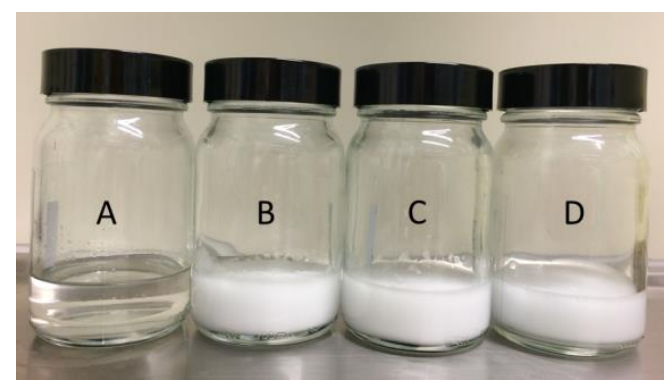

Figure 5.3. Bottle test results after $24 \mathrm{~h}$ for non-halogenide ILs. (A) $\mathrm{P}_{666,14}\left[\mathrm{~N}(\mathrm{CN})_{2}\right]$, (B) $\mathrm{P}_{666,14}[\mathrm{Phos}],(\mathrm{C}) \mathrm{P}_{666,14}\left[\mathrm{NTf}_{2}\right]$, and (D) $\mathrm{N}_{2224}\left[\mathrm{~N}(\mathrm{CN})_{2}\right]$.

Table 5.2. Predicted $\log _{10}\left(\mathrm{P}_{\mathrm{o} / \mathrm{w}}\right)$ of cations and anions of ILs with COSMO-RS

\begin{tabular}{llll}
\hline Cations & $\log _{10}\left(\mathrm{P}_{\mathrm{o} / \mathrm{w}}\right)$ & Anions or solvents & $\log _{10}\left(\mathrm{P}_{\mathrm{o} / \mathrm{w}}\right)$ \\
\hline $\mathrm{N}_{222,4}$ & 4.7 & Phos & -0.8 \\
$\mathrm{~N}_{111,8}$ & 5.3 & $\mathrm{NTf}_{2}$ & -3.1 \\
{$\left[\mathrm{C}_{6}\right.$ mim $]$} & 5.0 & $\mathrm{~N}(\mathrm{CN})_{2}$ & -8.3 \\
{$\left[\mathrm{C}_{8}\right.$ mim $]$} & 6.0 & $\mathrm{Cl}$ & -10.1 \\
{$\left[\mathrm{C}_{10} \mathrm{mim}\right]$} & 7.1 & $\mathrm{Br}$ & -10.7 \\
$\mathrm{P}_{4444}$ & 8.5 & $\mathrm{Octanol}$ & 3.2 \\
$\mathrm{P}_{444,14}$ & 13.6 & $\mathrm{H} \mathrm{H}_{2} \mathrm{O}$ & -1.3 \\
$\mathrm{P}_{8888}$ & 14.2 & & \\
$\mathrm{P}_{666,14}$ & 16.7 & & \\
\hline
\end{tabular}

\subsubsection{Demulsification with halogenide ILs}

For all nine halogenide ILs, the demulsification efficiencies were above $90 \%$ within 20 min, which was much faster than in the case of $\mathrm{P}_{666,14}\left[\mathrm{~N}(\mathrm{CN})_{2}\right]$. Figure 5.4 shows the demulsification efficiency patterns in time using the ILs $\mathrm{P}_{666,14} \mathrm{Cl}, \mathrm{P}_{666,14} \mathrm{Br}$, and 
$\mathrm{P}_{666,14}\left[\mathrm{~N}(\mathrm{CN})_{2}\right]$. It is clearly shown that the demulsification with $\mathrm{P}_{666,14}\left[\mathrm{~N}(\mathrm{CN})_{2}\right]$ proceeds slower than the other two ILs, both containing a halogen anion. Because all investigated ILs with halogen anions were demulsifying so fast and the $\mathrm{P}_{\mathrm{o} / \mathrm{w}}$ of the halogenide anions is about 100 times smaller than that of $\left[\mathrm{N}(\mathrm{CN})_{2}\right]$, it was concluded that the hydration of the halogen anions likely plays an important role in the demulsification. Although not shown on the time scale in Figure 5.4, also $\mathrm{P}_{666,14}\left[\mathrm{~N}(\mathrm{CN})_{2}\right]$ eventually separated the emulsion fully into heptane and aqueous phases.

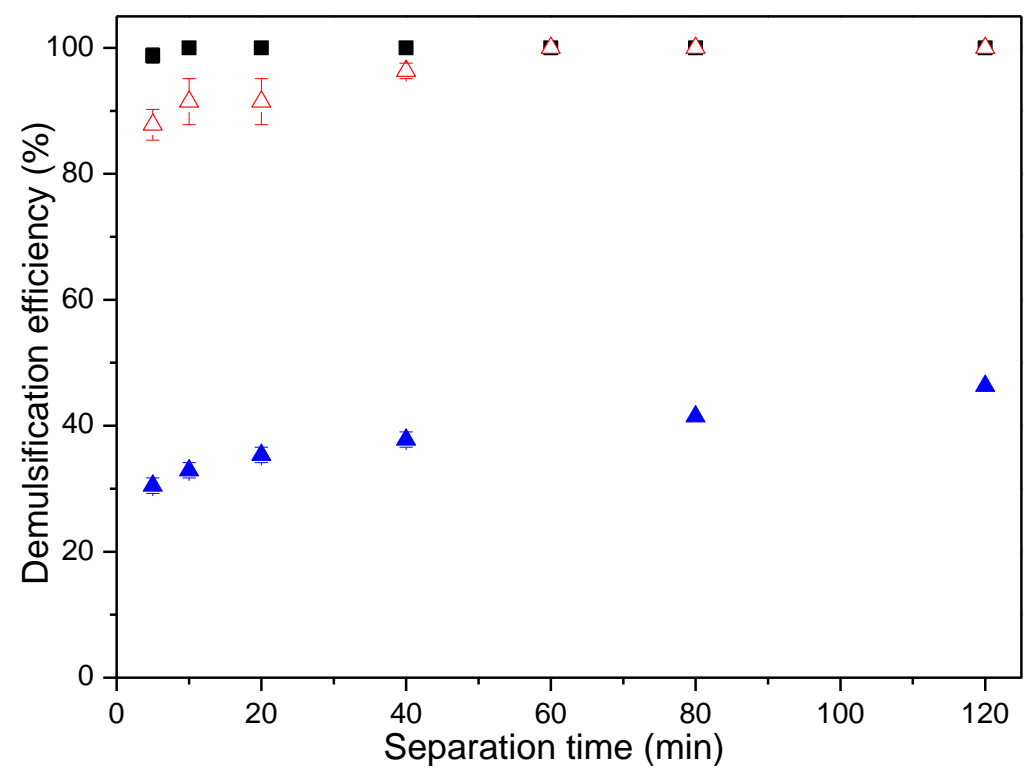

Figure 5.4. Demulsification efficiency of $\mathrm{P}_{666,14} \mathrm{Cl}, \mathrm{P}_{666,14} \mathrm{Br}$, and $\mathrm{P}_{666,14}\left[\mathrm{~N}(\mathrm{CN})_{2}\right]$ during the first $2 \mathrm{~h}$ at an IL/SDBS mole ratio of $1: 1$.

\subsubsection{Demulsification efficiency of ILs in tube tests}

Because of the very fast rate of demulsification with the halogenide ILs, it is difficult to investigate the effect of the cation alkyl chain length on the rate of demulsification with the bottle test; hence, the demulsifications were performed again, now, by tube tests. Because there was no stirring, the separating rate was slower and the separated heptane volume in time could be monitored more accurately, also as a result of the tube geometry. Tube tests were performed for ILs with different cations while keeping the halogen anions $\mathrm{Cl}^{-}$or $\mathrm{Br}^{-}$, and the constant molar ratio of IL/SDBS 0.8:1 was employed. All of the added ILs were 
diluted by isopropanol to $20 \mathrm{wt} \%$ to decrease viscosity of ILs for better controlling the amount of added ILs. The blank experiment was performed by adding the corresponding amount of isopropanol to emulsions, and the results showed that the treated emulsions were still stable after $24 \mathrm{~h}$. Therefore, it is concluded that the effect of isopropanol on demulsification was negligible.

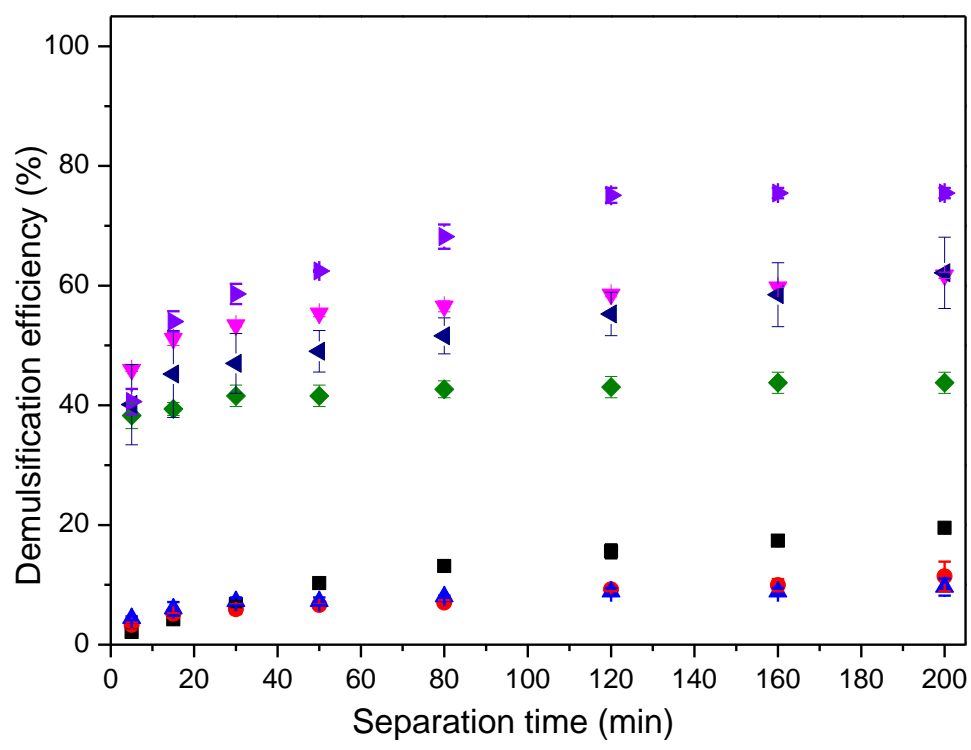

Figure 5.5. Tube test demulsification efficiency using ILs with halogen anions at the

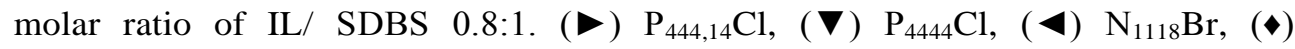
$\left[\mathrm{C}_{10} \mathrm{MIM}\right] \mathrm{Cl}$, (匹) $\mathrm{P}_{666,14} \mathrm{Cl},(\bullet) \mathrm{P}_{666,14} \mathrm{Br}$, and ( $\Delta$ ) $\mathrm{P}_{8888} \mathrm{Br}$.

The demulsification efficiency of different ILs are displayed in Figure 5.5. Among all studied ILs, $\mathrm{P}_{444,14} \mathrm{Cl}$ exhibited the highest separating rate, followed by $\mathrm{P}_{4444} \mathrm{Cl}$. The shorter cation of $\mathrm{P}_{4444} \mathrm{Cl}$ should exhibit a higher diffusivity as a result of its smaller size, but apparently, it also loses some of its surface activity, counteracting the faster diffusivity. A synergistic effect of molecular weight and surface-active property on diffusivity makes the separating rate in the following rank: $\mathrm{P}_{444,14} \mathrm{Cl}>\mathrm{P}_{4444} \mathrm{Cl}>\mathrm{P}_{666,14} \mathrm{Cl}>\mathrm{P}_{666,14} \mathrm{Br} \approx \mathrm{P}_{8888} \mathrm{Br}$. The similar separating rate of $\mathrm{P}_{8888} \mathrm{Br}$ and $\mathrm{P}_{666,14} \mathrm{Br}$ within the investigated time indicates that the total number of alkyl carbon in cation plays an important role in demulsification, while the number of alkyl carbon in each individual chain connected with phosphorus does not matter so much. In other words, the symmetry of the cation was found not to affect the rate of 
demulsification significantly. Furthermore, with the same cation, $\mathrm{P}_{666,14} \mathrm{Cl}$ demulsifies slightly faster than $\mathrm{P}_{666,14} \mathrm{Br}$ as a result of the smaller size of $\mathrm{Cl}^{-}$and the slightly lower Gibbs energy of hydration of $\mathrm{Cl}^{-}(-340 \mathrm{~kJ} / \mathrm{mol})$ than that of $\mathrm{Br}^{-}(-315 \mathrm{~kJ} / \mathrm{mol})$, once more confirming that the rate of the processes in these tube tests is governed by the diffusion of the ILs through the emulsion towards the interface between the droplets and the bulk phase.

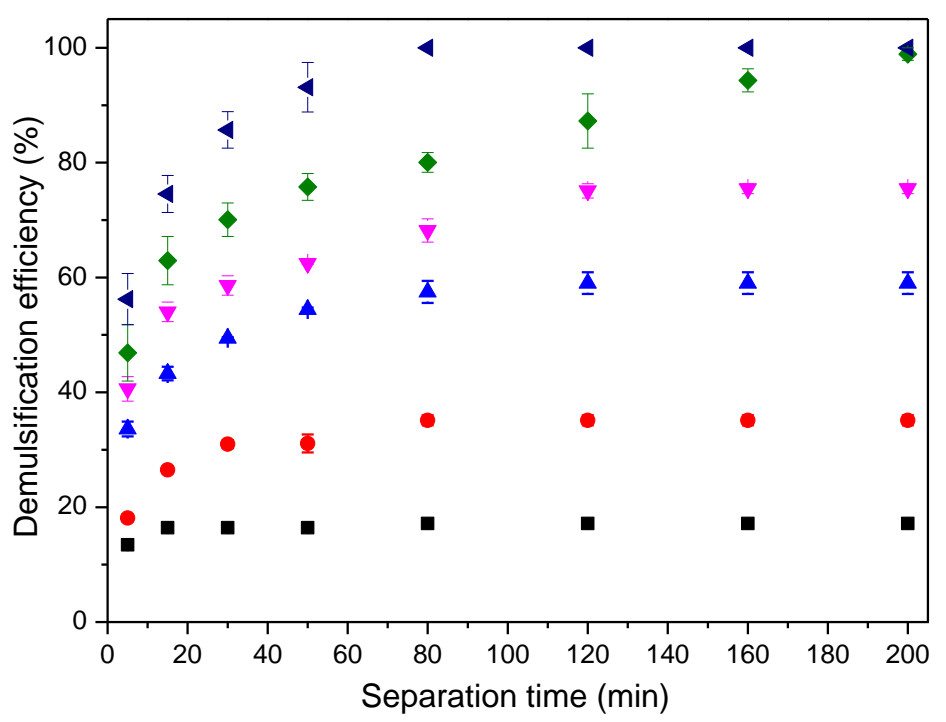

Figure 5.6. Demulsification efficiency of $\mathrm{P}_{444,14} \mathrm{Cl}$ with different mole ratio of IL/SDBS: $(\boldsymbol{\bullet}) 0.2,(\bullet) 0.4,(\boldsymbol{\Delta}) 0.6,(\boldsymbol{\nabla}) 0.8,(\bullet) 1.0$, and $(\bullet) 1.4$.

To further elucidate on the interaction of SDBS with ILs, demulsification tube tests were carried out with varying mole ratio of the $\mathrm{IL} \mathrm{P}_{444,14} \mathrm{Cl} / \mathrm{SDBS}$. It can be seen in Figure 5.6 that, after approximately 50-80 minutes, in all experiments, a plateau level of demulsification is reached. The eventual demulsification efficiency directly correlates the amount of added IL, and all samples with IL/SDBS of 1.0 or higher completely demulsified. This allows for the definition of the final demulsification efficiency correlation for halogenide ILs as in equation (5.3).

$$
\text { Demulsification efficiency } \cong\left\{\begin{array}{c}
\frac{\mathrm{n}_{\mathrm{IL}}}{\mathrm{n}_{\mathrm{SDBS}}} \text { for } \mathrm{n}_{\mathrm{IL}}<\mathrm{n}_{\mathrm{SDBS}} \\
1 \text { for } \mathrm{n}_{\mathrm{IL}} \geq \mathrm{n}_{\mathrm{SDBS}}
\end{array}\right\}
$$


where $n_{\mathrm{IL}}$ is the number of moles of added ILs and $n_{\mathrm{SDBS}}$ is the number of moles of SDBS in original emulsions.

\subsubsection{Demulsification mechanisms}

It was observed that, although very fast phase separation was always taking place with halogenide ILs, some haziness was observed for some of these ILs, both in the heptane and the aqueous phase. Even in a bottle test after settling for $24 \mathrm{~h}$, the phases were not always clear (see Figure 5.7). As clearly visible in picture $\mathrm{F}$ in Figure 5.7, which is the top view of the same bottle displayed in picture $\mathrm{C}$, the haziness is due to a solid precipitating from the samples instead of incomplete demulsification, which was also validated by the water content in the heptane phase. The water content determined by Karl Fisher titration was 1.73, 1.21, $0.93,0.28$, and $0 \%$, for $\left[\mathrm{C}_{6} \mathrm{mim}\right] \mathrm{Cl},\left[\mathrm{C}_{8} \mathrm{mim}\right] \mathrm{Cl},\left[\mathrm{C}_{10} \mathrm{mim}\right] \mathrm{Cl}, \mathrm{P}_{666,14} \mathrm{Cl}$, and $\mathrm{P}_{666,14}\left[\mathrm{~N}(\mathrm{CN})_{2}\right]$, respectively, indicating successful demulsification.

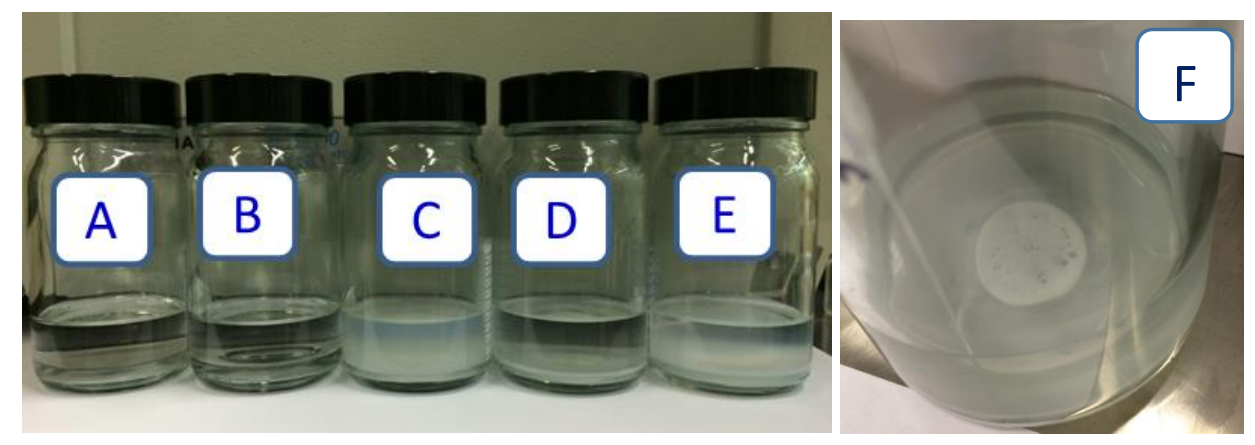

Figure 5.7. Demulsification bottle test results after settling for $24 \mathrm{~h}$ : (A) $\mathrm{P}_{666,14}\left[\mathrm{~N}(\mathrm{CN})_{2}\right],(\mathrm{B}) \mathrm{P}_{666,14} \mathrm{Cl}$, (C) $\left[\mathrm{C}_{10} \mathrm{mim}\right] \mathrm{Cl}$, (D) $\left[\mathrm{C}_{8} \mathrm{mim}\right] \mathrm{Cl}$, and (E) $\left[\mathrm{C}_{6} \mathrm{mim}\right] \mathrm{Cl}$. (F) Top view of bottle $\mathrm{C}$.

The flocculated compounds observed in Figure 5.7 were collected and characterized by ${ }^{1} \mathrm{H}$ NMR. A comparison of the ${ }^{1} \mathrm{H}$ NMR data to the ${ }^{1} \mathrm{H}$ NMR data of the DBS-based ILs that were synthesized for this purpose (section 5.2.5) showed that the spectra were identical, leading to the conclusion that ion exchange between the IL and the surfactant occurred, and the flocculates consist of the cation of the added ILs and the anion of the surfactant. Additional conformation of the ion exchange was obtained from analysis of the aqueous phase after demulsification. IC results showed that all $\mathrm{Na}^{+}$stayed in the aqueous phase, and around $87 \% \mathrm{Cl}^{-}$or $\mathrm{Br}^{-}$were also observed in aqueous phase. 
A closer look on the demulsified sample A in Figure 5.7 that was treated with $\mathrm{P}_{666,14}\left[\mathrm{~N}(\mathrm{CN})_{2}\right]$ allowed for the observation of three phases, and because of the respective densities, the heptane phase was on top and aqueous phase was on bottom, leaving IL drops as the middle phase. To understand the mechanism of demulsification, the amounts of DBS and $\mathrm{N}(\mathrm{CN})_{2}{ }^{-}$in the aqueous phase after demulsification were analyzed by HPLC. No DBS was detected, while $87 \% \mathrm{~N}(\mathrm{CN})_{2}{ }^{-}$was observed in the aqueous phase. In addition, IC results showed that all $\mathrm{Na}^{+}$stayed in the aqueous phase. It was thus concluded that the mechanism of demulsification using $\mathrm{P}_{666,14}\left[\mathrm{~N}(\mathrm{CN})_{2}\right]$ was also anion exchange.

The ion exchange reaction between ILs with hydrophilic anions and surfactant SDBS that occurred during demulsification is shown in Scheme 5.2. The large driving force leading to the fast demulsification with halogenide ILs can be explained by the Gibbs energy of hydration of $\mathrm{Cl}^{-}$and $\mathrm{Br}^{-}$, because the sodium salts of these anions are highly soluble in water (the Gibbs energy of ion hydration is $-315 \mathrm{~kJ} / \mathrm{mol}$ for bromide, $-340 \mathrm{~kJ} / \mathrm{mol}$ for chloride and $-365 \mathrm{~kJ} / \mathrm{mol}$ for sodium at $298.15 \mathrm{~K}$ [22]). In addition, the combination of the DBS and cations of the ILs does form a third phase, which is an additional driving force for the demulsification to reach completeness fast. Apparently, the cation-DBS combinations are too hydrophobic to dissolve in the aqueous phase, and the ionic character too strong to dissolve in the heptane phase.

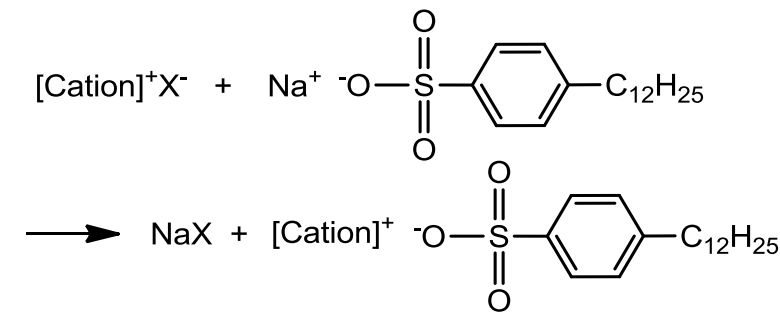

[Cation $]=\left[\mathrm{C}_{6}\right.$ mim $],\left[\mathrm{C}_{8}\right.$ mim $],\left[\mathrm{C}_{10} \mathrm{mim}\right], \mathrm{N}_{1118}$ or $\mathrm{P}_{666,14}$ $\mathrm{X}=\mathrm{Cl}, \mathrm{Br}$ or $\mathrm{N}(\mathrm{CN})_{2}$

Scheme 5.2. Reaction of anion exchange between ILs with hydrophilic anions and SDBS

A sketch of the demulsification mechanism for ILs with hydrophilic anions is presented in Figure 5.8. In Figure 5.8a, the oil droplets in the emulsion are stabilized by SDBS, which resides at the interface between the oil droplet and water, with the hydrophilic sulfonate headgroup facing water and hydrophobic chains dodecylbenzene group contacting with oil. 
This behavior have also been confirmed by the molecular simulations [23, 24]. The sodium ions are released in water and form an electrical double layer together with the sulfonate headgroup, which hinder droplet contact and droplet growth. After effective IL demulsifiers are added in the emulsions, the interface is deformed as a result of the ion exchange of the IL and surfactant, which reduces the electrostatic repulsion among drops and, hence, destabilizes the emulsions, as shown in Figure 5.8b. Eventually, the oil and aqueous phases are separated completely (Figure 5.8c), and the new formed flocculate materials precipitate to form the third phase (Figure 5.8d).

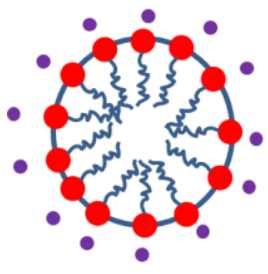

(a)

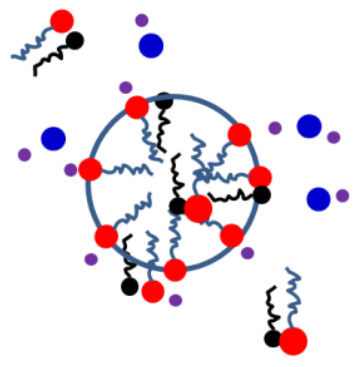

(b)

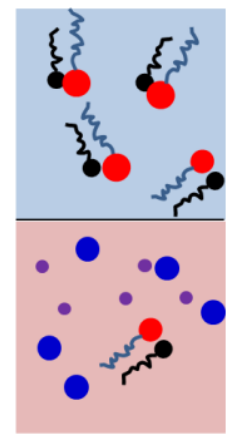

(c)

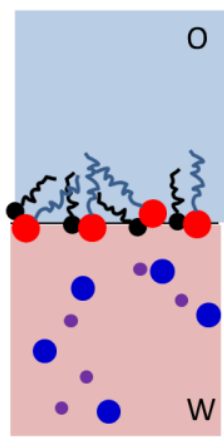

(d)

Figure 5.8. Demulsification mechanism of emulsions using ILs with hydrophilic anions. (a) The interfacial film structure of oil-in-water droplet was stabilized by SDBS, with the sulfonate headgroup in red and sodium cations in purple, with water molecules outside the drop, which are not shown. (b) New ILs were formed after adding [cation] $\mathrm{X}\left(\mathrm{X}=\mathrm{Cl}^{-}, \mathrm{Br}^{-}\right.$, or $\left.\mathrm{N}(\mathrm{CN})_{2}^{-}\right)$, where the cation is shown in black and anions are shown in blue. (c) Two liquid phases were formed after demulsifying, with the top layer being heptane and the bottom layer the aqueous phase, and the newly formed ILs were spread as flocculates in both phases as the third phase; (d) New ILs precipitate and form the third phase (position depended upon the density of these three phases, displayed here in between the water and oil phases).

From this subsections, it follows that several ILs could be highly efficient demulsifiers for oil-in- $\mathrm{H}_{2} \mathrm{O}$ emulsions, but unfortunately, the mechanism is not extraction but ion exchange. To make any of these IL-based demulsification processes economically attractive, proper regeneration methods should be developed. As a result of the ion exchange nature of the process, the anions are lost to the aqueous phase and the cations are combined with DBS. To 
regenerate these ILs and surfactant, reversed ion exchange processes are needed that probably limit the commercial applicability of ILs as demulsifiers. Therefore, further development of this type of demulsification is strongly dependent upon future regeneration studies using ion exchange techniques.

\subsection{Conclusions}

Halogenide ILs with hydrophobic cations as well as $\mathrm{P}_{666,14}\left[\mathrm{~N}(\mathrm{CN})_{2}\right]$ were found to be able to effectively demulsify oil-in-water emulsions, and complete demulsification was observed when equimolar amounts of IL to surfactant were applied. Bottle tests showed that halogenide ILs demulsify faster than $\mathrm{P}_{666,14}\left[\mathrm{~N}(\mathrm{CN})_{2}\right]$. Instead of the desired extraction mechanism, the mechanism was found to be anion exchange between surfactant SDBS and hydrophilic IL anions driven by the release of sodium salt to the aqueous phase, a process with a large Gibbs energy of hydration. To regenerate these ILs, reversed ion exchange processes are needed, probably limiting the commercial applicability of ILs as demulsifiers.

\section{Acknowledgements}

Prof. H.J. Heeres (University of Groningen, The Netherlands) is acknowledged for allowing us to do measurements with the FBRM-probe in his lab, and Erwin Wilbers is acknowledged for assisting with these measurements.

\section{References}

[1] A. Bera, A. Mandal, B.B. Guha, Synergistic Effect of Surfactant and Salt Mixture on Interfacial Tension Reduction between Crude Oil and Water in Enhanced Oil Recovery, Journal of Chemical and Engineering Data, 59 (2014) 89-96.

[2] J.R. Hou, Z.C. Liu, S.F. Zhang, X. Yue, J.Z. Yang, The role of viscoelasticity of alkali/surfactant/polymer solutions in enhanced oil recovery, J. Pet. Sci. Eng., 47 (2005) 219235.

[3] G.J. Hirasaki, C.A. Miller, O.G. Raney, M.K. Poindexter, D.T. Nguyen, J. Hera, Separation of Produced Emulsions from Surfactant Enhanced Oil Recovery Processes, Energy and Fuels, 25 (2011) 555-561.

[4] K.K. Salam, A.O. Alade, A.O. Arinkoola, A. Opawale, Improving the Demulsification Process of Heavy Crude Oil Emulsion through Blending with Diluent, Journal of Petroleum Engineering, 2013 (2013) 1-6. 
[5] M.A. Krawczyk, D.T. Wasan, C.S. Shetty, Chemical demulsification of petroleum emulsions using oil-soluble demulsifiers, Ind. Eng. Chem. Res., 30 (1991) 367-375.

[6] M. Razi, M.R. Rahimpour, A. Jahanmiri, F. Azad, Effect of a Different Formulation of Demulsifiers on the Efficiency of Chemical Demulsification of Heavy Crude Oil, J. Chem. Eng. Data, 56 (2011) 2936-2945.

[7] M. Nikkhah, T. Tohidian, M.R. Rahimpour, A. Jahanmiri, Efficient demulsification of water-in-oil emulsion by a novel nano-titania modified chemical demulsifier, Chem. Eng. Res. Des., 94 (2015) 164-172.

[8] D. Nguyen, N. Sadeghi, C. Houston, Chemical Interactions and Demulsifier Characteristics for Enhanced Oil Recovery Applications, Energy Fuels, 26 (2012) 2742-2750. [9] C. Dalmazzone, C. Noïk, J.-F. Argillier, Impact of Chemical Enhanced Oil Recovery on the Separation of Diluted Heavy Oil Emulsions, Energy Fuels, 26 (2012) 3462-3469.

[10] K.M. Ko, B.H. Chon, S.B. Jang, H.Y. Jang, Surfactant flooding characteristics of dodecyl alkyl sulfate for enhanced oil recovery, Journal of Industrial and Engineering Chemistry, 20 (2014) 228-233.

[11] O. Arjmand, A. Roostaei, Experimental Investigation of Viscous Surfactant Based Enhanced Oil Recovery, Pet. Sci. Technol., 32 (2014) 1607-1616.

[12] D. Guzman-Lucero, P. Flores, T. Rojo, R. Martinez-Palou, Ionic Liquids as Demulsifiers of Water-in-Crude Oil Emulsions: Study of the Microwave Effect, Energy \& Fuels, 24 (2010) 3610-3615.

[13] R.C.B. Lemos, E.B. da Silva, A. dos Santos, R.C.L. Guimaraes, B.M.S. Ferreira, R.A. Guarnieri, C. Dariva, E. Franceschi, A.F. Santos, M. Fortuny, Demulsification of Water-inCrude Oil Emulsions Using Ionic Liquids and Microwave Irradiation, Energy \& Fuels, 24 (2010) 4439-4444.

[14] E.B. Silva, D. Santos, D.R.M. Alves, M.S. Barbosa, R.C.L. Guimaraes, B.M.S. Ferreira, R.A. Guarnieri, E. Franceschi, C. Dariva, A.F. Santos, M. Fortuny, Demulsification of Heavy Crude Oil Emulsions Using Ionic Liquids, Energy \& Fuels, 27 (2013) 6311-6315.

[15] C.A. Flores, E.A. Flores, E. Hernandez, L.V. Castro, A. Garcia, F. Alvarez, F.S. Vazquez, Anion and cation effects of ionic liquids and ammonium salts evaluated as dehydrating agents for super-heavy crude oil: Experimental and theoretical points of view, J. Mol. Liq., 196 (2014) 249-257.

[16] C.H.C. Janssen, A. Sanchez, G.-J. Witkamp, M.N. Kobrak, A Novel Mechanism for the Extraction of Metals from Water to Ionic Liquids, ChemPhysChem, 14 (2013) 3806-3813.

[17] B. Schuur, G.N. Kraai, J.G.M. Winkelman, H.J. Heeres, Hydrodynamic features of centrifugal contactor separators: Experimental studies on liquid hold-up, residence time distribution, phase behavior and drop size distributions, Chem. Eng. Process., 55 (2012) 819. 
[18] F. Eckert, A. Klamt, Fast solvent screening via quantum chemistry: COSMO-RS approach, AlChE J., 48 (2002) 369-385.

[19] A. Klamt, F. Eckert, COSMO-RS: a novel and efficient method for the a priori prediction of thermophysical data of liquids, Fluid Phase Equilib., 172 (2000) 43-72.

[20] X. Li, S.R.A. Kersten, B. Schuur, Extraction of Guaiacol from Model Pyrolytic Sugar Stream with Ionic Liquids, Ind. Eng. Chem. Res., 55 (2016) 4703-4710.

[21] W.D. BANCROFT, the theory of emulsification, J. Phys. Chem., 17 (1913) 501-519.

[22] Y. Marcus, Thermodynamics of Solvation of Ions .5. Gibbs Free-Energy of Hydration at 298.15-K, J. Chem. Soc., Faraday Trans., 87 (1991) 2995-2999.

[23] A.R. Zolghadr, M.H. Ghatee, A. Zolghadr, Adsorption and Orientation of Ionic Liquids and Ionic Surfactants at Heptane/Water Interface, J. Phys. Chem. C, 118 (2014) 19889-19903. [24] W.X. Shi, H.X. Guo, Structure, Interfacial Properties, and Dynamics of the Sodium Alkyl Sulfate Type Surfactant Monolayer at the Water/Trichloroethylene Interface: A Molecular Dynamics Simulation Study, J. Phys. Chem. B, 114 (2010) 6365-6376. 


\section{Chapter 6}

\section{Studies on the effects of microgel}

\section{particles on drop size distributions and \\ extraction kinetics of guaiacol with ionic liquid-in-water emulsions}

Microgel particles can be applied to stabilize ionic liquid-in-water emulsions, and in this chapter the effects of such temperature responsive core-shell microgel particles (core: polystyrene; shell: poly(N-isopropylacrylamide-co-methacrylic acid)) on the drop size distributions and guaiacol extraction kinetics in a stirred vessel were investigated. The drop size distributions were measured with an in situ endoscope technique to study the effect of operational parameters (power input, particle concentration and temperature). Four ILs $\left[\mathrm{P}_{666,14}\right]\left[\mathrm{FeCl}_{4}\right]$ (synthesized), $\left[\mathrm{P}_{666,14}\right]\left[\mathrm{NTf}_{2}\right],\left[\mathrm{P}_{666,14}\right]\left[\mathrm{N}(\mathrm{CN})_{2}\right]$ and $[\mathrm{Bmim}]\left[\mathrm{NTf}_{2}\right]$ were employed to form emulsions, and under equal preparing conditions $\left(22^{\circ} \mathrm{C}\right.$ with power input of $0.4 \mathrm{~W})$ [Bmim] $\left[\mathrm{NTf}_{2}\right]$ exhibited the smallest Sauter mean diameter $(184 \mu \mathrm{m})$. With the power input or the particle concentration increasing, the drop sizes decreased. Below the lower critical solution temperature (LCST, $35^{\circ} \mathrm{C}$ ) of microgels, the Sauter mean diameter of IL drops decreased with temperature increasing. While above LCST, due to stronger IL drop coalescence, the increased temperature caused larger drop sizes. In addition, the influences of microgel particles on the extraction capacity and kinetics were studied using $\left[\mathrm{P}_{666,14}\right]\left[\mathrm{NTf}_{2}\right]$ for extraction of guaiacol from aqueous solution. It showed that in the studied range of microgel concentration (0-1.5 g/L), microgels did not change the equilibrium extraction capacity, but the extraction rate was slower in the system with particles than without particles, due to the coverage of microgels on the droplet surface. 


\subsection{Introduction}

Ionic liquids (ILs) have attracted increasing attention in the past decades, mainly due to their distinct properties, such as negligible vapor pressure, high thermal and chemical stability and poor flammability [1-3]. By tuning the combination of cation and anion, the properties of ILs (e.g. hydrophilicity) can be designed for specific applications. Besides the applications in the areas of synthesis, catalysis and energy production [1-4], ILs have also been widely applied in separations of (bio)chemicals [5-10]. For both separation and catalysis, small drops and hence large specific interfacial area are desired [11, 12]. However, the high viscosity [13] and high corrosivity [14] of ILs limit their industrial applications.

IL-based emulsion systems that make use of stabilizers can potentially overcome these drawbacks of ILs. On the one hand, the viscosity of emulsions is typically a few times that of water for volume fractions of droplets below 0.40, and they offer a large interfacial area [15]. On the other hand, the stabilizer (e.g. surfactants, polymers or particles) of IL-in-water emulsions, residing at the interface of IL and water, could limit or even avoid the direct contact of ILs with metal equipment, which might limit the corrosion due to the use of ILs.

The IL-based micro-emulsions that have been reported, are usually stabilized by non-ionic surfactants [16-19]. Some of these emulsions show fast coarsening and hence, the non-ionic surfactants cannot effectively stabilize these IL-based emulsions [20]. Additionally, the surfactants are often not biocompatible and have undesirable effect such as denaturation of proteins [21].

Recently, IL emulsions stabilized by microgel particles (solvent-swollen, cross-linked polymers) have been reported [20], which can be broken on-demand and show multiple responses to temperature, $\mathrm{pH}$, ionic strength, and even to magnetic fields when magnetic ILs are employed. After the separation, the microgel particles can be collected and reused for emulsification. Thus these emulsions may have great potential for smart applications in green (bio)chemical processes.

In the studies of Monteillet et al [20], these emulsions were prepared by mechanical vortexing or handshaking, which are laboratory techniques that have low reproducibility of droplet size distributions. Therefore, when aiming at potential use in larger scale operations, measurements should be done under more accurately controlled conditions. In addition, the densely packed IL-water interfaces were shown permeable and it was possible to observe extraction using a dye as solute [20], but a quantitative study on the influences of microgels on the equilibrium extraction capacity and kinetics has not been reported. 
Therefore, in this work the following studies are combined: 1) a study on the drop size distributions of several IL-in-water emulsions stabilized by core-shell microgel particles (core: crosslinked polystyrene; shell: poly(N-isopropylacrylamide-co-methacrylic acid (PNIPAM-co-MA)) in a stirred vessel with an online endoscope technique [22, 23]; 2) a study on the influences of microgel particles on the equilibrium extraction efficiency and extraction rates using a guaiacol-water extraction system. The structure of the core-shell microgel particle is shown in Figure 6.1, and the names, abbreviations and structures of four studied ILs are presented in Table 6.1.
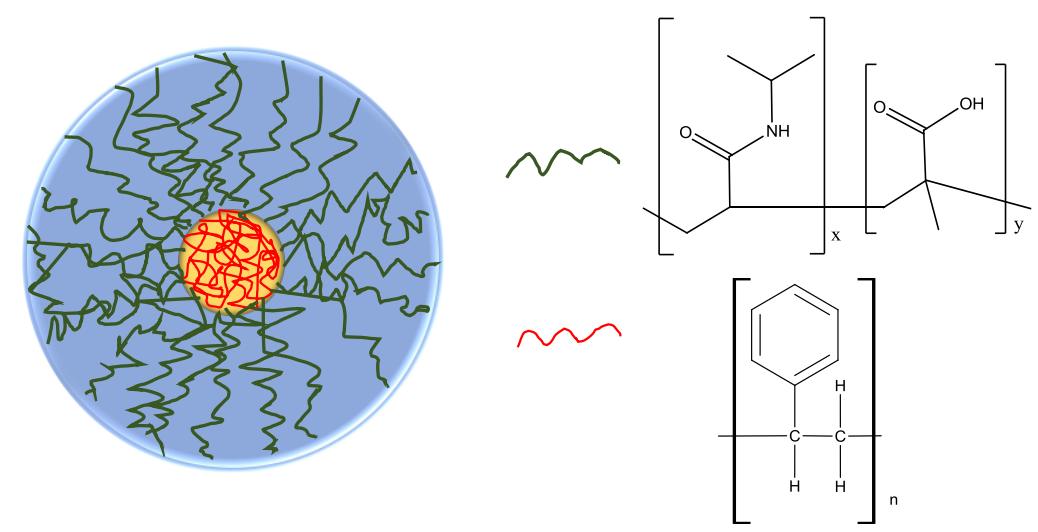

Figure 6.1. The structure of core-shell microgel particles (core: crosslinked polystyrene (red); shell: PNIPAM-co-MA (green)). The particle is drawn in swollen state.

\subsection{Experimental}

\subsubsection{Materials}

Guaiacol (99\%) was purchased from Sigma-Aldrich. ILs $\left[\mathrm{P}_{666,14}\right][\mathrm{Cl}],\left[\mathrm{P}_{666,14}\right]\left[\mathrm{N}(\mathrm{CN})_{2}\right]$, $\left[\mathrm{P}_{666,14}\right]\left[\mathrm{NTf}_{2}\right]$ and $[\mathrm{Bmim}]\left[\mathrm{NTf}_{2}\right]$ were supplied by Iolitec with a purity $>95 \mathrm{wt} \%$. All chemicals were used as received. The microgel particle solution was supplied by the Laboratory of Physical Chemistry and Colloid Science in Wageningen University, and the details of synthesis and characterization of microgels are presented in Appendix C. 
Table 6.1. The names, abbreviations and structures of four studied ILs.

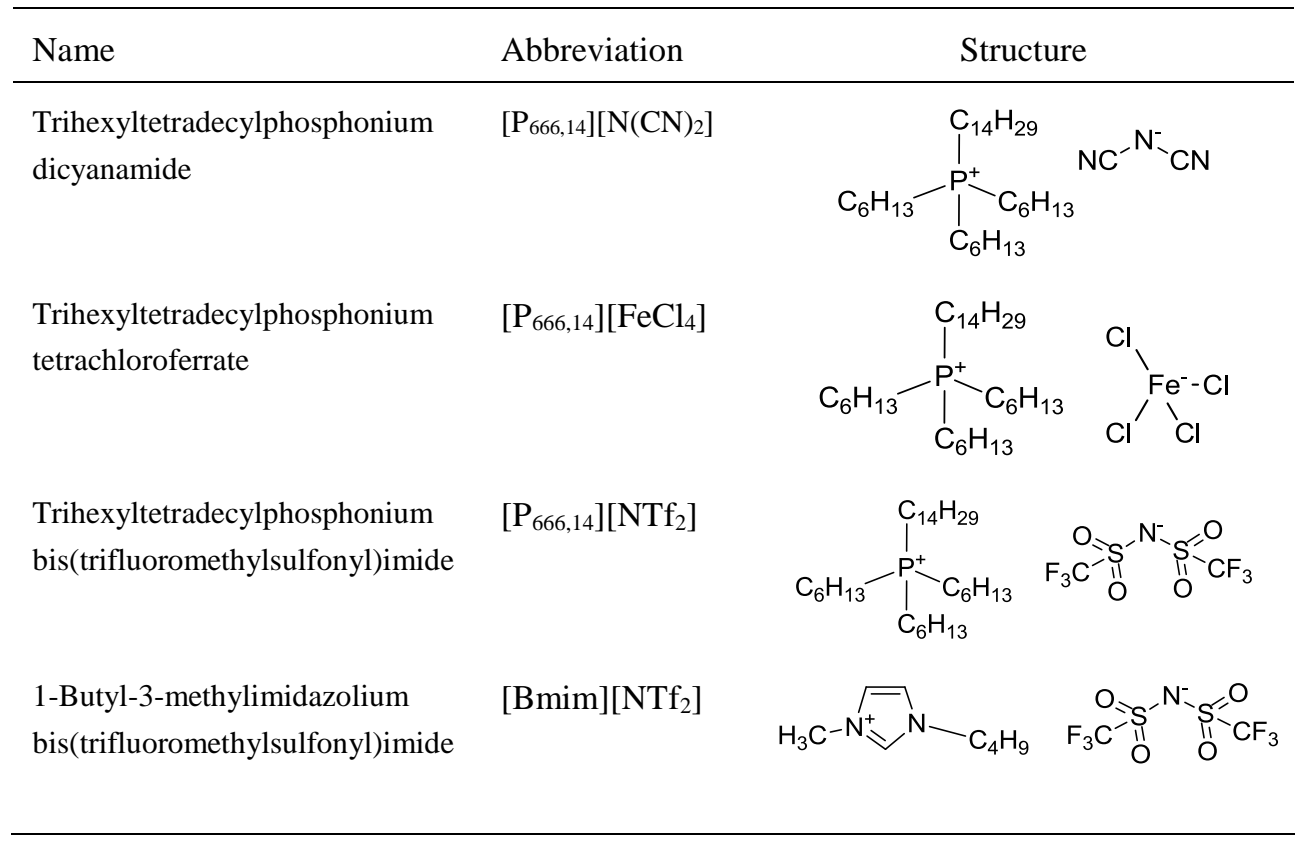

\subsubsection{Synthesis of $\left[P_{666,14}\right]\left[\mathrm{FeCl}_{4}\right]$}

The magnetic IL $\left[\mathrm{P}_{666,14}\right]\left[\mathrm{FeCl}_{4}\right]$ was prepared using the same method as in reference [20]. $\left[\mathrm{P}_{666,14}\right][\mathrm{Cl}](15.2048 \mathrm{~g})$ and iron(III) chloride $(4,7498 \mathrm{~g})$ were mixed in a $250 \mathrm{~mL}$ roundbottom flask under a $\mathrm{N}_{2}$ atmosphere at $50^{\circ} \mathrm{C}$ for $48 \mathrm{~h}$, yielding a dark brown liquid. The product could not be analyzed by NMR because of its paramagnetic property. Analysis was therefore limited to elemental analysis and moisture analyzer for the water content. The elemental analysis, calculated for $\mathrm{C}_{32} \mathrm{H}_{68} \mathrm{PFeCl}_{4}$, gave: $\mathrm{C} 56.39 \%, \mathrm{H} 9.99 \%$, experimentally found: C $56.84 \%, \mathrm{H} 10.22 \%$. The water content was $1.02 \%$.

\subsubsection{Drop size distribution measurement setup and methods}

The IL-in-water emulsions were prepared in a stirred vessel by mixing $3 \mathrm{~mL}$ IL with 27 $\mathrm{mL}$ of a $0.28 \mathrm{~g} / \mathrm{L}$ aqueous particle solution in a batch vessel. The effect of the operational parameters on drop size was studied by varing the power input $(0.4 \mathrm{~W}$ to $1.1 \mathrm{~W})$, particle contents $(0.07 \mathrm{~g} / \mathrm{L}$ to $0.84 \mathrm{~g} / \mathrm{L})$ and temperatures $\left(22,30,35\right.$ and $\left.40{ }^{\circ} \mathrm{C}\right)$. The aqueous particle solutions were prepared by diluting the $14.5 \mathrm{~g} / \mathrm{L}$ particle stock solution with milli-Q water to the desired concentration. The power input was controlled by adjusting the voltage of the stirring and was calculated from the voltage and current. The dimensions of the vessel and 
the stirrer, and the position of the SOPAT endoscope probe are given in Figure 6.2. In this figure, it can be seen that the vessel is jacketed and the jacket water inlet and outlet are indicated, allowing for temperature control. Furthermore, on the left, two $10 \mathrm{~mm}$ inlets/outlets are displayed, these can be used to operate the vessel as a continuous stirred tank. In the studies described here, however, the vessel was operated in batch.
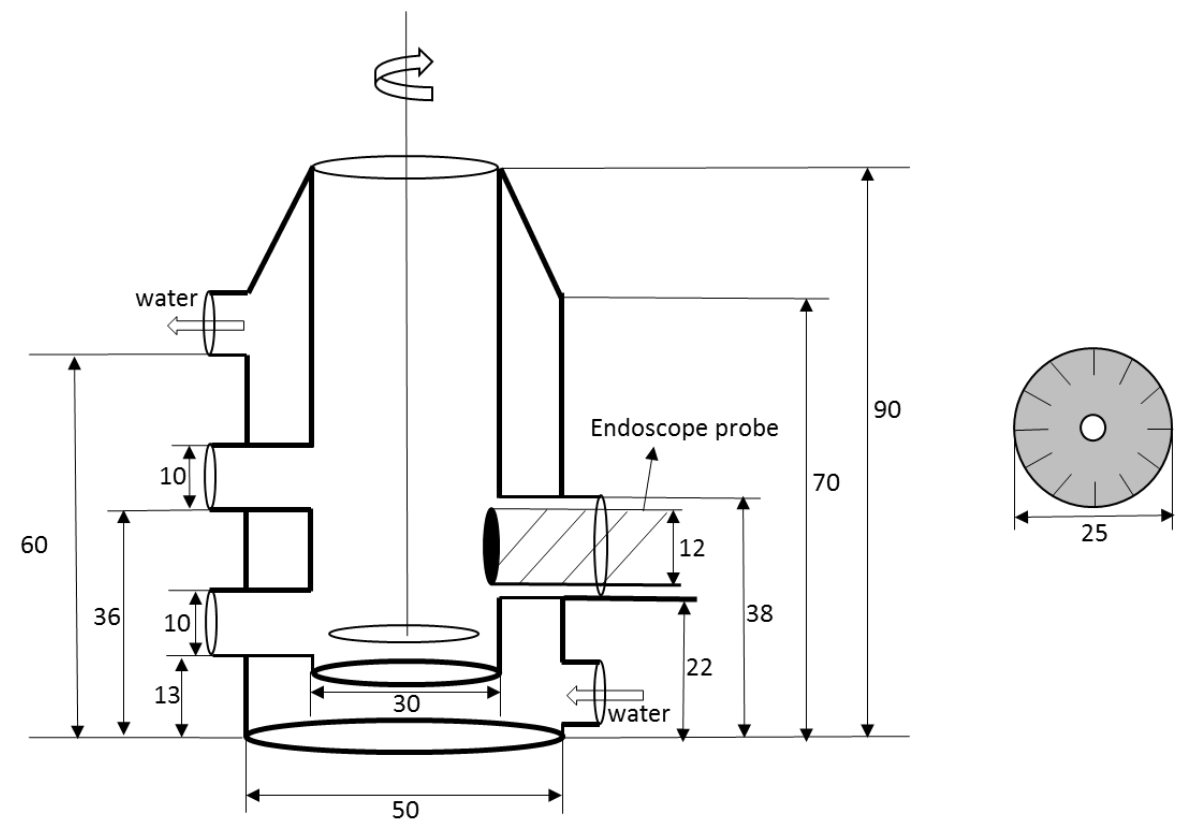

Figure 6.2. The dimensions of the vessel (left) and the stirrer (right). The unit of all numbers is $\mathrm{mm}$.

The IL drop sizes were measured with an in situ endoscope technique [22, 23]. A probe (SOPAT Gmbh, Berlin, Germany) with a 6-mm-thick endoscope in front of a CCD camera was put inside the vessel for image acquisition. Each experiment was stirred continuously for 5 min during which every $30 \mathrm{~s}$ a trigger of 100 pictures was recorded. The Sauter mean diameter $\left(\mathrm{D}_{32}\right)$ of the IL droplets defined in equation (6.1) was obtained from the image analysis:

$$
D_{32}=\frac{\sum_{i} N_{i} D_{i}^{3}}{\sum_{i} N_{i} D_{i}^{2}}
$$


where $D_{i}$ is the diameter of droplets in the class $i$ and $N_{i}$ is the number of droplets in that class.

\subsubsection{Extraction kinetics measurements}

The study on the extraction kinetics of guaiacol extraction was performed in the same stirred vessel shown in Figure 6.2, where $15 \mathrm{~mL}$ aqueous feed $(1.5 \%$ guaiacol in water or in $1 \mathrm{~g} / \mathrm{L}$ aqueous particle solutions) was mixed with $3 \mathrm{~mL}$ solvent $\left[\mathrm{P}_{666,14}\right]\left[\mathrm{NTf}_{2}\right]$ with power input of either $0.1 \mathrm{~W}$ or $0.4 \mathrm{~W}$. Samples $(1 \mathrm{~mL})$ were taken after stirring for $1,3,5,10$ and $15 \mathrm{~min}$, and the samples were centrifuged for $3 \mathrm{~min}$ at $14800 \mathrm{rpm}$ to achieve phase separation. The samples of the aqueous raffinate were then analyzed with high performance liquid chromatography (HPLC) to obtain the guaiacol content.

\subsubsection{Analysis}

The guaiacol concentration in the raffinate phases in the kinetic study was analyzed with HPLC (Agilent 1200), using a mobile phase of $5 \mathrm{mM}$ sulfuric acid at $0.6 \mathrm{~mL} / \mathrm{min}$, a Hi-Plex$\mathrm{H}$ column at $60{ }^{\circ} \mathrm{C}$ and a Variable Wavelength Detector at $285 \mathrm{~nm}$ (UV, with relative standard deviation from five measurements: $0.2 \%$ ).

\subsection{Results and discussions}

\subsubsection{Drop size distribution of IL-in-water emulsions}

Four different ILs were each mixed with $0.28 \mathrm{~g} / \mathrm{L}$ particle solutions with power input of $0.4 \mathrm{~W}$ to prepare their emulsions, including $\left[\mathrm{P}_{666,14}\right]\left[\mathrm{FeCl}_{4}\right],\left[\mathrm{P}_{666,14}\right]\left[\mathrm{N}(\mathrm{CN})_{2}\right],\left[\mathrm{P}_{666,14}\right]\left[\mathrm{NTf}_{2}\right]$ and $[\mathrm{Bmim}]\left[\mathrm{NTf}_{2}\right]$. The developing patterns of droplet size (Sauter mean diameter) as a function of time are shown in Figure 6.3. For $\left[\mathrm{P}_{666,14}\right]\left[\mathrm{NTf}_{2}\right]$ emulsions, in the first three minutes no reliable data was obtained, due to the viscous IL sticking on the lens, but it can be seen that the droplet sizes kept nearly constant in the last two minutes, thus the drop size distribution of this IL emulsion achieved steady state within five minutes. Clearly, the other three IL emulsions also reached steady droplet size distributions within five minutres stirring, actually all of them are stable within three minutes. At steady state the order of the Sauter mean drop sizes for IL emulsions is $\mathrm{Bmim}\left[\mathrm{NTf}_{2}\right]<\left[\mathrm{P}_{666,14}\right]\left[\mathrm{FeCl}_{4}\right]<\left[\mathrm{P}_{666,14}\right]\left[\mathrm{N}(\mathrm{CN})_{2}\right]<$ $\left[\mathrm{P}_{666,14}\right]\left[\mathrm{NTf}_{2}\right]$.

However, the Sauter mean diameter of the IL drops in this work was an order of magnitude larger than the droplets shown in the reported literature [20], where the same ILs and 
microgels were used. This remarkable difference may be due to the differences in the experimental techniques that were applied, i.e. a completely different mixing method and different microgel particle concentrations. The literature reporting pictures showing drop sizes of around $10-20$ micron employed a ten times higher microgel particle concentration than in this work, and the mixing method was mechanical vortexing, which could provide a substantially higher power input.

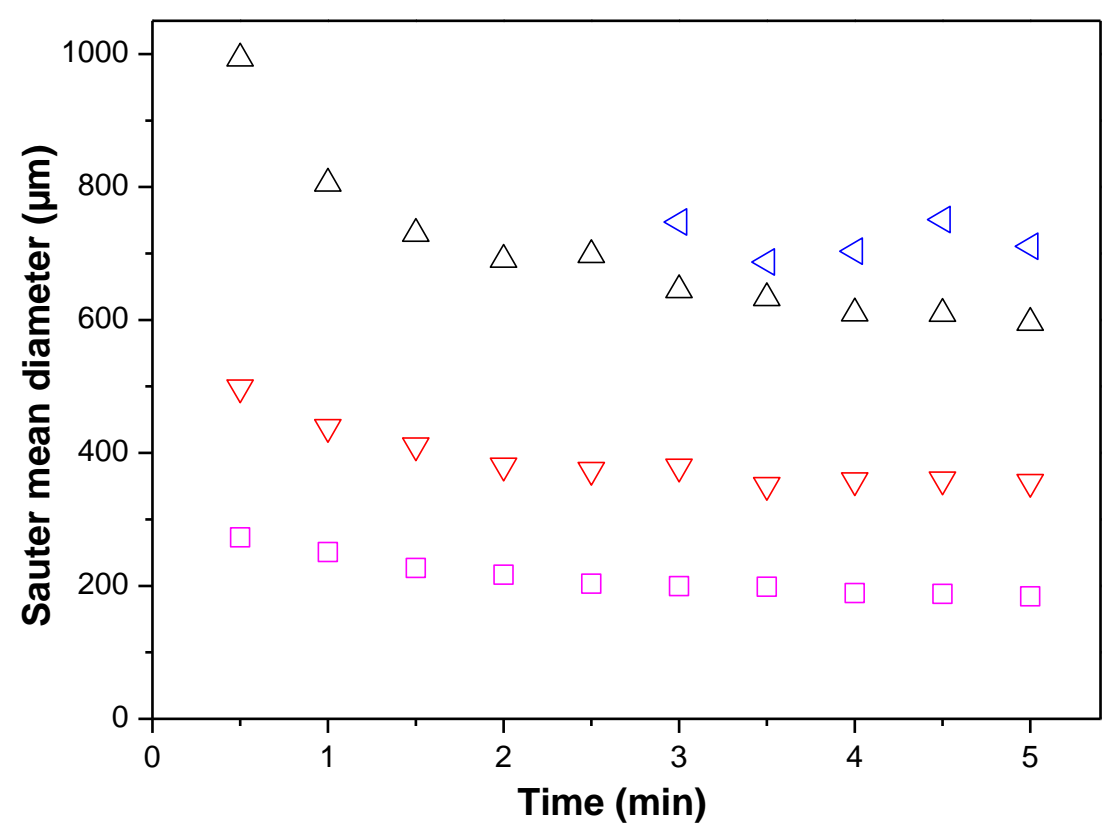

Figure 6.3. Sauter mean drop size developing patterns as a function of time for four ILs emulsions in $0.28 \mathrm{~g} / \mathrm{L}$ particle solution at $22{ }^{\circ} \mathrm{C}$ with a power input of $0.4 \mathrm{~W}$. $\square$ : $\operatorname{Bmim}\left[\mathrm{NTf}_{2}\right] ; \Delta:\left[\mathrm{P}_{666,14}\right]\left[\mathrm{N}(\mathrm{CN})_{2}\right] ; \triangleleft:\left[\mathrm{P}_{666,14}\right]\left[\mathrm{NTf}_{2}\right] ; \nabla:\left[\mathrm{P}_{666,14}\right]\left[\mathrm{FeCl}_{4}\right]$.

The cumulative volume distributions for all emulsions after 5 min stirring (in Figure 6.4) show that $[\mathrm{Bmim}]\left[\mathrm{NTf}_{2}\right]$ not only had smaller droplets on average but also exhibited the narrowest distribution and $80 \%$ drops were in the range of 124-288 $\mu \mathrm{m}$. Although $\left[\mathrm{P}_{666,14}\right]\left[\mathrm{N}(\mathrm{CN})_{2}\right]$ showed a smaller Sauter mean diameter than $\left[\mathrm{P}_{666,14}\right]\left[\mathrm{NTf}_{2}\right]$, the former IL emulsion had wider distribution. The drops spread from 200 to $1500 \mu \mathrm{m}$ and around $4 \%$ drops were even bigger than the largest drops observed with $\left[\mathrm{P}_{666,14}\right]\left[\mathrm{NTf}_{2}\right]$, which may due to its highest viscosity. 


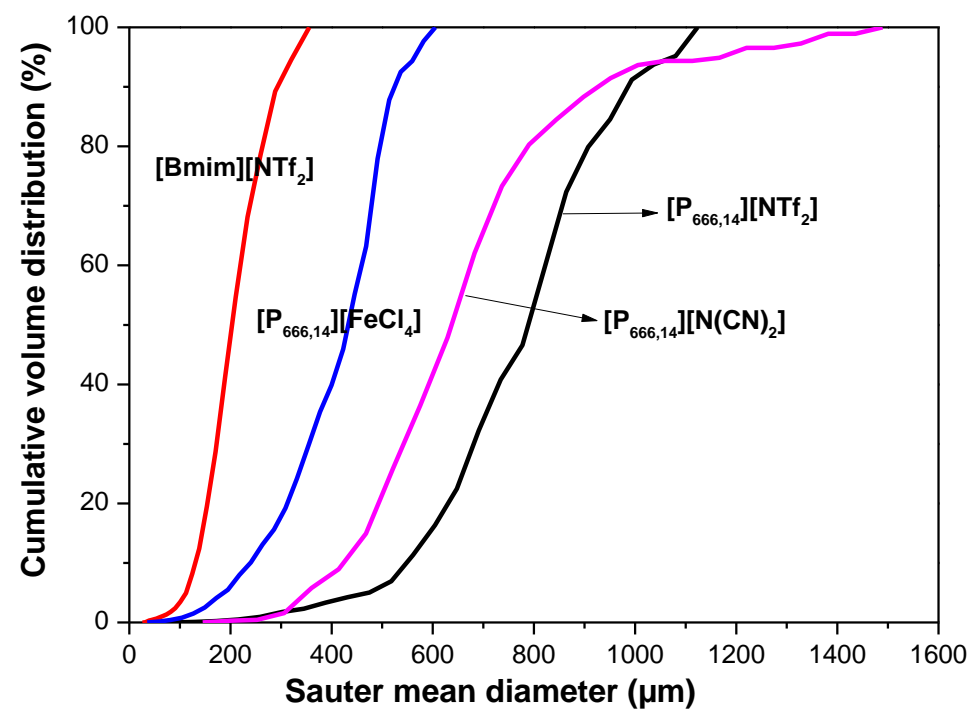

Figure 6.4. Cumulative volume distributions for all emulsions after 5 min stirring in $0.28 \mathrm{~g} / \mathrm{L}$ particle solution at $22{ }^{\circ} \mathrm{C}$ with a power input of $0.4 \mathrm{~W}$.

\subsubsection{Effect of operational parameters on drop sizes of IL-in-water emulsions}

In this section, the preparation conditions were varied to study the effect of power input, particle concentration and temperature on the drop size distributions of $\left[\mathrm{P}_{666,14}\right]\left[\mathrm{NTf}_{2}\right]$ emulsions.

\subsubsection{Influence of power input on IL drop sizes}

By varying the voltage of the stirring engine, the power input was controlled from $0.4 \mathrm{~W}$ to $1.1 \mathrm{~W}$ for $\left[\mathrm{P}_{666,14}\right]\left[\mathrm{NTf}_{2}\right]$-based emulsion preparation with $0.28 \mathrm{~g} / \mathrm{L}$ particle solution at $22{ }^{\circ} \mathrm{C}$. The mixtures were stirred at $0.4 \mathrm{~W}$ for $8 \mathrm{~min}$, because of the unreliable data in the first $3 \mathrm{~min}$. The power input was then increased to $0.6,0.8$ and $1.1 \mathrm{~W}$, and each condition was kept for $5 \mathrm{~min}$. The droplet size developing patterns as a function of time while varing the power input are shown in Figure 6.5, which shows that the droplet sizes clearly decreased with the power input increasing. Because the formation of emulsions is a nonspontaneous process, energy input is required to form small droplets, and the higher the engery input, the smaller drops. It also can be seen from Figure 6.5 that at higher energy input, the emulsions did not reach to the steady state within 5 minutes, as the drop sizes are still decreasing. 


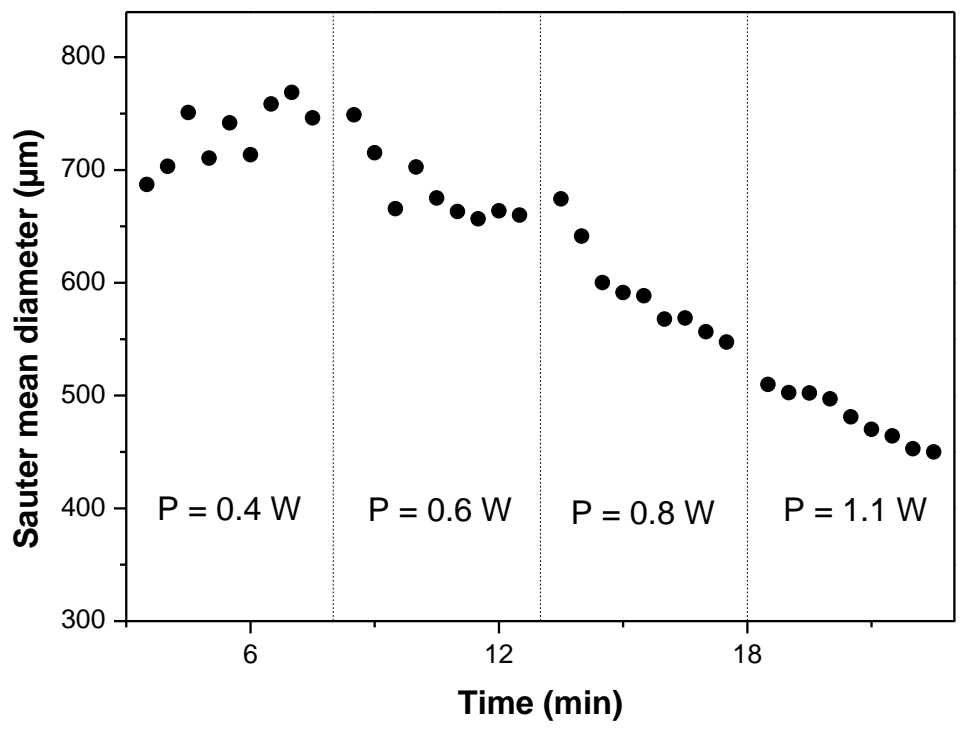

Figure 6.5. The Sauter mean droplet size developing patterns as a function of time while varying the power input for $\left[\mathrm{P}_{666,14}\right]\left[\mathrm{NTf}_{2}\right]$ emulsions at $22{ }^{\circ} \mathrm{C}$ in $0.28 \mathrm{~g} / \mathrm{L}$ particle solution.

\subsubsection{Influence of particle concentrations on IL drop sizes}

The influence of the particle concentration on the drop sizes was studied by varing the particle concentrations from $0.07 \mathrm{~g} / \mathrm{L}$ to $0.84 \mathrm{~g} / \mathrm{L}$. All the experiments were performed at the same conditions (stirring at either $0.4 \mathrm{~W}$ or $0.6 \mathrm{~W}$ and room temperature for $5 \mathrm{~min}$ ). It is shown in Figure 6.6 that the Sauter mean diameters of the droplets decreased as the particle concentration increased, as a result of the deceasing interfacial tension. As only 3 data points were available at $0.6 \mathrm{~W}$, the fitting might be unconvincing, thus the data at $0.4 \mathrm{~W}$ was chosen for linear fitting and the equation is shown below.

$$
D_{32}=-282 * x+776
$$

where $x$ is the particle concentration $(\mathrm{g} / \mathrm{L})$ in water. Under the assumption that indeed, the trend will continue as linear, the Sauter mean diameter of IL drops at other particle concentractions can be roughly estimated. At a particle concentration of $2.7 \mathrm{~g} / \mathrm{L}$, the concentration that was employed in literature, the predicted $\mathrm{D}_{32}(13 \mu \mathrm{m})$ is very close to the measured drop sizes by Monteillet et al. (around $10 \mu \mathrm{m}$ ) [20], which indicates that the much 
larger drop sizes measured in this study are not contradictory to the work by Monteillet et al [20].

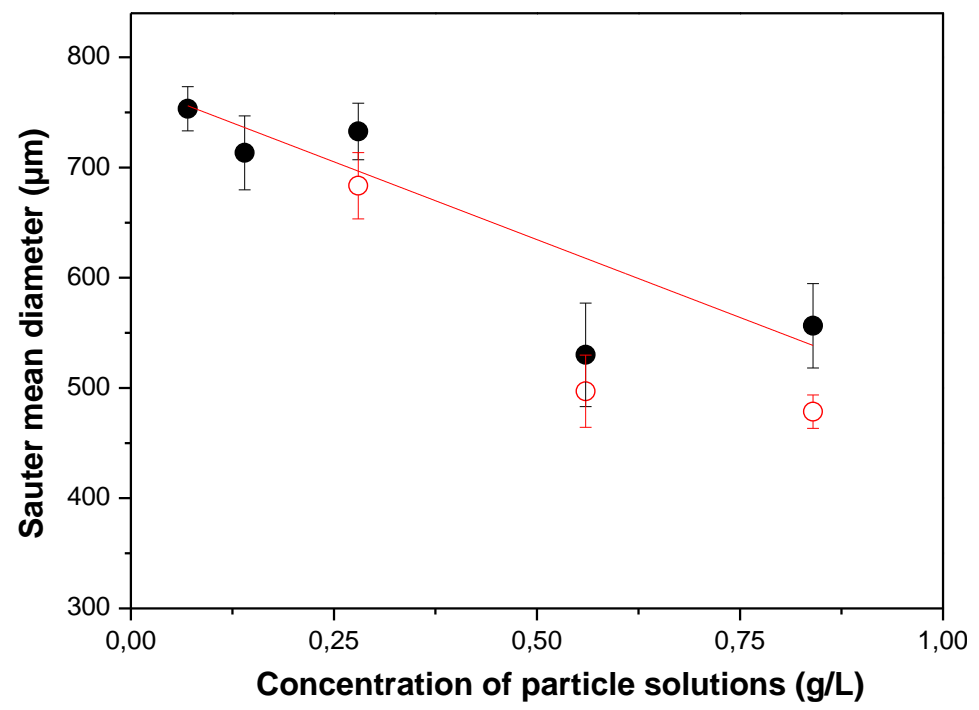

Figure 6.6. Influence of particle concentration on droplet sizes of $\left[\mathrm{P}_{666,14}\right]\left[\mathrm{NTf}_{2}\right]$ emulsions $(\bullet: 0.4 \mathrm{~W}$; $\circ: 0.6 \mathrm{~W})$ and the linear fit using Equation 6.4 for data with power input of $0.4 \mathrm{~W}$ at $22{ }^{\circ} \mathrm{C}$ in $0.28 \mathrm{~g} / \mathrm{L}$ particle solutions.

To study the effect of power input on the drop sizes at each of the particle concentrations, the emulsions with $0.28,0.56$ and $0.84 \mathrm{~g} / \mathrm{L}$ particle solutions were stirred continuously for 5 min while changing the power input from 0.4 to $0.6 \mathrm{~W}$, and the Sauter mean diameters showed a small decrease for all three emulsions, as shown by the hollow symbols in Figure 6.6. This observation that higher power input produced smaller drops is in line with the observed trend in section 6.3.2.1.

\subsubsection{Influence of temperature on IL drop sizes}

Because the synthesized core-shell microgels are temperature responsive, with a swollen state below lower critical solution temperature (LCST) and a collapsed state at temperatures above LCST, it was investigated whether changing the temperature significantly changes the Sauter mean drop size. IL Sauter mean drop sizes were measured at four different temperatures and the results are shown in Figure 6.7. Although the drop sizes at $22{ }^{\circ} \mathrm{C}$ and 
$30{ }^{\circ} \mathrm{C}$ had no big difference, the drop sizes clearly decreased at $35^{\circ} \mathrm{C}$, which might resulted from the decreasing viscosity, as it is known that the viscosity of ILs decreases with temperature increasing [24]. The particles were still in the swollen state at $35^{\circ} \mathrm{C}$, so that the particles kept staying on the interface of IL drops to prevent drop coalescence.

Whereas at $40{ }^{\circ} \mathrm{C}$ drop size data was not successfully obtained, due to severe sticking of IL on the endoscope lens. The so much more severe sticking of IL on the lens indicates that IL coalesced at $40{ }^{\circ} \mathrm{C}$, which was caused by the collapsed particles at this temperature. From Figure S6.1, a sharp decrease of hydrodynamic diameter of microgels was observed at $35^{\circ} \mathrm{C}$ which indicates that the particles collapsed quickly above this temperature. Correspondingly, the collapsed particles lost their surfactant properties, leading to IL drop coalescence. Figure S6.1 also showed that upon decreasing the temperature again to $20^{\circ} \mathrm{C}$, the particle diameter increased, implying that the particles were swollen again in the solvent and can then be used to stabilize IL drops. This suggests that indeed a small temperature trigger can affect emulsion stability on demand.

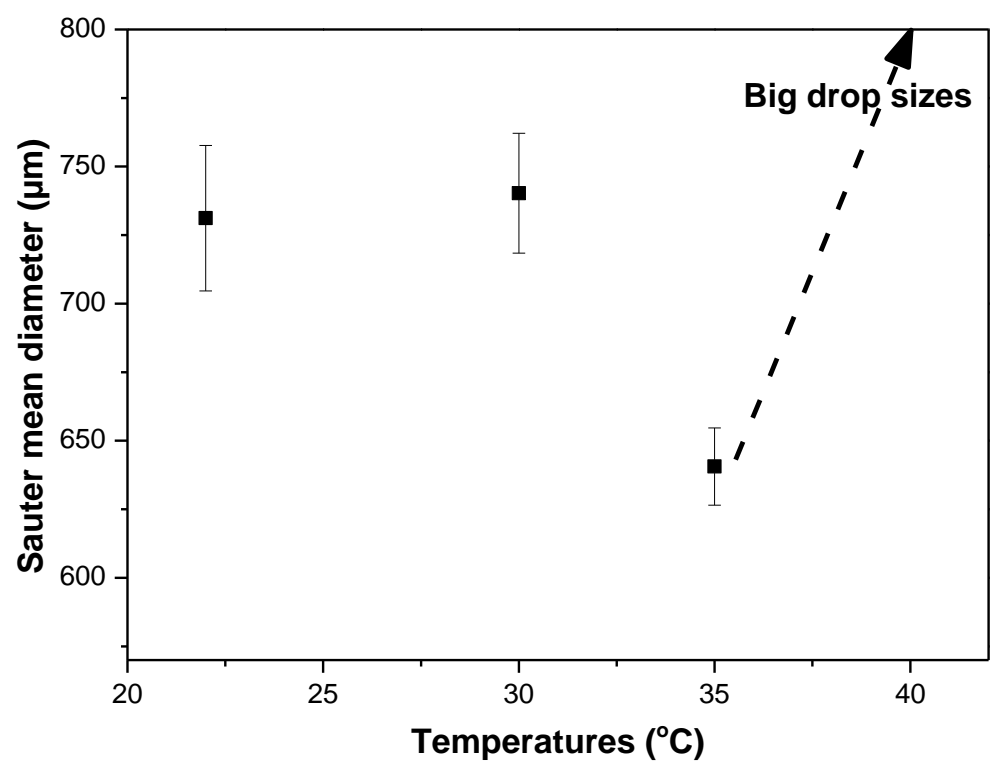

Figure 6.7. Influence of temperature on droplet sizes of $\left[\mathrm{P}_{666,14}\right]\left[\mathrm{NTf}_{2}\right]$ emulsions at $0.4 \mathrm{~W}$ in $0.28 \mathrm{~g} / \mathrm{L}$ particle solutions. 


\subsubsection{Influence of microgels on guaiacol extraction with $\left[\mathrm{P}_{666,14}\right]\left[\mathrm{NTf}_{2}\right]$}

A previous study showed that $\left[\mathrm{P}_{666,14}\right]\left[\mathrm{NTf}_{2}\right]$ has good affinity for guaiacol [6], hence guaiacol extraction with $\left[\mathrm{P}_{666,14}\right]\left[\mathrm{NTf}_{2}\right]$ was employed as model system to study the influence of the particle concentration on the equilibrium extraction capacity. Five different particle concentrations including $0,0.25,0.5,1.0$ and $1.5 \mathrm{~g} / \mathrm{L}$ in $1.5 \mathrm{wt} \%$ guaiacol aqueous solutions were chosen as feeds, which were extracted with $\left[\mathrm{P}_{666,14}\right]\left[\mathrm{NTf}_{2}\right]$ at a solvent to feed ratio of 1:5 (mass based). The equilibrium guaiacol concentrations in the raffinate phases were analyzed with HPLC. The same guaiacol concentration $(0.38 \mathrm{wt} \%)$ in all raffinates suggests that the particles on the interface had no effect on the equilibrium extraction capacity at all, so the extractability of ILs did not change in the stabilized emulsion system.

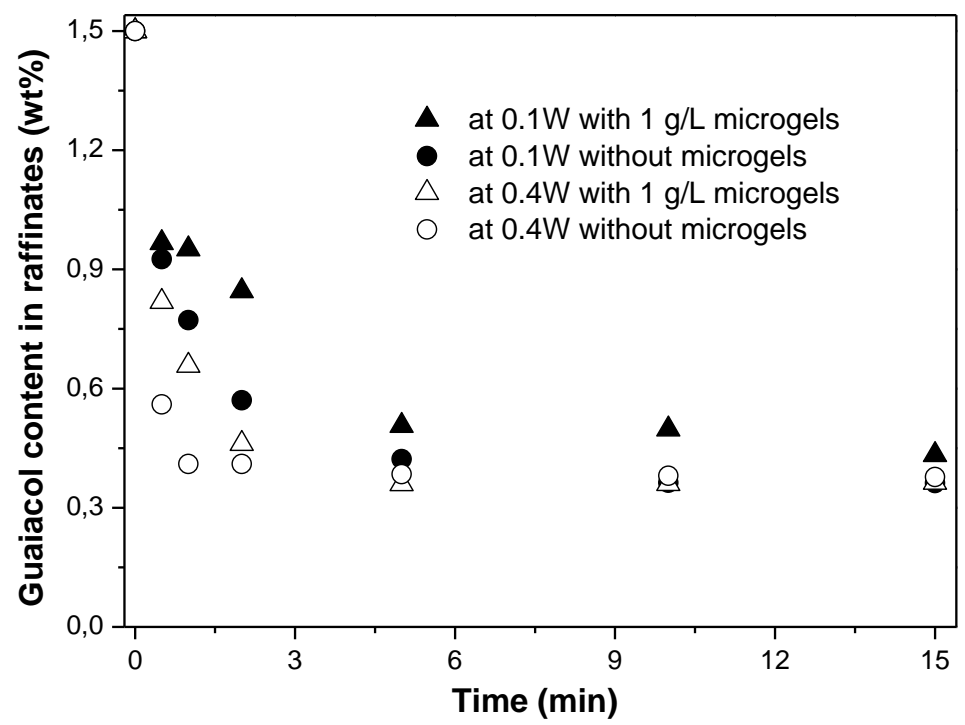

Figure 6.8. Extraction kinetics comparison at different particle concentration and different power input at $22{ }^{\circ} \mathrm{C}$.

The kinetics of guaiacol extraction from $1 \mathrm{~g} / \mathrm{L}$ particle solutions with $\left[\mathrm{P}_{666,14}\right]\left[\mathrm{NTf}_{2}\right]$ were compared with the kinetics of guaiacol extraction from an aqueous solution without particles. Figure 6.8 presents the guaiacol concentration in raffinates as a function of time. All the extractions achieved equlibrium within approximately $5 \mathrm{~min}$, but the extraction at higher power input reached equilibrium faster than at lower power input, as it was observed in the above section that under the former condition, smaller droplets could be produced which 
provides larger interfacial area between the two immiscible phases. Furthermore, it can be seen from Figure 6.8 that under similar condition of power input, the presence of microgel particles reduced the rates of extraction, indicating that the net contact area between IL and water decreased due to the coverage of particles on the interface. Although stable emulsions and smaller drops can be obtained with the aid of microgel particles, under the current conditions, the net contact area between two immiscible phases is not increased.

\subsection{Conclusions}

Four IL-in-water emulsions stabilized by microgels were prepared and under the applied operational conditions the Sauter mean diameters were in the range of 200-800 $\mu \mathrm{m}$. Stronger power input and higher microgel concentrations resulted in smaller droplets, but still in the level of hundreds of micrometers due to the relatively low microgel concentration. The study of temperature influence on droplet size distributions confirmed that IL emulsions could be broken on demand with a small temperature trigger. The microgels had no influence on the equilibrium extraction efficiency but slowed down the extraction rate, which was most likely due to the covered droplet surface with microgels. Studies with much higher particle concentrations are suggested to get more insights in drop size behavior, and the temperature responsive behavior in such particle stabilized systems.

\section{Acknowledgement}

The author would like to acknowledge Hélène Monteillet for the preparation of the microgel particles.

\section{References}

[1] J.P. Hallett, T. Welton, Room-Temperature Ionic Liquids: Solvents for Synthesis and Catalysis. 2, Chem. Rev., 111 (2011) 3508-3576.

[2] G. Chatel, R.D. Rogers, Review: Oxidation of Lignin Using Ionic Liquids-An Innovative Strategy To Produce Renewable Chemicals, ACS Sustain. Chem. Eng., 2 (2014) 322-339.

[3] S. Zhang, J. Sun, X. Zhang, J. Xin, Q. Miao, J. Wang, Ionic liquid-based green processes for energy production, Chem. Soc. Rev., 43 (2014) 7838-7869.

[4] G.W. Meindersma, A.R. Hansmeier, A.B. de Haan, Ionic Liquids for Aromatics Extraction. Present Status and Future Outlook, Ind. Eng. Chem. Res., 49 (2010) 7530-7540. 
[5] R.K. Desai, M. Streefland, R.H. Wijffels, M. H. M. Eppink, Extraction and stability of selected proteins in ionic liquid based aqueous two phase systems, Green Chemistry, 16 (2014) 2670-2679.

[6] X. Li, S.R.A. Kersten, B. Schuur, Extraction of Guaiacol from Model Pyrolytic Sugar Stream with Ionic Liquids, Ind. Eng. Chem. Res., 55 (2016) 4703-4710.

[7] X. Li, L.C. Luque-Moreno, S.R.G. Oudenhoven, L. Rehmann, S.R.A. Kersten, B. Schuur, Aromatics extraction from pyrolytic sugars using ionic liquid to enhance sugar fermentability, Bioresour. Technol., 216 (2016) 12-18.

[8] M.T.G. Jongmans, B. Schuur, A.B. de Haan, Ionic Liquid Screening for Ethylbenzene/Styrene Separation by Extractive Distillation, Ind. Eng. Chem. Res., 50 (2011) 10800-10810.

[9] E. Reyhanitash, B. Zaalberg, S.R.A. Kersten, B. Schuur, Extraction of volatile fatty acids from fermented wastewater, Sep. Purif. Technol., 161 (2016) 61-68.

[10] L.Y. Garcia-Chavez, C.M. Garsia, B. Schuur, A.B. de Haan, Biobutanol Recovery Using Nonfluorinated Task-Specific Ionic Liquids, Ind. Eng. Chem. Res., 51 (2012) 8293-8301.

[11] L. Schilder, S. Maaß, A. Jess, Effective and Intrinsic Kinetics of Liquid-Phase Isobutane/2-Butene Alkylation Catalyzed by Chloroaluminate Ionic Liquids, Ind. Eng. Chem. Res., 52 (2013) 1877-1885.

[12] H.J. Liu, Y. Zhang, H. Yao, W. Zhao, The Study on Ionic Liquids Oil-in-Water Emulsion Enhancing Carbon Dioxide Absorption, in: K.S. Thaung (Ed.) Future Material Research and Industry Application, Pts 1 and 2, 2012, pp. 991-997.

[13] G. Yu, D. Zhao, L. Wen, S. Yang, X. Chen, Viscosity of ionic liquids: Database, observation, and quantitative structure-property relationship analysis, AlChE J., 58 (2012) 2885-2899.

[14] M. Uerdingen, C. Treber, M. Balser, G. Schmitt, C. Werner, Corrosion behaviour of ionic liquids, Green Chemistry, 7 (2005) 321-325.

[15] H.J.M. Monteillet, Complex coacervates and microgels for emulsions : robust, responsive, reversible, in, Wageningen University, 2015, pp. 147.

[16] Y.a. Gao, N. Li, L. Zheng, X. Bai, L. Yu, X. Zhao, J. Zhang, M. Zhao, Z. Li, Role of Solubilized Water in the Reverse Ionic Liquid Microemulsion of 1-Butyl-3methylimidazolium Tetrafluoroborate/TX-100/Benzene, The Journal of Physical Chemistry B, 111 (2007) 2506-2513.

[17] J. Eastoe, S. Gold, S.E. Rogers, A. Paul, T. Welton, R.K. Heenan, I. Grillo, Ionic Liquidin-Oil Microemulsions, J. Am. Chem. Soc., 127 (2005) 7302-7303.

[18] R. Pramanik, S. Sarkar, C. Ghatak, V.G. Rao, N. Sarkar, Ionic Liquid Containing Microemulsions: Probe by Conductance, Dynamic Light Scattering, Diffusion-Ordered 
Spectroscopy NMR Measurements, and Study of Solvent Relaxation Dynamics, The Journal of Physical Chemistry B, 115 (2011) 2322-2330.

[19] O. Rojas, B. Tiersch, C. Rabe, R. Stehle, A. Hoell, B. Arlt, J. Koetz, Nonaqueous Microemulsions Based on N,N' -Alkylimidazolium Alkylsulfate Ionic Liquids, Langmuir, 29 (2013) 6833-6839.

[20] H. Monteillet, M. Workamp, X. Li, B. Schuur, J.M. Kleijn, F.A.M. Leermakers, J. Sprakel, Multi-responsive ionic liquid emulsions stabilized by microgels, Chem. Commun., 50 (2014) 12197-12200.

[21] A. Lee, S.K.Y. Tang, C.R. Mace, G.M. Whitesides, Denaturation of Proteins by SDS and Tetraalkylammonium Dodecyl Sulfates, Langmuir, 27 (2011) 11560-11574.

[22] S. Maass, S. Wollny, A. Voigt, M. Kraume, Experimental comparison of measurement techniques for drop size distributions in liquid/liquid dispersions, Exp. Fluids, 50 (2011) 259269.

[23] S. Maaß, J. Rojahn, R. Hänsch, M. Kraume, Automated drop detection using image analysis for online particle size monitoring in multiphase systems, Comput. Chem. Eng., 45 (2012) 27-37.

[24] J.J. Fillion, H. Xia, M.A. Desilva, M. Quiroz-Guzman, J.F. Brennecke, Phase Transitions, Decomposition Temperatures, Viscosities, and Densities of Phosphonium, Ammonium, and Imidazolium Ionic Liquids with Aprotic Heterocyclic Anions, J. Chem. Eng. Data, 61 (2016) 2897-2914. 


\section{Chapter 7}

\section{Extraction with a magnetically immobilized ionic liquid}

The work presented in this chapter aims at the development of liquid-liquid separations making use of magnetically immobilized magnetic ionic liquids (MILs) to enable extremely low solvent to feed ratios. A flow experiment was designed, further referred to as fixed liquid extraction, in which MIL droplets stabilized by microgels were fixed in a tube by the magnetic force while the feed was pumped through the MIL drops for extraction. Extraction of methyl isobutyl ketone (MIBK) from aqueous solutions was performed in this fixed liquid extraction process. It was observed that the MIL drops could be successfully fixated in the tube. Due to the short contact time of the two liquid phases and the relatively large MIL drops caused by coalescence in the pump, the extraction yield of MIBK was $50 \%$ of the thermodynamic maximum yield, but with these preliminary results, the concept of Fixed Liquid Extraction has been demonstrated for the first time. 


\subsection{Introduction}

Magnetic ionic liquids (MILs) are a subclass of ionic liquids (ILs), which have paramagnetic properties, induced by magnetic cations, anions or both. Their response to an external magnetic field allows them to be separated and recycled with the aid of magnetic field $[1,2]$. MILs have attracted great interest over the past decade. Since the first MIL, 1butyl-3-methylimidazolium tetrachloroferrate $\left(\mathrm{Bmim}\left[\mathrm{FeCl}_{4}\right]\right)$, was synthesized by Hayashi in 2004 [2], more MILs have been reported, which are mainly based on transition metal containing anions (e.g. $\left[\mathrm{FeCl}_{3} \mathrm{Br}\right],\left[\mathrm{Co}(\mathrm{NCS})_{4}\right]^{2-},\left[\mathrm{CoCl}_{4}\right]^{2-}$ and $\left.\left[\mathrm{MnCl}_{4}\right]^{2-}\right)$ [3-7], lanthanidemetal containing anions (e.g. $\left[\mathrm{GdCl}_{6}\right]^{3-}$ and $\left.\left[\mathrm{Dy}(\mathrm{SCN})_{6}(\mathrm{H} 2 \mathrm{O})_{2}\right]\right)[7,8]$, or organic radical ion containing cations or anions (e.g. 2,2,6,6-tetramethyl-1-piperidinyl-oxy-4-sulfate) [9, 10]. Besides magnetic behavior of MILs, they can also have photo-physical or catalytic properties, owning to the metal ions in their structures, and MILs have been studied in various lab applications, such as separations, synthesis and catalysis[11-19].

Some ILs have shown extremely high distribution coefficients (several thousands) for phenolic compounds [20,21], and in some reported cases, even higher equilibrium extraction yields with MILs were reported than with non-magnetic ILs, such as in the applications of phenolic removal and benzene absorption [21, 22]. With high distribution coefficients of solutes in these cases, only small amounts of MIL are required. When extreme small solvent to feed ratios are desired, traditional liquid-liquid contacting methods are not suitable. Thus, an alternative method of operation needs to be investigated.

IL emulsions stabilized by microgels have been reported recently, where microgel particles are solvent-swollen, cross-linked polymers and composed of poly $(\mathrm{N}$ isopropylacrylamide) or its copolymers [23]. These emulsions can be broken on-demand and show multiple responses to temperature, $\mathrm{pH}$, ionic strength and even to a magnetic field when MIL emulsions are employed [23]. It has been shown in Chapter 6 that stable $\mathrm{P}_{666,14}\left[\mathrm{FeCl}_{4}\right]$ based emulsions can be prepared in a stirred tank (power input $0.4 \mathrm{~W}$ ) with a Sauter mean drop size of $400 \mu \mathrm{m}$. When increasing the concentration of microgel particles, the MIL droplet size could be decreased significantly, and Monteillet et al showed drops of 2-20 $\mu \mathrm{m}$ obtained with $2.7 \mathrm{~g} / \mathrm{L}$ core-shell particles at room temperature and under intense mechanical vortex stirring [23].

Aiming to apply MIL in a continuous extraction process with a very low solvent to feed ratio $(<0.1)$, a novel separation process concept was explored in this work, in which MIL droplets stabilized by core-shell microgels were fixed in a column using a permanent magnetic field, and a feed stream was continuously pumped through the column. This new extraction technique is called fixed liquid extraction. To explore this mode of operation, 
extraction of a model contaminant (methyl isobutyl ketone, MIBK) from an aqueous feed was studied. For use in the studies, several MILs were synthesized in order to prepare MILemulsions, including one dicationic MIL, which should exhibit larger effective magnetic moments than the mono-cationic MILs, due to the doubled concentration of iron atoms per mole of compound [24].

Magnetic field effects on the transport phenomena have been observed in several separation processes upon application of an external magnetic field [25-30]. For example, it has been shown that a magnetic field with an intensity of $2 \mathrm{~T}$ can induce a decrease of $10 \%$ of the viscosity for $\left[\mathrm{C}_{4} \mathrm{mim}\right]\left[\mathrm{FeCl}_{4}\right]$ and even $15 \%$ for $\left[\mathrm{C}_{8} \mathrm{mim}\left[\mathrm{FeCl}_{4}\right]\right.$ [31]. A permeability increase of $51 \%$ for $\alpha$-pinene in dodecane through supported MIL membranes with $\mathrm{Bmim}\left[\mathrm{FeCl}_{4}\right]$ was observed under a magnetic field of $1.2 \mathrm{~T}$ [31]. Also a magnetic orientation upon solidification of [butyloctamethylferrocenium] $\left[\mathrm{NTf}_{2}\right]$ was observed in a magnetic field $(0.6 \mathrm{~T})$ near room temperature, where the liquid crystallized into needles arranged perpendicular to the field [32]. It has been reported that aromatic hydrocarbons are packed in the imidazolium ILs crystals with the form of cation-aromatic 'sandwich' [33]. When the magnetic alignment is possible in a liquid state of ILs, it might affect the IL-aromatics interactions, and hence, the distribution of the aromatic in an extraction system could then be manipulated by switching on and off a magnetic field. Therefore, in this study, also the magnetic field effects on the liquid-liquid equilibria were studied, for which toluene extractions from heptane with two imidazolium-based MILs were selected. This model system furthermore allows for comparison with a wide range of literature on aromaticsaliphatics separation.

\subsection{Experimental}

\subsubsection{Materials}

\subsubsection{Commercially acquired chemicals}

All the ILs (>95\%) shown in Table 7.1 were obtained from IoLiTec. MIBK $(>99.5 \%)$, heptane $(99 \%)$, toluene $(99.9 \%)$, 1,4-dichlorobutane (99\%), 1-butylimidazole (98\%), dimethyl sulfoxide- $\mathrm{d}_{6}\left(\mathrm{DMSO}_{6}, 99.96\right.$ atom\% D) and iron(III) chloride (>99.9\%) were purchased from Sigma Aldrich. 
Table 7.1. The names, abbreviations and structures of purchased ILs and the synthesized dicationic MIL.

\begin{tabular}{lcl}
\multicolumn{1}{c}{ Names } & Abbreviations \\
$\begin{array}{l}\text { 1-butyl-3- } \\
\text { methylimidazolium chloride }\end{array}$ & $\mathrm{BmimCl}$ \\
1-hexyl-3- \\
methylimidazolium chloride \\
Tetrabutylphosphonium \\
$\begin{array}{l}\text { Trihexyltetradecylphosphoni } \\
\text { um chloride }\end{array}$
\end{tabular}

\subsubsection{Synthesis and characterization of MILs}

Bmim[FeCl 4 ]. To prepare this $\mathrm{MIL}, \mathrm{BmimCl}(25.00 \mathrm{~g}, 0.14 \mathrm{~mol})$ was diluted in $25 \mathrm{~g}$ ethanol in a $100 \mathrm{~mL}$ round-bottom flask, to which iron chloride $(23.22 \mathrm{~g}, 0.14 \mathrm{~mol})$ was added slowly under $\mathrm{N}_{2}$ atmosphere at $50{ }^{\circ} \mathrm{C}$. After stirring for $24 \mathrm{~h}$ and removing ethanol by vacuum evaporation, a dark brown liquid was obtained. The product could not be analyzed by NMR because of its paramagnetic property. Analysis was therefore limited to Elemental analysis. The results of elemental analysis for all the synthesized MILs are shown in Table 7.2.

$\mathrm{Hmim}\left[\mathrm{FeCl}_{4}\right]$ was prepared in a procedure similar to that for $\mathrm{Bmim}\left[\mathrm{FeCl}_{4}\right]$, but now $\mathrm{HmimCl}$ was used as the starting material, and a dark brown liquid product was obtained and characterized by an elemental analyzer.

$\left[\mathrm{C}_{4} \mathrm{im}-\mathrm{C}_{4}-\mathrm{C}_{4} \mathrm{im}\right][\mathrm{FeCl}]_{2}$ was prepared in two steps. In the first step, 1,4-dichlorobutane $(0.1 \mathrm{~mol})$ was added dropwise to 1 -methylimidazole $(0.3 \mathrm{~mol})$ using a drop funnel. After vigorous stirring for $24 \mathrm{~h}$ at $90{ }^{\circ} \mathrm{C}$, the product was washed with ethyl acetate for three times 
to remove the unreacted materials, then dried in vacuum. The obtained white solid product was characterized on a Bruker NMR machine and an elemental analyzer. ${ }^{1} \mathrm{H}$ NMR $(400 \mathrm{MHz}$, DMSO-d $\left.{ }_{6}\right) \delta:$ 0.85-0.95 (t, 6H), 1.20-1.31 (m, 4H), 1.74-1.85 (m, 8H), 4.16-4.24 (t, 4H), 4.25-4.33 (t, 4H), $7.86(\mathrm{t}, 2 \mathrm{H}), 7.92(\mathrm{t}, 2 \mathrm{H}), 9.65(\mathrm{~s}, 2 \mathrm{H})$. Elemental analysis: calculated for $\mathrm{C}_{18} \mathrm{H}_{32} \mathrm{~N}_{4} \mathrm{Cl}_{2}$ : C $57.5 \%, \mathrm{H} 8.5 \%, \mathrm{~N} 14.9 \%$; experimentally found: C $53.9 \%, \mathrm{H} 8.5 \%, \mathrm{~N}$ $14.5 \%$. In the second step, equal molar amounts ( 0.05 mol) of $\left[\mathrm{C}_{4} \mathrm{im}-\mathrm{C}_{4}-\mathrm{C}_{4} \mathrm{im}\right] \mathrm{Cl}_{2}$ and $\mathrm{FeCl}_{3}$ were mixed in ethanol at room temperature for 24 hours. After removing the solvent by vacuum evaporation, a dark brown liquid product was obtained and characterized by an elemental analyzer.

Table 7.2. Elemental analysis results for all synthesized MILs

\begin{tabular}{llccc}
\hline MILs & & $\mathrm{N}(\%)$ & $\mathrm{C}(\%)$ & $\mathrm{H}(\%)$ \\
\hline $\mathrm{Bmim}\left[\mathrm{FeCl}_{4}\right]$ & calculated & 8.32 & 28.52 & 4.50 \\
& experimental & 8.56 & 28.75 & 4.68 \\
$\mathrm{Hmim}\left[\mathrm{FeCl}_{4}\right]$ & calculated & 7.68 & 32.91 & 5.26 \\
& experimental & 7.45 & 32.27 & 5.15 \\
{$\left[\mathrm{C}_{41 m}-\mathrm{C}_{4}-\mathrm{C}_{4} \mathrm{im}\right]\left[\mathrm{FeCl}_{4}\right]_{2}$} & calculated & 8.01 & 30.89 & 4.62 \\
& experimental & 7.70 & 30.25 & 4.63 \\
& calculated & 0 & 42.0 & 7.9 \\
$\mathrm{P}_{4444}\left[\mathrm{FeCl}_{4}\right]$ & experimental & 0 & 41.5 & 7.5 \\
& calculated & 0 & 56.4 & 10.0 \\
$\mathrm{P}_{666,14}\left[\mathrm{FeCl}_{4}\right]$ & experimental & 0 & 56.8 & 10.2 \\
\hline
\end{tabular}

$P_{4444}\left[\mathrm{FeCl}_{4}\right]$ was prepared in a procedure similar to that for $\mathrm{Bmim}\left[\mathrm{FeCl}_{4}\right]$, but $\mathrm{P}_{4444} \mathrm{Cl}$ was used as the starting material, and a brown solid was obtained and characterized by an elemental analyzer.

$P_{666,14}\left[\mathrm{FeCl}_{4}\right]$ was prepared in a procedure similar to that for $\mathrm{Bmim}\left[\mathrm{FeCl}_{4}\right]$, but $\mathrm{P}_{666,14} \mathrm{Cl}$ was used as the starting material. The obtained dark brown liquid product was characterized by an elemental analyzer. 


\subsubsection{Experimental setup}

\subsubsection{Magnetic system}

A dipole magnetic system was built with two Neodymium block magnets $(50 \times 50 \times 25$ $\mathrm{mm}$, N50) which were purchased from Magneten Specialist. The two magnets were connected with a steel yoke, as shown in Figure 7.1. The direction of the two magnetic poles were the same for both magnets and the distance between the two magnets was $16 \mathrm{~mm}$. This magnetic system was used for the study of magnetic field effects in batch extractions, and also for the continuous extraction in the fixed liquid extraction process. The magnetic field strength and the magnetic force on the magnetic droplets were calculated theoretically and the details are shown in Appendix D.

\subsubsection{Continuous flow setup}

A fixed liquid extraction process was designed in which the dispersed liquid was fixed with the aid of a magnetic field. The setup is drawn in Figure 7.2(a). The transparent glass tube $\left(D_{\text {in }}=0.6 \mathrm{~cm}\right)$ was placed in the center of the gap between the two magnets as shown in Figure 7.2(b). MIL emulsions were pumped in the first step aiming to fix the solvent drops in the tube by magnetic force. Then the feed stream was pumped though the tube for extraction. All the raffinates were collected in the 'Raffinate' outlet. By removing the magnets, the loaded MIL drops could be collected in the 'Extract' outlet. After putting back the magnets, the recycled MIL emulsions could be fed and fixed again for the next round of extraction.

\subsubsection{Experimental methods}

\subsubsection{Preparation of MIL emulsions}

MIL emulsions were prepared by mixing MIL with $1 \mathrm{~g} / \mathrm{L}$ core-shell particle solutions at a volume ratio of 1:9 with a vortex mixer for $1 \mathrm{~min}$. The core-shell particles were the same as described in Chapter 6.

\subsubsection{Liquid-liquid extractions}

\subsection{Toluene extraction}




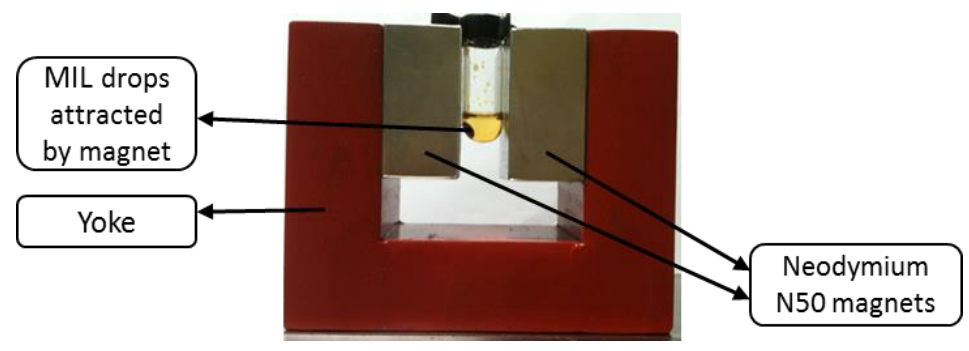

Figure 7.1. Magnetic setup used for both the batch experiments and for the continuous process, here displayed with a batch sample in the gap between the magnets.

(a)

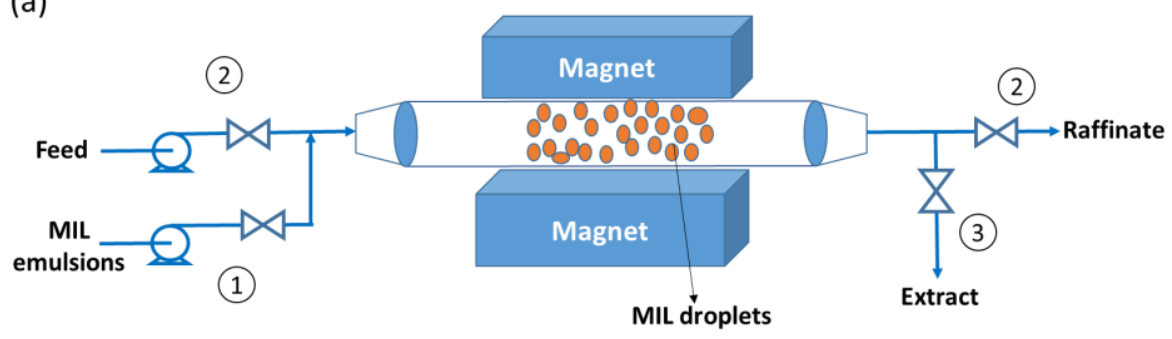

(b)

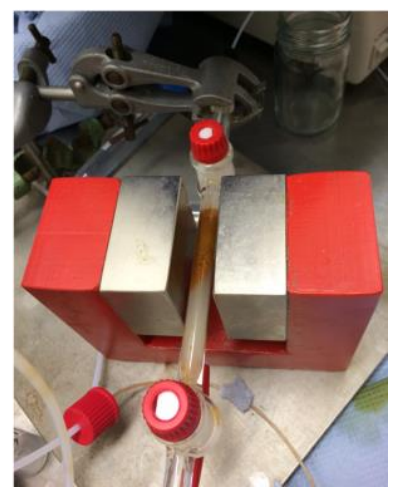

Figure 7.2. The designed FLE process (a) and experimental setup (b). The numbers in figure (a) indicates the operational steps: (1) feeding MIL emulsion; (2) switching valve to pump feed and collect raffinate, (3) removing magnets to collect extract (MIL droplets). 
The feed was prepared by mixing toluene and heptane with a volume ratio of 1:4. Liquidliquid extraction experiments were carried out in $15 \mathrm{~mL}$ glass tubes by mixing equal mass of feed and MIL ( $\mathrm{Bmim}\left[\mathrm{FeCl}_{4}\right]$ or $\mathrm{Hmim}\left[\mathrm{FeCl}_{4}\right]$ ) with a mechanical stirring paddle (Teflon) at room temperature for $30 \mathrm{~min}$. The mixtures were then allowed to settle down for $2 \mathrm{~h}$ to achieve phase separation. Both phases were then analyzed by gas chromatography (GC) to obtain the concentrations of heptane and toluene.

The magnetic extractions were performed with the same procedures described above except in a magnetic field, where the glass tube was put in between two magnets shown in Figure 7.1 (top part of the tube was cut from Figure 1), allowing the liquids in the tube to be in the center of the space in between two magnets. The experiments with and without magnetic field were repeated in triplicate.

\subsection{Batch extraction of MIBK}

Liquid-liquid equilibrium measurements for the extraction of MIBK from aqueous solutions were carried out in two different procedures to cover a wide range of equilibrium compositions. In the first method, the solvent $\mathrm{P}_{666,14}\left[\mathrm{FeCl}_{4}\right]$ was mixed with feed $(1.5 \mathrm{wt} \%$ MIBK aqueous solutions) at different solvent to feed mass ratio $(0.2<\mathrm{S} / \mathrm{F}<1)$ at $25{ }^{\circ} \mathrm{C}$ for $24 \mathrm{~h}$ in a shaking bath and then settled down for $2 \mathrm{~h}$ to achieve phase separation. The aqueous raffinates were analyzed by HPLC and IL extracts by GC to obtain the equilibrium concentrations of MIBK.

In the second series of equilibrium measurements, the MIBK was fed in $\mathrm{P}_{666,14}\left[\mathrm{FeCl}_{4}\right]$ in mass fractions from 10-90 wt $\%$. The $\mathrm{P}_{666,14}\left[\mathrm{FeCl}_{4}\right]$ and MIBK mixtures were then mixed for $24 \mathrm{~h}$ with water in equal weight. The settling and analysis procedures were similar as described above.

\subsection{MIBK extraction in the fixed liquid extraction process}

MIBK extraction was performed in the fixed liquid extraction process at room temperature as shown in Figure 7.2. In the first step, the prepared MIL-based emulsions (with $0.5205 \mathrm{~g}$ MIL and $9.5637 \mathrm{~g}$ of $1 \mathrm{~g} / \mathrm{L}$ microgel solutions) were pumped at a flow rate of $2.4 \mathrm{~mL} / \mathrm{min}$ into the transparent glass tube, where the MIL droplets were fixed due to the magnetic field. In the second step, the feed stream (1.5 wt\% MIBK in $1 \mathrm{~g} / \mathrm{L}$ microgel solutions) was pumped through the tube at a flow rate of $0.8 \mathrm{~mL} / \mathrm{min}$ to extract the MIBK by the static MIL droplets. Samples were collected from the outlet of the raffinate stream, and the concentrations of MIBK in the raffinates were analyzed with HPLC. 


\subsubsection{Analysis}

Heptane and toluene in the raffinate and extract phases were quantified with a Varian $\mathrm{CP}$ 3800 gas chromatography (GC) apparatus equipped with a Varian CP-SIL 5CB column (50 $\mathrm{m}, 1.2 \mu \mathrm{m})$ and a flame ionization detector (FID). Each raffinate sample $(0.25 \mathrm{~mL})$ was diluted with $1.48 \mathrm{~mL}$ acetone and $120 \mu \mathrm{L}$ internal standard cyclohexane. Each extract sample $(0.25 \mathrm{~mL})$ was diluted with $1.30 \mathrm{~mL}$ acetone and $25 \mu \mathrm{L}$ cyclohexane. $1 \mu \mathrm{L}$ of the sample was injected into the injector $\left(250{ }^{\circ} \mathrm{C}\right)$ with a split ratio of 50:1. All samples were injected three times to reduce analytical errors. Since ILs have a negligible vapor pressure, they were collected in a pre-column (cup-liner) to avoid contamination of the column. The cup-liner was changed every 100 injections.

Concentrations of MIBK in the aqueous raffinate phases were analyzed with a high performance liquid chromatography HPLC apparatus (Agilent 1200 system), which was equipped with a refractive index detector (RID, accuracy <1.5\%) and a Hi-Plex-H column operated at $60{ }^{\circ} \mathrm{C}$. A $5 \mathrm{mM}$ sulfuric acid solution was employed as the mobile phase at a flow rate of $0.6 \mathrm{~mL} / \mathrm{min}$. MIBK contents in the extract phases were analyzed with a gas chromatography (GC) apparatus equipped with a FID detector operated at $250{ }^{\circ} \mathrm{C}$ and a capillary column $(\mathrm{VF}-1701 \mathrm{~ms}, 60 \mathrm{~m} \times 0.25 \mathrm{~mm} \times 0.25 \mu \mathrm{m})$. Each sample was diluted tenfold with acetone (with $5 \mathrm{wt} \%$ internal standard heptane) and analyzed in triplicate.

\subsubsection{Definitions}

The equilibrium extraction performance of the solvents is expressed using the distribution coefficient of the solutes over the two phases as defined in equation (7.1):

$$
D_{i}=\frac{x_{i}^{I}}{x_{i}^{I I}}
$$

where $x_{i}^{I}$ and $x_{i}^{I I}$ represent the weight fraction of solute $i$ in phase I (the extract phase) and phase II (the raffinate phase), respectively.

\subsection{Results and discussion}

\subsubsection{Magnetic field effect on liquid-liquid equilibria}

The distribution coefficients of heptane $\left(D_{\text {heptane }}\right)$ and toluene $\left(D_{\text {toluene }}\right)$ in MILs were compared for extractions with and without magnetic field. 
It is shown in Figure 7.3 that no magnetic field effects on the equilibrium distributions were observed under the applied conditions, as the differences of both $\mathrm{D}_{\text {heptane }}$ and $\mathrm{D}_{\text {toluene }}$ between the magnetic extraction and zero-field extraction were in the range of the experimental deviations for both MILs investigated.

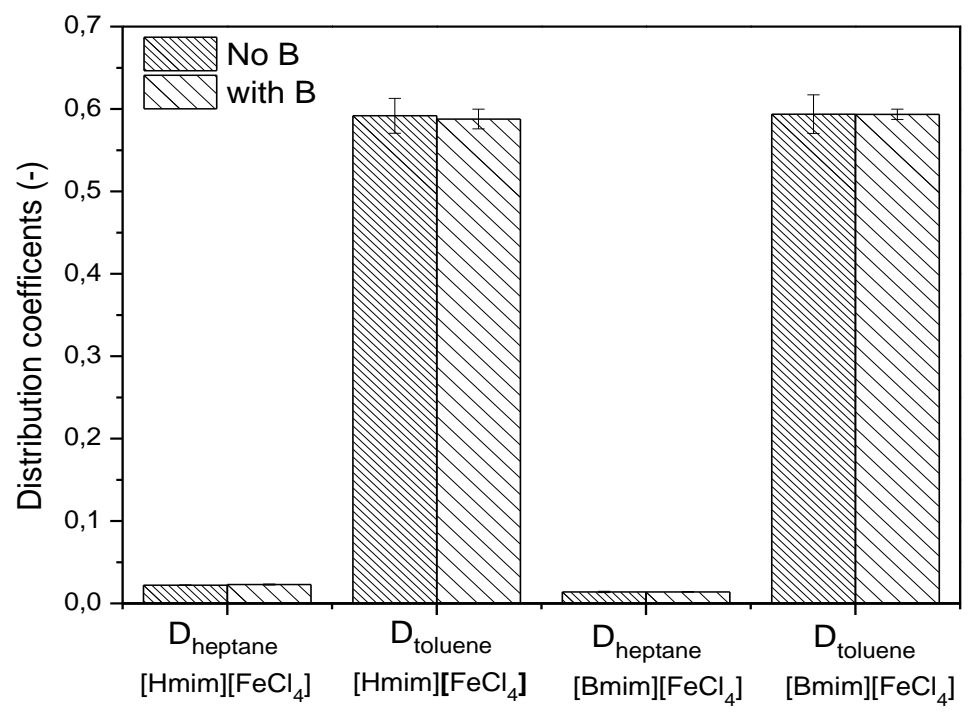

Figure 7.3. Distribution coefficients of heptane and toluene in $\mathrm{Hmim}\left[\mathrm{FeCl}_{4}\right]$ and $\mathrm{Bmim}\left[\mathrm{FeCl}_{4}\right]$ in liquid-liquid equilibria via extractions with and without magnetic field.

In order to support this experimental result, a theoretical comparison was made for the energy due to the magnetic field and the thermal energy (random motion). To realign a magnetic body due to a magnetic field, the forces due to the magnetic field should exceed the forces exerted by the Brownian motion. For a single electron in a magnetic field, the magnetic energy $E_{m}$ is quantified with the Bohr magneton $\mu_{B}$ in equation (7.2), and the Bohr magneton definition is given in equation (7.3) [34]:

$$
\begin{gathered}
E_{m}=-\mu_{B} \cdot \vec{B} \\
\mu_{B}=\frac{e \hbar}{2 m_{e}}=9.27 \times 10^{-24} \frac{\mathrm{J}}{\text { tesla }}
\end{gathered}
$$


where e is the elementary charge, $1.6 \times 10^{-19} \mathrm{C}, \hbar$ the reduced Planck constant, $1.05 \times 10^{-34} \mathrm{~J} \cdot \mathrm{s}$ and $m_{e}$ the mass of an electron, $9.109 \times 10^{-31} \mathrm{~kg}$. It follows that the magnetic energy $\left(\mathrm{E}_{\mathrm{m}}\right)$ of one electron in a magnetic field (B) of 1 tesla is $9.27 \times 10^{-24} \mathrm{~J}$. Effective magnetic moments are measured per ion, typically $\mu_{\mathrm{EFF}}=4-7 \mu_{\mathrm{B}}$ for MILs [35], and since Fe has four unpaired $3 d$-electrons, it is expected that $\mathrm{FeCl}_{4}{ }^{-}$-anions experience a $\mu_{\mathrm{EFF}}=4$.

The scaling factor for thermal energy is kT [36], and e.g. for electrons can be calculated from equation (7.4):

$$
E_{k i n} \propto k T
$$

where $\mathrm{k}$ is Boltzmann constant, $1.38 \times 10^{-23} \mathrm{~J} / \mathrm{K}$ and $\mathrm{T}$ is temperature in $\mathrm{K}$. At $300 \mathrm{~K}$, the thermal energy of an electron, $E_{\text {kin }}$ scales at $4.14 \times 10^{-21} \mathrm{~J}$, which is 447 times as large as the magnetic energy that one electron experiences due to the magnetic field of 1 tesla. From this, it follows that it is logical that no magnetic effect was observed on the distribution of toluene in bulk liquid MIL. Similarly, for the studies where a magnetic effect was observed, such as an increased permeability through a MIL-impregnated membrane, or during crystallization $[31,32]$, it is likely a macroscopic effect of an entire patch of MIL, that is affected by the magnetic field, rather than a single ion pair.

Although the measurements were intended to investigate whether an effect could be measured of the magnetic field on the equilibrium distribution of toluene and heptane, the toluene/heptane system has often been used as model system, and the results in Figure 7.3 can also be compared with other studies on the extraction of toluene. The results show that both MILs exhibit high selectivities for toluene over heptane. Selectivities for [ $\mathrm{Hmim}]\left[\mathrm{FeCl}_{4}\right]$ and $[\mathrm{Bmim}]\left[\mathrm{FeCl}_{4}\right]$ were 26 and 42 respectively, which are comparable with other reported ILs and slightly higher than the conventional organic solvent sulfolane [37]. With this selectivity, a few stages are sufficient for full separation of aromatics and aliphatics.

\subsubsection{Preparation of emulsions with MILs and aqueous core-shell particle solutions}

Using the four MILs that were synthesized (including imidazolium and phosphonium based cations with iron containing anions), it was attempted to form emulsions with aqueous core-shell particle solutions. One prerequisite for an MIL-based emulsion is that the MIL is liquid. One of the MILs, $\mathrm{P}_{4444}\left[\mathrm{FeCl}_{4}\right]$, was solid at room temperature. It is attributed to the symmetric cation structure of the IL that the melting point was higher. Both $\mathrm{Bmim}\left[\mathrm{FeCl}_{4}\right]$ and $\left[\mathrm{C}_{4} \mathrm{im}-\mathrm{C}_{4}-\mathrm{C}_{4} \mathrm{im}\right]\left[\mathrm{FeCl}_{4}\right]_{2}$ were liquids at room temperature, but were miscible with the 
aqueous core-shell particle solutions. With $\mathrm{P}_{666,14}\left[\mathrm{FeCl}_{4}\right]$ stable emulsions could be formed at room temperature, and therefore this MIL was applied in the fixed liquid extraction study.

\subsubsection{Distribution coefficient of $\mathrm{MIBK}$ in $\mathrm{P}_{666,14}\left[\mathrm{FeCl}_{4}\right]$}

Before applying MIBK extraction with $\mathrm{P}_{666,14}\left[\mathrm{FeCl}_{4}\right]$ in the fixed liquid extraction process, batch extraction experiments were conducted to study the distribution coefficient of MIBK ( $\mathrm{D}_{\text {MIBK }}$ ) in $\mathrm{P}_{666,14}\left[\mathrm{FeCl}_{4}\right]$ at $25^{\circ} \mathrm{C}$. It can be seen in Figure 7.4 that under the applied conditions, $\mathrm{D}_{\mathrm{MIBK}}$ has values ranging from about 23 to 28 , and only showed a slight decrease when varying the solvent to feed ratio $(\mathrm{S} / \mathrm{F})$ from 1 down to 0.2 .This indicates that the affinity of MIL for MIBK is strong and only a small S/F ratio is needed for proper extraction, hence, the system is suitable for investigating on the concept of fixed liquid extraction.

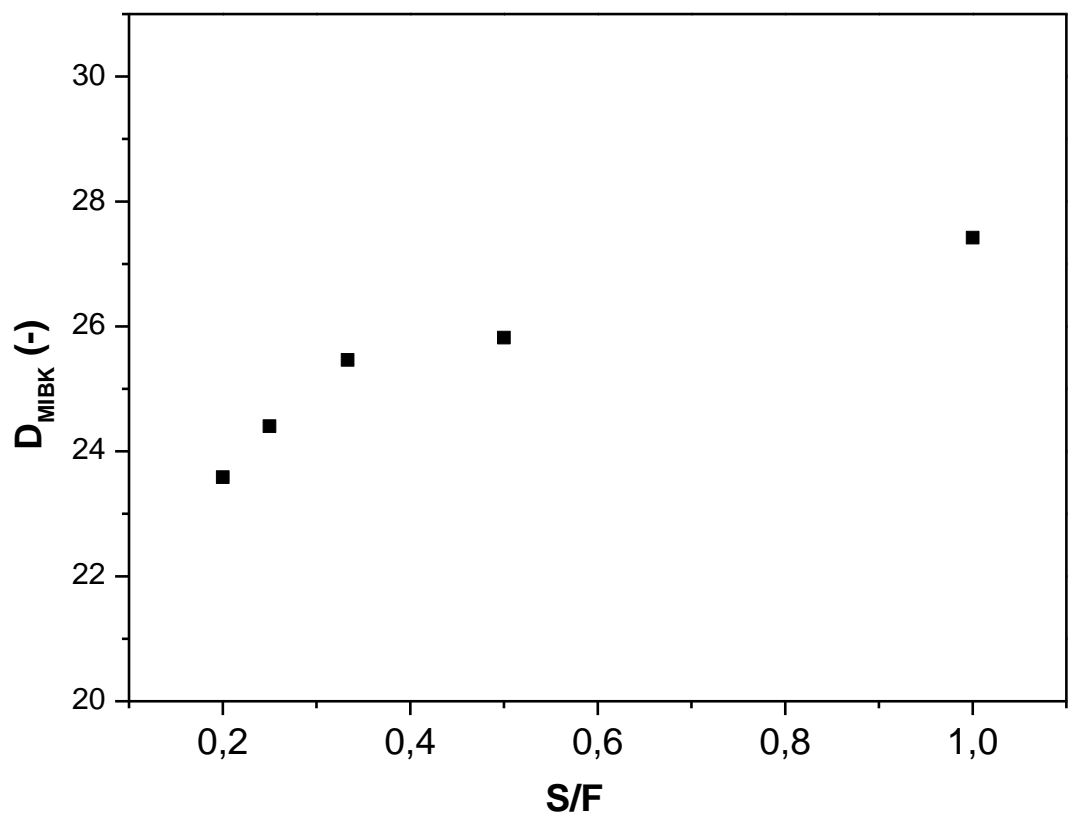

Figure 7.4. Distribution coefficient of MIBK ( $\mathrm{D}_{\mathrm{MIBK}}$ ) in $\mathrm{P}_{666,14}\left[\mathrm{FeCl}_{4}\right]$ with varying solvent to feed ratio $(\mathrm{S} / \mathrm{F})$ in equilibrium state at $25^{\circ} \mathrm{C}$.

To obtain the full pattern of the liquid-liquid equilibrium data, a series of liquid-liquid equilibrium measurements at $\mathrm{S} / \mathrm{F}=1 / 1$ were conducted by varying the initial concentration of MIBK in $\mathrm{P}_{666,14}\left[\mathrm{FeCl}_{4}\right]$. The resulting concentrations of MIBK in the raffinate and extract 
phases at equilibrium state are presented in Figure 7.5. It can be seen that MIBK is highly soluble in $\mathrm{P}_{666,14}\left[\mathrm{FeCl}_{4}\right]$ and $\mathrm{D}_{\text {MIBK }}$ varied over the entire concentration range from 17 to 51 . For an inlet MIBK concentration in the aqueous feed stream ( $\left.x_{i n}\right)$ of $1.5 \mathrm{wt} \%$ and a target removal fraction of 0.99 , the minimum solvent to feed ratio was calculated using equation (7.5):

$$
S_{\text {min }}=F \frac{X_{\text {in }}-X_{\text {out }}}{Y_{\text {out } \text { max }}-Y_{\text {in }}} \text { with } Y_{\text {out } \text { max }}=D X_{\text {in }}
$$

assuming that the incoming feed is in equilibrium with the outgoing extract stream. With $\mathrm{x}_{\text {in }}$ $=1.5 \mathrm{wt} \%$, the $\mathrm{D}$ was 34 , and the calculated $\mathrm{S}_{\min } / \mathrm{F}$ was 0.029 . With this low $\mathrm{S}_{\min } / \mathrm{F}$, it is not applicable to operate in a traditional continuous extraction column. Therefore, with high $\mathrm{D}_{\text {MIBK }}$ and low $\mathrm{S}_{\min } / \mathrm{F}$, MIBK extraction with $\mathrm{P}_{666,14}\left[\mathrm{FeCl}_{4}\right]$ is a suitable case to be operated in the designed magnetic fixed liquid extraction process.

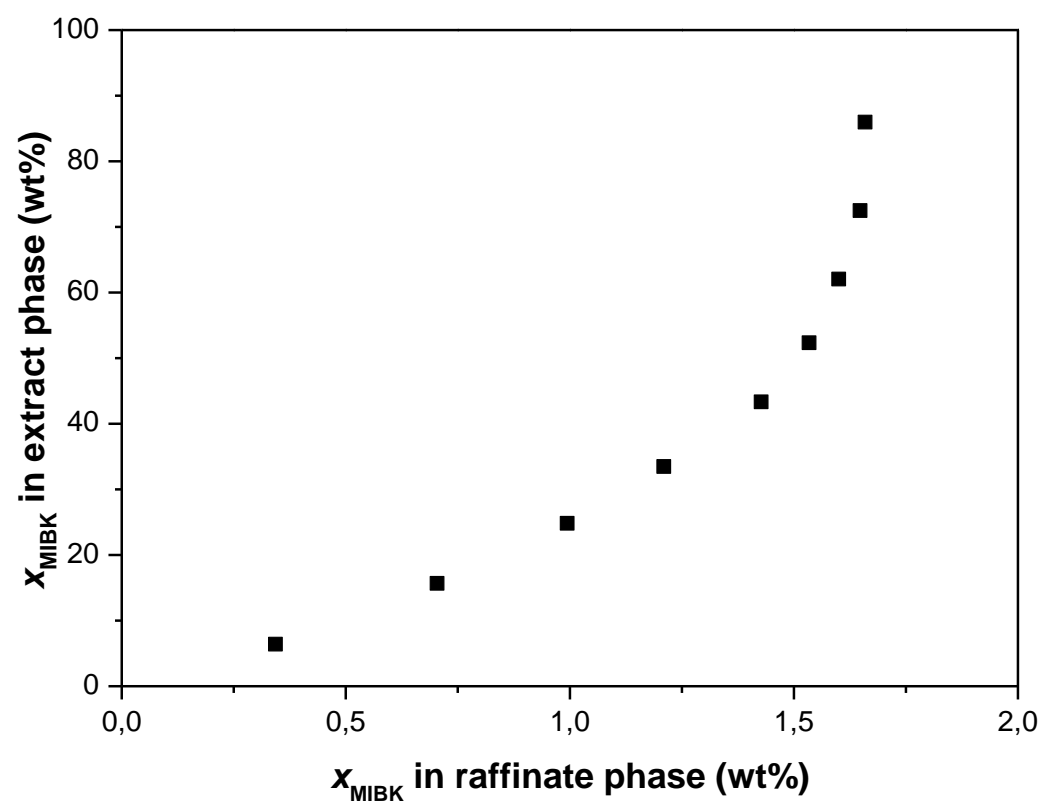

Figure 7.5. Concentrations of MIBK in the raffinate and extract phases in equilibrium state at $\mathrm{S} / \mathrm{F}$ of $1 / 1$ at $25^{\circ} \mathrm{C}$. 


\subsubsection{MIBK extraction in a fixed liquid extraction process}

The MIBK extraction was performed in the designed continuous flow process shown in Figure 7.2. It was observed that after pumping $\mathrm{P}_{666,14}\left[\mathrm{FeCl}_{4}\right]$-based emulsions, all the aqueous solutions passed through the tube, but all the MIL droplets stabilized by microgels were attracted in the part of the tube located in between the two magnets as shown in Figure 7.8, owing to the magnetic force on the droplets which is proportional to the magnetic field strength (B) and field gradient $\left(\frac{\partial B}{\partial x}\right)$ as shown in equation (7.6) [38],

$$
F=V k B \frac{\partial B}{\partial x}
$$

where $\mathrm{V}$ is the volume of the magnetic body, $\mathrm{k}$ is paramagnetic susceptibility.

After the MIL drops were positioned in the tube, the feed stream was pumped through the tube at the lowest possible flow rate of the used pump $(0.8 \mathrm{~mL} / \mathrm{min})$, to maximize the contact time of feed and solvent phases. The raffinate was collected in the raffinate outlet at different time intervals and the MIBK concentration in each sample is shown in Figure 7.7.

At flow rate of $0.8 \mathrm{~mL} / \mathrm{min}$, the feed needs around $5 \mathrm{~min}$ (measured) to flow from the inlet point to the outlet point, thus the first sample collected from 2-4 min had nearly no MIBK detected. The MIBK concentration in the raffinates increased with the pumping time increasing. After $8 \mathrm{~min}, x_{\mathrm{MIBK}}$ was about $0.8 \mathrm{wt} \%$ and this value kept stable during the rest of the experiment, indicating that approximately half of MIBK in the feed was removed. This means that based on the high distribution ratios measured in the batch experiments, the solvent is still far from saturated, and ideally, a much lower concentration should be measured in the outlet, but due to the short contact time (around $1 \mathrm{~min}$ ) between feed and MILs and the relatively large droplets may have caused mass transfer limitations. This is further confirmed by the flat concentration profile after $8 \mathrm{~min}$, which was not the inlet concentration but lower, indicating that because the concentration in the outlet was not changing, the rate of uptake by the MIL droplets was also unchanged, hence, the droplets are still far from their maximum extraction capacity because the driving force for extraction was unchanged. 


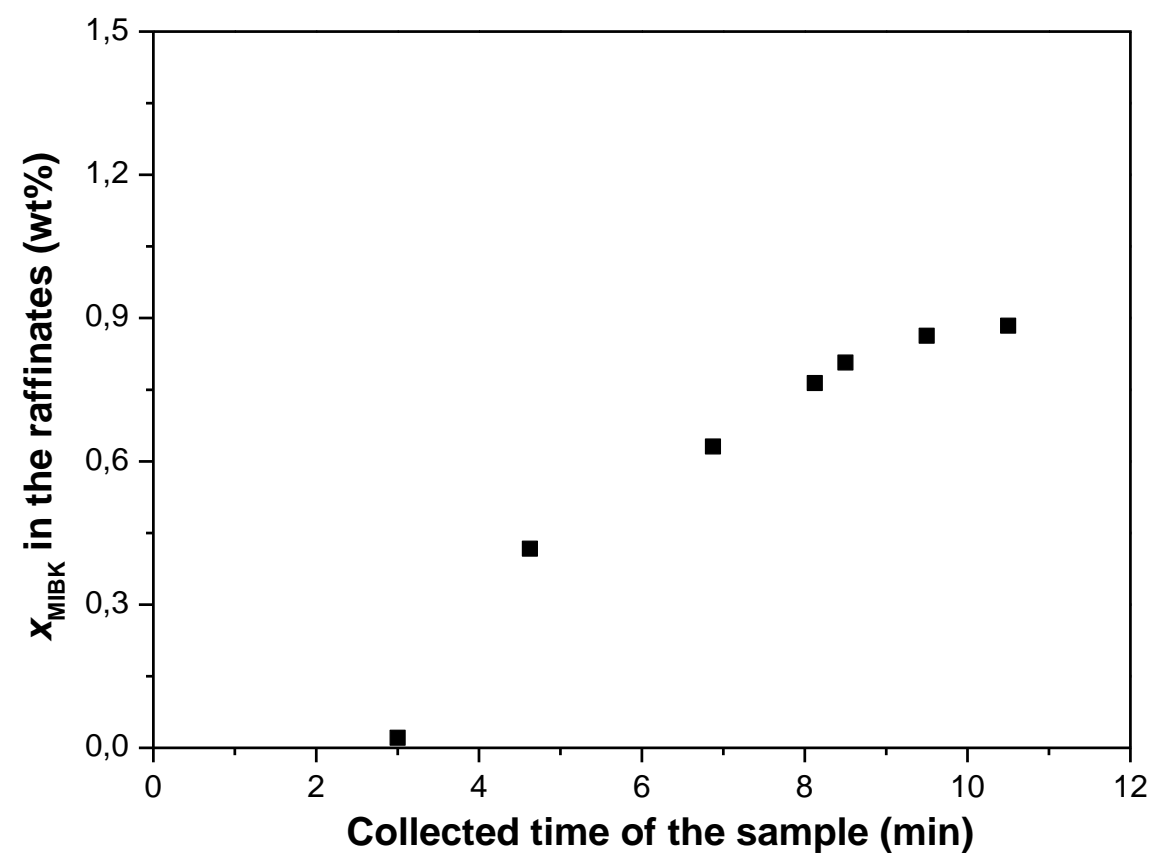

Figure 7.7. Concentration of MIBK in the raffinate samples collected at different time after extraction with $\mathrm{P}_{666,14}\left[\mathrm{FeCl}_{4}\right]$ in the continuous process.

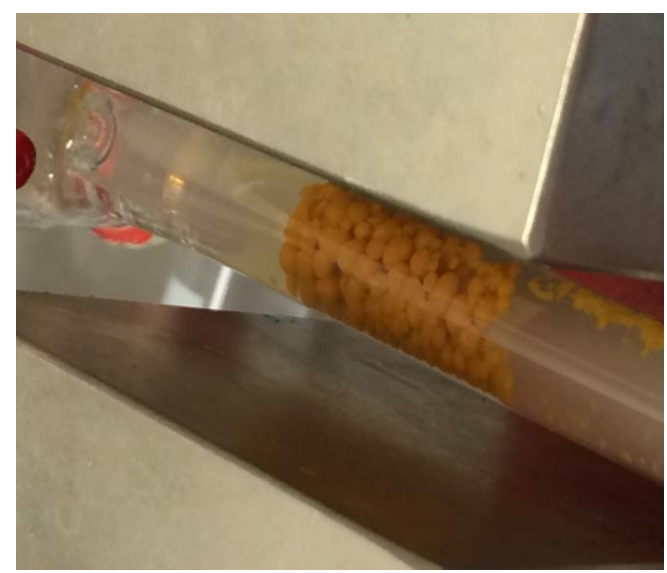

Figure 7.8. The fixed MIL drops in the continuous flow magnetic setup. 
As shown in Figure 7.8, all the MIL drops stayed densely on the wall of the tube because of the magnetic force (Equation 7.6), which largely decreased the interfacial area of the two immiscible phases. In order to well disperse the drops, it is suggested to use iron needles or wires in the tube, which could be magnetized by the magnets and generate large field gradient locally, and hence attract efficiently also smaller MIL drops.

Also, it was observed that the drops in the tube were larger than the drops in the storage bottle where the MIL emulsions were pumped from, thus drop coalescence happened during pumping. To keep the flow stream intact, a peristaltic pump was chosen. However, a rotor was used to compress the flexible tube to pump the fluid to move through the tube. In this process the MIL drops were pressed and deformed, thus the adjacent drops might be coalesced by the mechanical force. Therefore, to keep the MIL drops as small as they were in the initial state, the pump needs to be optimized.

This work only focused on demonstrating the concept of the fixed liquid extraction process. Due to restrictions in time, no optimization work has been done to improve the extraction efficiency of the fixed liquid extraction, and no studies on the recovery of the MIL have been performed. It is proposed here that IL may be recovered by removing the magnets and continuously pumping fluids. An alternative approach for MIL recovery is to pump a solvent that has a higher solute affinity than MIL in an opposite direction as pumping feed, without removing magnets. After the MIL is washed, a fresh feed containing microgels can be pumped again for extraction.

\subsection{Conclusions}

No magnetic field effect was observed in liquid-liquid equilibrium of heptane-tolueneMIL in a magnetic field of $1 \mathrm{~T}$ at room temperature, which could be explained by the low magnetic energy. A liquid fixed-bed process was designed with the aid of magnetic field which could successfully fix MIL emulsion droplets by magnetic force in the center of the gap between two magnets. It is clearly shown that the designed process can be used for MIBK removal from aqueous solutions, but further tuning of the process is required in the future towards a process with smaller droplets and faster mass transfer.

\section{References}

[1] Y.-M. Koo, S.H. Lee, S.H. Ha, C.-Y. You, Recovery of magnetic ionic liquid bmim FeCl4 using electromagnet, The Korean Journal of Chemical Engineering, 24 (2007) 436-437. 
[2] S. Hayashi, H.O. Hamaguchi, Discovery of a magnetic ionic liquid bmim FeCl4, Chemistry Letters, 33 (2004) 1590-1591.

[3] S. Hayashi, S. Saha, H.O. Hamaguchi, A new class of magnetic fluids: bmim FeCl4 and nbmim FeCl4 ionic liquids, Ieee Transactions on Magnetics, 42 (2006) 12-14.

[4] M. Li, S.L. De Rooy, D.K. Bwambok, B. El-Zahab, J.F. DiTusa, I.M. Warner, Magnetic chiral ionic liquids derived from amino acids, Chemical Communications, (2009) 6922-6924. [5] I. de Pedro, D.P. Rojas, J. Albo, P. Luis, A. Irabien, J.A. Blanco, J. Rodriguez Fernandez, Long-range magnetic ordering in magnetic ionic liquid: Emim FeCl4, Journal of PhysicsCondensed Matter, 22 (2010).

[6] T. Peppel, M. Kockerling, M. Geppert-Rybczynska, R.V. Ralys, J.K. Lehmann, S.P. Verevkin, A. Heintz, Low-viscosity paramagnetic ionic liquids with doubly charged [Co(NCS)4]2- ions, Angew Chem Int Ed Engl, 49 (2010) 7116-7119.

[7] R.E. Del Sesto, T.M. McCleskey, A.K. Burrell, G.A. Baker, J.D. Thompson, B.L. Scott, J.S. Wilkes, P. Williams, Structure and magnetic behavior of transition metal based ionic liquids, Chemical Communications, (2008) 447-449.

[8] B. Mallick, B. Balke, C. Felser, A.-V. Mudring, Dysprosium room-temperature ionic liquids with strong luminescence and response to magnetic fields, Angewandte ChemieInternational Edition, 47 (2008) 7635-7638.

[9] C.-X. Miao, J.-Q. Wang, B. Yu, W.-G. Cheng, J. Sun, S. Chanfreau, L.-N. He, S.-J. Zhang, Synthesis of bimagnetic ionic liquid and application for selective aerobic oxidation of aromatic alcohols under mild conditions, Chemical Communications, 47 (2011) 2697-2699. [10] Y. Yoshida, H. Tanaka, G. Saito, Organic Paramagnetic Ionic Liquids Based on Anion Containing 2,2,6,6-Tetramethyl-1-piperidinyloxyl Radical Moiety, Chemistry Letters, 36 (2007) 1096-1097.

[11] K.D. Clark, O. Nacham, H. Yu, T. Li, M.M. Yamsek, D.R. Ronning, J.L. Anderson, Extraction of DNA by Magnetic Ionic Liquids: Tunable Solvents for Rapid and Selective DNA Analysis, Analytical Chemistry, 87 (2015) 1552-1559.

[12] T. Yao, S. Yao, C.H. Pan, X.Z. Dai, H. Song, Deep Extraction Desulfurization with a Novel Guanidinium-Based Strong Magnetic Room-Temperature Ionic Liquid, Energy \& Fuels, 30 (2016) 4740-4749.

[13] W. Jiang, W. Zhu, H. Li, J. Xue, J. Xiong, Y. Chang, H. Liu, Z. Zhao, Fast Oxidative Removal of Refractory Aromatic Sulfur Compounds by a Magnetic Ionic Liquid, Chemical Engineering \& Technology, 37 (2014) 36-42.

[14] W. Zhu, P. Wu, L. Yang, Y. Chang, Y. Chao, H. Li, Y. Jiang, W. Jiang, S. Xun, Pyridinium-based temperature-responsive magnetic ionic liquid for oxidative desulfurization of fuels, Chemical Engineering Journal, 229 (2013) 250-256. 
[15] M. Khodajoo, S. Sayyahi, S.J. Saghanezhad, Straightforward and solvent-free synthesis of 2-amino-4H-chromenes in the presence of a choline-based magnetic ionic liquid as catalyst, Russian Journal of General Chemistry, 86 (2016) 1177-1181.

[16] B.M. Goodajdar, S. Soleimani, One-pot and efficient synthesis of triazolo 1,2-a indazole-triones catalyzed by poly(ethylene glycol) based magnetic dicationic ionic liquid, Iranian Journal of Catalysis, 6 (2016) 43-49.

[17] A. Akbari, Tri(1-butyl-3-methylimidazolium) gadolinium hexachloride, ( bmim (3) GdCl6 ), a magnetic ionic liquid as a green salt and reusable catalyst for the synthesis of tetrasubstituted imidazoles, Tetrahedron Letters, 57 (2016) 431-434.

[18] S. Sayyahi, S. Shabani, S. Ghasemi, A. Azin, S.M. Hasani, Magnetic Ionic Liquid bmim $\mathrm{FeCl} 4$ as an Efficient Catalyst for the Synthesis of 2-Aryl Benzimidazoles and 2-Aryl Benzothiazoles Derivatives, Oriental Journal of Chemistry, 31 (2015) 1773-1778.

[19] J. Wang, H. Yao, Y. Nie, L. Bai, X. Zhang, J. Li, Application of Iron-Containing Magnetic Ionic Liquids in Extraction Process of Coal Direct Liquefaction Residues, Industrial \& Engineering Chemistry Research, 51 (2012) 3776-3782.

[20] X. Li, S.R.A. Kersten, B. Schuur, Extraction of Guaiacol from Model Pyrolytic Sugar Stream with Ionic Liquids, Industrial \& Engineering Chemistry Research, (2016).

[21] N. Deng, M. Li, S.L. de Rooy, B. El-Zahab, I.M. Warner, Highly Efficient Extraction of Phenols from Aqueous Solution Using Magnetic Room Temperature Ionic Liquids, in: D.M. Fox, M. Mizuhata, H.C. DeLong, R.A. Mantz, P.C. Trulove (Eds.) Molten Salts and Ionic Liquids 17, 2010, pp. 73-77.

[22] Y. Jiang, C. Guo, H. Liu, Magnetically rotational reactor for absorbing benzene emissions by ionic liquids, China Particuology, 5 (2007) 130-133.

[23] H. Monteillet, M. Workamp, X. Li, B. Schuur, J.M. Kleijn, F.A.M. Leermakers, J. Sprakel, Multi-responsive ionic liquid emulsions stabilized by microgels, Chemical Communications, 50 (2014) 12197-12200.

[24] P. Brown, C.P. Butts, J. Eastoe, E. Padron Hernandez, F.L. Machado, R.J. de Oliveira, Dication magnetic ionic liquids with tuneable heteroanions, Chem Commun (Camb), 49 (2013) 2765-2767.

[25] S.H. Lee, S.H. Ha, S.-S. Ha, H.-B. Jin, C.-Y. You, Y.-M. Koo, Magnetic behavior of mixture of magnetic ionic liquid bmim $\mathrm{FeCl}(4)$ and water 10.1063/1.2710462, Journal of Applied Physics, 101 (2007).

[26] E. Santos, J. Albo, C.I. Daniel, C.A.M. Portugal, J.G. Crespo, A. Irabien, Permeability modulation of Supported Magnetic Ionic Liquid Membranes (SMILMs) by an external magnetic field, Journal of Membrane Science, 430 (2013) 56-61.

[27] C.I. Daniel, A.M. Rubio, P.J. Sebastiao, C.A.M. Afonso, J. Storch, P. Izak, C.A.M. Portugal, J.G. Crespo, Magnetic modulation of the transport of organophilic solutes through 
Supported Magnetic Ionic Liquid Membranes, Journal of Membrane Science, 505 (2016) 3643.

[28] Q. Yang, H.H. Himstedt, X. Qian, M. Ulbricht, S.R. Wickramasinghe, Magnetically Responsive Membranes, Procedia Engineering, 44 (2012) 221-224.

[29] D. Wandera, S.R. Wickramasinghe, S.M. Husson, Stimuli-responsive membranes, Journal of Membrane Science, 357 (2010) 6-35.

[30] S. Darvishmanesh, X.H. Qian, S.R. Wickramasinghe, Responsive membranes for advanced separations, Current Opinion in Chemical Engineering, 8 (2015) 98-104.

[31] C.I. Daniel, A.M. Rubio, P.J. Sebastião, C.A.M. Afonso, J. Storch, P. Izák, C.A.M. Portugal, J.G. Crespo, Magnetic modulation of the transport of organophilic solutes through Supported Magnetic Ionic Liquid Membranes, Journal of Membrane Science, 505 (2016) 3643.

[32] Y. Funasako, T. Mochida, T. Inagaki, T. Sakurai, H. Ohta, K. Furukawa, T. Nakamura, Magnetic memory based on magnetic alignment of a paramagnetic ionic liquid near room temperature, Chemical Communications, 47 (2011) 4475-4477.

[33] J.D. Holbrey, W.M. Reichert, M. Nieuwenhuyzen, O. Sheppard, C. Hardacre, R.D. Rogers, Liquid clathrate formation in ionic liquid-aromatic mixtures, Chemical Communications, (2003) 476-477.

[34] J.M.D. Coey, Magnetism and Magnetic Materials, Cambridge University Press, 2010.

[35] J. Albo, E. Santos, L.A. Neves, S.P. Simeonov, C.A.M. Afonso, J.G. Crespo, A. Irabien, Separation performance of CO2 through Supported Magnetic Ionic Liquid Membranes (SMILMs), Separation and Purification Technology, 97 (2012) 26-33.

[36] J.N. Israelachvili, Intermolecular and Surface Forces, Elsevier Science, 2015.

[37] F.F. Cai, W. Zhu, Y.B. Wang, T.Z. Wang, G.M. Xiao, Dialkylphosphate-Based Ionic Liquids as Solvents to Extract Toluene from Heptane, Journal of Chemical and Engineering Data, 60 (2015) 1776-1780.

[38] M. Yamaguchi, Magneto-science magnetic field effects on materials ; fundamentals and applications Springer, Berlin; Heidelberg, 2007. 


\section{Chapter 8}

Conclusions and recommendations 
Separation operations are important for industrial chemical processes, where one or more components need to be purified from the produced mixtures. Among all separation techniques, solvent extraction is often employed for separation of heat-sensitive materials, high-boiling components present in small concentrations in a lower boiling mixture, inorganic substances and close-boiling liquids or azeotropic mixtures. Currently, organic compounds are the most used solvents in industrial extraction processes. However, most of them exhibit a high volatility and flammability (e.g. ethanol), while others are toxic (e.g. tetrachloride-hexane). Some organic solvents are considered as carcinogenic (e.g., benzene and trichloroethylene), while some are confirmed reproductive hazards (e.g., 2-ethoxyethanol and methyl chloride), which makes them unfriendly to human beings and our environment. This thesis aimed to study the feasibility of ionic liquids (ILs) as alternative for organic solvents in three challenging cases.

\subsection{Fractionation of pyrolysis oil}

The work in chapter 2 and 3 showed that ILs applied as solvents have effectively removed aromatics from aqueous fraction of first condenser oil by liquid-liquid extraction, and the detoxified sugar streams were further fermented to ethanol in a close to the theoretical maximum yield, indicating the toxic molecules were extracted effectively. However, only $70 \%$ aromatics were removed by IL $\mathrm{P}_{666,14}\left[\mathrm{~N}(\mathrm{CN})_{2}\right]$ in a single extraction stage, so there is still room for enhancing the extraction yield. Multistage counter-current extraction may be applied for this.

ILs were successfully regenerated by vacuum evaporation of the solutes (aromatics), and the regenerated ILs showed stable extraction performance in four cycles. However, in each regeneration cycle, aromatics were not completely evaporated from the extract; i.e., aromatics were accumulated in the regenerated IL. Furthermore, although the temperature for IL regeneration $\left(220^{\circ} \mathrm{C}\right)$ is lower than the decomposition temperature of $\mathrm{P}_{666,14}\left[\mathrm{~N}(\mathrm{CN})_{2}\right]$ $\left(395^{\circ} \mathrm{C}\right)$ [1], IL may slowly decompose as a result of long time heating [2]. Therefore, more IL recycle rounds need to be conducted in future work to gain the information on the influence of the accumulated aromatics on extraction efficiency of the regenerated ILs, and on the IL stability with long-term heating.

The conceptual process design study showed that an IL-based process $(2.15 \mathrm{MJ} / \mathrm{kg}$ guaiacol) could save approximately $80 \%$ energy and required much less equipment compared to an organic solvent (EA) based process. However, for a comprehensive techno-economic analysis, other factors should also be taken into account, such as material costs, because ILs are often much more expensive than conventional organic solvents. 
For oxygenates extraction from pyrolysis oil cuts, the use of the studied ILs was not beneficial compared to the benchmark organic mixture $(40 \mathrm{wt} \%$ tri- $n$-octylamine in 1-octanol: TOA/1-octanol). Because both ILs and TOA/1-octanol showed high affinity either for HAc and glycolaldehyde or for acetol, none of these solvents could be applied to remove all oxygenates from the aqueous solution in a single extraction step. Furthermore, it was difficult to evaporate oxygenates from phosphonium ILs as a result of strong interactions.

$\operatorname{Hmim}\left[\mathrm{B}(\mathrm{CN})_{4}\right]$ showed the highest distribution coefficient of acetol among all studied solvents in this work as well as the reported solvents [3]. Also $\mathrm{P}_{666,14}$ [Phos] has a 2-4 times higher distribution coefficient of glycolaldehyde than other studied solvents when extracting from single solute solution. Thus, on the basis of the good affinity of the imidazolium ILs for acetol, a two-step extraction process was proposed where $\operatorname{Hmim}\left[\mathrm{B}(\mathrm{CN})_{4}\right]$ can be used to extract acetol and HAc in the first step and be regenerated by evaporation of the solutes, and P666,14[Phos] can be applied to extract glycolaldehyde in the second step and be regenerated by back-extraction with water.

Glycolaldehyde is difficult to be extracted from aqueous solutions due to its strong polarity. The studied ILs in this work and other reported organic solvents exhibited low distribution coefficients of glycolaldehyde $(<1)$ as a result of physical extraction [4, 5]. Reactive extraction with primary amines has achieved high extraction yield of glycolaldehyde, but the regeneration is challenging due to the high stability of the formed Schiff-base [6]. In this work, a new reactive extraction of glycolaldehyde was confirmed by NMR analysis using $\mathrm{P}_{666,14}\left[\mathrm{~N}(\mathrm{CN})_{2}\right]$ in the presence of HAc, and the distribution coefficient of glycolaldehyde was as high as 13 at $40{ }^{\circ} \mathrm{C}$. Unfortunately, the reaction mechanism is not known yet, as well as its reversibility. Further studies on the exact reaction mechanism and investigation on the reversibility of this reaction are suggested for future work. If the reaction is reversible, then IL can be regenerated, so that this IL can be a good candidate for glycolaldehyde extraction.

\subsection{Demulsification of oil-in-water emulsions with ILs}

Surfactants are often injected to the reservoir in chemical enhanced oil recovery (CEOR) techniques. However, the expensive surfactants limit the application of CEOR in real oil industry. Therefore, in this thesis the possibility of surfactant recovery by ionic liquids was investigated. Since the surfactants are usually present in the oil emulsions, here demulsification of oil emulsions was first studied using ILs.

Thirteen ILs including 9 halogenide and 4 non-halogenide ILs were tested for demulsification of heptane-in-water emulsion stabilized by sodium dodecylbenzenesulfonate (SDBS). All halogenide ILs with hydrophobic cations as well as $\mathrm{P}_{666,14}\left[\mathrm{~N}(\mathrm{CN})_{2}\right]$ were found 
to be able to effectively demulsify oil-in-water emulsions, and complete demulsification was observed when equimolar amounts of IL to surfactant were applied. Halogenide ILs showed faster demulsification rate than $\mathrm{P}_{666,14}\left[\mathrm{~N}(\mathrm{CN})_{2}\right]$. However, instead of the desired extraction mechanism, the mechanism was found to be anion exchange between surfactant SDBS and hydrophilic IL anions driven by the release of sodium salt to the aqueous phase, a process with a large Gibbs energy of hydration. Therefore, on the basis of the results in this work, none of the studied ILs could be commercially applied in an economical process, unless the IL could be recovered successfully, e.g., through regeneration of ILs by a reversed ion exchange processes.

\subsection{Development of a fixed liquid extraction process}

A novel separation process concept was explored, named as fixed liquid extraction (FLE) process, aiming to apply liquid-liquid extraction techniques for an extremely small $\mathrm{S} / \mathrm{F}$, where traditional liquid-liquid contacting methods are not suitable. To develop this process, an emulsion system is required to form smaller stable IL drops, and a magnetic setup and magnetic ionic liquids (MILs) are needed to realize fixed liquid in the process.

With regard to the emulsion system, four IL-in-water emulsions stabilized by microgels were prepared and the Sauter mean diameters were in the range of 200-800 $\mu \mathrm{m}$. Stronger power input and higher microgel concentrations resulted in smaller droplets, but still in the range of hundreds of micrometers due to the relatively low microgel concentration. The study on the effect of temperature on drop size distributions confirmed that the formed IL emulsions could be broken on demand, due to the temperature responsive microgels. Studies with much higher particle concentrations are suggested to get more insights in drop size behavior, temperature responsive behavior in such particle stabilized systems.

The comparison of guaiacol extraction from aqueous microgel solutions with extraction where no microgels were involved, showed that the microgels have no influence on the equilibrium extraction yield but slowed down the extraction rate, which was most likely due to the (partly) covered droplet surface with microgels. Therefore, in the emulsion system, smaller droplets do not necessarily indicate larger net contact area for two immiscible phases.

Prior to the development of the FLE process, the magnetic field effect on liquid-liquid equilibrium of heptane-toluene-MIL was studied in a magnetic field of $1 \mathrm{~T}$ at room temperature. No magnetic field effect was observed, which could be explained by the low magnetic energy, as compared to the thermal energy. 
A FLE process was then designed with the aid of a magnetic field which could successfully fixate MIL emulsion droplets by magnetic force in the center of the gap between two magnets. It was clearly shown that the designed process could be used for MIBK removal from aqueous solutions, but further tuning of the process is required in the future towards a process with smaller droplets and faster mass transfer.

\subsection{Recommendations}

It is known that ILs have unique physicochemical properties and are considered as environmentally friendly solvents. Their designability allows them to be applied in various fields as an alternative for organic solvents. However, for the design of an industrial scale process for solvent extraction using ILs, several factors still need to be studied:

1) IL regeneration. Full recovery of ILs for an economical process design is desired. Therefore, it is suggested that not only the application of ILs, but also the followed regeneration steps need to be investigated in future research.

2) Transport phenomenon. Often ILs have high viscosity, which may result in technical difficulties, e.g. with pumping and mixing, slow mass transfer rate. Furthermore the chance of forming stable emulsions that cannot be demulsified on demand will increase the phase separation time.

3) Long term thermal stability. ILs are often claimed as thermally stable on the basis of their high decomposition temperatures $\left(\mathrm{T}_{\mathrm{d}}\right)$ which are obtained from the thermogravimetric analysis (TGA) often with heating rate of $10{ }^{\circ} \mathrm{C} / \mathrm{min}$. However, ILs can also decompose at temperatures lower than $T_{d}$ with long term isothermal heating [7]. Therefore, when ILs are applied at high temperature for longer terms, it is necessary to perform isothermal TGA measurements to gain the information of long term thermal stability of ILs.

When all the above mentioned factors are taken into account, and indeed ILs have long term thermal stability and can be regenerated effectively, then ILs can be considered for an industrial process design.

\section{References}

[1] R.E. Del Sesto, C. Corley, A. Robertson, J.S. Wilkes, Tetraalkylphosphonium-based ionic liquids, Journal of Organometallic Chemistry, 690 (2005) 2536-2542.

[2] J. Salgado, M. Villanueva, J.J. Parajo, J. Fernandez, Long-term thermal stability of five imidazolium ionic liquids, Journal of Chemical Thermodynamics, 65 (2013) 184-190. 
[3] C.B. Rasrendra, B. Girisuta, H.H. van de Bovenkamp, J.G.M. Winkelman, E.J. Leijenhorst, R.H. Venderbosch, M. Windt, D. Meier, H.J. Heeres, Recovery of acetic acid from an aqueous pyrolysis oil phase by reactive extraction using tri-n-octylamine, Chem. Eng. J., 176 (2011) 244-252.

[4] C.R. Vitasari, G.W. Meindersma, A.B. de Haan, Glycolaldehyde co-extraction during the reactive extraction of acetic acid with tri-n-octylamine/2-ethyl-1-hexanol from a wood-based pyrolysis oil-derived aqueous phase, Separation and Purification Technology, 95 (2012) 3943.

[5] C.R. Vitasari, G.W. Meindersma, A.B. de Haan, Laboratory scale conceptual process development for the isolation of renewable glycolaldehyde from pyrolysis oil to produce fermentation feedstock, Green Chemistry, 14 (2012) 321-325.

[6] C.R. Vitasari, G.W. Meindersma, A.B. de Haan, Renewable glycolaldehyde isolation from pyrolysis oil-derived aqueous solution by reactive extraction with primary amines, Separation and Purification Technology, 95 (2012) 103-108.

[7] C. Maton, N. De Vos, C.V. Stevens, Ionic liquid thermal stabilities: decomposition mechanisms and analysis tools, Chemical Society Reviews, 42 (2013) 5963-5977. 


\section{Appendix A}

\section{Supplementary information of Chapter 2}

In this supplementary, the following contents are presented: $\sigma$-Profiles of IL anions obtained by COSMO-RS (Figure S2.1); Liquid-liquid equilibrium data for ternary system EA + guaiacol + $\mathrm{H} 2 \mathrm{O}$ (Table S2.1); NRTL binary parameters for the ternary system EA + guaiacol $+\mathrm{H} 2 \mathrm{O}$ (Table S2.2); Optimization for DST1 and DST2 columns in Process with EA solvent (Figure S2.2-S2.6); Liquid-liquid equilibrium data for ternary system $\mathrm{P}_{666,14}\left[\mathrm{~N}(\mathrm{CN})_{2}\right]+$ guaiacol $+\mathrm{H} 2 \mathrm{O}$ (Table S2.3); Thermodynamics properties of guaiacol, water and $\mathrm{P}_{666,14}\left[\mathrm{~N}(\mathrm{CN})_{2}\right]$ used for energy consumption calculation (Table S2.4). 


\section{S2.1. $\sigma$-Profiles of guaiacol, levoglucosan, water and IL anions obtained by COSMO-RS}

$\sigma$-Profiles $p(\sigma)$ describe the quantity of surface with screening charge polarity $\sigma$ on the surface of the molecule. The $\sigma$-profiles and COSMO-cavities of guaiacol, levoglucosan and water are shown in Figure S2.1. The entire $\sigma$-profile of water spans the range of $-0.020<\mathrm{e} / \AA^{2}$ $<0.022$. Two major peaks are arising from the negative charged regions of the oxygen atom (thus at a positive value of $\sigma$ due to the larger electron density) and from the positively charged hydrogen atoms (thus at negative values of $\sigma$ ). Generally, the $\sigma$-regions beyond \pm 0.01 e/ $\AA^{2}$ are considered as strongly polar and potentially hydrogen bonding (HB), and the rest as weakly polar or non-polar. Therefore, the surface with charge below $-0.01 \mathrm{e} / \AA^{2}$ is considered as a HB donor region, while the HB acceptor region is located above $+0.01 \mathrm{e} / \AA^{2}$. The $\sigma$ profile of guaiacol shows its hydrophobicity, since the $\sigma$-surface is mainly located in the nonpolar region. However, the hydroxyl hydrogen shows a peak at $-0.017 \mathrm{e} / \AA^{2}$, which can be HB donor. As for levoglucosan, the peak at $+0.014 \mathrm{e} / \AA^{2}$ results from the negative charged surfaces of the hydroxyl oxygens, and the peak at $-0.015 \mathrm{e} / \AA^{2}$ is caused by the electron deficiency on the surfaces of hydroxyl hydrogen atoms. Having three HB donor and three $\mathrm{HB}$ acceptor regions, and in addition a smaller surface area in the hydrophobic region than guaiacol, it follows that levoglucosan should be much more hydrophilic than guaiacol.

$p(\sigma)$ of IL anions obtained by COSMO-RS are shown in Figure S2.2. From the $\sigma$-profiles, it follows that the polarity of the anions ranks as follows: Phos $>\mathrm{Cl}>\mathrm{N}(\mathrm{CN})_{2}>\mathrm{B}(\mathrm{CN})_{4}>$ $\mathrm{NTf}_{2}>\mathrm{PF}_{6}$. 


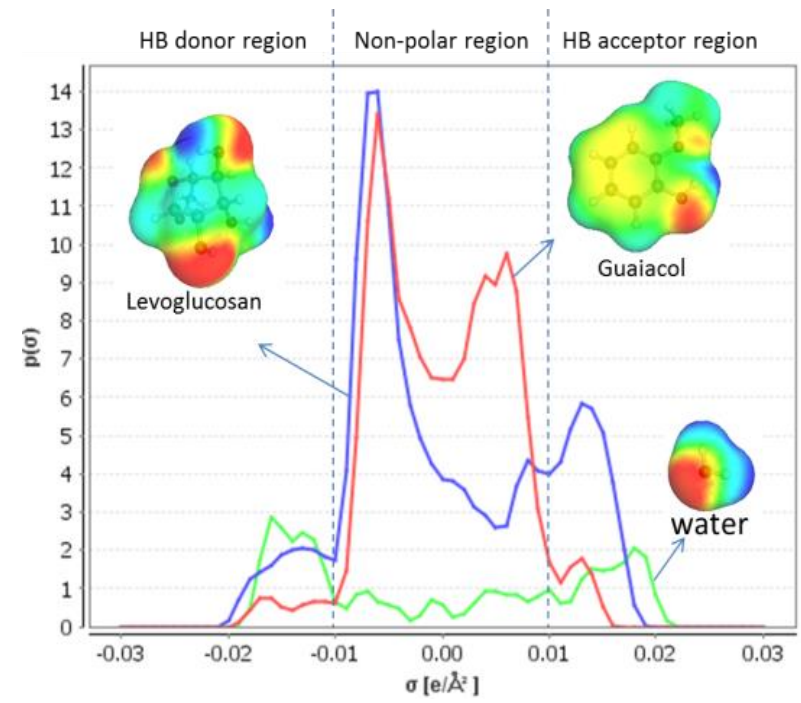

Figure S2.1. $\sigma$-Profiles and COSMO-cavities of guaiacol, levoglucosan and water. The blue color indicates a negative screening charge resulting from positive partial charges within the molecule. The red color indicates a positive screening charge resulting from electronegative surface elements, and green corresponds to almost neutral charges

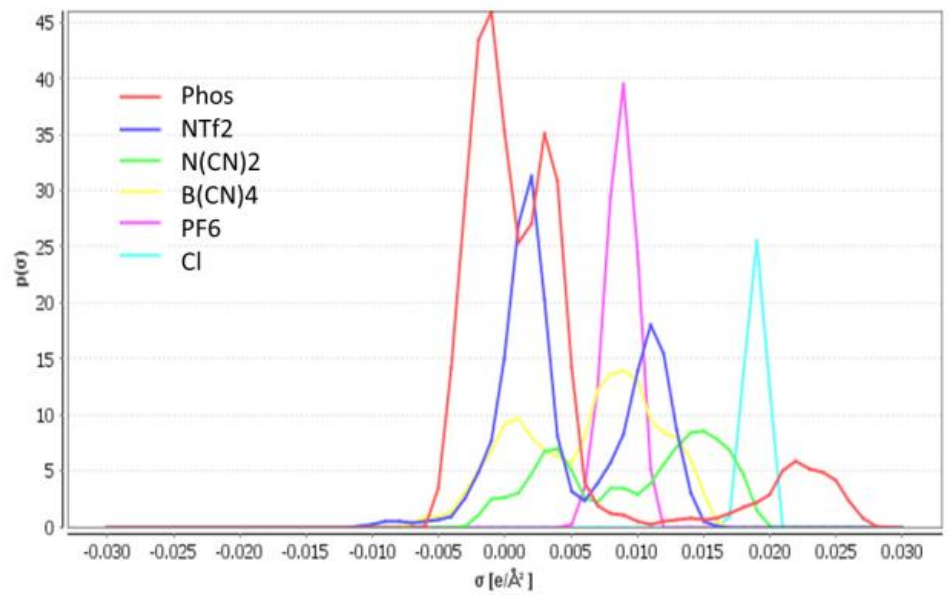

Figure S2.2. $\sigma$-Profiles of IL anions obtained by COSMO-RS 


\section{S2.2. Liquid-liquid equilibrium data for ternary system EA + guaiacol + H2O}

The experimental ternary phase diagram was developed by contacting water with guaiacol solutions in ethyl acetate (EA) with guaiacol mass fractions of $0.05<\mathrm{x}<0.95$ at room temperature at a mass ratio of 0.5 (EA phase / water). After mixing for 30 minutes, the phases were separated by centrifuging for $5 \mathrm{~min}$ at $9000 \mathrm{rpm}$. Both phases were analyzed by HPLC to obtain the guaiacol concentration, and by Karl Fischer to get the $\mathrm{H}_{2} \mathrm{O}$ concentration. The ternary equilibrium data are listed in Table S2.1.

Table S2.1. Experimental data (relative standard deviation $<3 \%$ ) for ternary system $\mathrm{EA}+$ guaiacol $+\mathrm{H}_{2} \mathrm{O}$ based on mole fraction

\begin{tabular}{rrrrrr}
\hline$x_{E A}^{a q}$ & $x_{g u a i}^{a q}$ & $x_{\mathrm{H}_{2} \mathrm{O}}^{a q}$ & $x_{E A}^{E A}$ & $x_{\text {guai }}^{E A}$ & $x_{\mathrm{H}_{2} \mathrm{O}}^{E A}$ \\
\hline 0.0011 & 0.0031 & 0.9958 & 0.0506 & 0.6962 & 0.2532 \\
0.0024 & 0.0028 & 0.9948 & 0.1307 & 0.6265 & 0.2428 \\
0.0038 & 0.0026 & 0.9936 & 0.203 & 0.5587 & 0.2383 \\
0.0055 & 0.0023 & 0.9923 & 0.2791 & 0.4771 & 0.2438 \\
0.0072 & 0.0019 & 0.9909 & 0.363 & 0.4067 & 0.2303 \\
0.0091 & 0.0016 & 0.9894 & 0.4494 & 0.3275 & 0.2231 \\
0.0108 & 0.0012 & 0.9880 & 0.5370 & 0.2510 & 0.2120 \\
0.0127 & 0.0008 & 0.9865 & 0.6305 & 0.1720 & 0.1974 \\
0.0144 & 0.0004 & 0.9852 & 0.7316 & 0.0948 & 0.1736 \\
0.0148 & 0.0003 & 0.9849 & 0.7851 & 0.0606 & 0.1544 \\
\hline
\end{tabular}




\section{S2.3. NRTL model fitting for $\mathrm{EA}+$ guaiacol $+\mathrm{H}_{2} \mathrm{O}$}

The full ternary phase diagram was experimentally investigated, and a thermodynamic description of the system EA + guaiacol $+\mathrm{H}_{2} \mathrm{O}$ was developed using the NRTL model.

This included fitting the binary interaction parameters in equation (S2.1) for the NRTL model, which was done using the ASPEN PLUS Data Regression tool. The regressed parameters are presented in Table S2.2.

$$
\tau_{i j}=a_{i j}+\frac{b_{i j}}{T}, G_{i j}=\exp \left(\alpha_{i j} \tau_{i j}\right), \alpha_{i j}=\alpha_{j i}
$$

Table S2.2. NRTL binary parameters for the ternary LLE data of the system (EA + guaiacol $+\mathrm{H} 2 \mathrm{O}$ )

\begin{tabular}{lccccc}
\hline System & $\mathrm{a}_{12}$ & $\mathrm{a}_{21}$ & $\mathrm{~b}_{12}$ & $\mathrm{~b}_{21}$ & $\alpha$ \\
\hline EA (1) - H2O (2) ${ }^{\mathrm{a}}$ & $-3,7198$ & 9,4632 & 1286,14 & $-1705,6$ & 0,2 \\
EA (1) - Guaiacol (2) & 0 & 0 & 1487,5 & 265,7 & 0,3 \\
Guaiacol (1) -H2O (2) & 0 & 0 & $-1.859,7$ & 1390,6 & $-0,055$ \\
\hline
\end{tabular}

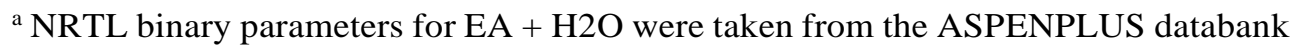
"APV84 LLE-ASPEN" in version 8.4.

The $r R M S D$ was calculated to describe the goodness of the NRTL model agreement with the experimental data. The rRMSD is defined as

$$
r R M S D=\sqrt{\frac{\sum_{i}^{N}\left(\frac{x^{e x p}-x^{c a l}}{x^{e x p}}\right)^{2}}{n}}
$$

where $n$ represents the number of data points and $x$ is the mole fraction. From the agreement between the experimental and calculated ternary diagrams in Figure 5, it was concluded that the NRTL model properly describes the experimental ternary data of system $\mathrm{EA}+$ guaiacol $+\mathrm{H}_{2} \mathrm{O}$, this was confirmed by the $r R M S D$ of 0.041 . 


\section{S2.4. Minimum S/F ratio calculation for Process with EA solvent}

All the calculations are based on the following four assumptions.

1) the resulting extract flow approximately equals the solvent flow and the raffinate flow approximately equals the feed flow;

2) the incoming feed is in equilibrium with the outgoing extract stream;

3) $99.995 \%$ of the solute was extracted by the solvent;

4) the extraction was operated at $20{ }^{\circ} \mathrm{C}$

According to the equation S2.3

$$
S_{\text {min }}=F \frac{X_{\text {in }}-X_{\text {out }}}{Y_{\text {out }, \text { max }}-Y_{\text {in }}} \quad \text { with } Y_{\text {out }, \text { max }}=D X_{\text {in }}
$$

where $S_{\text {min }}$ is the minimum solvent, $F$ is Feed, $X_{\text {in }}, X_{\text {out }}, Y_{\text {out } \max }, Y_{\text {in }}$ is solute weigh ratio in feed, raffinate, extract, solvent respectively, and $\mathrm{D}$ is the distribution coefficient.

In our case, $X_{\text {in }}$ is 0.015 and $\mathrm{D}$ is 44.7 , then $Y_{\text {out,max }}$ can be calculated and therefore minimum solvent $\mathrm{S} / \mathrm{F}$ ratio is 0,022 . A reasonable starting value for $\mathrm{S} / \mathrm{F}$ is usually $1.5 * \mathrm{~S} / \mathrm{Fmin}$ which is 0.034 . However, the solubility of EA in water is $83 \mathrm{~g} / \mathrm{L}$, so to get good phase separation after extraction, $\mathrm{S} / \mathrm{F}$ ratio 0.2 was used to calculate other streams. 


\section{S2.5. Optimization for DST1 and DST2 columns in Process with EA solvent}

To calculate the energy consumption for ethyl acetate recovery by distillation, the distillation columns were simulated in ASPEN Plus. Without thoroughly optimizing the required number of equilibrium stages (NTS), the DST1 column was simulated with NTS = 20 , and the feed stream added above the $10^{\text {th }}$ stage. The liquid compositions of the three components through the column are shown in Figure S2.3. From the graph, it can be seen that stages 11-20 do not contribute to the separation. Therefore the NTS was decreased and after some iterations, NTS was set to 8 , as there were useless stages when NTS $>8$. The feed stream was added above the $5^{\text {th }}$ stage. The liquid compositions of three components throughout the column are shown in Figure S2.4 for NTS $=8$.

The distillation column DST1 was modeled for different distillate rates and reflux ratios (R) to investigate whether these ratios have a large effect on the solvent recovery efficiency and reboiler heat duty, keeping the makeup solvent flow EA $=1 \mathrm{~kg} / \mathrm{h}$, feed flow $=1000 \mathrm{~kg} / \mathrm{h}$ and for DST2 column distillate rate $=86 \mathrm{~kg} / \mathrm{h}$ and $\mathrm{R}=0.5$. Firstly, the $\mathrm{R}$ of DST 1 was set as 0.1 to evaluate the effect of distillate rate. The results for solvent (EA) recovery efficiency and reboiler heat duty for DST1 column as function of distillate rate are shown in Figure S2.5. Both the solvent recovery efficiency and reboiler heat duty increase with the increase of distillate rate. To recovery $99 \%$ of solvent EA, the distillate rate needs to be $124 \mathrm{~kg} / \mathrm{h}$.

Secondly, the effect of $\mathrm{R}$ was evaluated based on the distillate rate $124 \mathrm{~kg} / \mathrm{h}$. The results for solvent recovery efficiency and reboiler heat duty for DST1 column as function of R are shown in Figure S2.6. The solvent recovery efficiency was hardly dependent on the R and kept at $99.23 \%$, while the Qreb increased with increasing R. Therefore, the minimum R 0.1 was chosen for DST1.

The optimization of DST2 column was done by the same method as for DST1 column, the NTS 8 was used and the feed stream was added on the stage 5 . Then the same method was used to optimize the R for DST2 column, on a basis of a distillate rate of $86 \mathrm{~kg} / \mathrm{h}$ which is shown in Figure $\mathrm{S} 2.7 . \mathrm{R}=0.5$ was needed to recovery $99.9 \%$ solvent EA. When $\mathrm{R}$ was set as 0.5 , the distillate rate could only be 87 or $86 \mathrm{~kg} / \mathrm{h}$ to make the process continuously running. A distillate rate of $86 \mathrm{~kg} / \mathrm{h}$ was chosen for DST2, since it meets the requirement of $99.9 \%$ solvent recovery and shows a lower Qreb. 


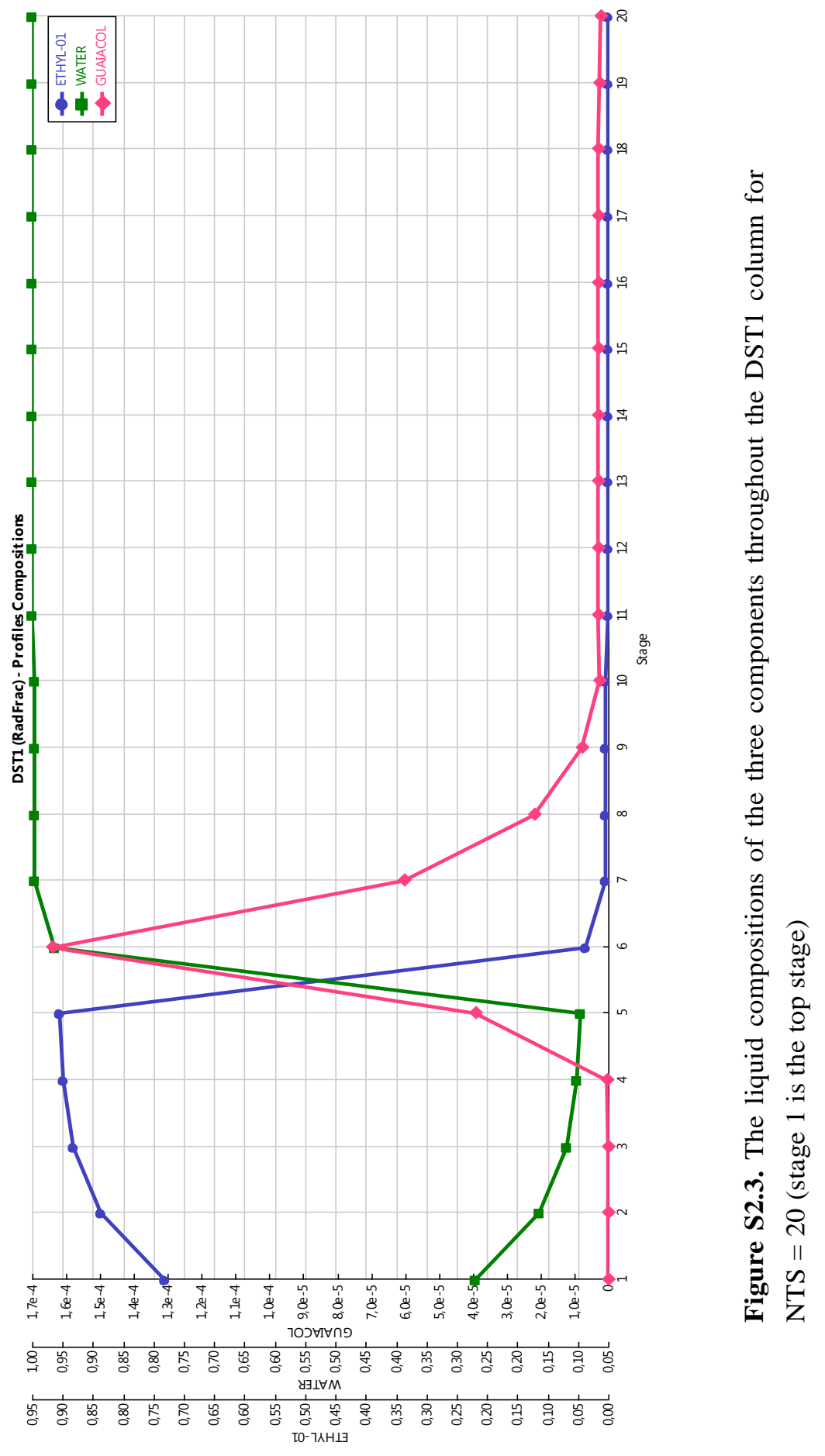




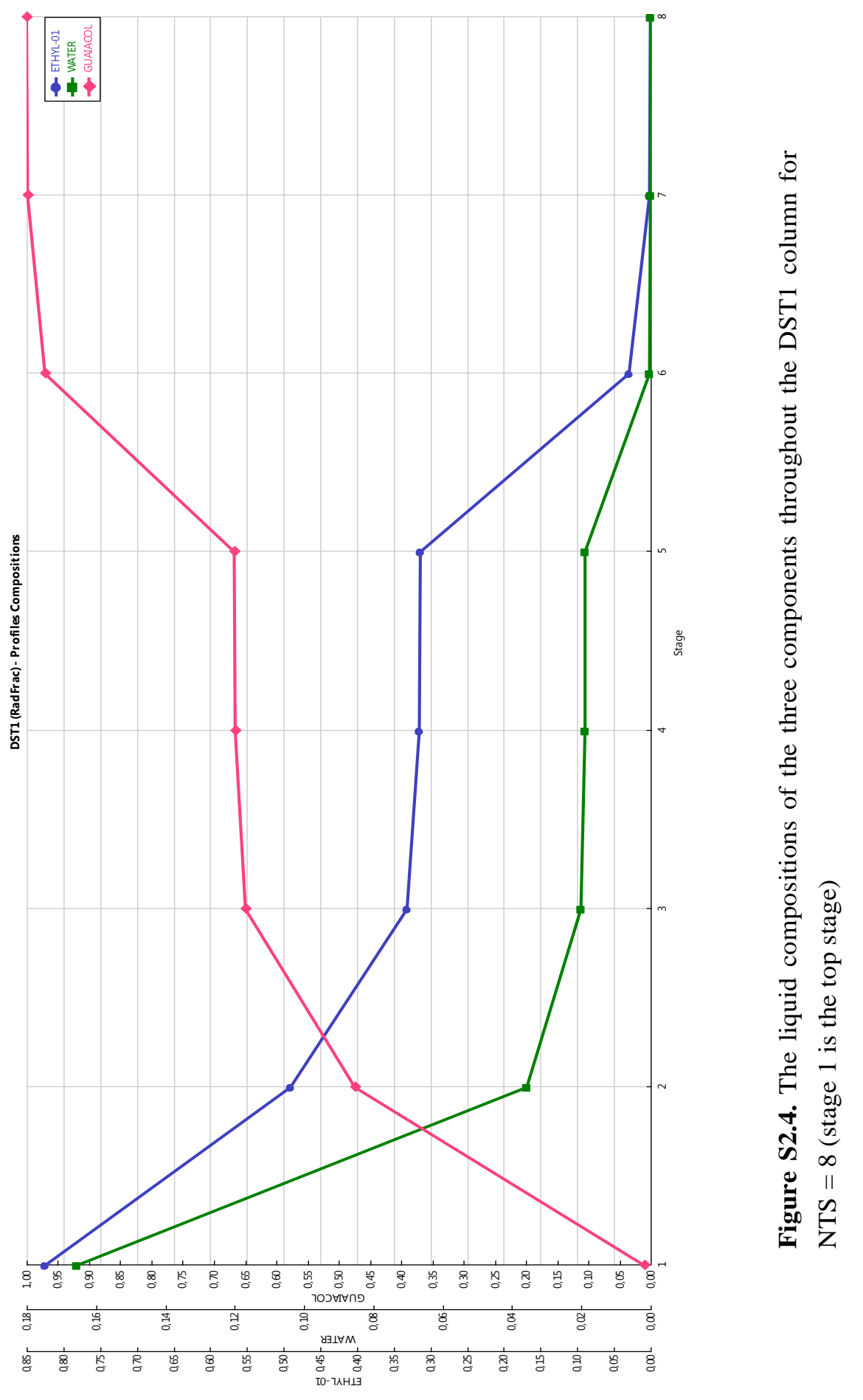



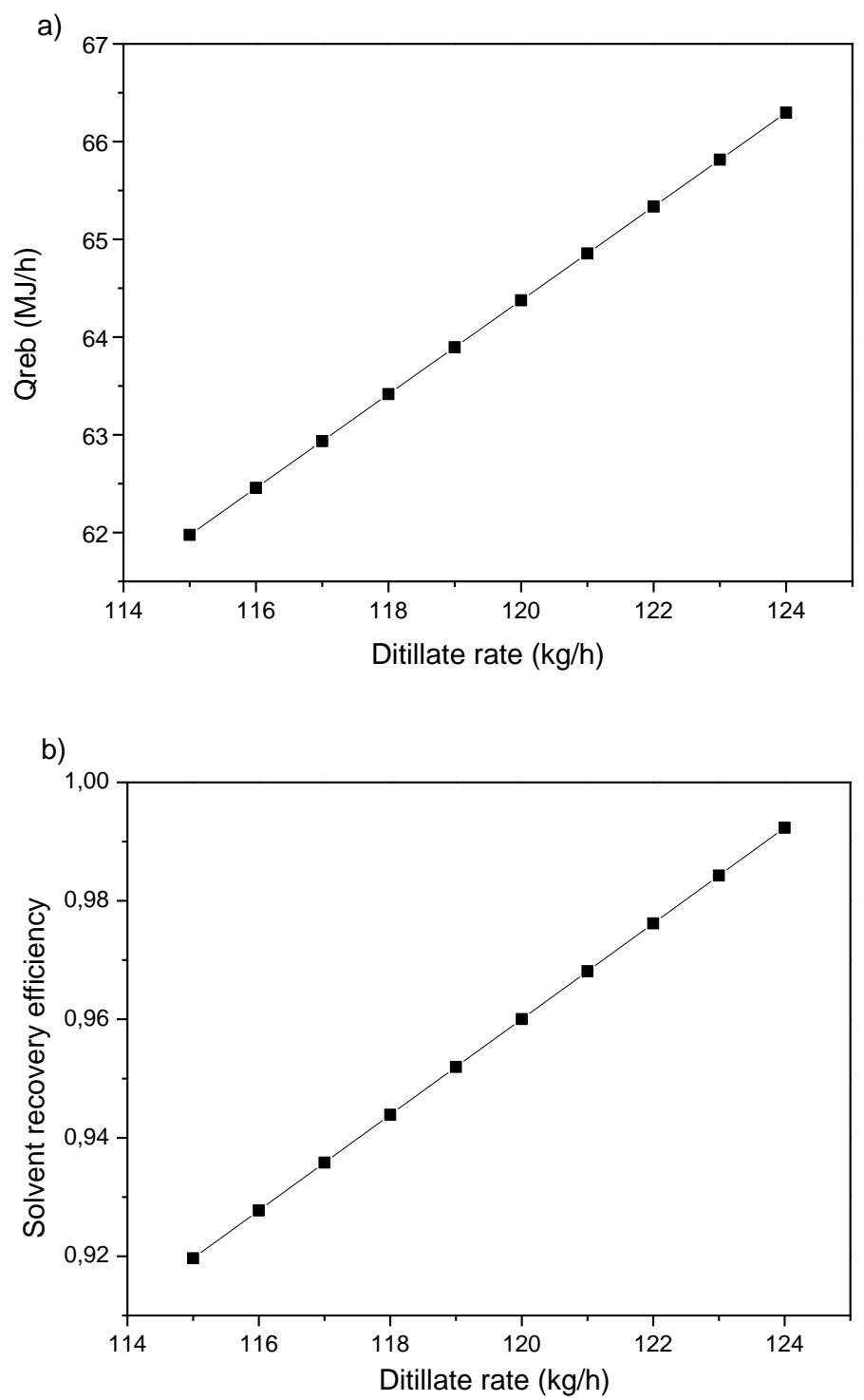

Figure S2.5. a) reboiler heat duty Qreb and b) solvent recovery efficiency of DST1 column as function of Distillate rate, based on $\mathrm{R}=0.1$ for DST1. 

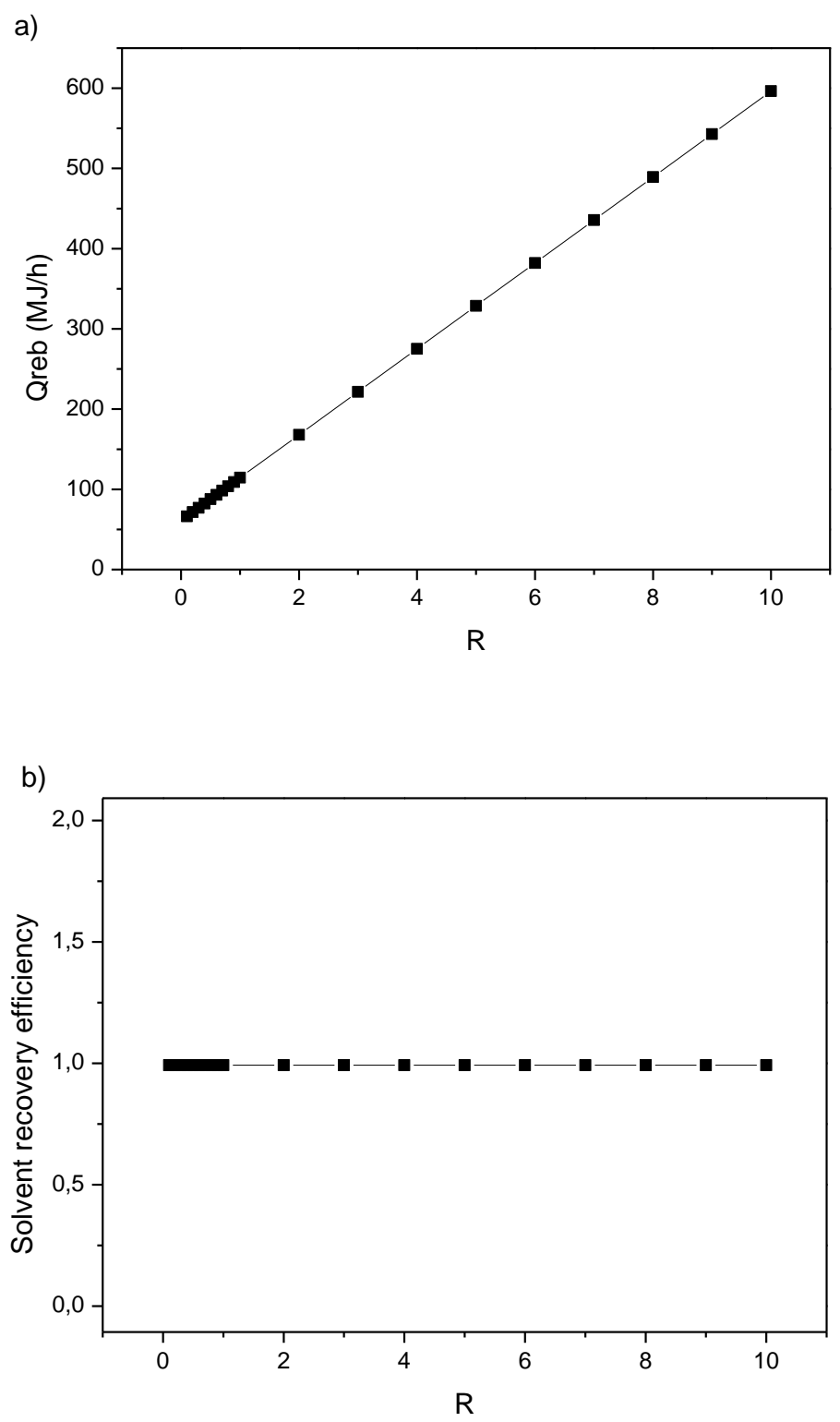

Figure S2.6. a) reboiler heat duty Qreb and b) solvent recovery efficiency of DST1 column as function of reflux ratio $\mathrm{R}$, based on distillate rate $124 \mathrm{~kg} / \mathrm{h}$ for DST1. 

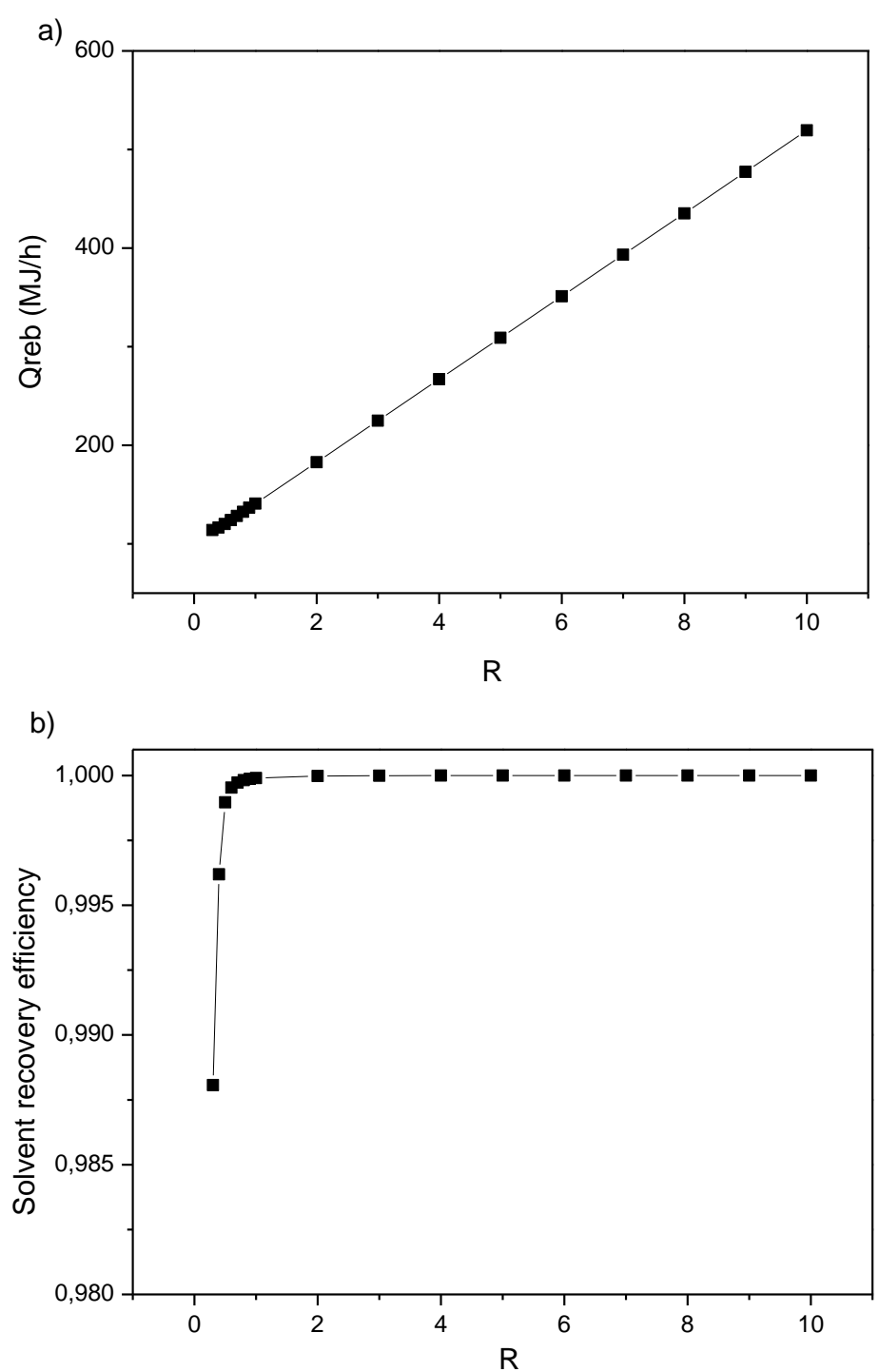

Figure S2.7. a) reboiler heat duty Qreb and b) solvent recovery efficiency of DST2 column as function of reflux ratio $\mathrm{R}$, based on distillate rate $86 \mathrm{~kg} / \mathrm{h}$ for DST2. 


\section{S2.6. Liquid-liquid equilibrium data for ternary system $\mathrm{P}_{666,14}\left[\mathrm{~N}(\mathrm{CN})_{2}\right]$ + guaiacol $+\mathrm{H}_{2} \mathrm{O}$}

Liquid-liquid extraction experiments for this system were similar as for system EA + guaiacol $+\mathrm{H}_{2} \mathrm{O} . \mathrm{P}_{666,14}\left[\mathrm{~N}(\mathrm{CN})_{2}\right]$ and guaiacol solutions in the IL with guaiacol mass fractions of $0.05<x<0.95$ were mixed with water at a mass ratio of 0.5 (IL phase / water) for $30 \mathrm{~min}$, then centrifuged for 5 min to get two separated phases. The aqueous phase was analyzed by HPLC to determine the guaiacol content, and both phased were analyzed by Karl Fischer to determine the water content. The guaiacol content in the IL phase was determined by mass balance. The equilibrium results are shown in Table S2.3.

Table S2.3. Experimental data for ternary system $\mathrm{P}_{666,14}\left[\mathrm{~N}(\mathrm{CN})_{2}\right]+$ guaiacol $+\mathrm{H} 2 \mathrm{O}$ based on mass fraction (relative standard deviations are lower than $3 \%$ )

\begin{tabular}{lrrrrrr}
\hline $\begin{array}{l}x_{I L}^{a q} \\
(\mathrm{ppm})\end{array}$ & $x_{\text {guai }}^{a q}$ & $x_{H_{2} O}^{a q}$ & $x_{I L}^{I L}$ & $x_{\text {guai }}^{I L}$ & $x_{H_{2} O}^{I L}$ & $\mathrm{D}_{\text {guai }}$ \\
\hline $46 \pm 10$ & 0.00035 & 0.9996 & 0.9237 & 0.0496 & 0.0267 & 142 \\
$50 \pm 2$ & 0.00087 & 0.9991 & 0.8785 & 0.0977 & 0.0238 & 112 \\
$53 \pm 0$ & 0.00244 & 0.9975 & 0.7912 & 0.1905 & 0.0183 & 78 \\
$50 \pm 2$ & 0.00566 & 0.9943 & 0.6907 & 0.2928 & 0.0165 & 52 \\
$62 \pm 5$ & 0.01033 & 0.9896 & 0.5884 & 0.3961 & 0.0155 & 38 \\
$83 \pm 1$ & 0.0149 & 0.9850 & 0.4842 & 0.4978 & 0.0181 & 33 \\
$83 \pm 4$ & 0.01853 & 0.9814 & 0.3895 & 0.5901 & 0.0205 & 32 \\
$80 \pm 1$ & 0.02113 & 0.9788 & 0.2719 & 0.7053 & 0.0228 & 33 \\
$80 \pm 2$ & 0.02272 & 0.9772 & 0.1433 & 0.8277 & 0.0290 & 36 \\
$89 \pm 1$ & 0.02421 & 0.9757 & 0.0989 & 0.8655 & 0.0355 & 36 \\
\hline
\end{tabular}




\section{S2.7. NTS of extraction column for process with IL as solvent}

The NTS of an extraction process with IL as solvent was calculated using equations (S2.4) and (S2.5)

$$
\begin{gathered}
\frac{x_{R}}{x_{F}}=\frac{E-1}{E^{N+1}-1} \\
E=D \frac{S}{F}
\end{gathered}
$$

where $x_{\mathrm{R}}$ and $x_{\mathrm{F}}$ are the guaiacol concentrations in the raffinate and feed stream, respectively, and $\mathrm{N}$ is the number of stages. $\mathrm{E}$ is the extraction factor and $\mathrm{S} / \mathrm{F}$ is solvent to feed ratio. $\mathrm{D}$ is the distribution coefficient, for which 50 was taken as it is the average value for a multistage extraction.

In the extraction case, $x_{\mathrm{F}}$ was 0.015 , the required $x_{\mathrm{R}}$ was 0.00005 and $\mathrm{S} / \mathrm{F}$ was 0.045 , then the calculated $\mathrm{N}$ amounts to 6.31. Therefore, the required NTS was 7.

\section{S2.8. Thermodynamics properties of water, guaiacol and $P_{666,14}\left[N(C N)_{2}\right]$}

Thermodynamics properties of water, guaiacol and $\mathrm{P}_{666,14}\left[\mathrm{~N}(\mathrm{CN})_{2}\right]$ are shown in Table S2.4.

Table S2.4. Thermodynamics properties of water, guaiacol and $\mathrm{P}_{666,14}\left[\mathrm{~N}(\mathrm{CN})_{2}\right]$

\begin{tabular}{lccc}
\hline Compounds & $\mathrm{C}_{\mathrm{p}}(\mathrm{J} /(\mathrm{g} \cdot \mathrm{K}))$ & $\Delta \mathrm{H}_{\mathrm{vap}}(\mathrm{J} / \mathrm{g})$ & $\mathrm{T}_{b}\left({ }^{\circ} \mathrm{C}\right)$ \\
\hline Water & 4,18 & 2260 & 100 \\
Guaiacol & 1,98 & 371 & 205 \\
$\mathrm{P}_{666,14}\left[\mathrm{~N}(\mathrm{CN})_{2}\right]$ & 2,18 & & $>300$ \\
\hline
\end{tabular}




\section{Appendix B}

\section{Supplementary information of Chapter 4}

In this supplementary information, the following contents are presented: 1 . the $\sigma$-Profiles of acetic acid (HAc), glycolaldehyde (gly), acetol and IL anions obtained by COSMO-RS; 2. the NMR spectra of the binary mixtures and the ternary mixture of HAc, gly and $\mathrm{P}_{666,14}\left[\mathrm{~N}(\mathrm{CN})_{2}\right] ; 3$. the proposed reaction mechanism of reactive extraction of gly and HAc with $\mathrm{P}_{666,14}\left[\mathrm{~N}(\mathrm{CN})_{2}\right]$. 


\section{S4.1. $\sigma$-Profiles of HAc, gly, acetol and IL anions obtained by COSMO- RS}

$\sigma$-Profiles $p(\sigma)$ describe the quantity of surface with screening charge polarity $\sigma$ on the surface of the molecule. The $\sigma$-profiles of oxygenates HAc, gly and acetol are shown in Figure S4.1. Generally, the $\sigma$-regions beyond $\pm 0.01 \mathrm{e} / \AA^{2}$ are considered as strongly polar and potentially hydrogen bonding (HB), and the rest as weakly polar or non-polar. Therefore, the surface with charge below $-0.01 \mathrm{e} / \AA^{2}$ is considered as a HB donor region, while the HB acceptor region is located above $+0.01 \mathrm{e} / \AA^{2}$. The $\sigma$-profile of HAc shows its strongest surface polarity, resulting from the hydroxyl hydrogen with a peak from -0.015 to $-0.022 \mathrm{e} / \AA^{2}$ which can be a strong HB donor. As for gly and acetol, both of them have the positively charged surface at $-0.013 \mathrm{e} / \AA^{2}$ which indicates they have similar surface polarity and both can be HB donors. Also the less positively charged surfaces imply that they both have less polarity than HAc. Therefore, the order of HB donating properties of the solutes is: HAc $>$ Gly $\approx$ acetol.

The $p(\sigma)$ of IL anions obtained by COSMO-RS are shown in Figure S4.2. From the $\sigma$ profiles, it follows that the polarity of the anions (the $\mathrm{HB}$ accepting properties) ranks as follows: $\mathrm{Phos}>\mathrm{Cl}>\mathrm{N}(\mathrm{CN})_{2}>\mathrm{B}(\mathrm{CN})_{4}$.

\section{S4.2. ${ }^{13} \mathrm{C}$ NMR and ${ }^{1} \mathrm{H}$ NMR spectra of the binary mixtures and the ternary mixture of $\mathrm{P}_{666,14}\left[\mathrm{~N}(\mathrm{CN})_{2}\right]$, HAc and gly}

The ${ }^{13} \mathrm{C}$ NMR spectra of the binary mixtures, HAc $+\mathrm{P}_{666,14}\left[\mathrm{~N}(\mathrm{CN})_{2}\right]$, gly $+\mathrm{P}_{666,14}\left[\mathrm{~N}(\mathrm{CN})_{2}\right]$, $\mathrm{HAc}+$ gly and the ternary mixture $\mathrm{HAc}+$ gly $+\mathrm{P}_{666,14}\left[\mathrm{~N}(\mathrm{CN})_{2}\right]$, are shown in Figure S4.3, and the ${ }^{1} \mathrm{H}$ NMR spectra of these mixtures are shown in Figure S4.4. Compared with the NMR spectra of the pure components (not shown here), the chemical shifts for specific groups are obtained and shown on the spectra. Due to the existence of gly-monomer and various molecular species of gly-dimers, which is well known for gly [1], the NMR spectra for gly are complicate. Multiple peaks are generated from gly at $\delta=60-105$ in ${ }^{13} \mathrm{C}$ NMR in Figure S4.3b. However, it is obvious that both ${ }^{13} \mathrm{C}$ NMR and ${ }^{1} \mathrm{H}$ NMR spectra of the binary mixtures are only the combination of pure components, but the spectra of the ternary mixture have new emerging and diminishing peaks shown in Figure S4.3d and Figure S4.4c. 


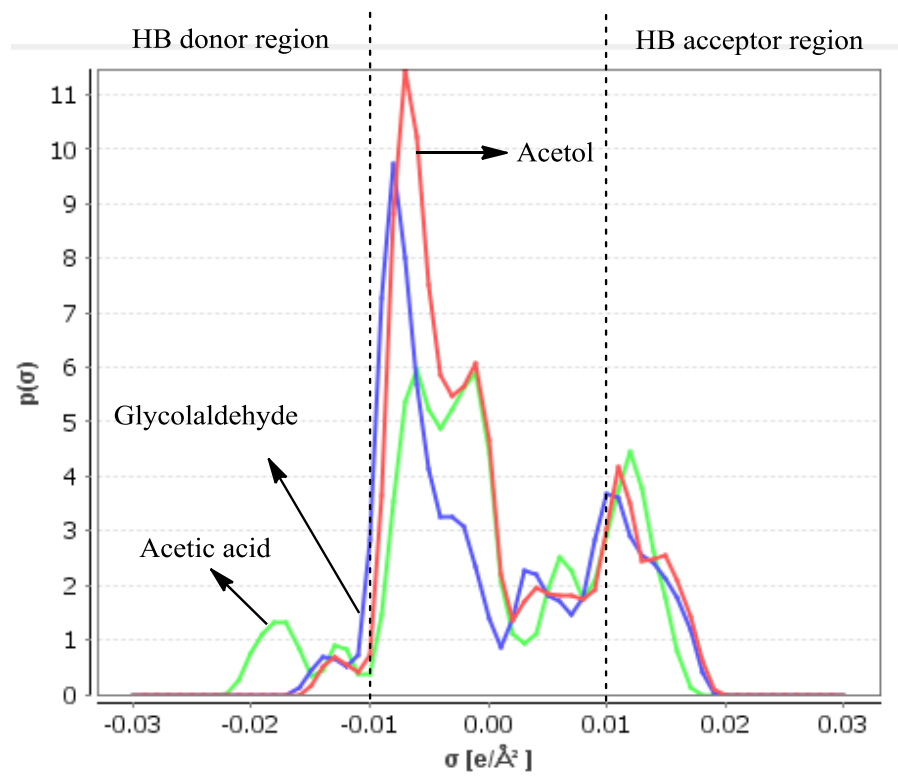

Figure S4.1. $\sigma$-profiles of acetic acid, glycolaldehyde and acetol.

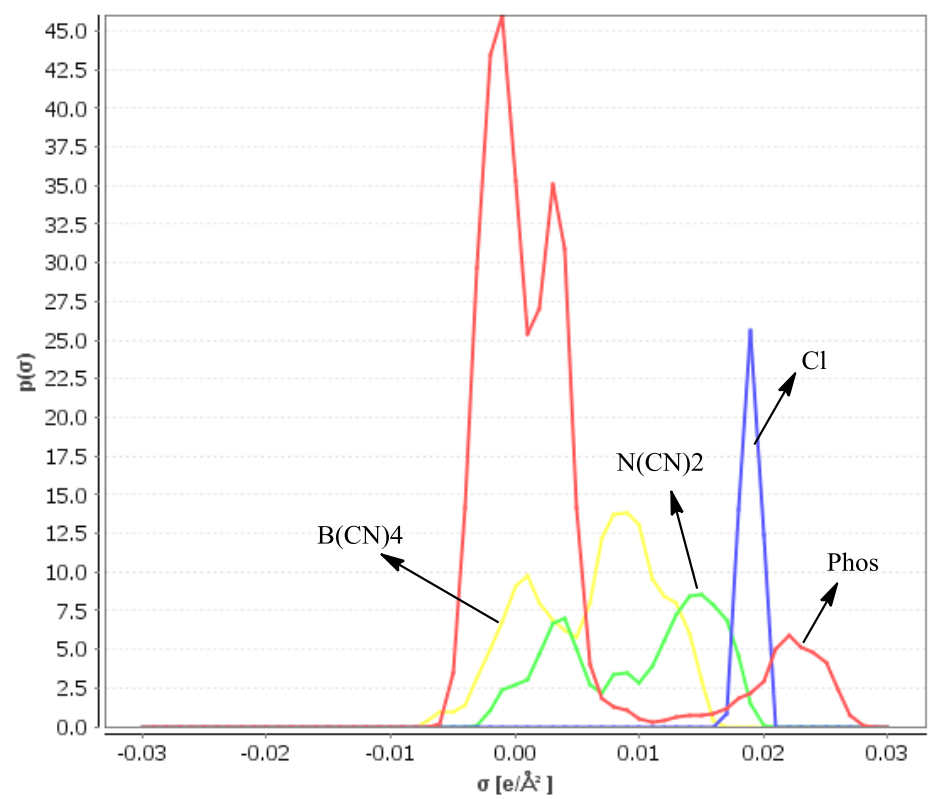

Figure S4.2. $\sigma$-profiles of anions of ILs. 

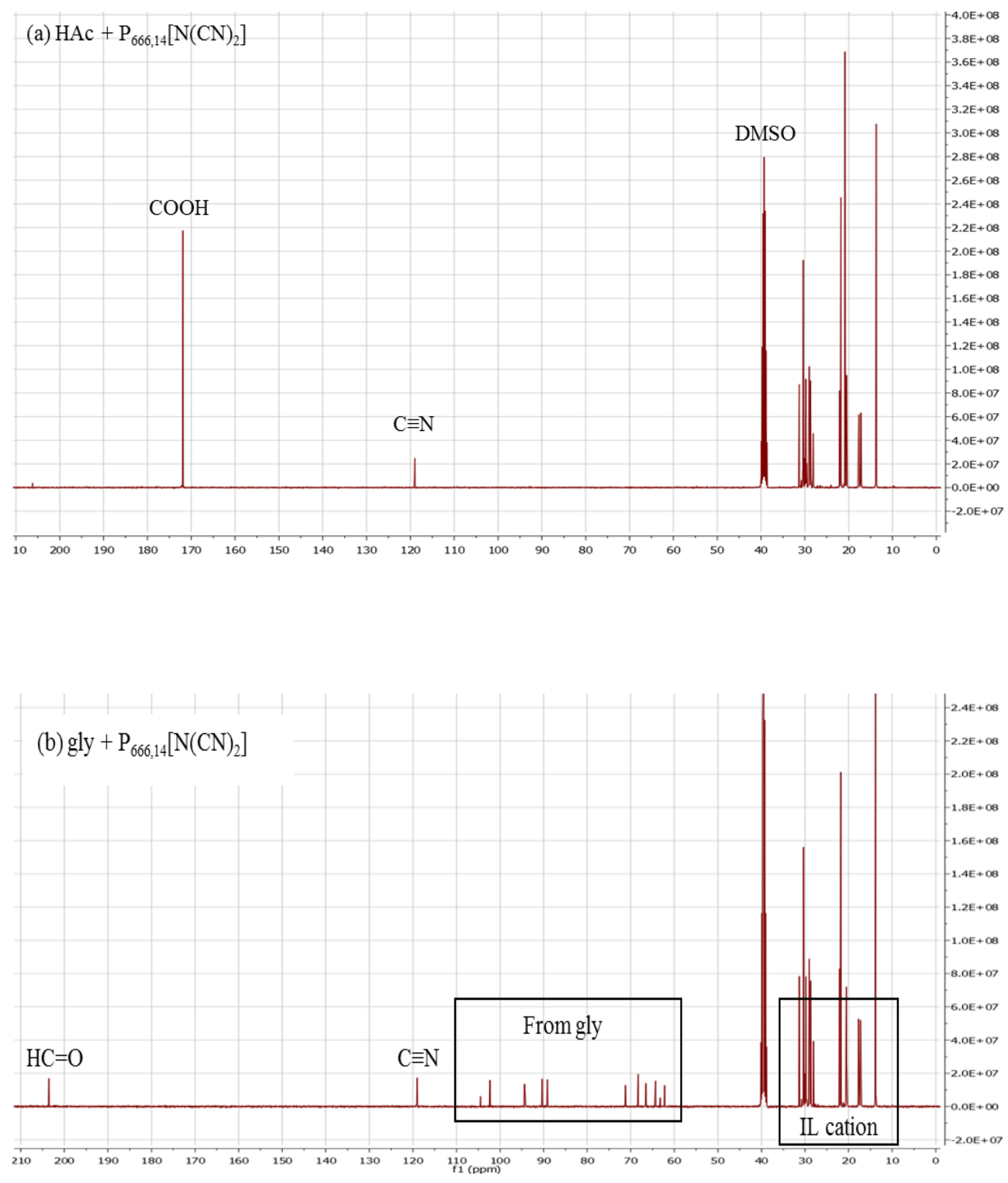

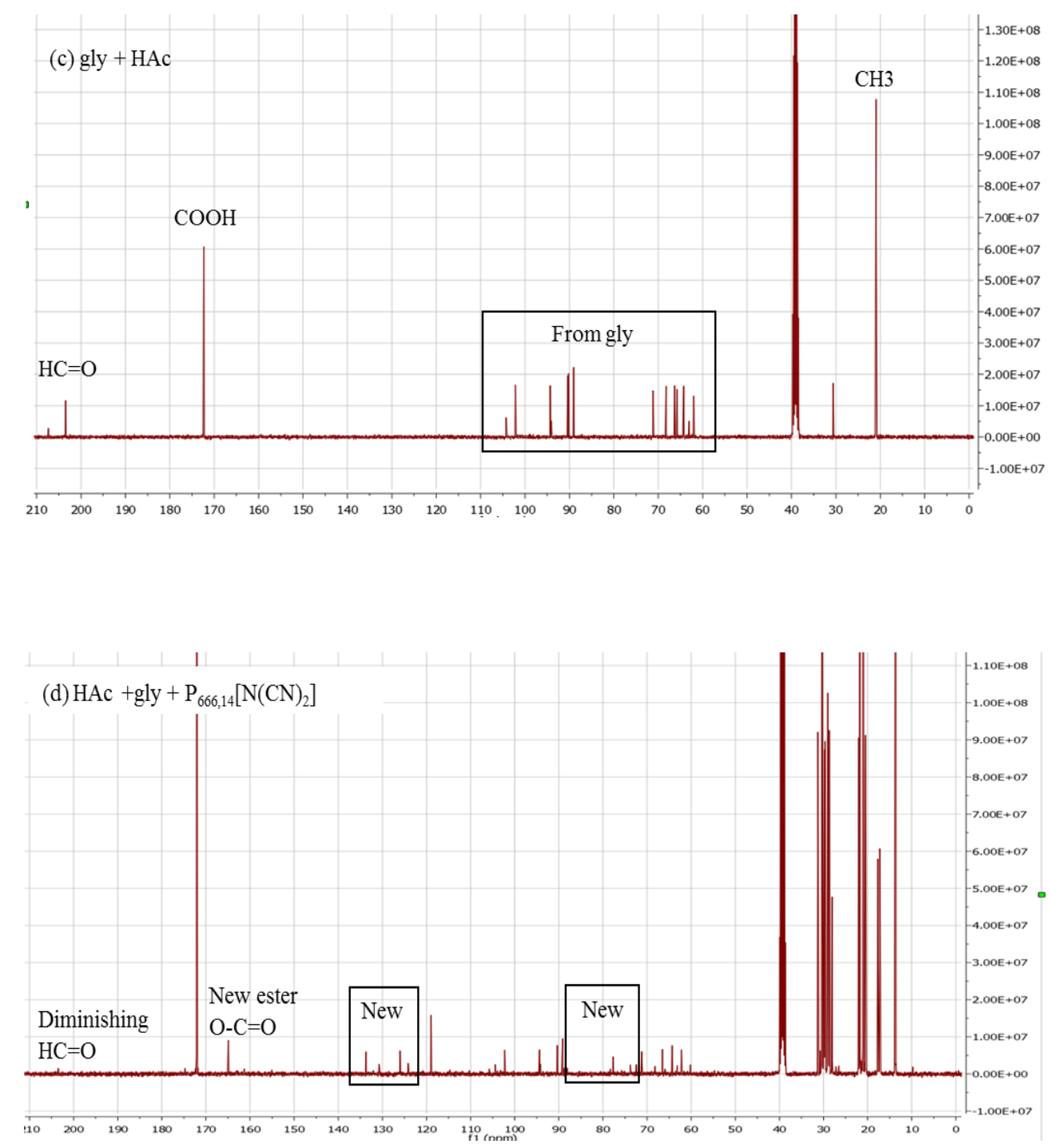

Figure S4.3. ${ }^{13} \mathrm{C}$ NMR spectra of the $\mathrm{P}_{666,14}\left[\mathrm{~N}(\mathrm{CN})_{2}\right]$ and mixtures with glycolaldehyde and acetic acid. 
(a) $\mathrm{HAc}+\mathrm{P}_{666,14}\left[\mathrm{~N}(\mathrm{CN})_{2}\right]$

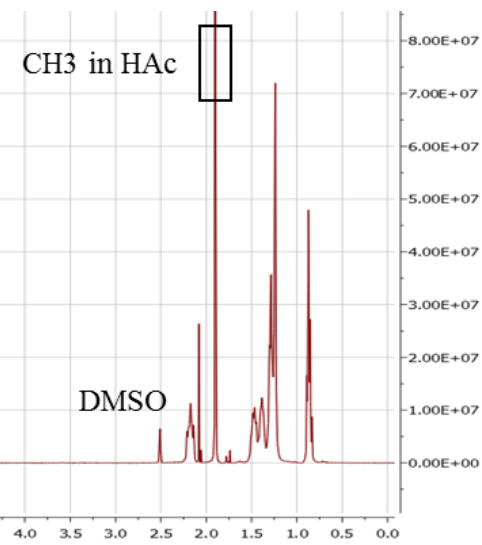

(b) gly $+\mathrm{P}_{666,14}\left[\mathrm{~N}(\mathrm{CN})_{2}\right]$

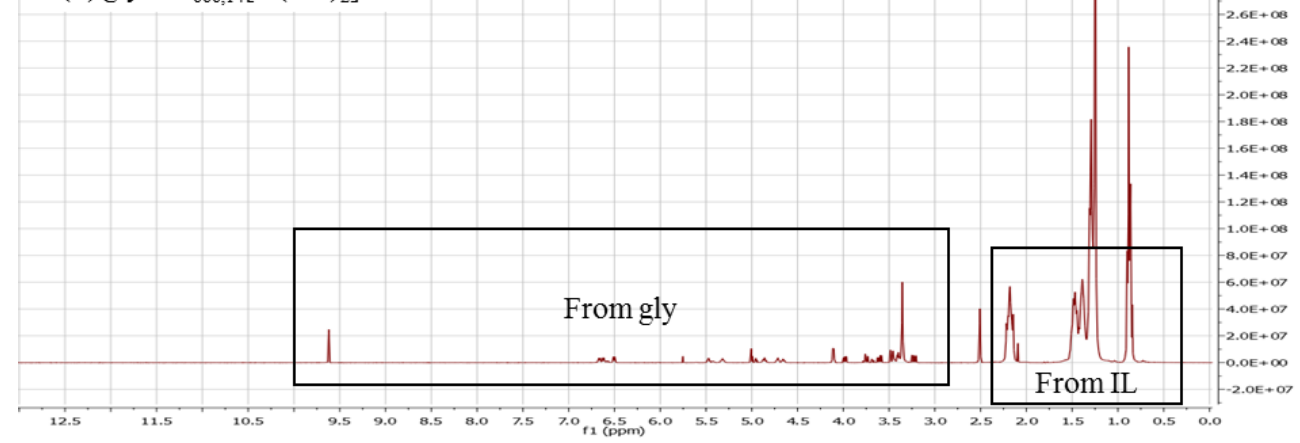

(c) $\mathrm{HAc}+\mathrm{gly}+\mathrm{P}_{666,14}\left[\mathrm{~N}(\mathrm{CN})_{2}\right]$

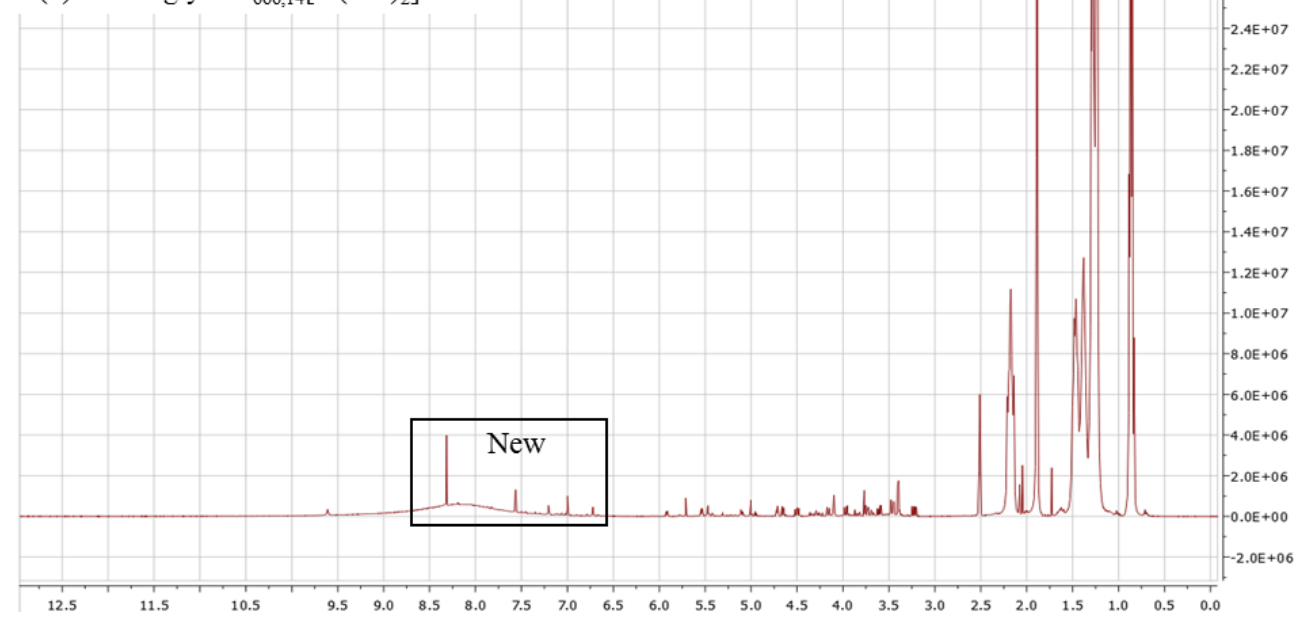

Figure S4.4. ${ }^{1} \mathrm{H}$ NMR spectra of the $\mathrm{P}_{666,14}\left[\mathrm{~N}(\mathrm{CN})_{2}\right]$ and mixtures with glycolaldehyde and acetic acid. 


\section{S4.3. The proposed mechanism for the reactions between gly, $\mathrm{P}_{666,14}\left[\mathrm{~N}(\mathrm{CN})_{2}\right]$ and HAc}

The possible reactions between gly, $\mathrm{P}_{666,14}\left[\mathrm{~N}(\mathrm{CN})_{2}\right]$ and HAc are shown in Scheme S4.1. In the first step, the negatively charged $\mathrm{N}$ in the anion of IL acts as a nucleophile, attacking the carbonyl carbon and forming a new $\mathrm{C}-\mathrm{N}$ single bond, transferring the electron from carbon to oxygen in the ketone group, resulting in the negatively charged oxygen. In the second step, the electron pairs on the negative charged oxygen of the new formed anion could again attack the carbonyl carbon of gly to form a new anion, or attack the carbonyl carbon of HAc and form a new ester and one hydroxyl anion. However, it is difficult to prove this possible reaction route, due to the complicate NMR spectra and the low intensity of the signals.
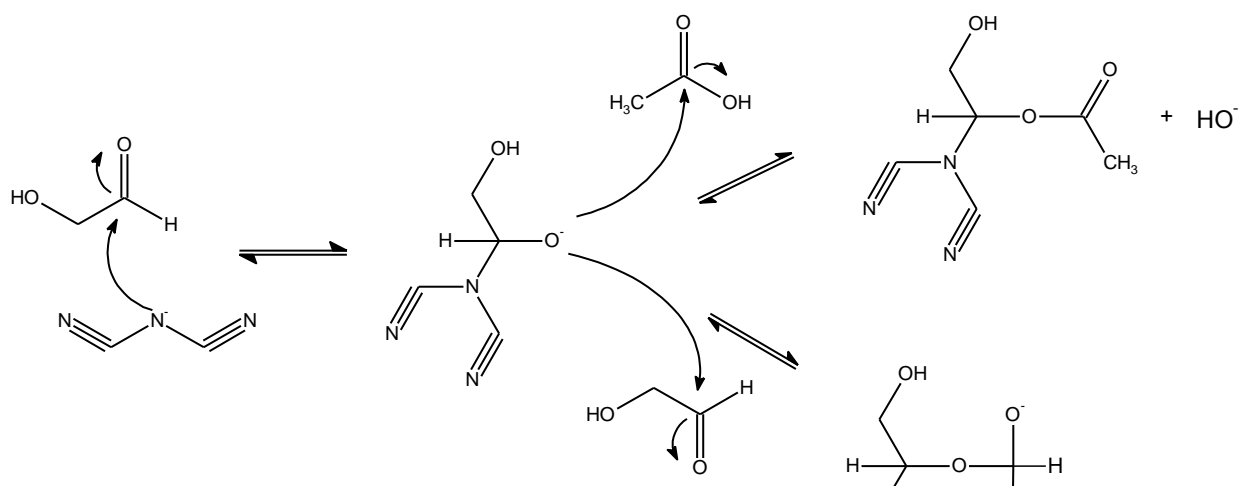

Scheme S4.1. The proposed reactions between glycolaldehyde, HAc and $\mathrm{P}_{666,14}\left[\mathrm{~N}(\mathrm{CN})_{2}\right]$

\section{Reference}

[1] Y. Kobayashi, H. Takahashi, Conformational studies of glycolaldehyde and 1,3dihydroxyacetone in solution by $1 \mathrm{H}-\mathrm{NMR}$, Spectrochimica Acta Part A: Molecular Spectroscopy, 35 (1979) 307-314. 


\section{Appendix C}

\section{Supplementary information of Chapter 6}

It is presented in this supplementary information that the details of synthesis and characterization of microgel particles. 


\section{S6.1. Materials}

N-isopropylacrylamide (NIPAM), N,N'-methylbisacrylamide (NNMBA), methacrylic acid (MA), potassium peroxodisulfate (KPS), styrene, sodium dodecyl sulfate (SDS) and Brij-98 were purchased from Sigma-Aldrich. Potassium nitrate $\left(\mathrm{KNO}_{3}\right)$ was obtained from Merck. The fluorescent dye Pyrromethene 546 was purchased from Exciton.

\section{S6.2. Synthesis of the core-shell particles}

The core-shell microgels were synthesized via two steps and contain a fluorescent polystyrene core and a PNIPAM-co-MA shell, using the same method as the reference [19]. First, fluorescent cores were synthesized by emulsion polymerization. To this end, $3.7 \mathrm{~g}$ NIPAM, $49.0 \mathrm{~g}$ styrene, $100 \mathrm{mg}$ SDS and $50 \mathrm{mg}$ fluorescent dye pyrromethene 546 were dissolved in $130 \mathrm{~mL}$ milli-Q water. The mixture was stirred at $500 \mathrm{rpm}$, heated to $75^{\circ} \mathrm{C}$ and purged with $\mathrm{N}_{2}$ for 15 minutes. The reaction was initiated by the addition of $110 \mathrm{mg}$ KPS dissolved in $5 \mathrm{~mL}$ milli-Q water and the reaction was left to proceed overnight. The reaction mixture was filtered and the cores were cleaned by repeated centrifugation (2000 g) and resuspension in milli-Q water. Second, a shell of NIPAM, MA and NNMBA was grown around the cores by precipitation polymerization. $0.98 \mathrm{~g}$ NIPAM, $100 \mu \mathrm{L}$ MA and $42 \mathrm{mg}$ NNMBA were dissolved in $100 \mathrm{~mL}$ of milli-Q water. Then, $1.0 \mathrm{~mL}$ cores was added and the mixture was sonicated for $2 \mathrm{~min}$. The mixture was stirred at $500 \mathrm{rpm}$, heated to $75^{\circ} \mathrm{C}$ and purged with $\mathrm{N}_{2}$ for 15 minutes. The reaction was initiated by the addition of $100 \mathrm{mg}$ KPS dissolved in $5 \mathrm{ml}$ milli-Q water and the reaction was left to proceed for 2 hours. The reaction mixture was filtered and the core shell microgels were cleaned by repeated centrifugation $(2500 \mathrm{~g})$ and resuspension in milli-Q water (three times). The particle content in the aqueous solutions was determined by drying method, which was $14.5 \mathrm{~g} / \mathrm{L}$.

\section{S6.3. Characterization of microgel particles}

The hydrodynamic diameters of core and core-shell particles as a function of temperature from 20 to $50{ }^{\circ} \mathrm{C}$ were measured in hundred fold diluted at $\mathrm{pH} 7.6$ with Dynamic Light Scattering (DLS).

\section{S6.4. Results and discussion}

The average diameters of microgel core and core-shell particles, measured with DLS were $127 \mathrm{~nm}$ and $718 \mathrm{~nm}$ at $20^{\circ} \mathrm{C}$, respectively. The average diameter as a function of temperature 
was measured in dilute solutions without added salt at $\mathrm{pH} 7.6$ and the results are shown in Figure S6.1. It is shown that the synthesized particles were indeed temperature responsive. As the temperature increased from 20 to $50{ }^{\circ} \mathrm{C}$, a sharp decrease of hydrodynamic diameter of microgels was observed at $35{ }^{\circ} \mathrm{C}$ which was identified as the lower critical solution temperature (LCST), indicating that the particles collapsed quickly above LCST. Upon decreasing the temperature again to $20{ }^{\circ} \mathrm{C}$, the particle diameter increased, implying that the particles were swollen again in the solvent. This swelling behavior can be useful for emulsions breaking on demand with a small temperature trigger.

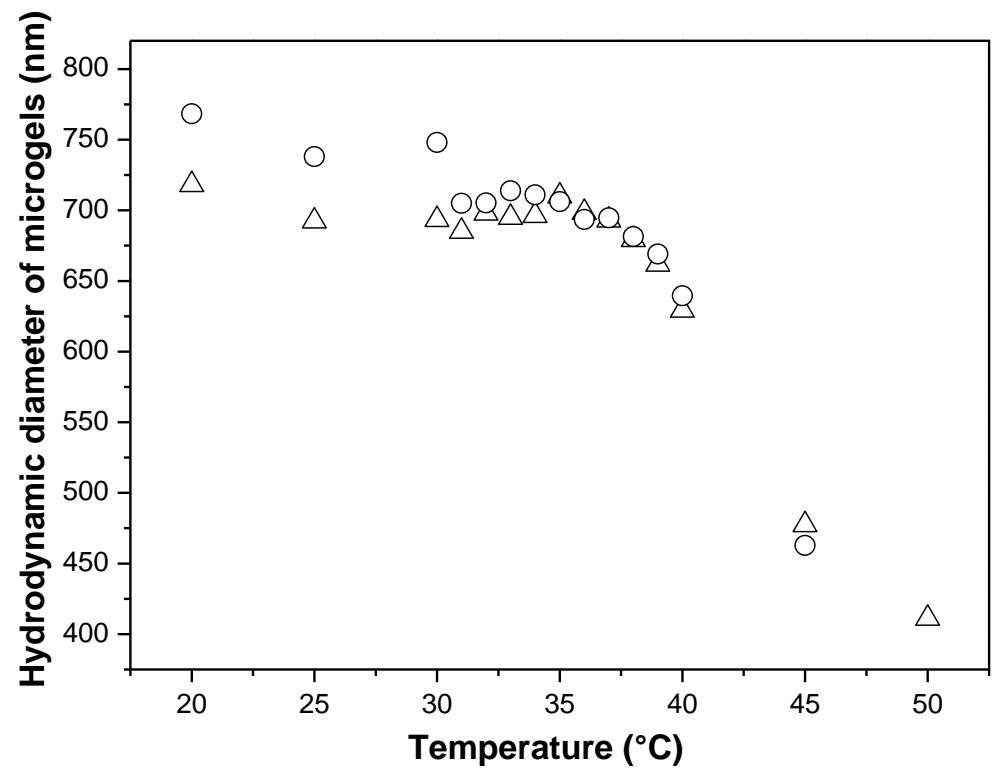

Figure S6.1. The hydrodynamic diameter of synthesized microgel particles as a function of temperature. $\Delta$ : increasing temperature from 20 to $50{ }^{\circ} \mathrm{C}$; $\circ$ : decreasing temperature from 50 to $20^{\circ} \mathrm{C}$.

\section{S6.5. Conclusions}

Core-shell microgel particles were synthesized and the lower critical solution temperature was identified as $35{ }^{\circ} \mathrm{C}$. DLS analysis showed that these microgels were temperature responsive particles. 


\section{Appendix D}

\section{Supplementary information of Chapter 7}

\section{S7.1. Magnetic field strength}

The magnetic field strength is presented as magnetic flux density, also called B field or magnetic induction. For a single block magnet as shown in Figure S7.1(a), the magnetic field $\mathrm{B}$ along $x$ axis $\left(\mathrm{B}_{x}\right)$ is calculated according the equation (S7.1) [1]:

$$
\begin{aligned}
B_{x}= & \frac{B_{r}}{\pi}\left[\arctan \left(\frac{L W}{2 x \sqrt{4 x^{2}+L^{2}+W^{2}}}\right)\right. \\
& \left.-\arctan \left(\frac{L W}{2(T+x) \sqrt{4(T+x)^{2}+L^{2}+W^{2}}}\right)\right]
\end{aligned}
$$

where $\mathrm{B}_{\mathrm{r}}$ is the residual field, independent of the magnet's geometry, which is 1.40-1.46 tesla for N50 Neodymium magnets [2] and here 1.45 was used for the calculations; L, W and T are the length, width and thickness of the block, which are $50 \mathrm{~mm}, 50 \mathrm{~mm}$ and $25 \mathrm{~mm}$, respectively for the used magnet in this work; $x$ is the distance from a pole surface along the symmetry axis.

For a dipole magnetic system as shown in Figure S7.1(b), the calculation includes both poles. Generally, when a steel yoke is fully contacting with a magnet, the thickness is doubled, i.e. 2T [3]. Thus, the magnetic flux density inside the gap of two magnets connected by a steel yoke corresponds to the sum of the fields generated by both magnets, each with a thickness 2T. The magnetic flux density in the airgap generated by the left magnet and yoke, named $B_{x, 1}$, is calculated with equation (S7.1), but the thickness of magnet $T$ is replaced by $2 \mathrm{~T}$ to account for the yoke. The same calculation is employed for the magnetic flux density in the airgap generated by the right magnet and steel yoke, named $B_{x, 2}$. Thus, the total $B_{x}$ within the airgap is the sum of the flux densities $B_{x, 1}$ and $B_{x, 2}$.

In Figure S7.2, the magnetic flux density along $\mathrm{x}$ axis within the airgap as calculated with Eq. S7.1 is shown. The field strength in the center of the gap is 0.91 tesla. 

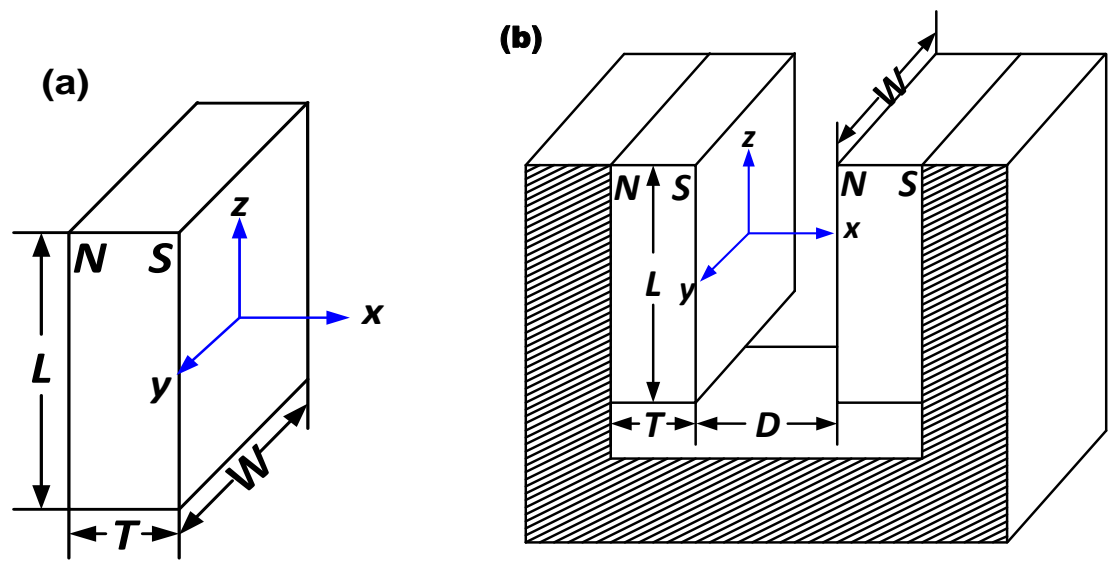

Figure S7.1 Single magnet (a) and a dipole magnetic system (b).

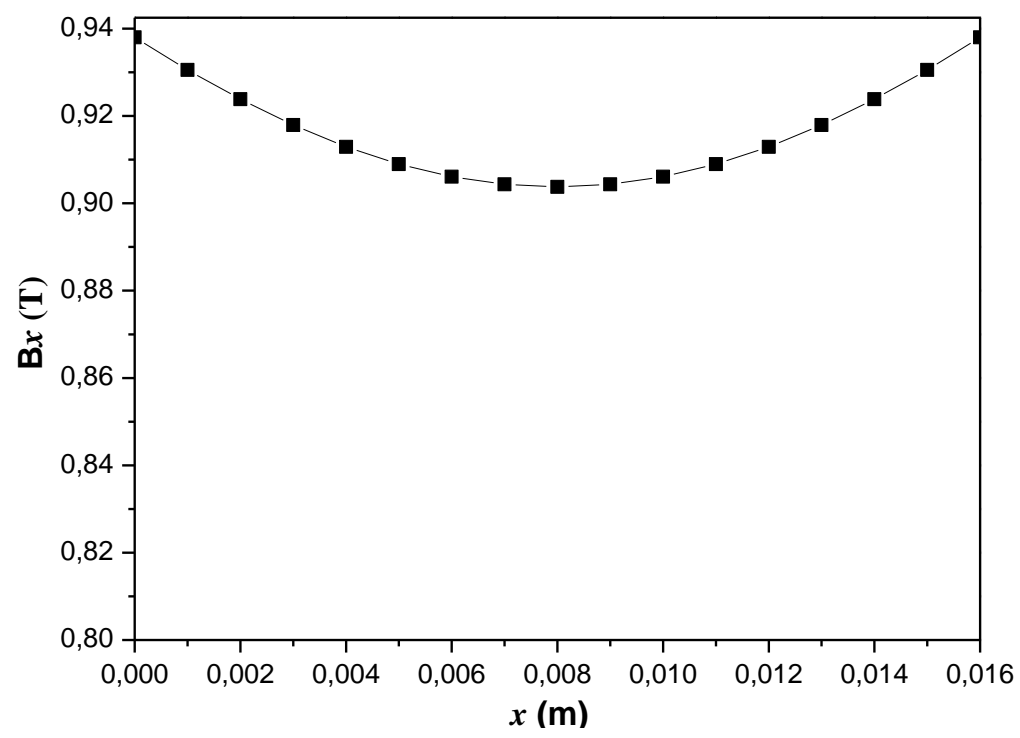

Figure S7.2. Calculated magnetic flux density B $x$ along $x$ axis within the airgap. 


\section{S7.2. Magnetic energy on droplets}

For larger clusters of magnetizable atoms in a single domain patch (where the spins are aligned, so that their net effect (the sum of their individual contributions) is nonzero, in contrary to e.g. dilute aqueous solutions of iron (III) salts, which exhibit random spin orientations, and no net magnetic effect is observed) the magnetic energy is proportional to the volume of the paramagnetic bodies (Equation S7.2) [4],

$$
E_{m}=-V \vec{M} \cdot \vec{B}=-\mathrm{VMB} \cos \theta
$$

where $\mathrm{V}$ is the volume of the magnetic body, $\theta$ is the angle between the magnetization $\mathrm{M}$ and the field B. As a consequence, the body undertakes the magnetic torque $\tau$ [4] as

$$
\tau=-\frac{\partial E_{m}}{\partial \theta}=V M B \sin \theta
$$

Thus the magnetic torque can overcome the forces due to random thermal motion when the molecular assembly with certain volume is formed, in which the electrons are aligned in the magnetic field (single domain patch) [5]. The exact value depends on the magnetizability and the angle of the magnetization of the droplets, however, as the results showed in chapter 7 , no magnetic field effect was observed on equilibrium distributions of toluene and heptane.

\section{References}

[1]https://www.supermagnete.nl/eng/faq/How-do-you-calculate-the-magnetic-fluxdensity, in 2016.

[2] https://www.supermagnete.nl/eng/data table.php, in 2016.

[3]https://www.dextermag.com/resource-center/magnetic-field-calculators/fieldcalculations-for-permanent-magnet-dipole, in 2016.

[4] M. Yamaguchi, Magneto-science magnetic field effects on materials ; fundamentals and applications Springer, Berlin; Heidelberg, 2007.

[5] J. Torbet, J.M. Freyssinet, G. Hudry-Clergeon, Oriented fibrin gels formed by polymerization in strong magnetic fields, Nature, 289 (1981) 91-93. 


\section{List of Publications}

1. Li, X.; Kersten, S. R. A.; Schuur, B., Extraction of Guaiacol from Model Pyrolytic Sugar Stream with Ionic Liquids. Industrial \& Engineering Chemistry Research 2016, 55, 4703-4710.

2. Li, X.; Luque-Moreno, L. C.; Oudenhoven, S. R. G.; Rehmann, L.; Kersten, S. R. A.; Schuur, B., Aromatics extraction from pyrolytic sugars using ionic liquid to enhance sugar fermentability. Bioresource technology 2016, 216, 12-18.

3. Li, X.; Kersten, S. R. A.; Schuur, B., Efficiency and Mechanism of Demulsification of Oil-in-Water Emulsions Using Ionic Liquids. Energy \& Fuels 2016, 30, 7622 7628.

4. Li, X.; Kersten, S. R. A.; Schuur, B., Extraction of acetic acid, glycolaldehyde and acetol from aqueous solutions mimicking pyrolysis oil cuts using ionic liquids. Separation and Purification Technology 2016, 175, 498-505.

5. Monteillet, H.; Workamp, M.; Li, X.; Schuur, B.; Kleijn, J. M.; Leermakers, F. A. M.; Sprakel, J., Multi-responsive ionic liquid emulsions stabilized by microgels. Chemical Communications 2014, 50, 12197-12200.

6. Desai, R. K.; Monteillet, H.; Li, X.; Schuur, B.; Kleijn, J. M.; Leermakers, F. A. M.; Sprakel, J.; Wijffels, R. H.; Eppink, M. H. M., Novel mild separation concept for functional biomolecules using IL based emulsions. (Submitted)

7. Li, X.; Desai, R. K.; Monteillet, H.; Kersten, S. R. A.; Eppink, M. H. M.; Schuur, B., Studies on the effects of microgel particles on drop size distributions and extraction kinetics of guaiacol with ionic liquid-in-water emulsions. (In preparation)

\section{Conference presentations}

1. Li, X.; Kersten, S. R. A.; Schuur, B., Separation of aromatics and sugars in pyrolysis oil with ionic liquids. NPS14, Utrecht, the Netherlands. 3-5 November 2014. Oral presentation. 
2. Li, X.; Kersten, S. R. A.; Schuur, B., Demulsification of oil-in-water emulsions with ionic liquids. ECCE10 + ECAB3 + EPIC5. Nice, France. 27 September - 1 October 2015. Oral presentation.

3. Li, X.; Kersten, S. R. A.; Schuur, B., Separation of aromatics and sugars in pyrolysis oil with ionic liquids: COSMO-RS simulation, experiments and process design. Chains 2015. Veldhoven, the Netherlands. 1-3 December 2015. Poster presentation.

\section{Publication prior to $\mathrm{PhD}$ thesis}

1. Zhang, S.; Lu, X.; Zhou, Q.; Li, X.; Zhang, X.; and Li,. S., Ionic liquids: Physicochemical Properties. Burlington: Elsevier B.V., 2009, p. 1-477. 


\section{Acknowledgement}

The almost five years' journey of my $\mathrm{PhD}$ study is relatively long, but absolutely valuable, enjoyable and memorable. I have learned, experienced and enjoyed so much from both work and life. It would not be possible to finish this thesis without the contribution from many people, to whom I would like to express my sincere gratitude here.

First of all, I would like to thank my promotor Sascha Kersten and co-promotor Boelo Schuur for giving me this opportunity to do my $\mathrm{PhD}$ research in SPT group. Sascha, thanks for your guidance for my research and efforts in correcting my papers and thesis. I will always be impressed by all your critical questions which have strongly inspired me to improve the integrity, precision and clarity of this thesis. Boelo, thanks for your invaluable support, limitless effort, and thoughtful guidance for my entire PhD study in all these years. I have learned a lot from you with respect to the knowledge of separations, and expression and writing skills. Thanks for not pushing me on my work but always trying to release my stresses. Thanks for your patience and efforts on correcting all my papers and thesis. Without your significant contributions, this thesis would not have been completed.

I wish to express my gratitude to all the committee members Prof.dr. S. Zhang, Prof.dr.ir. N.E. Benes, Prof.dr. J.P. Lange, Prof.dr.ir. A.B. de Haan and Dr.ir. A.G.J. van der Ham for spending time to read my thesis, for allowing me to give defense, and for taking part in the defense ceremony.

I am grateful to all staff members in the SPT group. Firstly to all the technicians: Erna, Benno, Johan and Karst. Erna, thanks for introducing me to all the analytical equipment. Especially in the first year of my $\mathrm{PhD}$, we spent more than half a year to fix the old GC instrument. Usually one problem was solved and the other came. The problems were never stopped, but you always showed your patience and tried to solve them. I am happy to see that it is working well now and often fully booked for analysis recently. Benno, thank you for making the setups that I needed for the experiments and always being willing to help me no matter how busy you were. Your tremendous knowledge on setups has greatly impressed me and you always give solutions for my problems. Yvonne, I really appreciate all your helps with respect to the administrative procedures and daily supports. Louis, many thanks for your great helps with ASPEN PLUS software and for sharing your knowledge of Unisim. Jeanpaul, although we only had one meeting during these five years, I already got surprised by the knowledge that you have. Thanks for teaching me about the reaction mechanism. Wim, thanks for not asking me as one of your teaching assistants for your FTV course $:$. 
Special thanks to Stijn and Ying for being my paranymphs. Stijn, you were one of the most helpful colleagues regarding to my project since you know almost everything about pyrolysis and I knew nothing at the very beginning. I have learned a lot from you about pyrolysis oil. Ying (Cindy), we have shared many memorable moments. We have many interests in common, such as playing tennis, badminton, and swimming (though I still cannot swim now). All the adventures we had still remain in my mind: tree-to-tree, wadlopen and our travelling in the north Europe, and of course all the dinners and parties. I am grateful to have you as my colleague, my officemate and one of my best friends.

I am fortunate to have so many lovely colleagues in such a wonderful group. I like all the activities that we had together. Although I joined less and less in the final year, all the crazy borrels and parties, and the amazing group trips still remain in my mind. Here I express my gratitude to all the SPT members: Caroline, Chiel, Dion, Daniel (thanks for your help with the elemental analysis). Special thanks to Lisette for your help with the Dutch summary. Ehsan (thanks for your help with HPLC and IC, for many valuable discussions, and for sharing ionic liquids). Maria (you are my great teacher with respect to dancing and skiing). Mariek, Michal and Sandra, (I like the tetratea you guys brought but will stay away from it as far as I can ()). Varsha, Rens and Pavlina (your tips of job hunting really helped me a lot). Martin (thanks for your help with the translation of my Dutch letters), Muthia, Ozge, Pushkar (thanks for your help with GPC), Qian, Roel, Sam, Stevia, Sushil, Surika and Thomas. Thank you all once again for giving me such a nice time in the group.

I also would like to express my gratitude to my students Arjan, Inger and Maarten. You all contributed a lot to my research, though you spent only short time in the group. Without your help, the work could not have been done so much. I wish you all have a bright future.

I am also grateful to have so many wonderful Chinese friends in Enschede. Jingwei and Zhonghua, thank you for the delicious dinners that you made. Jingwei, I really enjoyed a lot every time chatting with you and thanks for making me feel better when I felt sad and confused. Leilei and Xiaobin, I love our trip to Belgium, which would not be amazing without you guys. Xingwu, you are always generous to help and indeed you helped a lot for our house moving, and I like your spirit of drinking. Junwen and Ye Liang, I am glad to work together with you in ACSSE which connected us together and since then, we spent more enjoyable occasions together. Honglin, thanks for all your help in these years and the trips we went for together. Zhengchao, Jiajia, Mengdi, Youwen, Hairong, Hainan, Aijie, Wang Yi, Wang Lei, Yali, I enjoyed a lot in all the dinner parties that we had together. Special thanks to my badminton companies or teachers, Lantian, Liufei, Xiaokui, Dongfang and Lin. I am glad that I joined the ACSSE where I met many friends: Jianghan, Jiabiao, Luzhou, Qibo, Luyao, 
Linghua, Gaopeng, Tianpei, Xie Sijia, Yan Sijia, Yufan, Yuxi, Lijie, Yunlong, Xichen and others. Thank you all for your help with the organization of ACSSE events.

I would like to thank our 10-person weekend group (this name is given by Yin): Kenan, Wei Ye, Rong, Wenlong, Tao Yin, Xiaolin, Manman, Letian and Fangzhou. I remember all the crazy weekends we spent together in 2014. The funny jokes, the sporting activities, the amazing trips and parties, all of these are valuable experience of my life. Fanyu, I met with you just few weeks after arriving in Enschede. I appreciate to have you as one of my best friends. Rong, as one and a half year's housemate, we have done many amazing things and shared many memorable moments. Besides all those crazy weekends, together we have learned dancing, travelled to many cities, made wonderful friends, and organized many ACSSE events. I will definitely cherish all these wonderful memories.

I wish to express my special thanks to Yan Xiaolin and Xu Hong. I am glad to have you as my friends. Although you are professors and I am a student, we had lots of common topics. Thanks for your trust, encouragement and support. I am glad that we still keep in touch and hope we will see each other in the near future.

I also wish to thank my old friends in China: Xiaoyu, Gedan, Junbo, Dongxia and Yuting. We are thousands miles away and do not often see each other, but in my heart you are so close to me. I know you will always give all your support whenever I need it. I will cherish our friendship forever.

Finally, I deeply thank my family for their limitless support. Without you I could not reach this point of my life. Kenan, I am deeply grateful to have you in my life. You have made my life so much better and happier. Thank you for giving your great support for all my decisions. Thank you for everything. I believe our life will be better and better.

Xiaohua

January, 2017 


\section{About the author}

Xiaohua Li was born on $9^{\text {th }}$ October 1984 in Anyang, Henan Province. After obtaining her Bachelor degree of Chemical Engineering in Henan University in July of 2007, she moved to Beijing for her Master study in the Institute of Process Engineering, Chinese Academy of Sciences. She worked on the topic "study on the synthesis and physicochemical properties of magnetic ionic liquids" and "database of ionic liquids", under the supervision of Prof.dr. Suojiang Zhang and Dr. Qing Zhou. She graduated and obtained her Master degree of Chemical Engineering in July of 2010. Afterwards, she continued to work in the same group on the topic of "synthesis of dicationic magnetic ionic liquids" as a research assistant.

In March of 2012, she moved to Enschede in the Netherlands for her PhD study in University of Twente on a STW project of "smart separations", under the supervision of Prof.dr. S.R.A. Kersten and Dr.ir. Boelo Schuur. This thesis is the result of the research project.

From November of 2016, she started her work as a postdoc researcher in KU Leuven in Belgium on an ERC advanced grant of "Solvometallurgy for critical metals" with Prof. Koen Binnemans. 
ISBN: 978-90-365-4293-7 